QA: NA

REV 00

BECHTEL

April 2003

SAIC COMPANYLC

\title{
Resolution Strategy for \\ Geomechanically-Related Repository Design and Thermal-Mechanical Effects (RDTME)
}

By

Mark Board

Prepared for:

U.S. Department of Energy

Office of Civilian Radioactive Waste Management

Office of Repository Development

P.O. Box 364629

North Las Vegas, Nevada 89036-8629

Prepared by:

Bechtel SAIC Company, LLC

1180 Town Center Drive

Las Vegas, Nevada 89144

Under Contract Number

DE-AC28-01RW12101 


\section{DISCLAIMER}

This report was prepared as an account of work sponsored by an agency of the United States Government. Neither the United States Government nor any agency thereof, nor any of their employees, nor any of their contractors, subcontractors or their employees, makes any warranty, express or implied, or assumes any legal liability or responsibility for any third party's use or the results of such use of any information, apparatus, product, or process disclosed, or represents that its use would not infringe privately owned rights. Reference herein to any specific commercial product, process, or service by trade name, trademark, manufacturer, or otherwise, does not necessarily constitute or imply its endorsement, recommendation, or favoring by the United States Government or any agency thereof or its contractors or subcontractors. 
RESOLUTION STRATEGY FOR GEOMECHANICALLY-RELATED REPOSITORY DESIGN AND THERMAL-MECHANICAL EFFECTS (RDTME)

April 2003

Preparation:

$$
\text { Nat Brand }
$$

Mark Board

Senior Staff, Repository Design Project

Approval:

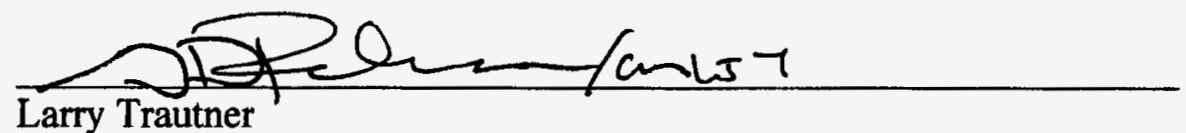

Project Manager, Repository Design Project

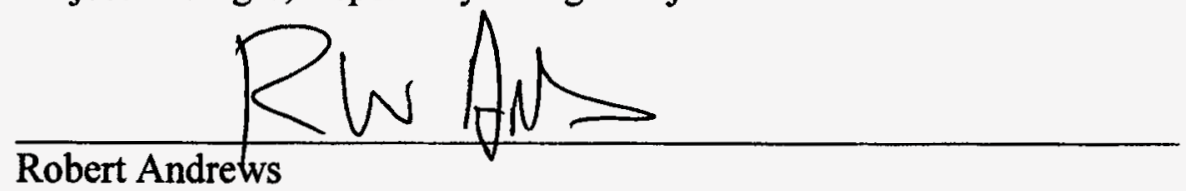

Project Manager, Performance Assessment

Reviewed by:

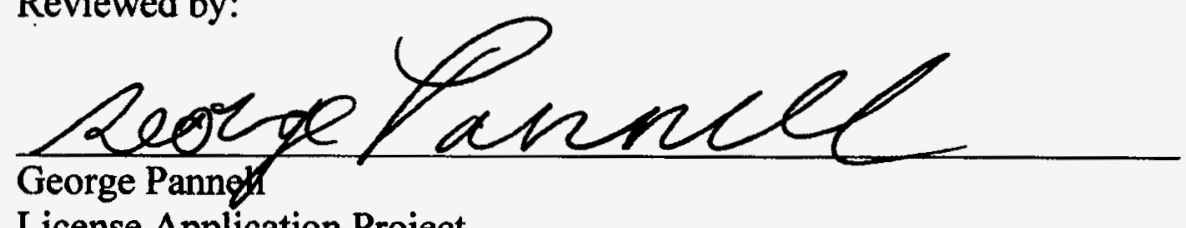

License Application Project
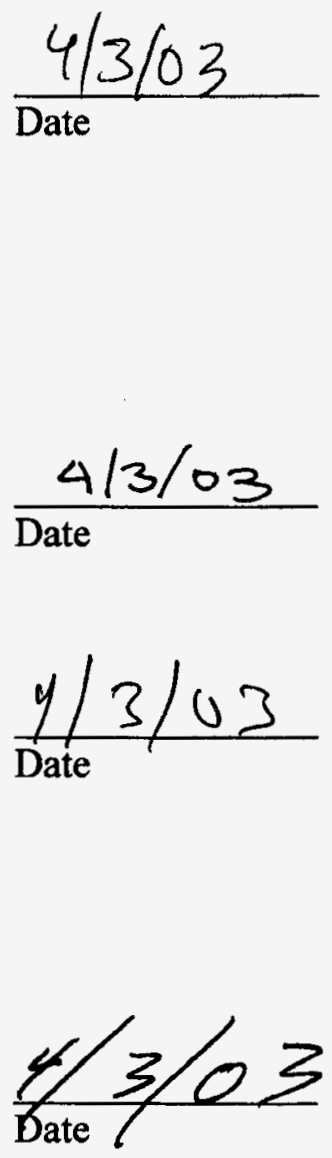

Resolution Strategy for Geomechanically- Related

Repository Design and Thermal-Mechanical Effects

iii

Rev. 00 April 2003 


\section{ACKNOWLEDGMENTS}

This report is the cooperative effort of several different consultants, organizations and U.S. Government agencies and was produced for the U.S. Department of Energy, Office of Civilian Radioactive Waste Management, Office of Repository Development (ORD). Roger Keller, Fei Duan, Dwayne Kicker, Ming Lin, Laurence Costin, Ronald Price, and Steven Beason were all contributing authors to this report. These authors would like to gratefully acknowledge the contributions of the members of a Geotechnical Review Panel, convened in May 2001, to examine basic geomechanics and ground support issues. This panel developed the basic approach to KTI resolution described in this document. The members of this panel, in addition to the report authors, included:

Nick Barton, Nick Barton Associates

Kirk Lachman, U.S. Department of Energy

Jaime Gonzalez, U.S. Department of Energy

Cliff Howard, Sandia National Laboratory

Yiming Sun, BSC

Jaak Daemen, University of Nevada, Reno

Robert Lung, John Steigner, U.S. Bureau of Reclamation

Hemi Kalia, Los Alamos National Laboratory

Moses Karakuzian, Nick Hudyma, University of Nevada, Las Vegas

In addition to the panel, a number of other ORD staff members contributed to this report. Robert Elayer of BSC provided review for the sampling plan. Michael Sholley of Bechtel Environmental, Ed Cikanek of BSC, and Janelle Hubbard of BSC provided the data collection that was necessary to develop this approach. Junghun Leem of BSC has assisted in development of the approach for determining time dependent joint behavior. Roger Keller and David Rasmussen of BSC coordinated activities dealing with the resolution of these KTI agreements. 


\section{EXECUTIVE SUMMARY}

This document provides an approach to resolution of the geomechanically-related Repository Design and Thermal-Mechanical Effects Key Technical Issue agreements. These Key Technical Issue agreements were jointly developed between the U.S. Department of Energy and the U.S. Nuclear Regulatory Commission staffs at the Technical Exchange and Management Meeting held on February 6-8, 2001, in Las Vegas, Nevada. A list of the agreements and their exact wording can be found in Appendix A. This document reviews these agreements and gives a detailed background regarding their derivation and resolution.

\section{The Key Technical Issue Agreements}

Geomechanically-related Repository Design and Thermal-Mechanical Effects agreements (see Appendix A) can be subdivided into five primary areas:

A. Rock mass properties and geotechnical characterization

1. Development of a basic understanding of how the structural characteristics of the repository host horizon impacts rock mass behavior and, consequently, the design and performance properties. This work can be used to establish a connection between geologic characteristics and their use in models and calculations.

2. Develop an understanding of the variability of geologic structure and, using the developments of the above item, identify how variability affects rock mass thermomechanical behavior.

3. Enhance the database of thermomechanical materials properties of repository rock units, including mechanical and thermal testing of lithophysal rocks, estimation of the mechanical properties of rock fractures, and determination of the time-dependent response of lithophysal rocks. Development or choice of proper constitutive models for the different distinct rock units is a portion of this effort.

B. Modeling

1. Determination or development of the proper type of modeling tools to use for sensitivity studies of excavation stability under gravitational, thermal and seismic loading. Specific agreements cited in the Key Technical Issue include:

a. Under what circumstances are continuum and discontinuum models appropriate?

b. Under what circumstances are two- and three-dimensional models appropriate?

c. Under what circumstances are assumptions of rock mass homogeneity or anisotropy appropriate? 
2. Determination of the proper model boundary and initial conditions

a. Need to address the initial stress state for models and inclusion of thermally induced stress history from regional models applied to local scale models for problems such as rockfall

b. Need to address special boundary conditions for dynamic analyses, including non-reflecting and free-field boundaries

c. Need for development of preclosure and postclosure site-specific ground motion time histories

3. Seismic Stability

a. Use of site-specific ground motions

b. Use of appropriate dynamic models for estimation of rockfall induced by seismic shaking

c. Methodology for inclusion of geologic structure and its variability into models for estimation of rockfall

4. Thermal and Long-term Degradation

a. Need to examine potential for thermal-stress induced rockfall

b. Need to examine impact of long-term static fatigue of the rock mass and its impact on drift degradation and rockfall

5. Ground Support and Drift Degradation

a. Verification of the functional and operational requirements and specification of ground support during the preclosure period

b. Development of a plan for observation and maintenance of the ground support

c. Estimation of the effect of postclosure in situ thermal and seismically induced stresses on the degradation and potential rockfall of the emplacement drifts. Included here is the potential effect of time-related static fatigue mechanisms in intact rock and joints. 


\section{Resolution Strategy}

The strategy described in this document for resolving the above primary areas involves a phased approach based on the following combination of analyses, studies and calculations (Figure i).

- Evaluation and geotechnical analysis of the existing, extensive geological mapping and geotechnical field characterization data from surface and underground mapping of lithology, structure and rock quality.

- Perform additional laboratory and in situ thermomechanical testing, primarily of lithophysal rocks, to provide information for confirmation of the material models and property ranges to be used in design and performance sensitivity studies.

- Calibration and validation of numerical models capable of representing the thermomechanical behavior of lithophysal and non-lithophysal rocks.

- Use of the validated models to explore the impact of geologic variability (porosity, lithophysae shape and distribution, fracture density) on the geomechanical response, primarily of lithophysal rocks. Validated models are used to supplement the materials properties data base by extrapolating the effects of geologic variability.

- Thermally and time-related model sensitivity studies to examine preclosure ground support and postclosure drift degradation and seismic stability issues.

There are two points of particular importance in this strategy:

1. Because the performance of the tuff rock mass is primarily a function of geologic structure (e.g., fractures and lithophysal porosity), modeling tools must be based on geologic information gathered from the field and laboratory. It is the goal of this strategy to demonstrate a direct linkage between the basis of our models and the geologic reality in the field.

2. Because the behavior of the rock mass, particularly the lithophysal rocks, is porosityand size-dependent, rock mass property derivation via typical "empirically based" rock mass classification schemes or "statistically based" testing programs using small core samples are not particularly applicable to lithophysal rocks.

The porosity- and size-dependence means that, for rock mass properties estimates, reliance must be placed on performing a limited number of large-core laboratory and in situ tests to determine the thermal and mechanical properties of this material. Since this will necessarily result in a relatively small data base, our goal is to validate numerical models with the lab and field testing to provide a predictive capability that will represent the basic mechanisms of mechanical behavior of the lithophysal rocks. These validated numerical models can then be used for "test bed" extrapolation purposes to examine effects such as the impact of lithophysae size, shape and porosity on rock material model and property ranges. 


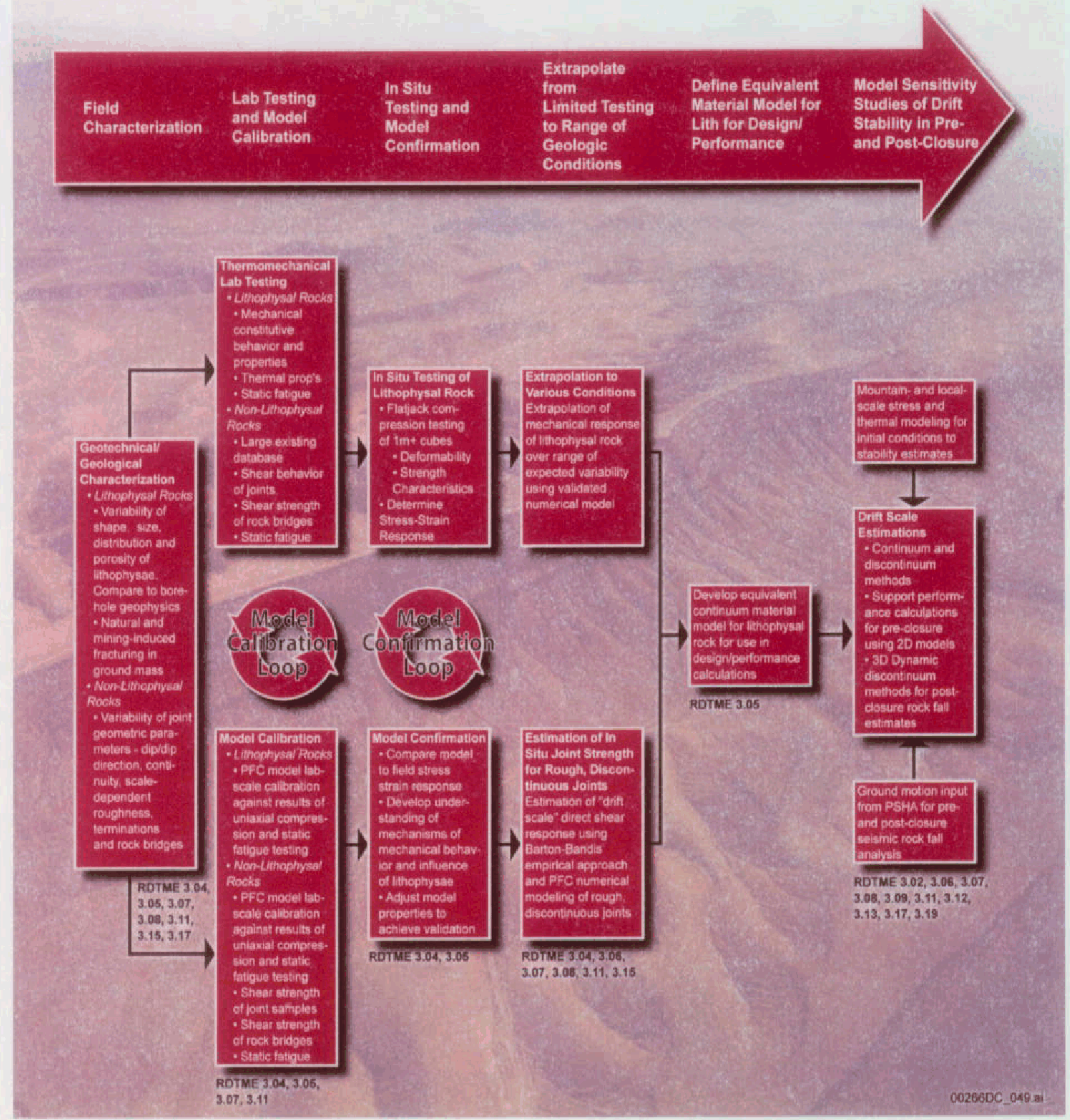

NOTE: Process starts with compilation and analysis of basic geotechnical mapping, followed by laboratory and field testing and model validation to develop rock mass property estimates for design and performance sensitivity studies.

Figure I General Approach to Resolution of the Geomechanically-Related Key Technical Issue 


\section{CONTENTS}

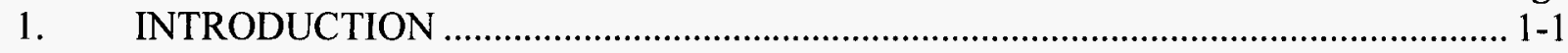

2. THE REPOSITORY DESIGN AND THERMAL MECHANICAL EFFECTS AGREEMENTS AND HOW THEY ARE BEING ADDRESSED ................................... 2-1

2.1 GENERAL DISCUSSION OF AGREEMENTS .............................................. 2-1

2.2 RESOLUTION STRATEGY .......................................................................... 2-2

2.2.1 Overall Approach ..................................................................................... 2-2

2.2.2 Geological and Engineering Methods Proposed to Resolve RDTME KTI Agreements .......................................................................................... 2-3

2.3 OVERVIEW OF THE RESOLUTION STRATEGY FOR EACH GEOMECHANICALLY-RELATED KEY TECHNICAL ISSUE

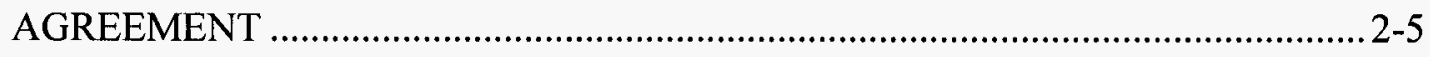

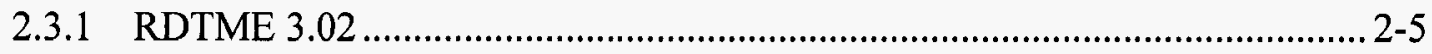

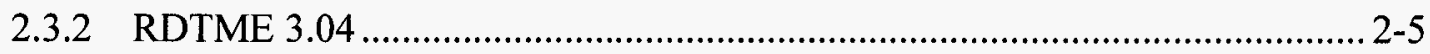

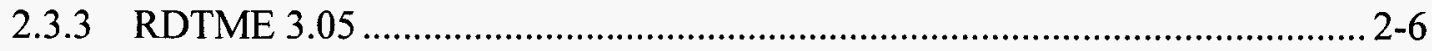

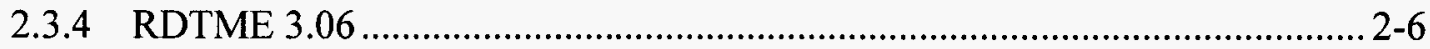

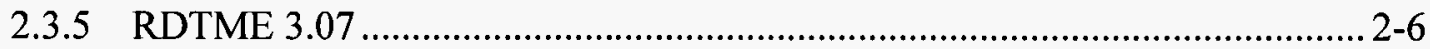

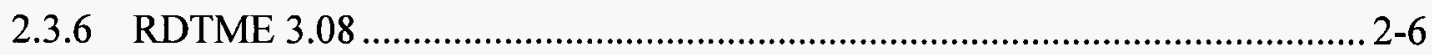

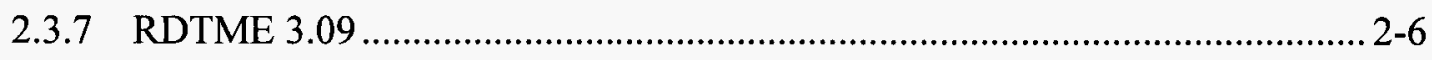

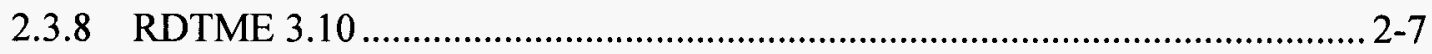

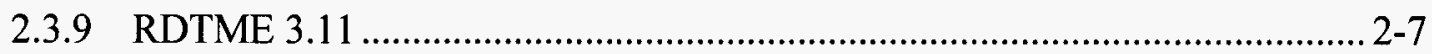

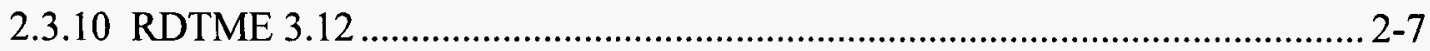

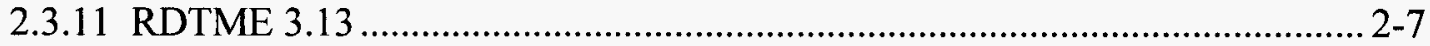

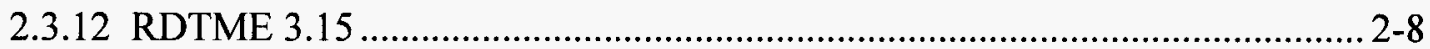

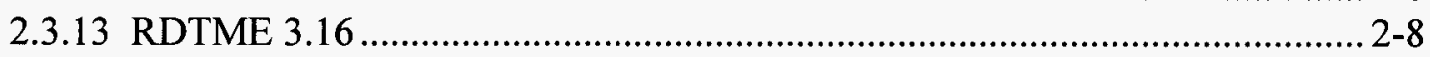

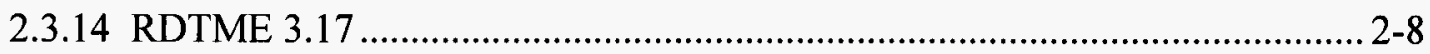

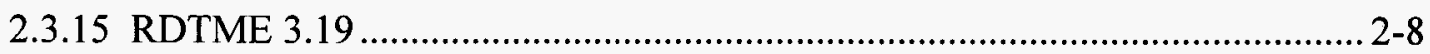

3. REVIEW OF SITE GEOLOGY AND GEOTECHNICAL CHARACTERIZATION ACTIVITIES

3.1 INTRODUCTION - CURRENT DATA COLLECTION PROGRAM ……............... 3-1

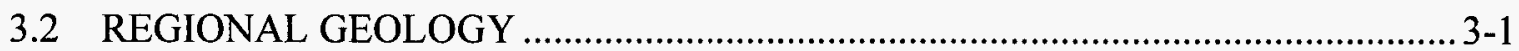

3.3 LITHOSTRATIGRAPHY AT THE REPOSITORY HORIZON ................................ 3-3

3.4 GEOTECHNICAL CHARACTERIZATION..................................................... 3-5

3.5 DISCUSSION OF ENGINEERING CHARACTERISTICS OF ROCK MASS IMPORTANT TO GEOMECHANICAL DESIGN AND PERFORMANCE..............3-6

3.5.1 Fracturing ……………………........................................................ 3-7

3.5.2 Lithophysae .................................................................................... 3-13

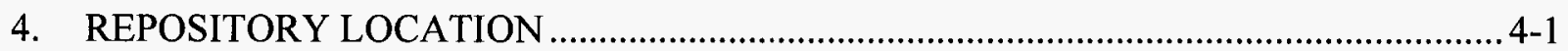

5. GEOMECHANICAL ISSUES AND DATA NEEDS FOR USE IN DESIGN AND PERFORMANCE ASSESSMENT STUDIES............................................................. 5-1

5.1 INTRODUCTION......................................................................................... 5-1 
CONTENTS (Continued)

Page

5.2 MATERIALS PROPERTIES AND GEOTECHNICAL

CHARACTERIZATION ISSUES

5.2.1 Materials Properties and Geotechnical Characterization Issues/Needs .......... 5-1

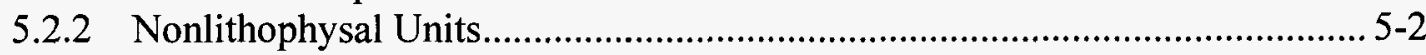

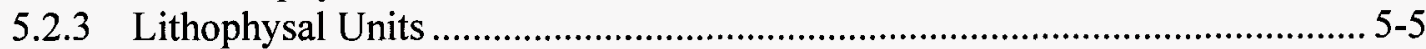

5.3 NUMERICAL MODELING ISSUES........................................................ 5-10

5.3.1 Continuum vs. Discontinuum Methods (Associated RDTME KTIs 3.11,

$3.12,3.20)$

5.3.2 Two vs. Three Dimensions, Isotropic vs. Anisotropic Models

(Associated RDTME KTI 3.10)

5.3.3 Geologic "Realism" in Numerical Models (Associated RDTME KTIs $3.04,3.05,3.08,3.10,3.15,3.16,3.17,3.19,3.20)$..

5.3.4 Quasi-Static vs. Dynamic Models (Associated RDTME KTIs 3.12, $3.13,3.19$ )

5.3.5 Initial and Boundary Conditions (Associated RDTME KTIs 3.13)........... 5-13

5.4 CONCLUSIONS

6. APPROACH TO RESOLVING THE AGREEMENTS

6.1 PROGRAM ELEMENT A - GEOTECHNICAL AND GEOLOGICAL

CHARACTERIZATION OF THE TOPOPAH SPRING FORMATION

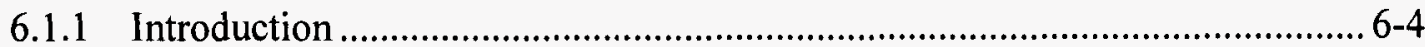

6.1.2 Generation of a Representative Fracture Volume for Ground Support and Rockfall Studies.

6.2 PROGRAM ELEMENTS B-E-SUPPLEMENTAL MATERIAL

PROPERTIES TESTING AND NUMERICAL MODEL VALIDATION

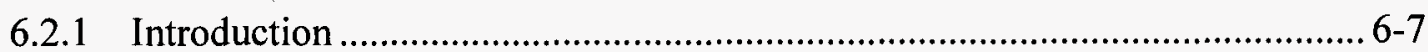

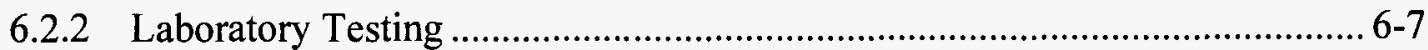

6.2.3 In Situ Compression Testing .................................................................. 6-8

6.2.4 Model Calibration and Determination of a Rock Mass Mechanical Constitutive Model for Lithophysal Rocks 6-9

7. GEOMECHANICAL DESIGN AND PERFORMANCE ASSESSEMENTPRECLOSURE GROUND SUPPORT AND POSTCLOSURE DRIFT

DEGRADATION ANALYSES 7-1

7.1 ANALYSIS OF ROCKFALL UNDER POSTCLOSURE SEISMIC

SHAKING

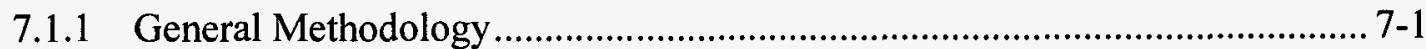

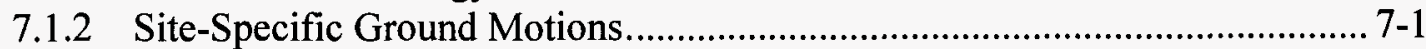

7.1.3 Numerical Modeling Approach................................................................... 7-2

7.2 THERMAL LOADING EFFECTS AND LONG-TERM STRENGTH

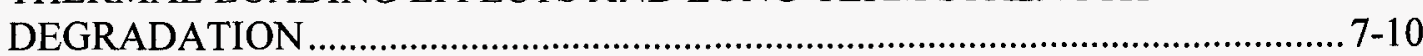

7.2.1 Discussion .................................................................................... 7-10

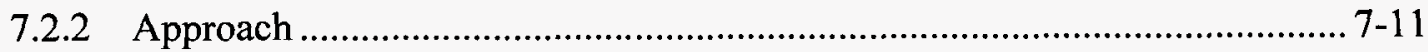

7.3 GROUND SUPPORT DESIGN AND EVALUATION ................................... $7-15$ 
CONTENTS (Continued)

Page

7.3.1 Current Drift Stability and Ground Support Function Under Gravitational Loading at Repository Depths-Predictions and Correspondence to Observations in the ESF and the ECRB Cross-Drift..... 7-16

7.3.2 Ground Support Design and Assessment Methodology 7-21

7.3.3 Methodology for Use of Numerical Models in Determining Ground Support Functions Under Repository Loading....

8. SUMMARY $8-1$

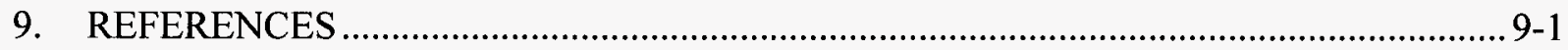

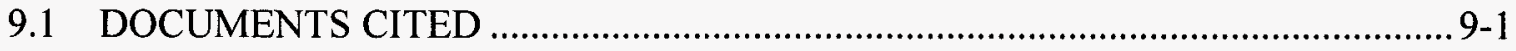

9.2 CODES, STANDARDS, REGULATIONS, AND PROCEDURES .......................9-4

9.3 SOURCE DATA, LISTED BY DATA TRACKING NUMBER ..............................9-4

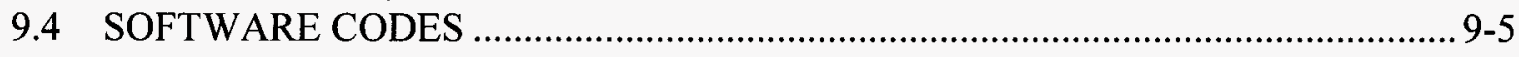

APPENDIX A: OVERVIEW OF THE RESOLUTION STRATEGY FOR EACH

GEOMECHANICALLY-RELATED KTI AGREEMENT A-1

APPENDIX B: THERMAL AND MECHANICAL ROCK PROPERTIES

DATA BASE. B-1 


\section{FIGURES}

i General Approach to Resolution of the Geomechanically-Related Key Technical Issue viii

1. Resolution Flow Chart of Key Technical Issue Agreements for Rockfall and Drift Degradation $1-3$

2. Resolution Flow Chart of Key Technical Issue Agreements for Ground Support Design in the Emplacement Drifts. $1-4$

3. Geologic Cross Section through the ECRB Cross-Drift (approximately East-West).........3-4

4. Schematic Illustration of the Structure of the Topopah Spring Formation........................... 3-8

5. Composite Plot of Fracture Frequency and Lithophysal Porosity as a Function of Distance along the ECRB Cross-Drift .

6. Fracture Trace Length as a Function of Depth in the ECRB Cross-Drift and by Sub-Unit of the Tptp from Detailed Line Surveys.. 3-10

7. Ilustrative Example of a Full Periphery Fracture Map from the ESF, Tptpmn ................ 3-11

8. Fractures in Wall of the ECRB Cross-Drift in Middle Nonlithophysal Unit ................... 3-12

9. Low-Angle Vapor-Phase Partings in Tptpmn................................................................ 3-12

10. Comparison of Lithophysae and Fracturing in the Tptpul and Tptpll ............................. 3-13

11. Lithophysal Panel Mapping from the Tptpll........................................................... 3-15

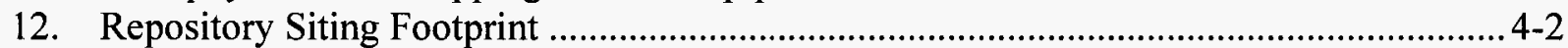

13. Conceptual Layout of the Repository within the Siting Footprint Boundary ...................... 4-3

14. Overlay of the Topopah Spring Geologic Sub-Unit on Repository Layout ....................... 4-4

15. Number of Basic Mechanical Tests Conducted on Various Sub-Zones of the Topopah Spring Tuff as of 2001 ................................................................................ 5-3

16. Location of Uniaxial Compressive Strength Test Samples ................................................ 5-4

17. Intact Rock Modulus and Strength as a Function of Effective Porosity ..............................5-6

18. Effects of Sample Size on the Uniaxial Compressive Strength of Welded Tuff from the Middle Nonlithophysal Zone (Tptpmn) ................................................................ 5-7

19. Photograph of a 10.5-in Diameter Core Sample ............................................................... 5-8

20. Relationship of Uniaxial Compressive Strength and Young's Modulus for Large Core Testing from the Tptpul, Busted Butte....................................................................5-9

21. General Approach to Resolution of the RDTME KTI Agreements .................................... 6-2

22. Methodology for Generation and Verification of Fracture Geometries in

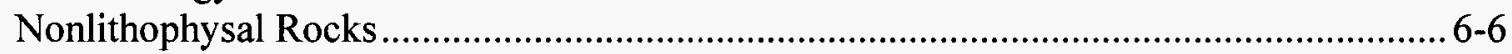

23. Slot Test Combining Parallel Slots and a Central Drilled Hole........................................ 6-10

24. Repository Layout with Overlay of the Topopah Spring Sub-Unit................................. 6-13

25. Physical Basis of the PFC Modeling Approach......................................................... 6-14

26. Example of a PFC Model Calibration..................................................................... 6-16

27. PFC Model of Uniaxial Compression........................................................................... 6-17

28. Extrapolation Strategy to Define the Range in Design and Performance Properties

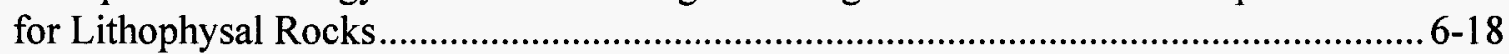

29. Static-Fatigue Curve vs. Stress Level for Lac du Bonnet Granite .................................... 6-19 


\section{FIGURES (CONTINUED)}

30. Comparison of URL Mine-By Tunnel Time-Dependent Notch Formation with PFC Excavation-Scale Model with Bond Strength Governed by Time Dependent Degradation of Rock Strength Governed by Stress Corrosion (Upper Right) after 2 Months

31. General Procedure for Rockfall Analysis $7-3$

32. General Methodology for Rockfall Calculations in the Nonlithophysal Rocks ............... 7-6

33. Methodology for Rockfall Analysis in Lithophysal Rocks ........................................ 7-6

34. Example of a Core Sample from the Tptpll ............................................................ 7-7

35. Conceptual UDEC Model of Lithophysal Rocks......................................................... 7-8

36. Example of UDEC model Calibration Approach ..................................................... 7-9

37. PFC Model of a Rough Joint ................................................................................ 7-14

38. Example of PFC Prediction of Damage Induced in Asperities for a Particular Case of Normal Stress as a Joint is Sheared.

39. Comparison of PFC Model Results to Barton-Bandis Empirical Joint Constitutive Model for Joint Shear and Normal Response

40. Mining-Induced Stress Around Quarter-Symmetry Tunnel ....................................... 7-18

41. Yield Zone Around Tunnels in Tptpll ..................................................................... 7-19

42. Typical Ground Support for Various Joint Densities and Stress Levels Showing Conditions Typical of the Tptpmn and Tptpll.

43. Ground Support Design and Assessment Methodology ......................................... 7-23

B-1. Intact Rock Modulus and Strength as a Function of Effective Porosity ............................. 4

B-2. Photograph of Busted Butte Sample from the Upper Lithophysal Zone (Tptpul)................ 5

B-3. Effect of Sample Size on the Uniaxial Compressive Strength of Welded Tuff from the Middle Nonlithophysal Zone (Tptpmn)

B-4. Modulus (a), Compressive Strength (b), and Tensile Strength (c) as Functions of Porosity

B-5. Thermal Conductivity vs. Porosity for Oven-Dried Specimens from NRG Boreholes 


\section{TABLES}

Page

1. Stratigraphic and Thermal Mechanical Units Relevant to the ECRB Cross-Drift ........... 3-2

2. General Characteristics of Fracture Sets in the Middle Nonlithophysal Unit

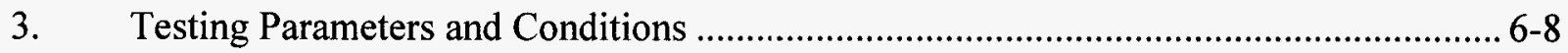

4. In Situ Stress Estimates at Yucca Mountain Site ....................................................... 7-17

B-1. Low Temperature $\left(<100^{\circ} \mathrm{C}\right)$ Rock Thermal Conductivities ${ }^{(a)}$.................................... 10

B-2. High Temperature $\left(>100^{\circ} \mathrm{C}\right)$ Rock Thermal Conductivities ${ }^{(a)}$...................................... 10

B-3. Mean Coefficient of Thermal Expansion During Heat-Up............................................. 12

B-4. Thermal Capacitance ( $\rho \cdot \mathrm{Cp}$ ) of Topopah Spring Tuff.................................................. B-13 


\section{ACRONYMS AND ABBREVIATIONS}

BSC Bechtel SAIC Company, LLC

CAD computer-aided drafting

DOE U.S. Department of Energy

ECRB Enhanced Characterization of the Repository Block

ESF Exploratory Studies Facility

KTI Key Technical Issue

MCTE mean thermal coefficients of thermal expansion

MTHM metric tons of heavy metal

NRC U.S. Nuclear Regulatory Commission

ORD Office of Repository Development

Q

quality system

RDTME Repository Design and Thermal-Mechanical Effects

RMR Rock Mass Rating

$\mathrm{RQD} \quad$ rock quality designator

TBM tunnel boring machine

UCS uniaxial compressive strengths

URL Underground Research Laboratory

USBR U.S. Bureau of Reclamation

YMP Yucca Mountain Project 
INTENTIONALLY LEFT BLANK 


\section{INTRODUCTION}

In September of 2000, the U.S. Nuclear Regulatory Commission (NRC) issued an Issue Resolution Status Report (NRC 2000). The Key Technical Issue (KTI) agreements on Repository Design and Thermal-Mechanical Effects (RDTME) were jointly developed at the Technical Exchange and Management Meeting held on February 6-8, 2001 in Las Vegas, Nevada. In that report, a number of geomechanically-related issues were raised regarding the determination of rock properties, the estimation of the impacts of geologic variability, the use of numerical models, and the examination of drift degradation and design approach to the ground support system for the emplacement drifts. Ultimately, the primary end products of the KTI agreement resolution processes are an assessment of the preclosure stability of emplacement drifts and the associated ground support requirements. There is also an assessment of the postclosure degradation of the excavations when subjected to thermal and seismic-related stresses as well as in situ loading over time.

Subsequent to that report, several teleconferences were held with the NRC to discuss technical differences. The outcomes of those discussions were formulated into agreements for resolution at the NRC/DOE Technical Exchange and Management Meeting on RDTME held in February of 2001.

As a result of the February RDTME Technical Exchange with the NRC, a number of agreements related to geomechanical design and performance assessment must be addressed. This report specifically addresses how the DOE proposes to resolve those agreements related specifically to geomechanical concerns. The specific RDTME agreements addressed by this document are listed in Appendix A.

The RDTME agreements cover a number of technical issues regarding the assessment methodologies and rock mechanics data available to support these assessments. These agreements address such concerns as:

- The robustness of estimates of rock mass properties

- The robustness of numerical models and the physical representations of rock mass structure and input loading conditions used in these models for performance evaluations

- The representation and assessment of the impact of the spatial variability of properties

- The methodology for representing time-related degradation of strength in the modeling approach and its impact on excavation stability and rock mass performance

- The ability to establish conservatism in the calculations

- The ability to predict the performance of ground support measures over preclosure time frames

- The ability to predict postclosure drift degradation due to various factors including seismic shaking, thermal loading and static fatigue. 
Because of the complexity of RDTME agreements (particularly dealing with lithophysal rock, for which little contemporary experience is available), the Office of Repository Development (ORD) convened a panel of experts to assess these items and the means for resolving them. The panel consisted of experts in the fields of geology, geotechnical assessment, and mining engineering, both from within and outside the ORD. The members of this panel are listed as authors or acknowledged in this paper.

In May of 2001, the panel conducted a three-day series of meetings in Las Vegas. During these meetings, the panel reviewed the current geomechanical design and performance assessment methodology and discussed the issues associated with the approach. They also looked at the types of tests conducted to date, the results of these tests, and all currently available data. Finally, they toured the Exploratory Studies Facility (ESF) and the Enhanced Characterization of the Repository Block (ECRB) Cross-Drift to view the rock mass and test areas firsthand. The panel came to three basic conclusions:

- The current base of geomechanical data (Appendix B) is incomplete in certain areas.

- Large-scale laboratory and in situ testing is required to assess the geomechanical design and performance properties of the lithophysal rock. Empirical techniques alone (common to the mining and construction industries) were judged inadequate for estimating site-specific mechanical properties of the lithophysal rocks.

- Alternative and/or additional modeling applications are needed.

Based on these findings, the panel formulated a plan and proposed a series of tests needed to understand the rock behavior and provide adequate input for a design.

Following this meeting, individual participant organizations developed proposals regarding laboratory and in situ testing and numerical modeling methods that could be used to more confidently predict the behavior of the lithophysal and nonlithophysal rocks. The geotechnical panel reconvened in June of 2001 to review test proposals, prioritize the work, and finalize their recommendations for resolution.

This report provides a proposed approach toward resolution of these issues, as suggested by the panel, and developed in the months since their discussions. However, there are a number of key junctures in the plan that will require review and reassessment in order to come to resolution. Meetings will be conducted at the key junctures in the process to update the NRC on progress, changes, or additions to the program. This plan may be adjusted over time as new information is gained, altered, or new approaches are required.

Figure 1 and Figure 2 are intended to demonstrate this approach for the two primary end-products of the geomechanical program: rock support and drift degradation analyses.

In developing the issues, methodologies and approaches presented in this document, it was necessary to perform a number of scoping calculations. These calculations (e.g., stresses around excavations, estimates of possible yielding mode and yielding extent into the rock mass) are 
given purely for preliminary estimation or demonstration purposes and have thus not been subjected to rigorous checking.
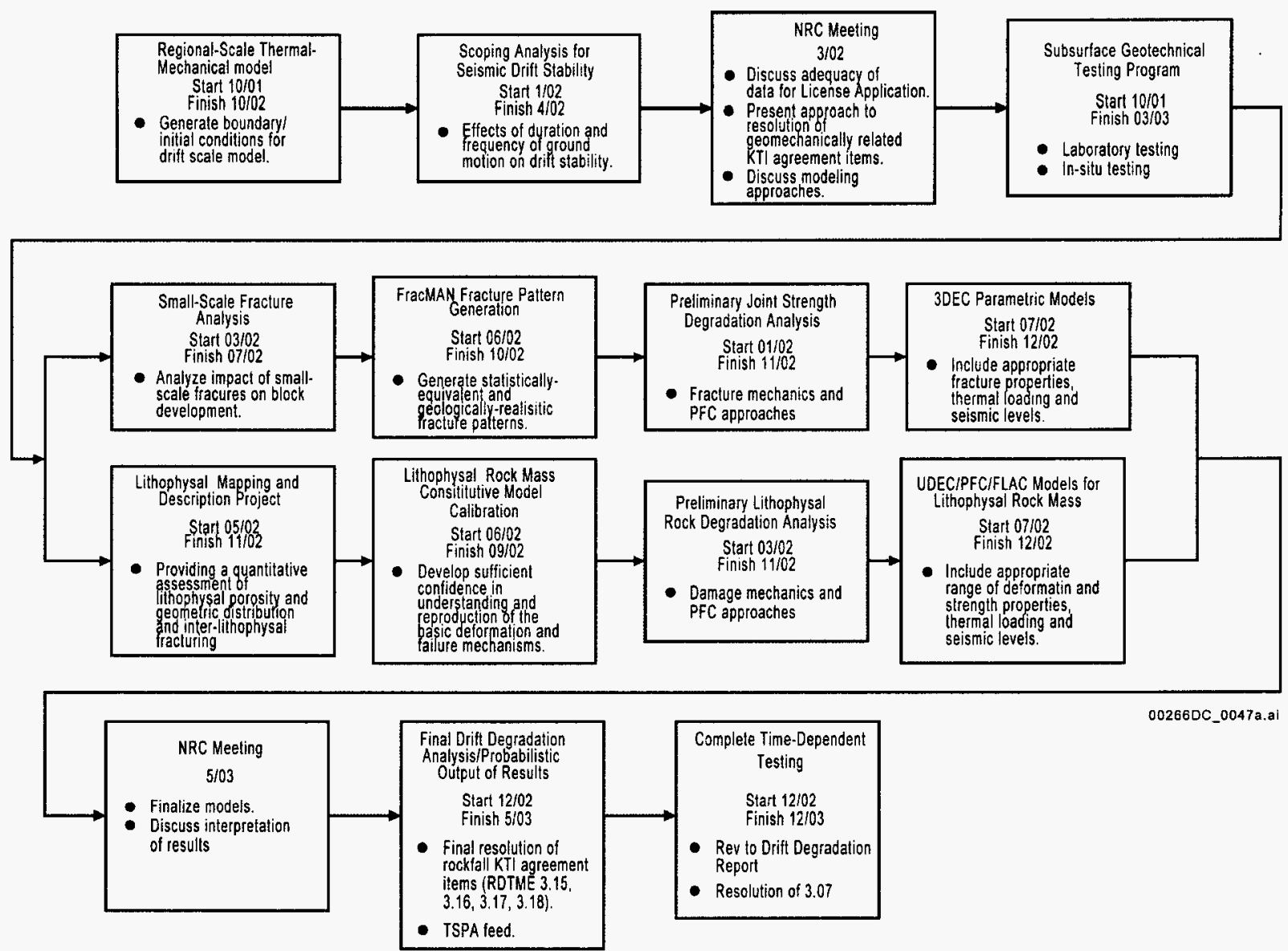

Figure 1. Resolution Flow Chart of Key Technical Issue Agreements for Rockfall and Drift Degradation 


\begin{tabular}{|c|c|c|c|}
\hline $\begin{array}{l}\begin{array}{l}\text { Design Parameters } \\
\text { Analysis REV } 00\end{array} \\
\text { Start } 4 / 01 \\
\text { Finish } 2 / 03 \\
\text { - Evaluation of adequacy of } \\
\text { current data. } \\
\text { - Identify additional testing } \\
\text { required. } \\
\text { - Ropresentative sampling } \\
\text { plan. }\end{array}$ & $\begin{array}{l}\text { NRC Meeting } \\
\qquad 3 / 02 \\
\text { - Review current state of data, } \\
\text { - Discuss additional testing } \\
\text { proposals. } \\
\text { - Present approach to } \\
\text { resolution of KTls relating } \\
\text { to ground support. }\end{array}$ & $\begin{array}{c}\text { Subsurface } \\
\text { Geotechnical } \\
\text { Testing Program } \\
\text { Start 10/01 } \\
\text { Finish } 2 / 03 \\
\text { - Laboratory testing } \\
\text { - In-situ Testing } \\
\text { - Fractures studies }\end{array}$ & $\begin{array}{l}\text { NRC Meeting } \\
\text { 5/03 } \\
\text { - Discuss adequacy of } \\
\text { data for License } \\
\text { Application Design. } \\
\text { - Discuss approach to } \\
\text { assessing uncertainties } \\
\text { of data. }\end{array}$ \\
\hline
\end{tabular}

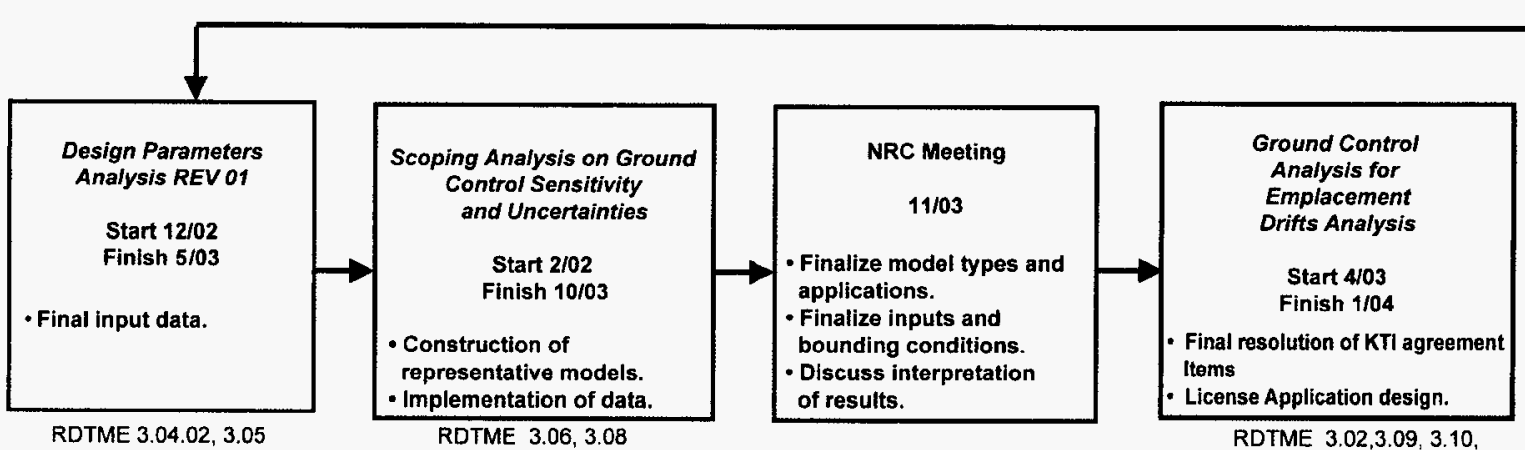
$3.11,3.12,3.13$

00266DC_048a.ai

Figure 2. Resolution Flow Chart of Key Technical Issue Agreements for Ground Support Design in the Emplacement Drifts 


\section{THE REPOSITORY DESIGN AND THERMAL MECHANICAL EFFECTS AGREEMENTS AND HOW THEY ARE BEING ADDRESSED}

\subsection{GENERAL DISCUSSION OF AGREEMENTS}

Geomechanically-related RDTME agreements (Appendix A) can be subdivided into five primary areas:

A. Rock mass properties and geotechnical characterization

1. Development of a basic understanding of how the structural characteristics of the repository host horizon impacts rock mass behavior and, consequently, the design and performance properties. This work can be used to establish a connection between geologic characteristics and their use in models and calculations.

2. Develop an understanding of the variability of geologic structure and, using the developments of the above item, identify how variability affects rock mass thermomechanical behavior.

3. Enhance the data base of thermomechanical materials properties of repository rock units, including mechanical and thermal testing of lithophysal rocks, estimation of the mechanical properties of rock fractures, and determination of the time-dependent response of lithophysal rocks. Development or choice of proper constitutive models for the different distinct rock units is a portion of this effort.

B. Modeling

1. Determination or development of the proper type of modeling tools to use for sensitivity studies of excavation stability under gravitational, thermal and seismic shaking. Specific agreements cited in the KTI include:

a. Under what circumstances are continuum and discontinuum models appropriate?

b. Under what circumstances are two- and three-dimensional models appropriate?

c. Under what circumstances are assumptions of rock mass homogeneity or anisotropy appropriate?

2. Determination of the proper model boundary and initial conditions

a. Need to address the initial stress state for models and inclusion of thermally induced stress history from regional models applied to local scale models for problems such as rockfall

b. Need to address special boundary conditions for dynamic analyses, including non-reflecting and free-field boundaries 
c. Need for development of preclosure and postclosure site-specific ground motion time histories.

C. Seismic Stability

1. Use of site-specific ground motions

2. Use of appropriate dynamic models for estimation of rockfall induced by seismic shaking

3. Methodology for inclusion of geologic structure and its variability into models for estimation of rockfall.

D. Thermal and Long-term Degradation

1. Need to examine potential for thermal-stress induced rockfall

2. Need to examine impact of long-term static fatigue of the rock mass and its impact on drift degradation and rockfall.

E. Ground Support and Drift Degradation

1. Verification of the functional and operational requirements and specification of ground support during the preclosure period.

2. Development of a plan for observation and maintenance of the ground support.

3. Estimation of the effect of postclosure in situ, thermal and seismically induced stresses on the degradation and potential rockfall of the emplacement drifts. Included here is the potential effect of time-related static fatigue mechanisms in intact rock and joints.

\subsection{RESOLUTION STRATEGY}

\subsubsection{Overall Approach}

The strategy described in this document for resolving these issues is based on the following combination of analyses, studies and calculations (see also Figure 1 and Figure 2).

- Evaluation and geotechnical analysis of the existing, extensive geological mapping and geotechnical characterization data from surface and underground mapping of lithology, structure and rock quality.

- Additional laboratory and in situ thermomechanical testing, primarily of lithophysal rocks, to provide information for confirmation of the material models and property ranges to be used in design and performance sensitivity studies. 
- Calibration and validation of numerical models capable of representing the thermomechanical behavior of lithophysal rocks.

- Use of the validated models to explore the impact of geologic variability (porosity, lithophysae shape and distribution, and fracture density) on the geomechanical response, primarily of lithophysal rocks. Validated models are used to supplement the material properties data base by extrapolating the effects of geologic variability.

- Numerical model sensitivity studies to examine preclosure ground support and postclosure drift degradation and seismic stability issues.

There are two points of particular importance in this strategy:

1. Because the performance of the tuff rock mass is primarily a function of geologic structure (e.g., fractures and lithophysal porosity), modeling tools must be based on geologic information gathered from the field and laboratory. It is the goal of this strategy to demonstrate a direct linkage between the basis of the models and the geologic reality in the field.

2. Rock mass property derivations via typical "empirically based" rock mass classification schemes or "statistically based" testing programs using small core samples are not particularly applicable to lithophysal rocks because the behavior of the rock mass is porosity- and size-dependent.

The porosity- and size-dependence means that, for rock mass property estimates, assurance must be provided by a limited number of large-core laboratory and in situ tests to determine the thermal and mechanical properties of the material. Since this will necessarily result in a relatively small data base, the goal is to closely couple numerical models with the lab and field testing to provide a predictive capability that will represent the basic mechanisms of mechanical behavior of the lithophysal rocks. These validated numerical models can then be used for "test bed" extrapolation purposes to examine effects such as the impact of lithophysal size, shape and porosity on rock material model and property ranges.

\subsubsection{Geological and Engineering Methods Proposed to Resolve RDTME KTI Agreements}

The basic geological and engineering methods, described in detail in this document, include the following:

- Geological Characterization-This includes geological mapping and engineering geologic description of joints and lithophysae in the ESF and ECRB. Techniques include analysis of the extensive existing data base of full periphery structure maps, which are detailed line surveys of fracturing that includes fracture orientation, trace length, alteration and roughness information. The FracMAN program (FracMAN, 10114-2.511-00 V.2.511) will be used with these data as a basis for development of statistically representative fracture volumes, which will then form the basis of input to numerical analysis of rockfall in the non-lithophysal rocks. 
Lithophysae panel mapping studies conducted in the lower lithophysal unit within the ECRB, combined with surface-based geophysical porosity studies, will form the basis for estimating the geometric characteristics and variability of lithophysae. This information will be used for input to thermal and mechanical models of porosity-dependent properties.

- Materials Property Measurement-Analysis of the existing rock properties data base (Appendix B) has identified additional data collection needs. The data base will be enhanced through additional testing and through validation and extrapolation of numerical models capable of representing lithophysal rock behavior. The required additional data includes estimates of joint shear constitutive behavior and thermomechanical properties of lithophysal rocks. Joint shear response will be determined using laboratory direct shear tests on large and small samples. This will be supplemented by large-scale field roughness estimates that will be used in empirical relations for estimating shear strength and dilation for each major joint set. Lithophysal rock properties are both size and porosity-dependent, necessitating the use of large sample sizes. A laboratory program of thermomechanical testing of large diameter (12 in. $[30.5 \mathrm{~cm}])$ core samples will be conducted to derive mechanical and thermal properties of rock samples large enough to contain many lithophysae. A number of in situ heating and compression experiments (1-m scale) will be conducted for deformation modulus, strength and thermal conductivity measurement on a representative scale. It is proposed to validate the numerical PFC 2D (PFC 2D, 10828-2.0-00 V.2.0) and PFC 3D (PFC 3D, 10830-2.0-00 V.2.0) modeling program (collectively referred to as "PFC" in remainder of document) against the laboratory and field testing of the lithophysal rock. The PFC program is a large displacement, discontinuum "micromechanical" modeling tool that physically represents the mechanical behavior of bonded particle materials such as rock. It has the advantage of allowing holes in the rock as well as interlithophysal fracturing, and thus provides a methodology for representing and understanding the basic mechanical response of lithophysal rocks through back-analysis of compression testing. Since only limited access to the repository horizon is available and only a limited number of large-scale compression tests are possible, the validated numerical model will be used to supplement the test data by extrapolation. In other words, the model will be used as a numerical "test bed" for exploring the impact of lithophysae shape, size, distribution and porosity on its mechanical properties and failure modes. Finally, time-dependent strength properties (i.e., static fatigue) need to be determined for nonlithophysal and lithophysal materials.

- Modeling and Design Tools-Although empirical methods are typically employed in rock engineering for design, they have only limited applicability here due to the general lack of experience base in lithophysal rocks and to the complex loading states generated by heating and seismic forces. Therefore, numerical models will be used as primary methods of design and performance assessment, with empirical methods as confirmatory tools. The non-lithophysal rocks are typical, strong, fractured materials whose behavior is expected to be largely controlled by the fracture geometry and surface properties, and will be anisotropic in nature. Consequently, reliance for rockfall analysis under thermal and seismic loading is placed on the use of three-dimensional discontinuum analysis 
methods (e.g., 3DEC [3DEC, 10025-2.0-00 V.2.0.]). The thermomechanical behavior of the lithophysal rocks is expected to be isotropic, but controlled by lithophysal porosity. It is the intention of the project to develop a rock mass constitutive model to describe the shear and possible compaction response of the material, whose material properties are porosity-dependent. The approach suggested is to embed this constitutive response into two-dimensional numerical models for purposes of representation of yield and deformation response to thermal and seismic load. To enable estimates of physical rock degradation and rockfall, two-dimensional discontinuum modeling approaches (i.e., UDEC [UDEC V.3.0, 10173-3.0-00 V.3.0]) will be used as described in detail in this document. A program of model calibration and validation against the field tests, and current tunnel observations in the ESF and ECRB, is planned to provide confidence in their application. Preclosure ground support design will be accomplished using a combination of empirical methods as used in industrial practice, which will be confirmed using numerical analysis techniques.

\subsection{OVERVIEW OF THE RESOLUTION STRATEGY FOR EACH GEOMECHANICALLY-RELATED KEY TECHNICAL ISSUE AGREEMENT}

The relevant geomechanically-related issue agreements and an overview of the resolution strategy is given in Appendix A for each of the KTI agreements covered by this document. Details of the overall resolution strategy are given in Sections 5 and 6 of this report. The following KTI agreements are addressed in this report with quoted pertinent sections:

\subsubsection{RDTME 3.02}

Provide the critical combinations of in-situ, thermal, and seismic stresses, together with their technical bases, and their impacts on ground support performance. The DOE will examine the critical combinations of in-situ, thermal, and seismic stresses, together with their technical bases and their impacts on preclosure ground support performance. These results will be documented in a revision to Ground Control for Emplacement Drifts for SR, ANL-EBS-GE-000002 (or other document) supporting any potential license application. This is expected to be available to NRC in FY 2003.

\subsubsection{RDTME 3.04}

Provide in the Design Parameter Analysis Report (or some other document) sitespecific properties of the host rock, as a minimum those included in the NRC handout, together with the spatial and temporal variations and uncertainties in such properties, as an update to the information contained in the March 1997 Yucca Mountain Site Geotechnical Report. The DOE will: (1) evaluate the adequacy of the currently available measured and derived data to support the potential repository licensing case and identify areas where available data may warrant additional field measurements or testing to reduce uncertainty. DOE will provide a design parameters analysis report (or other document) that will include the results of these evaluations, expected to be available to the NRC in FY 2002; and (2) acquire data and/or perform additional analyses as necessary to respond 
to the needs identified in 1 above. The DOE will provide these results prior to any potential license application.

\subsubsection{RDTME 3.05}

Provide the Rock Mass Classification Analysis (or some other document) including the technical basis for accounting for the effects of lithophysae. The DOE will provide a rock mass classification analysis (or other document), including the technical basis for accounting for the effects of lithophysae, expected to be available to NRC in FY 2002.

\subsubsection{RDTME 3.06}

Provide the design sensitivity and uncertainty analyses of the rock support system. The DOE will prepare a scoping analysis to determine the significance of the input parameters for review by NRC staff by August 2002. Once an agreed set of significant parameters has been determined by the DOE and NRC staff, the DOE will prepare an analysis of the sensitivity and uncertainty of the preclosure rock support system to design parameters in a revision to Ground Control for Emplacement Drifts for SR, ANL-EBS-GE-000002 (or other document) supporting any potential license application. This is expected to be available to NRC in FY 2003.

\subsubsection{RDTME 3.07}

The DOE should account for the effect of sustained loading on intact rock strength or provide justification for not accounting for it. The DOE will assess the effects of sustained loading on intact rock strength. The DOE will provide the results of this assessment in a design parameters analysis report (or other document), expected to be available to NRC in FY 2002.

\subsubsection{RDTME 3.08}

Provide the design sensitivity and uncertainty analyses of the fracture pattern (with respect to Subissue 3, Component 1). The DOE will provide sensitivity and uncertainty analysis of fracture patterns (based on observed orientation, spacing, trace length, etc) on the preclosure ground control system design in a revision to Ground Control for Emplacement Drifts for SR, ANL-EBS-GE-000002 (or other document) supporting any potential license application. This is expected to be available to NRC in FY 2003.

\subsubsection{RDTME 3.09}

Provide appropriate analysis that shows rock movements in the invert are either controlled or otherwise remain within the range acceptable to provide for retrieval and other necessary operations within the disposal drifts. DOE will provide appropriate analysis that shows rock movements in the floor of the emplacement drift are within the range acceptable for preclosure operations. The 
analysis results will be provided in a revision to Ground Control for Emplacement Drifts for SR, ANL-EBS-GE-000002 (or other document) supporting any potential license application. This is expected to be available to NRC in FY 2003.

\subsubsection{RDTME 3.10}

Provide technical basis for the assessment that two-dimensional modeling of emplacement drifts is considered to be adequate, considering the fact that neither the in-situ stress field nor the principle fracture orientation are parallel or perpendicular to emplacement drift orientation. The DOE will provide the technical bases for the modeling methods used in ground control analysis in a revision to Ground Control for Emplacement Drifts for SR, ANL-EBS-GE-000002 (or other document) supporting any potential license application. This is expected to be available to NRC in FY 2003.

\subsubsection{RDTME 3.11}

Provide continuum and discontinuum analyses of ground support system performance that take into account long-term degradation of rock mass and joint strength properties. The DOE will justify the preclosure ground support system design (including the effects of long-term degradation or rock mass and joint strength properties) in a revision to Ground Control for Emplacement Drifts for $S R, A N L-E B S-G E-000002$ (or other document) supporting any potential license application. This is expected to be available to NRC in FY 2003.

\subsubsection{RDTME 3.12}

Provide dynamic analyses (discontinuum approach) of ground support system performance using site-specific ground motion history as input. The DOE will provide appropriate analyses to include dynamic analyses (discontinuum approach) of preclosure ground support systems, using site-specific ground motion time histories as input, in a revision to Ground Control for Emplacement Drifts for $S R, A N L-E B S-G E-000002$ (or other document) supporting any potential license application. This is expected to be available to NRC in FY 2003.

\subsubsection{RDTME 3.13}

Provide technical justification for boundary conditions used for continuum and discontinuum modeling used for underground facility design. The DOE will provide the technical justification for boundary conditions used in modeling for preclosure ground control analyses, in a revision to Ground Control for Emplacement Drifts for SR, ANL-EBS-GE-000002 (or other document) supporting any potential license application. This is expected to be available to NRC in FY 2003. 


\subsubsection{RDTME 3.15}

Provide field data and analysis of rock bridges between rock joints that are treated as cohesion in DRKBA modeling together with a technical basis for how a reduction in cohesion adequately accounts for thermal effects. The DOE will provide clarification of the approach and technical basis for how reduction in cohesion adequately accounts for thermal effects, including any additional applicable supporting data and analyses. Additionally, the adequacy of the cohesion reduction approach will be verified according to the approach described in Subissue 3, Agreement 22, of the Repository Design and Thermal-Mechanical Effects Technical Exchange. This will be documented in a revision to the Drift Degradation Analysis, ANL-EBS-MD-000027, expected to be available to NRC in FY 2003.

\subsubsection{RDTME 3.16}

Provide a technical basis for the DOE position that the method used to model joint planes as circular discs does not under-represent the smaller trace-length fractures. The DOE will analyze the available small trace-length fracture data from the Exploratory Studies Facility and Enhanced Characterization of the Repository Block, including their effect on block development. This will be documented in a revision to the Drift Degradation Analysis, ANL-EBS-MD000027 , expected to be available to NRC in FY 2003.

\subsubsection{RDTME 3.17}

Provide the technical basis for effective maximum rock size including consideration of the effect of variation of the joint dip angle. The DOE will provide the technical basis for effective maximum rock size including consideration of the effect of variation of the joint dip angle. This will be documented in a revision to Drift Degradation Analysis, ANL-EBS-MD-000027 in FY 2003.

\subsubsection{RDTME 3.19}

The acceptability of the process models that determine whether rockfall can be screened out from performance assessment abstractions needs to be substantiated by the DOE by doing the following: (1) provide revised DRKBA analyses using appropriate range of strength properties for rock joints from the Design Analysis Parameters Report, accounting for their long-term degradation; (2) provide an analysis of block sizes based on the full distribution of joint trace length data from the Fracture Geometry Analysis Report for the Stratigraphic Units of the Repository Host Horizon, including small joints trace lengths; (3) verify the results of the revised DRKBA analyses using: (a) appropriate boundary conditions for thermal and seismic loading; (b) critical fracture patterns from the DRKBA Monte Carlo simulations (at least two patterns for each rock unit); (c) thermal and mechanical properties for rock blocks and joints from the Design 
Analysis Parameters Report; (d) long-term degradation of rock block and joint strength parameters; and (e) site-specific ground motion time histories appropriate for postclosure period; provide a detailed documentation of the analyses results; and (4) in view of the uncertainties related to the rockfall analyses and the importance of the outcome of the analyses to the performance of the repository, evaluate the impacts of rockfall in performance assessment calculations. DOE believes that Drift Degradation Analysis is consistent with current understanding of the Yucca Mountain site and the level of detail of the design to date. As understanding of the site and the design evolve, DOE will: (1) provide revised DRKBA analyses using appropriate range of strength properties for rock joints from a design parameters analysis report (or other document), accounting for their long-term degradation; (2) provide an analysis of block sizes based on the full distribution of joint trace length data from the Fracture Geometry Analysis for the Stratigraphic Units of the Repository Host Horizon, ANL-EBS-GE-000006, supplemented by available small joint trace length data; (3) verify the results of the revised DRKBA analyses using: (a) appropriate boundary conditions for thermal and seismic loading; (b) critical fracture patterns from the DRKBA Monte Carlo simulations (at least two patterns for each rock unit); (c) thermal and mechanical properties for rock blocks and joints from a design parameters analysis report (or other document); (d) long-term degradation of joint strength parameters; and (e) site-specific ground motion time histories appropriate for postclosure period. This will be documented in a revision to Drift Degradation Analysis, ANL-EBS-MD-000027, expected to be available to NRC in FY 2003. Based on the results of the analyses above and subsequent drip shield calculation revisions, DOE will reconsider the screening decision for inclusion or exclusion of the rockfall in performance assessment analysis. Any changes to screening decisions will be documented in analyses prior to any potential license application. 


\section{INTENTIONALLY LEFT BLANK}




\section{REVIEW OF SITE GEOLOGY AND GEOTECHNICAL CHARACTERIZATION ACTIVITIES}

\subsection{INTRODUCTION - CURRENT DATA COLLECTION PROGRAM}

Geologic and geotechnical data collection has been a central focus of the YMP since its inception in 1982. Several reports specifically discussing geotechnical data for underground excavations have been produced for the YMP. Prior to construction of the ESF, Brechtel et al. (1995) completed a report incorporating data from preconstruction drilling and surface mapping for construction of the North Ramp. Kicker et al. (1997) produced a similar report for the ESF Main Drift. Following excavation, four reports were produced summarizing the as-built geology and rock mass rating for the ESF (Beason et al. 1996; Barr et al. 1996; Albin et al. 1997; and Eatman et al. 1997). Finally, one report was produced summarizing the geology and geotechnical characterization of the ECRB Cross-Drift (Mongano et al. 1999).

Two systems of stratigraphic nomenclature are used in the presentation of data: thermal-mechanical (Ortiz et al. 1985) and lithostratigraphic (Buesch et al. 1996). Correlation between these two stratigraphic systems is given in Table 1.

A comprehensive series of mechanical property measurements were conducted on specimens prepared from cores recovered from boreholes NRG-5, NRG-6, NRG-7/7A, SD-9 and SD-12, and to a limited extent from core recovered from boreholes in the ESF (Appendix B). The sampling plan for laboratory-determined geotechnical properties of intact rock was designed for data analysis by thermal mechanical units that are relatively thick, providing a large statistical base. The numbers of measurements performed in determining the geotechnical properties of intact rock are presented in Section 4.2. It should be noted that the principal sampling was for the middle nonlithophysal unit (Tptpmn) while limited sampling, analysis and testing are available for the lower lithophysal and nonlithophysal units (Tptpll, Tptpln). Extensive new drilling of 12-in. $(30.5-\mathrm{cm})$ diameter core is underway in the ECRB Cross-Drift and the ESF. The core from these holes is being used for additional thermomechanical testing of lithophysal rocks and for shear testing of joints.

Rock mass quality assessments were made to evaluate rock mass properties, tunnel stability, and ground support requirements. These assessments utilized the Norwegian Geotechnical Institute rock quality system ( $Q$ system) and data from boreholes and full-peripheral tunnel mapping from the ESF and ECRB Cross-Drift (Barton et al. 1974).

\subsection{REGIONAL GEOLOGY}

Yucca Mountain lies in southern Nevada, in the Great Basin, which is part of the Basin and Range structural/physiographic province. In the Yucca Mountain area, pre-Tertiary rocks (consisting of a thick sequence of Proterozoic and Paleozoic sedimentary rocks) underlie approximately 1000 to $3000 \mathrm{~m}$ of Miocene volcanic rocks (Gibson et al. 1990). 
Table 1. Stratigraphic and Thermal Mechanical Units Relevant to the ECRB Cross-Drift

\begin{tabular}{|c|c|c|}
\hline Unit Description & $\begin{array}{c}\text { Stratigraphic } \\
\text { Notation }\end{array}$ & $\begin{array}{c}\text { Thermal } \\
\text { Mechanical } \\
\text { Notation }\end{array}$ \\
\hline Upper Tiva Canyon, undifferentiated & Tpc & \multirow{2}{*}{ TCw } \\
\hline Lower densely-welded subunit of the Tiva Canyon Tuff & Tpcpv3 & \\
\hline Partially to nonwelded lower subzones of the Tiva Canyon Tuff & Tpcpv1-2 & \multirow{2}{*}{ PTn } \\
\hline Pre-Tiva Canyon Tuff bedded tuff & Tpbt4 & \\
\hline Yucca Mountain Tuff & Tpy & \multirow{5}{*}{ PTn } \\
\hline Pre-Yucca Mountain Tuff bedded tuff & Tpbt3 & \\
\hline Pah Canyon Tuff & Tpp & \\
\hline Pre-Pah Canyon Tuff bedded tuff & Tpbt2 & \\
\hline Topopah Spring Tuff: upper partially to non-welded zones & Tptrv2-3 & \\
\hline Topopah Spring Tuff: upper densely-welded vitrophyre & Tptrv1 & \multirow{5}{*}{ TSw1 } \\
\hline Topopah Spring Tuff: crystal-rich, nonlithophysal zone & Tptrn & \\
\hline Topopah Spring Tuff: crystal-rich, lithophysal zone & Tptrl & \\
\hline Topopah Spring Tuff: lithic-rich zone & Tptf & \\
\hline Topopah Spring Tuff: crystal-poor, upper lithophysal zone & Tptpul & \\
\hline Topopah Spring Tuff: crystal-poor, middle nonlithophysal zone & Tptpmn & \multirow{3}{*}{ TSw2 } \\
\hline Topopah Spring Tuff: crystal-poor, lower lithophysal zone & Tptpll & \\
\hline Topopah Spring Tuff: crystal-poor, lower nonlithophysal zone & Tptpln & \\
\hline Topopah Spring Tuff: crystal-poor, lower densely-welded vitrop & Tptpv3 & TSw3 \\
\hline
\end{tabular}

The Miocene volcanic sequence exposed at Yucca Mountain includes units of the Paintbrush and Timber Mountain Groups (Sawyer et al. 1994). The Paintbrush Group consists of pyroclastic rock and lava that originate from the Claim Canyon Caldera (approximately $6 \mathrm{~km}$ north of the study area) and are from 12.8 to 12.7 million years old (Byers et al. 1976; Sawyer et al. 1994). The Paintbrush Group includes a homoclinal sequence consisting of four formations, the Tiva Canyon, Yucca Mountain, Pah Canyon, and Topopah Spring Tuffs. These formations consist of pyroclastic-flow and pyroclastic-fall deposits with interbedded lava that dip 5 to 10 degrees to the east (Byers et al. 1976; Christiansen et al. 1977; Broxton et al. 1993). Two of these formations, the Topopah Spring and Tiva Canyon Tuffs, are voluminous, densely-welded, compositionally-zoned pyroclastic outflow sheets that grade upward from rhyolite composition to quartz latite composition (Lipman et al. 1966; Byers et al. 1976; Schuraytz et al. 1989). The tuff and ash flows of the Timber Mountain Group were erupted from Timber Mountain Caldera complex and consist of the Ammonia Tanks Tuff and the Rainer Mesa Tuff (Sawyer et al. 1994).

Yucca Mountain is bounded by the Yucca Wash to the north, by the Solitario Canyon fault to the west, and the Bow Ridge fault to the east. Alluvium-filled structural valleys, consisting mostly of alluvial fan deposits (fluvial and colluvial sediments) and some thin eolian deposits, lie adjacent to the Bow Ridge and Solitario Canyon faults on the east and west sides, respectively. The Yucca Mountain area is cut by steeply dipping normal faults which strike north to south and separate the Tertiary volcanics into blocks one to four kilometers wide (Scott 1990). The repository block is bounded by the Solitario Canyon fault to the west and the Ghost Dance fault 
to the east. Both faults dip steeply toward the west, and displacement, amount of brecciation, and number of associated splays vary considerably along their trace (Scott and Bonk 1984; Day et al. 1998). The Solitario Canyon fault has normal down-to-the-west displacement of about $260 \mathrm{~m}$ in the vicinity of the repository block. The Ghost Dance fault is in the central part the repository block and is a generally north-striking normal fault zone, with down to the west displacement. The Sundance fault is located in the north-central portion of the repository block. It is a northwest-striking, east-dipping normal fault with a maximum cumulative down-to-the-northeast displacement of 6 to $11 \mathrm{~m}$ (Day et al. 1998). Numerous smaller faults and fault zones are present throughout the repository block, generally north-trending with offsets less then $5 \mathrm{~m}$ (Mongano et al. 1999).

\subsection{LITHOSTRATIGRAPHY AT THE REPOSITORY HORIZON}

All of the rocks of the repository host horizon lie within the Topopah Spring Tuff, specifically within the crystal-poor member. The repository host horizon includes rock from the lower part of the upper lithophysal zone (Tptpul) of the TSw1 thermal mechanical unit, and all of the TSw2 thermal mechanical unit, including the middle nonlithophysal zone (Tptpmn), the lower lithophysal zone (Tptpll), and the lower nonlithophysal zone (Tptpln) (see Table 1 and Figure 3). These lithologies are described in this section (Mongano et al. 1999).

Tptpul-The crystal-poor upper lithophysal zone is exposed in both the ESF and ECRB Cross-Drift. The ECRB Cross-Drift begins in the upper central portion of the zone and it exposes rocks of the central and lower portions of the zone from Station $0+00$ to $10+15$. The upper portion of the upper lithophysal zone is also exposed in the hanging wall of the eastern strand of the Solitario Canyon fault zone from Station $25+90$ to $26+57.5$. In both exposures, the unit is moderately to densely welded, devitrified, and vapor-phase altered. In general, the rock appears grayish red-purple (5RP4/2) and contains 10 to 40 percent vapor-phase spots, stringers, and partings. The central and lower parts of the zone (Station $0+00$ to 10+15) are composed of 0 to 15 percent pumice, 1 to 3 percent phenocrysts, 0 to 5 percent lithic fragments, 10 to 60 percent lithophysae, and 40 to 90 percent matrix. The upper part of the zone (Station $25+90$ to $26+57.5$ ) is composed of 5 to 15 percent pumice, 2 to 5 percent phenocrysts, less than 1 percent lithic fragments, 3 to 20 percent lithophysae, and 60 to 90 percent matrix.

Tptpmn-The ESF is excavated in the middle nonlithophysal zone from Stations $27+21$ to $57+29$, from $58+78$ to $63+08$, and from $70+58$ to $71+68$. The ECRB Cross-Drift exposes the middle nonlithophysal zone from Station $10+15$ to $14+44$. In general, the moderately to densely welded, devitrified and variably vapor-phase altered unit is composed of less than 5 to 10 percent pumice (locally 25 to 35 percent), 1 to 2 percent phenocrysts, 1 to 2 percent lithic fragments, 0 to 1 percent lithophysae, and 85 to 93 percent matrix. Vapor-phase spots, stringers, and partings comprise from 1 to 15 percent of the rock. Smooth, high-angle fractures are typical of the zone, but it also contains occasional low-angle, continuous shears and cooling joints. Another feature characteristic of the Tptpmn is the presence of low-angle concentrations of vapor-phase minerals. These features appear as continuous partings subparallel to the dip of the unit. 


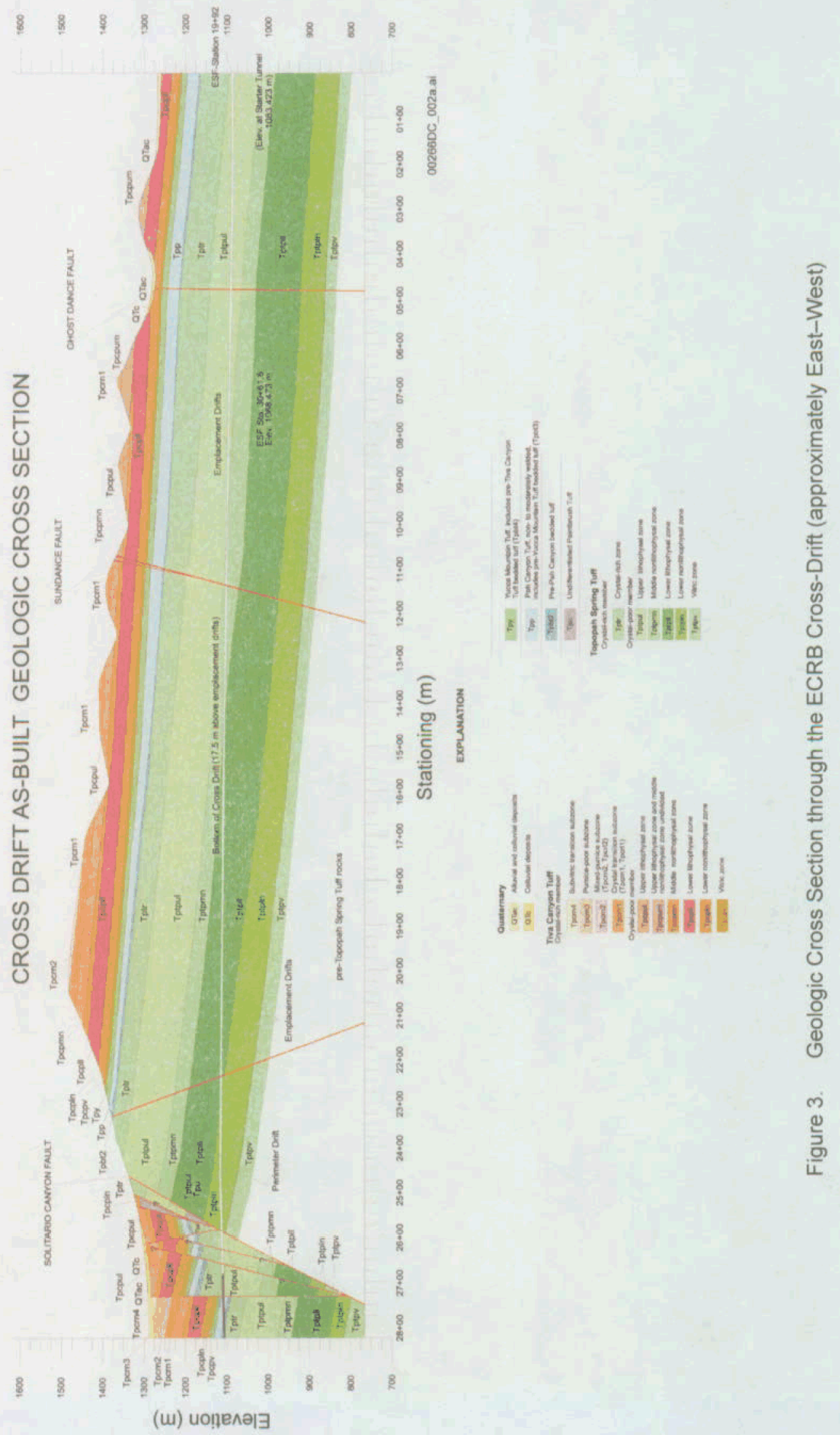


Tptpll-The ESF exposes a small portion of the upper contact of the lower lithophysal zone from Station $57+29$ to $58+78$. The lower lithophysal zone is exposed along the ECRB Cross-Drift from Station $14+44$ to $23+26$. In general, the moderately to densely welded, devitrified, and vapor-phase altered unit is composed of 3 to 7 percent pumice (locally 10 to 35 percent), 1 to 2 percent phenocrysts, 1 to 5 percent lithic fragments (locally 12 to 15 percent), 5 to 30 percent lithophysae (locally 1 to 5 percent), and 56 to 90 percent matrix. Lithophysae vary in size from ten centimeters to greater than 1 meter in diameter. Throughout most of the unit, vapor-phase spots, stringers, and wisps comprise between 3 and 12 percent of the rock. In several intervals, however, vapor-phase alteration products form 15 to 40 percent of the rock.

Tptpln-The Tptpln, exposed only in the ECRB Cross-Drift from Station $23+26$ to $25+85$, comprises moderately to densely welded, devitrified pyroclastic-flow material. It is generally composed of 3 to 20 percent pumice, 1 to 2 percent phenocrysts, 3 to 7 percent lithic fragments, 0 to 5 percent lithophysae, and 66 to 93 percent matrix. Vapor-phase alteration products form a minor component of the rock in some portions of the unit. Rocks of the lower nonlithophysal zone vary from a heterogeneous mix of grayish red and grayish orange pink (5YR7/2) to comparatively homogeneous pale red, light brown, pale brown, or grayish brown (5YR6/4). In proximity to the Solitario Canyon fault zone, the unit is brecciated and altered. In this area, the breccia matrix varies from moderate reddish brown to grayish orange pink to pale red; breccia clasts are locally bleached to very light gray adjacent to the fault plane.

\subsection{GEOTECHNICAL CHARACTERIZATION}

Geotechnical data were collected based on two empirical rock mass classification systems: the Q system (Barton et al. 1974) and the Geomechanics Rock Mass Rating system (RMR system) (Bieniawski 1989). Ratings are assigned to a five-meter length of tunnel using both rock classification systems. The use of this relatively short rating length may have the disadvantage of introducing variations in some evaluated parameters which may be expected to be stable; yet it has the advantage of capturing expected variations in more unstable parameters. For example, considering the $\mathrm{Q}$ system, one might assume the number of joint sets would be constant over a long reach of tunnel. Using a five-meter rating length permits evaluation of the actual occurrence of a particular joint set; therefore the rating value for the number of joint sets may vary within a ten-meter reach of tunnel. On the other hand, the five-meter rating length permits a description of the changes in fracture frequency represented by the rock quality designation (RQD). Overall, the five-meter rating length emphasizes changes in rock quality from one length to the next. When longer reaches of the tunnel or various stratigraphic units are compared, differences in the trends of the five-meter ratings and differences in the average ratings are meaningful.

Tptpul-The Tptpul (Station $0+00$ to $10+15$ and Station $23+26$ to $25+85$ ), the longest reach of the ECRB Cross-Drift, has the lowest RQD rating (36 poor), yet the highest $Q$ system rating ( 14 good). Its RMR value ( 57 fair) ${ }^{1}$ equals the RMR value of the Tptpll. Its lithophysae content range from 10 to 40 percent by volume. These cavities average $10 \mathrm{~cm}$ in diameter. Fractures are difficult to distinguish, with an average of only one joint set. No keyblocks are expected to form

\footnotetext{
${ }^{1}$ Note that the RMR or Q systems are based on fracturing and alteration as the primary structural features that weaken an in situ rock mass. There are no explicit allowances in these methods for lithophysae. Consequently, the lithophysae were accounted for through the RQD in attempting to apply this system to the Tptpul and Tptpll.
}

Resolution Strategy for Geomechanically-Related 
within this unit; however, there are occasionally some horizontal cooling joints. It has 11 faults, 1 fault zone, and 25 shears or shear zones.

Tptpmn-The Tptpmn (Station 10+15 to 14+44) has a mean horizontal RQD rating of 60 (fair), including lithophysae, and 62 (fair), excluding lithophysae. The projected $Q$ rating from the predictive report agrees with this assessment. The RMR system rates the Tptpmn and the Tptpln as the highest, with a rating of 60 (fair). The unit is generally characterized by less than 3 percent lithophysae by volume. The Tptpmn has 430 meters of exposure in the ECRB Cross-Drift and has the least amount of fault/shear activity with a total of 1 fault zone, 6 faults, and 13 shears. It has an average of three to three+ random joint sets. The horizontal joint sets, or vapor-phase partings, cause significant problems with keyblocks at Station $10+80$ to $11+55$ and Station $13+10$ to $13+15$.

Tptpll-The Tptpll (Station 14+44 to $23+26$ ) has a horizontal RQD rating of 42 (poor). Its tunnel-calculated Q rating is 7.9 (fair), the lowest in the ECRB Cross-Drift. The RMR system estimates for this unit at 57 (fair). The Tptpll is generally characterized by lithophysae of 5 to 30 percent by volume and range in size from 5 to $130 \mathrm{~cm}$. The larger lithophysal cavities tend to be irregular or ellipsoidal features that exhibit prismatic fracturing. The unit has an average of two+ random joint sets; however no keyblock problems are apparent. The Tptpll has 4 faults and 30 shears exposed in 882 meters of rated tunnel.

Tptpln. The Tptpln (Station $23+26$ to $25+85$ ) has the best horizontal RQD ratings: 62 (fair), including lithophysae, and 67 (fair), excluding the lithophysal cavities. Its tunnel-calculated $\mathrm{Q}$ rating is 12.3 (good). The RMR system rates this unit a 60 (fair). This unit is characterized by generally less than three percent lithophysal cavities by volume. It has an average of three joint sets, with no keyblock problems. The Tptpln has 6 faults and 36 shear or shear zones.

\subsection{DISCUSSION OF ENGINEERING CHARACTERISTICS OF ROCK MASS IMPORTANT TO GEOMECHANICAL DESIGN AND PERFORMANCE}

As discussed in Section 6.1, the structure of the rock mass plays what is perhaps the most important role in defining the properties and structural response of the repository to thermal and mechanical loading. In particular, the fracture geometry and properties and the degree of lithophysal porosity are the primary geologic structures of importance. Extensive geotechnical mapping of fractures has been performed in the entire ESF and the ECRB Cross-Drift (CRWMS M\&O 1998b, Mongano et al. 1999). Figure 4 shows a schematic of the Topopah Spring Formation illustrating the general occurrence of fracturing and lithophysae in the various sub-units of the flow. The occurrence of fractures and lithophysae are roughly inversely proportional. This is illustrated schematically in Figure 4 and demonstrated quantitatively in Figure 5, where the fracture density (fractures with trace length greater than $1 \mathrm{~m}$ ), determined from detailed line mapping, and the approximate percentage of lithophysal porosity in the ECRB Cross-Drift are shown. The density of fractures with trace length greater than $1 \mathrm{~m}$ is significantly larger in the Tptpmn and Tptpln $(20-35$ fractures/10 m), as compared to 5 fractures/10 $\mathrm{m}$ or less in the Tptpul and Tptpll. 


\subsubsection{Fracturing}

Full periphery and detailed line maps, consisting of a description of orientation, trace length, small and large scale roughness, and end terminations for all fractures with trace lengths of greater than or equal to one meter was performed in all drifts. The data base consists of over 35,000 entries and is recorded in CAD drawings as well as spreadsheets.

There are, in general, four sets of fractures in the Tptpmn with the following characteristics:

Table 2. General Characteristics of Fracture Sets in the Middle Nonlithophysal Unit

\begin{tabular}{|c|c|c|c|l|}
\hline Set & $\begin{array}{c}\text { Mean } \\
\text { Azimuth/Dip }\end{array}$ & $\begin{array}{c}\text { Mean } \\
\text { Spacing }(\mathrm{m})\end{array}$ & $\begin{array}{c}\text { Mean Trace Length } \\
(\mathbf{m})\end{array}$ & \multicolumn{1}{c|}{ Comment } \\
\hline 1 & $122 / 84$ & 0.5 & 2.3 & Rough to smooth, planar \\
\hline 2 & $195 / 85$ & 1.48 & 1.9 & Smooth but curved \\
\hline 3 & $306 / 09$ & 4.2 & 2.7 & $\begin{array}{l}\text { Vapor phase partings, } \\
\text { rough, cohesive with } \\
\text { coating minerals, planar }\end{array}$ \\
\hline 4 & variable/20-45 & - & 1.7 & $\begin{array}{l}\text { Random fractures with } \\
\text { generally flat to moderate } \\
\text { dip }\end{array}$ \\
\hline
\end{tabular}

Source: Mongano et al. 1999

The fractures, particularly the high angle sets (sets 1 and 2) have relatively short continuous trace lengths (Figure 6), with ends often terminating either against other fractures or in solid rock, leaving a solid rock "bridge" between joint tracks. Full periphery maps that logged all fracture traces with length greater than one meter were created behind the tunnel boring machine as the ESF and the ECRB Cross-Drift were driven. A typical full periphery map showing all fractures is shown in Figure 7 with these fractures subdivided into three sets (two sub-vertical, one sub-horizontal plus random) in the lower panels. Figure 8 shows the discontinuous nature of the fractures in each set. This figure shows a photograph typical of the wall of the ECRB Cross-Drift within the Tptpmn. During the detailed line mapping, the fracture traces were painted as seen in this photo. Each fracture termination was logged as being against another fracture, within solid rock, or continuous. The photo shows the common occurrence of fractures that terminate in solid rock ( $\mathrm{T}$-junctions) as opposed to continuous structures (arrowheads). The sub-vertical fractures, in particular, often have curved surfaces with large-amplitude (dozens of centimeters) asperities and wavelength of meters. Fractures often terminate in solid rock with discontinuous interconnection to adjacent joint tracks or against other joints.

The sub-horizontal vapor phase partings (Figure 9) are relatively continuous structures seen throughout the Tptpmn. These continuous, but anastamosing fractures are sub-parallel to the dip of the rock unit, and are filled with concentrations of vapor-phase mineralization (primarily tridymite and cristobalite). The surfaces are rough on a small scale, and, unlike the sub-vertical fractures, have cohesion as a result of the mineral filling. 


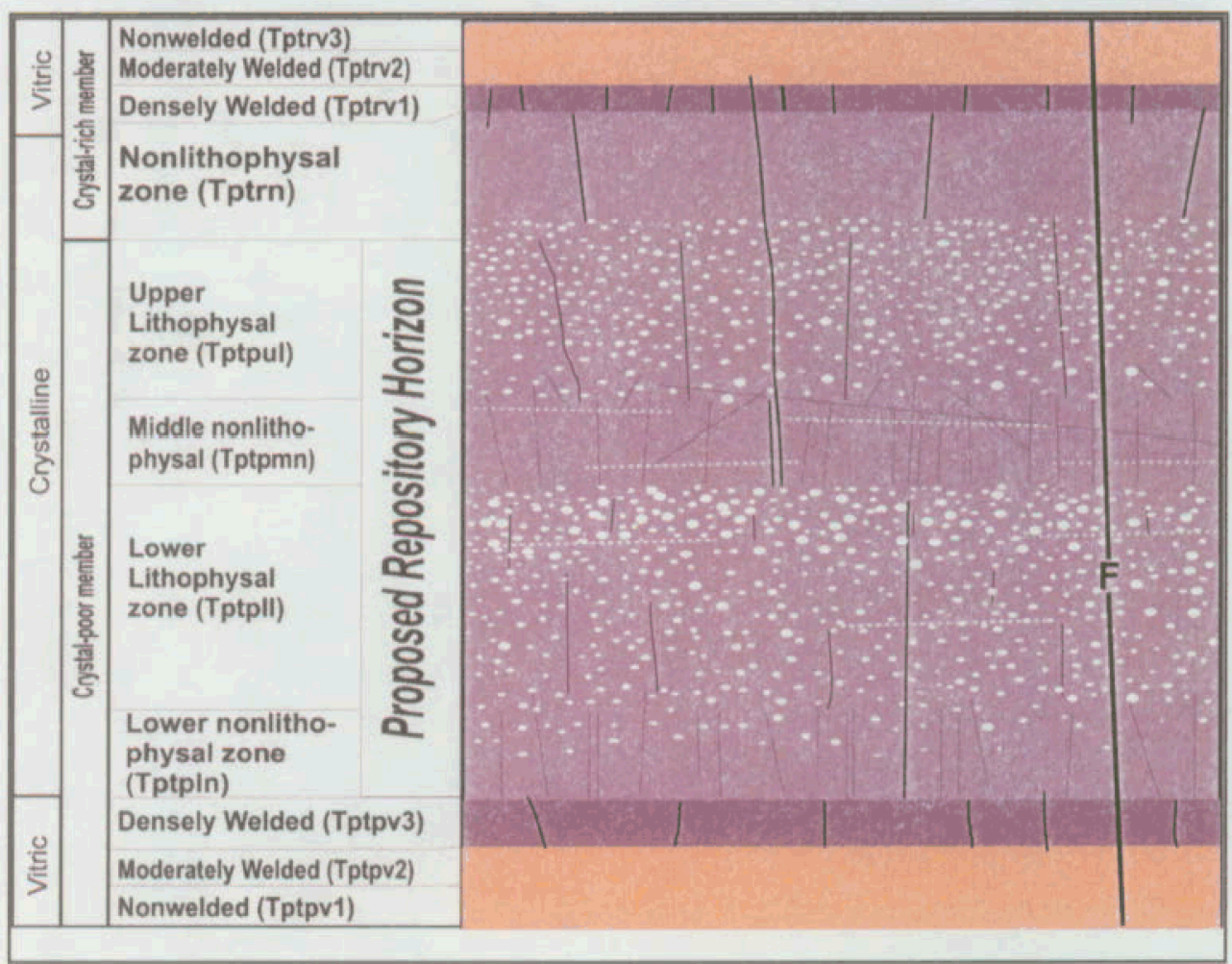

002660C_003.a
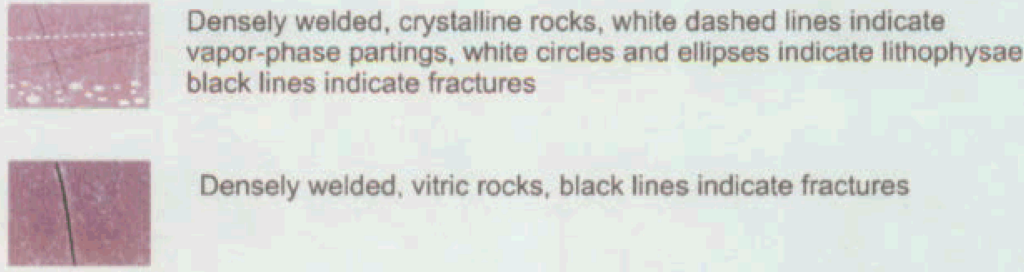

Densely welded, vitric rocks, black lines indicate fractures

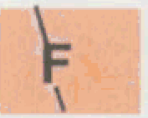

Nonwelded to moderately welded, vitric rocks, black lines with " $F$ " designation indicate faults

NOTE: The greater intensity and more continuous fracturing occurs in the nonlithophysal units (Tptpmn and Tptpln), with more widely-spaced, shorter fractures occurring in the lithophysal rocks.

Figure 4. Schematic Illustration of the Structure of the Topopah Spring Formation 


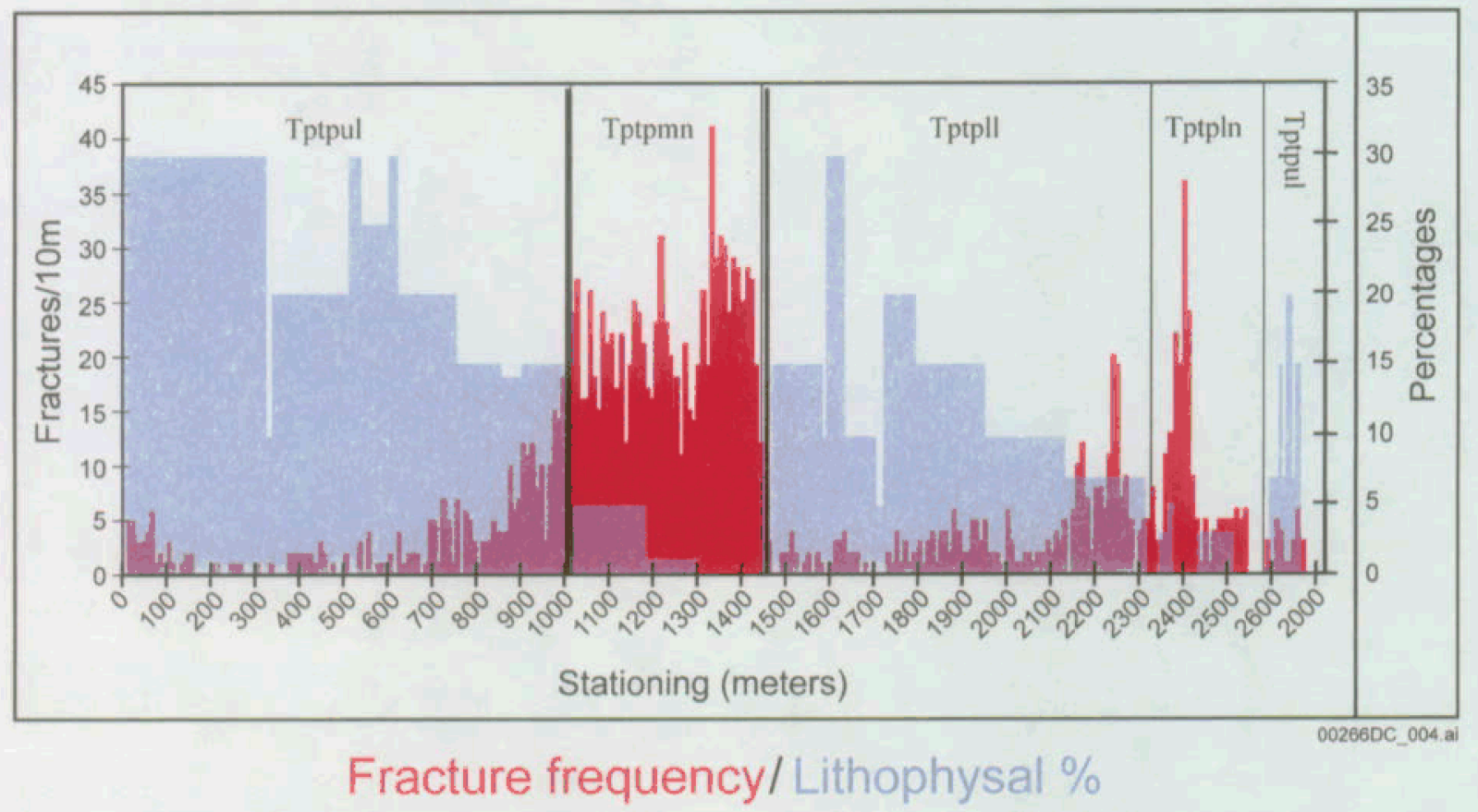

Source: Mongano et al. 1999.

NOTE: Note the inverse relationship between fracture density and lithophysal porosity.

Figure 5. Composite Plot of Fracture Frequency and Lithophysal Porosity as a Function of Distance along the ECRB Cross-Drift

The nature of the fracture geometry is extremely important to estimates of the stability of the rock mass, particularly under seismic shaking, as well as to estimates of the support function and level of required ground support. Most rock mass classification schemes are based on experience of rock masses with continuous joint sets that create regular, blocky masses (e.g., Hoek 2000). In the Tptpmn, the relatively short trace lengths and non-persistent joints create relatively few kinematically removable blocks. This is evidenced by the fact that only a very small number of rock blocks have actually been removed in the ECRB Cross-Drift. Those blocks removed actually occurred under the action of the TBM or were scaled out of the back and walls.

Short-length fractures (less than $1 \mathrm{~m}$ trace length), coupled with the lithophysae, are the most important features that govern stability in the Tptpll. Whereas the Tptpul tends to have little small-scale inter-lithophysal fracturing (Figure 10a), the Tptpll has abundant fracturing. Figure 10b, from the upper portion of the Tptpll, shows the intensive fracturing that exists between lithophysae. The fractures, which exist throughout the Tptpll, have a primary vertical orientation, and have lateral spacing of a few centimeters. In some cases, it is difficult to distinguish whether these fractures have been disturbed by mining, or induced by in situ stresses, or whether they are newly created by mining along a weakness fabric in the rock. However, it is clear that the Tptpll has a ubiquitous fracture fabric that is most evident when large diameter core is removed from boreholes. The core, although competent, has numerous fractured surfaces that break into small blocks when stressed (This is discussed further in Section 7.1.3.2). Lithophysae and occasional horizontal fractures tend to create blocks with dimensions on the order of about $10 \mathrm{~cm}$ or less on a side. Thin section analyses of the fracturing in the Tptpll and the Tptpmn 
show vapor phase alterations on many of the fracture surfaces within the rock mass away from the tunnel wall, indicating there are numerous natural fractures (i.e., not mining-induced) and were formed during the cooling process.

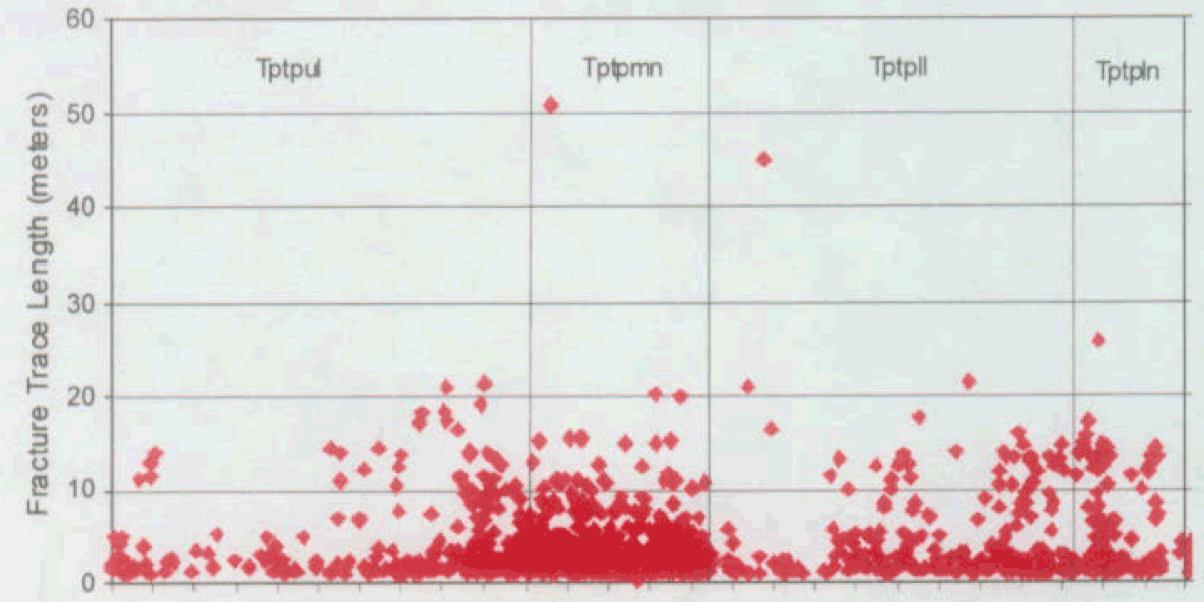

Stationing (meters)
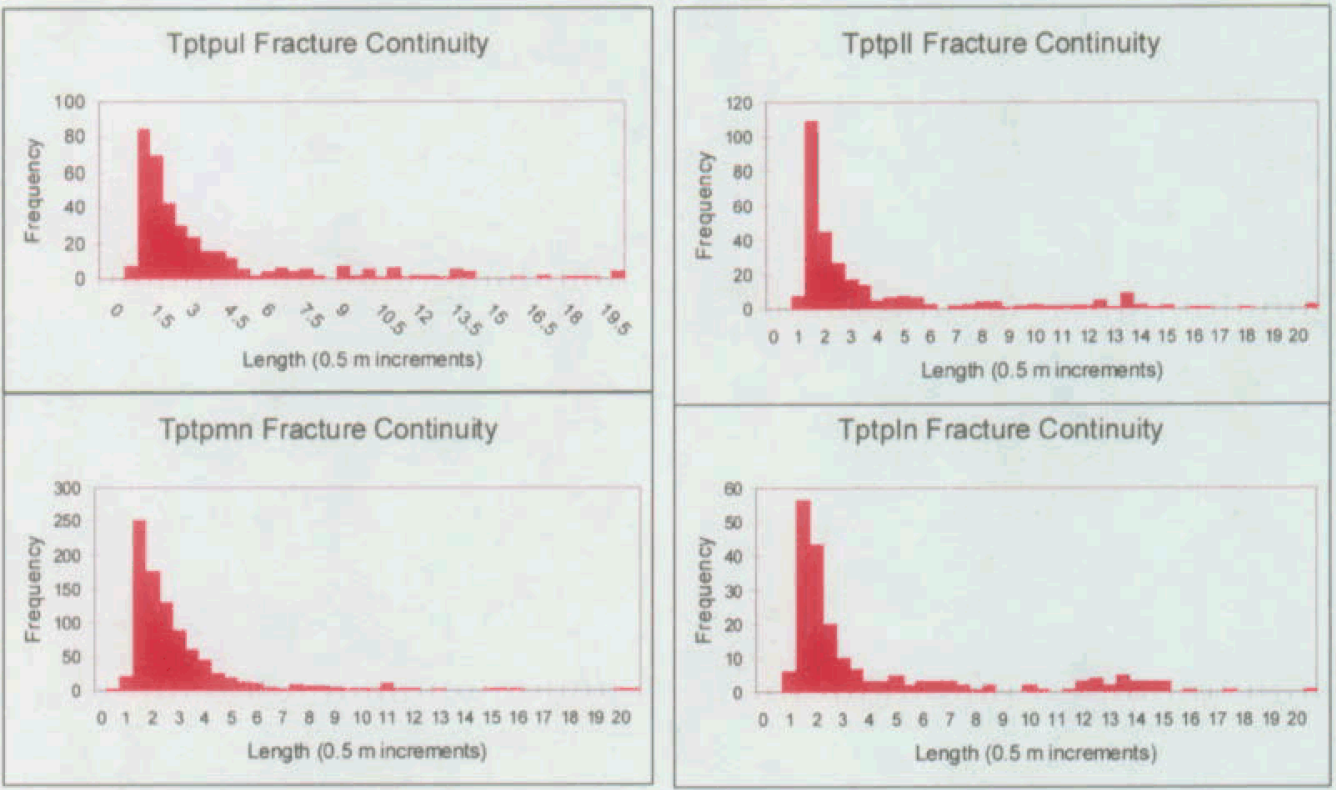

00266DC 005.ai

Source: Mongano et al. 1999.

Figure 6. Fracture Trace Length as a Function of Depth in the ECRB Cross-Drift and by Sub-Unit of the Tptp from Detailed Line Surveys 


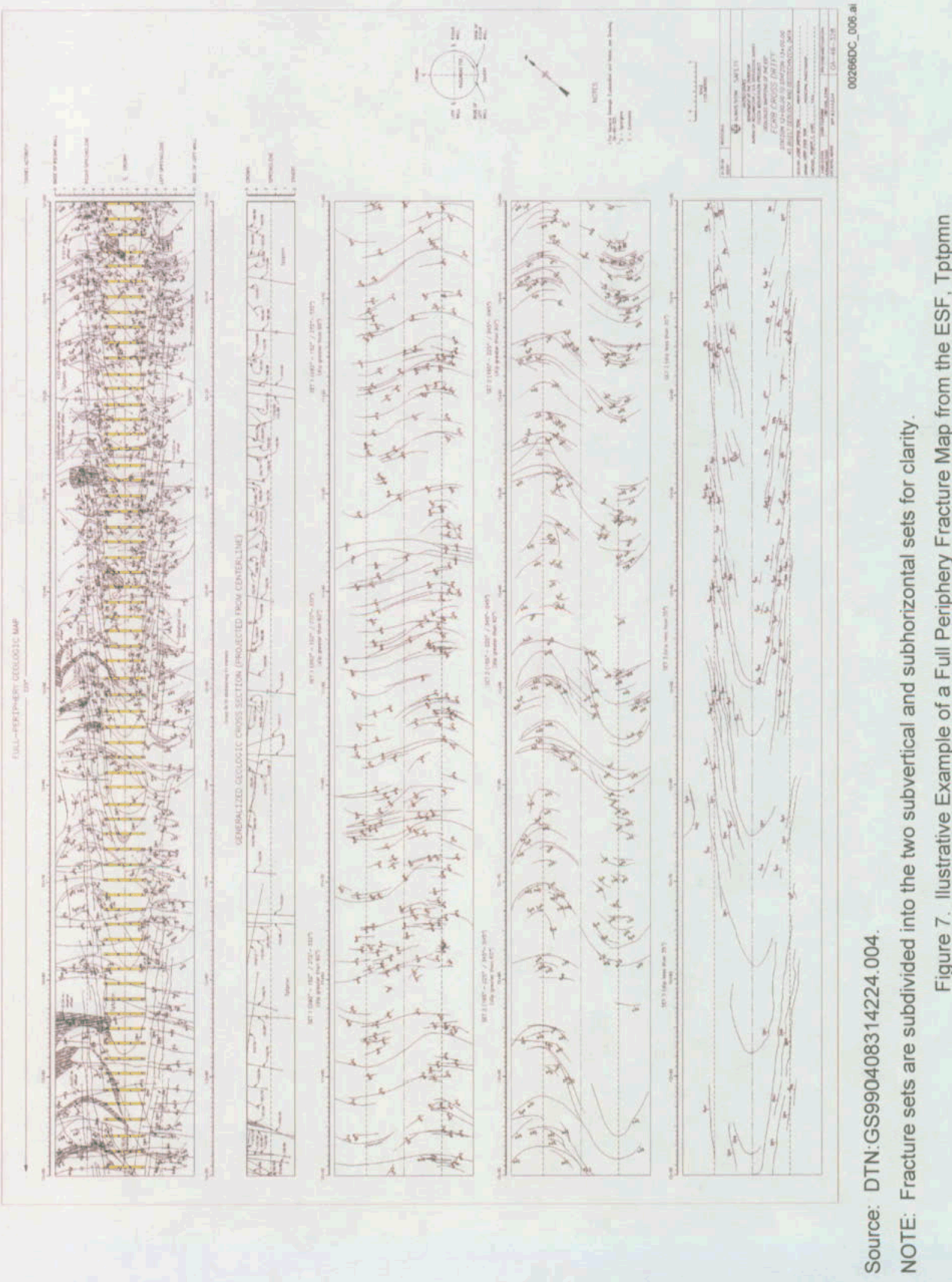

Resolution Strategy for Geomechanically-Related 


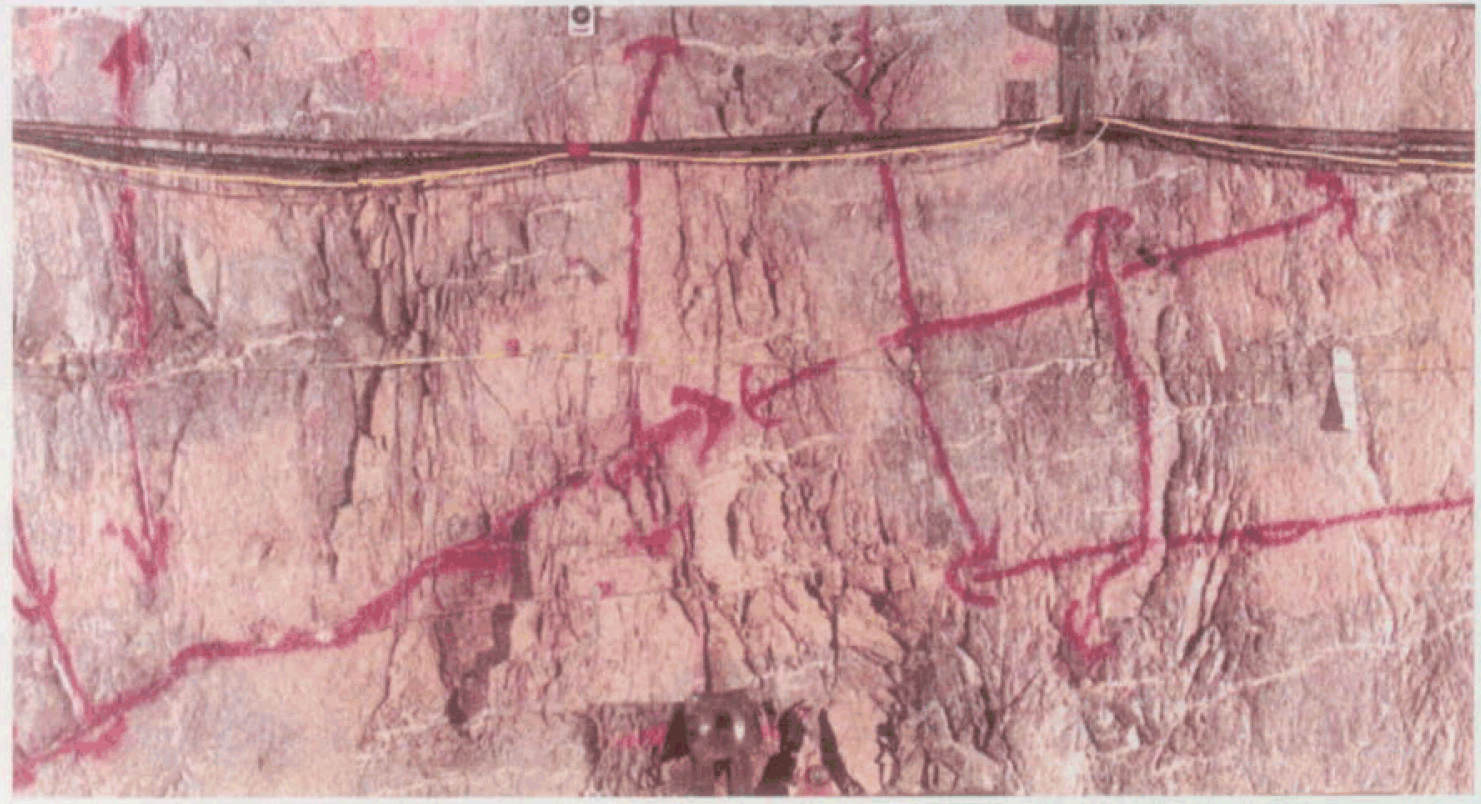

00266DC 007 .ai

Source: Mongano et al. 1999.

NOTE: T-junctions on fractures indicate terminations; arrowheads show continuous features.

Figure 8. Fractures in Wall of the ECRB Cross-Drift in Middle Nonlithophysal Unit

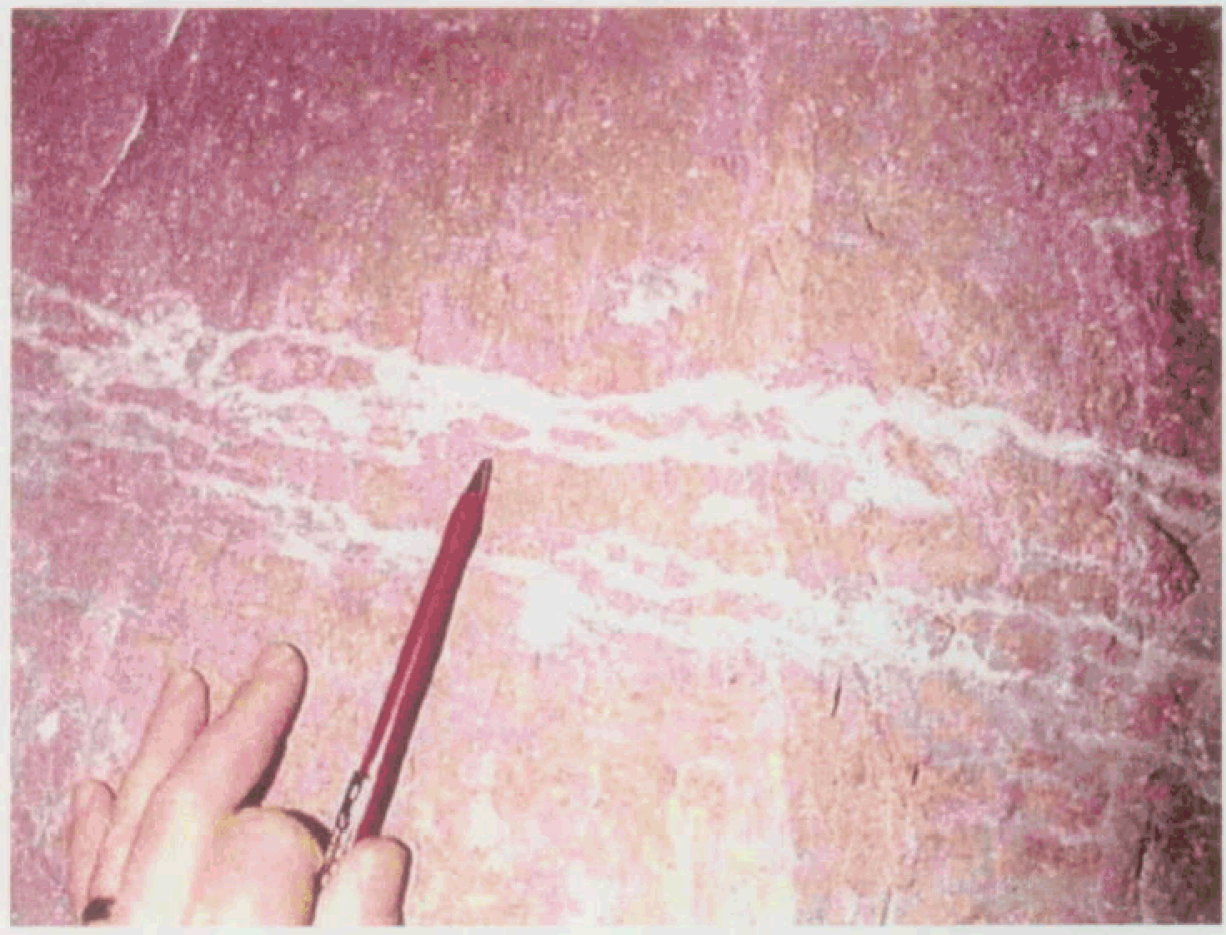

00266DC_008. a

Source: Mongano et al. 1999.

Figure 9. Low-Angle Vapor-Phase Partings in Tptpmn 
(a)

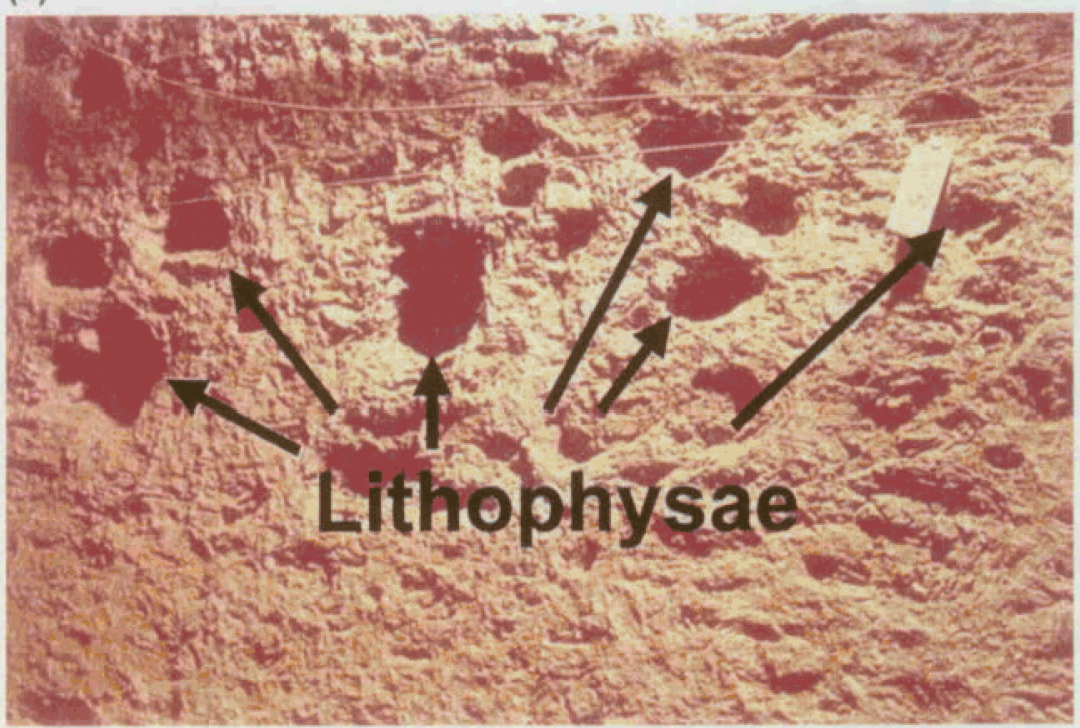

(b)

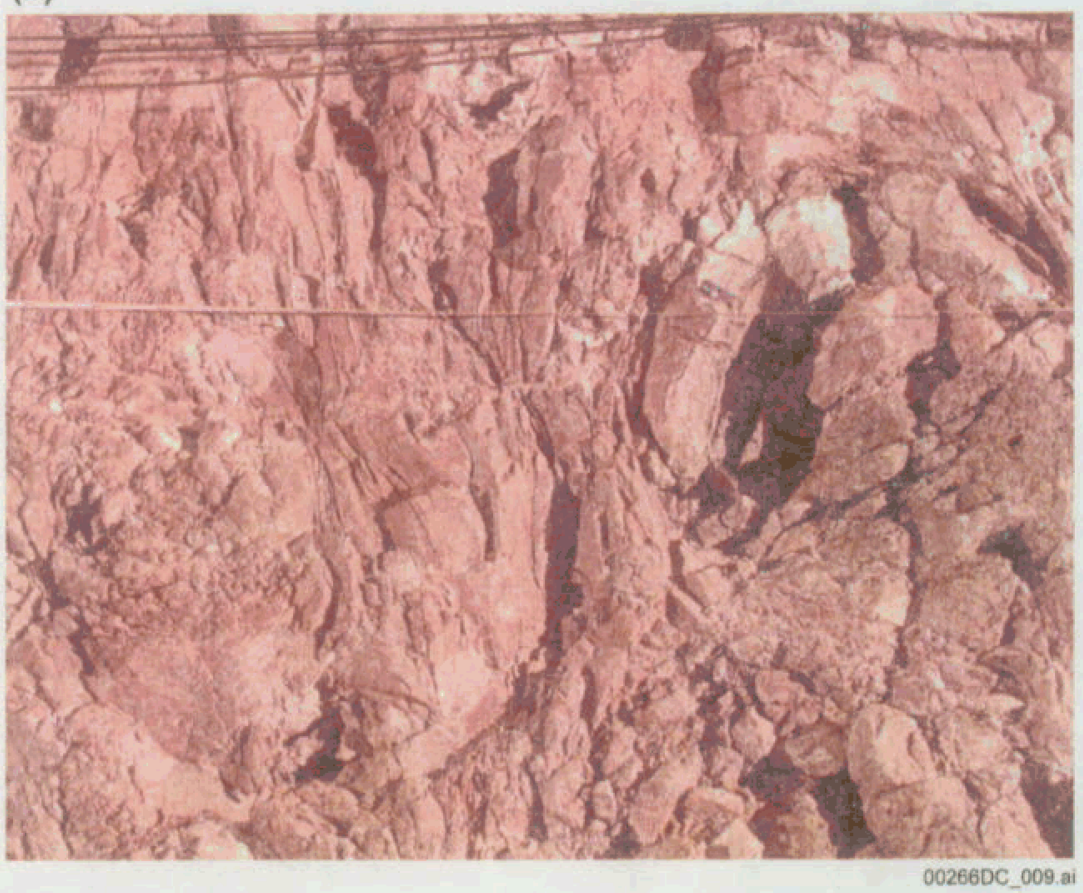

Source: Mongano et al. 1999

NOTES: The Tptpul (a) is characterized by a relatively unfractured matrix between lithophysae whereas the Tptpll (b) is abundant in natural, short length fractures that interconnect lithophysae.

Spacing of the fractures is general less than $5 \mathrm{~cm}$.

Figure 10. Comparison of Lithophysae and Fracturing in the Tptpul and Tptpll

\subsubsection{Lithophysae}

Although the character of the lithophysae varies between the Tptpul and Tptpll as shown in Figure 10, the mineralogy of the matrix material within both of these units is the same as in the nonlithophysal units. 
The lithophysae in the Tptpul:

- Tend to be smaller (roughly 1 to $10 \mathrm{~cm}$ in diameter)

- Are more uniform in size and distribution within the unit

- Vary in infilling and rim thickness

- Have a volume percentage that varies consistently with stratigraphic position

- Are stratigraphically predictable.

In contrast, the lithophysae in the Tptpll tend to be highly variable in size, from roughly $1 \mathrm{~cm}$ to $1.8 \mathrm{~m}$ in size. They also:

- Have shapes that are highly variable from smooth and spherical to irregular and sharp boundaries

- Have infilling and rim thickness that vary widely with vertical and horizontal spacing

- Have volume percentages that vary consistently with stratigraphic position

- Are stratigraphically predictable.

Currently, a lithophysal mapping and description project within the Tptpll is nearing completion. This project aims at providing a quantitative assessment of lithophysal porosity, shape, size distribution, alteration and a description of inter-lithophysal fracturing. A total of $181 \times 3 \mathrm{~m}$ panels have been mapped in detail, and percentages of lithophysae, alteration rims and spots determined. Figure 11 shows a photograph from one of the panels. Photographs are used for classification of the lithophysae, rims and spots and allow determination of the inter-lithophysal fracture density. Current plans call for the results of the lithophysal study to be available in the electronic data management system along with the fracture geometric interpretation in the second quarter of fiscal year 2003, with a Science and Analysis Report to be developed in the first quarter of fiscal year 2004. 


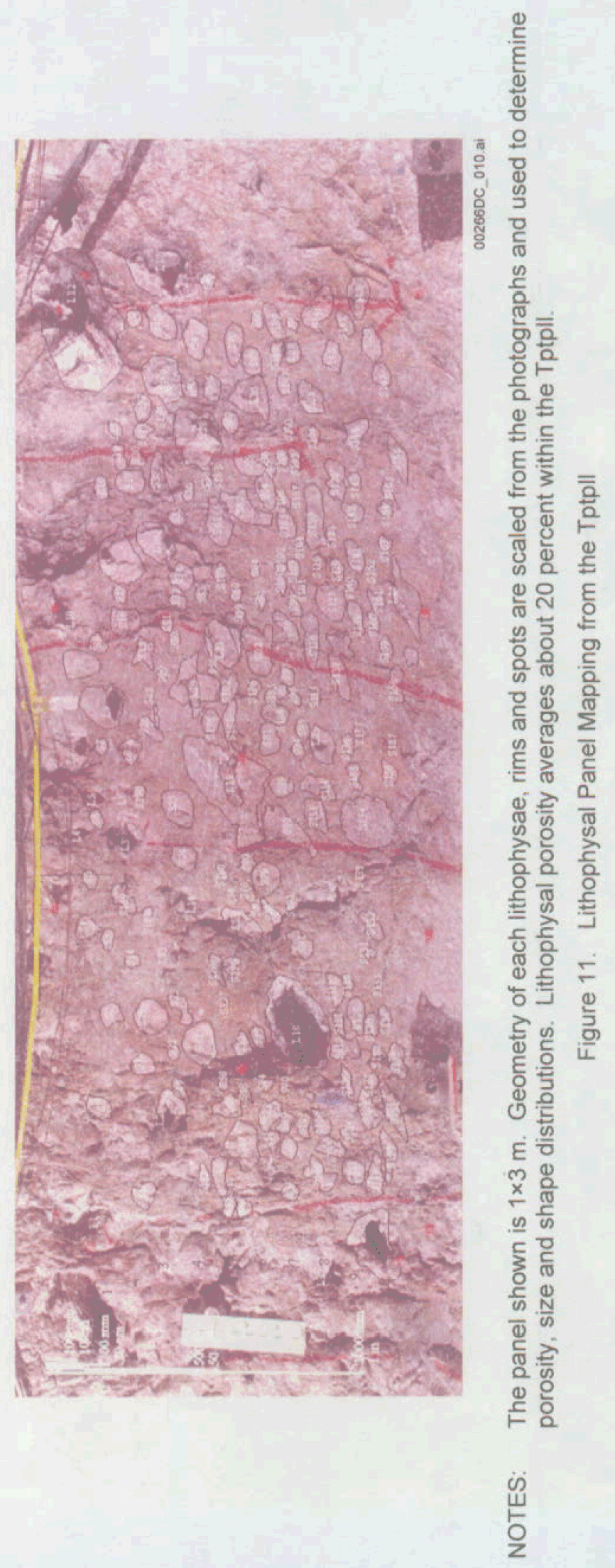

Resolution Strategy for Geomechanically-Related Repository Design and Thermal-Mechanical Effects 
INTENTIONALLY LEFT BLANK 


\section{REPOSITORY LOCATION}

A repository concept re-evaluation study was recently completed (Board et al. 2002). In this study, the general location of the repository horizon and layout were re-examined in an attempt to minimize performance uncertainties as well as to provide for a flexible or modular layout. Performance uncertainties are minimized through location of the repository within the most heavily characterized geologic region. The purpose of the modular layout is to provide for greater ease in accommodating an incremental approach to exploration and construction as well as accommodation of varying waste types and receipt rates.

The general footprint within which the repository is to be sited is given in Figure 12. This footprint, determined largely on performance criteria, encompasses most of the Site Recommendation "primary block" and "lower block" regions (DOE 2002). Within this footprint, the repository itself is laid out within the Topopah Spring Formation. The repository layout in plan view is given in Figure 13. The primary difference between the current and Site Recommendation layouts is that the revised configuration is based on a series of smaller panels serviced by surrounding access mains that allow greater flexibility in design and ability to accommodate varying waste receipt rates and thermal profiles. Each panel is developed by first constructing the surrounding access mains. This excavation provides the opportunity for progressively more-intensive exploration and testing of the rock mass as construction proceeds.

The layout consists of five panels, numbered as shown in Figure 13. Panels 1, 2, 3 and 5 all lie in the upper elevation plane (the elevation of the ESF Main lateral. Panel 4 lies approximately $80 \mathrm{~m}$ below at the same elevation as the "lower block" of the Site Recommendation layout (the elevation varies from the north to the south end of the repository).

The emplacement drifts are oriented at $72^{\circ}$ azimuth for minimization of the formation of removable rock wedges (CRWMS M\&O 1999), and have been given nominal lengths of $600 \mathrm{~m}$ for ventilation efficiency purposes. The panels are developed by first constructing $7.62 \mathrm{~m}$ diameter access mains around the circumference of each panel, followed by development of the $5.5 \mathrm{~m}$ diameter emplacement drifts. All emplacement and access drifts are to be driven with tunnel boring machines.

Development of a Performance Confirmation Testing Program is currently underway. This program will provide details on the exploration drilling, geological and geotechnical mapping and in situ testing that will be conducted during construction as well as during the preclosure period. The circumferential development of the mains will allow exploration of the rock mass comprising the panel prior to emplacement drift development.

The various Topopah Spring sub-zones that are intersected by the drifts are shown in Figure 14 . As seen, the emplacement drifts are found primarily within the Tptpll (roughly 72 percent), and the Tptpmn (roughly 20 percent). Emplacement within the Tptpul and Tptpln comprise the remaining roughly 8 percent of the layout. 


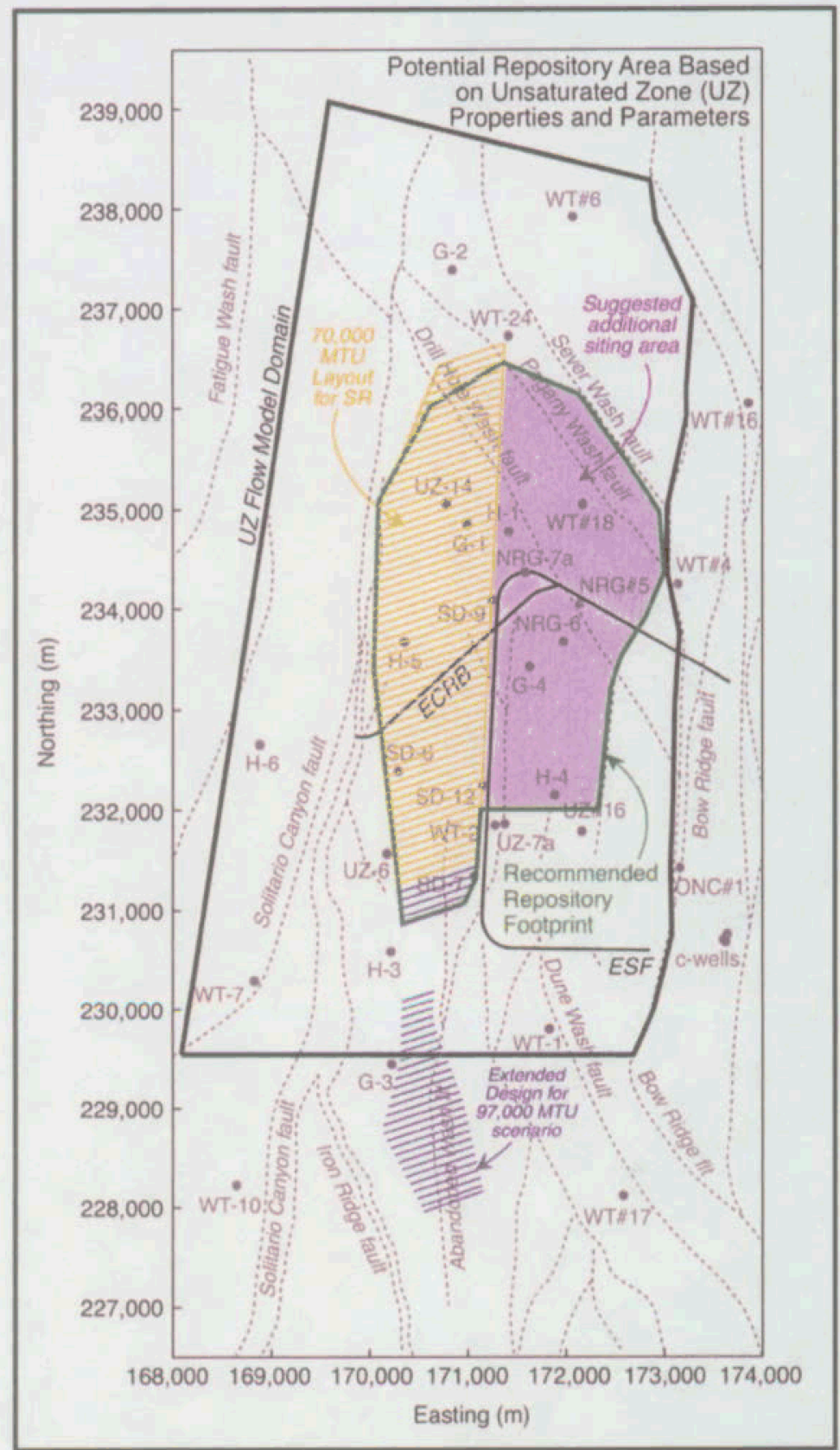

$00266 \mathrm{DC}$ 011 ai

Source: Board et al. 2002.

NOTES: The repository footprint is outlined in green. The figure also includes geologic structure and location in relation to the Site Recommendation layout.

Figure 12. Repository Siting Footprint 

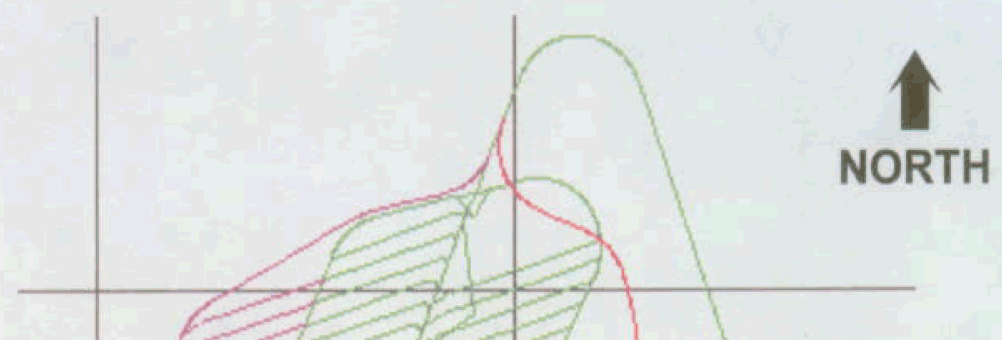

(1)

2

(3)
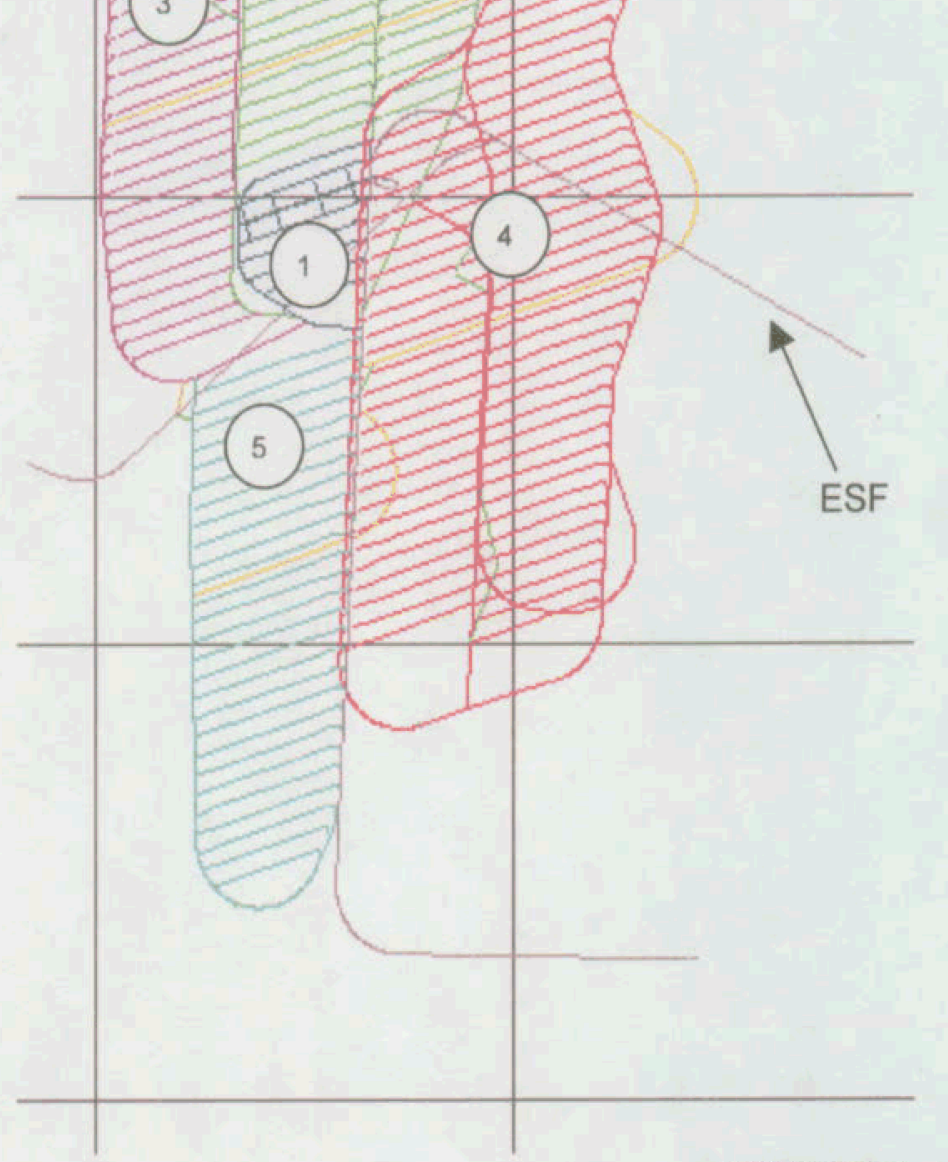

00266DC_012a.ai

Source: Board et al. 2002.

NOTES: The layout consists of five panels located on two elevations. Only panels 1, 2, 3 and a portion of panel 4 are needed for the 70,000 MTHM layout. See also Figures 12 and 14 . The repository waste panel loading sequence is still under consideration. Grid spacing is 2000 meters.

Figure 13. Conceptual Layout of the Repository within the Siting Footprint Boundary 


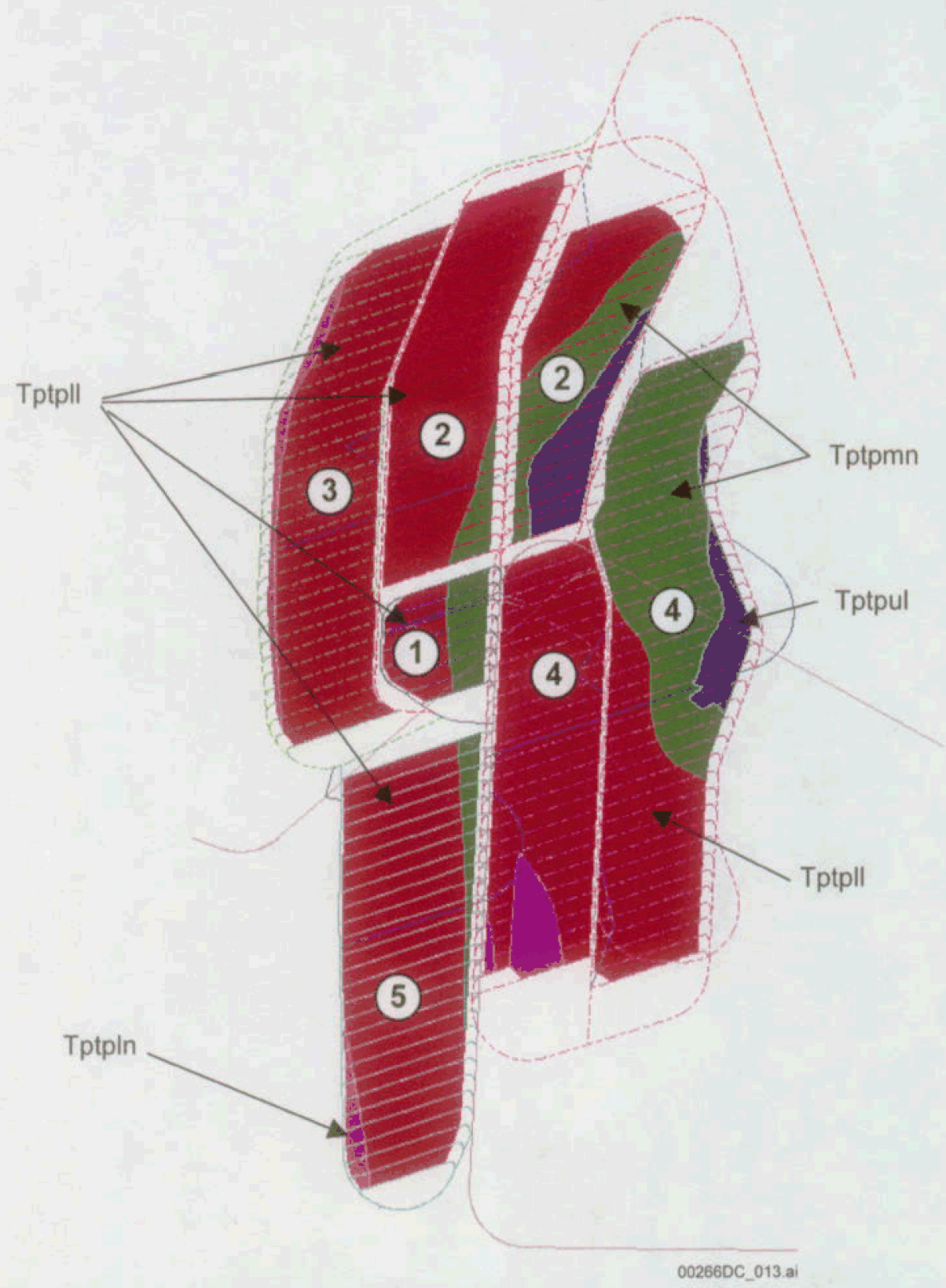

NOTE: Panel 4 to the east is on an elevation approximately $80 \mathrm{~m}$ below Panels $1,2,3$ and 5 .

Figure 14. Overlay of the Topopah Spring Geologic Sub-Unit on Repository Layout 


\section{GEOMECHANICAL ISSUES AND DATA NEEDS FOR USE IN DESIGN AND PERFORMANCE ASSESSMENT STUDIES}

\subsection{INTRODUCTION}

The broad geomechanical KTI agreements that the ORD must resolve are similar in many respects to issues that confront many large underground construction projects. The uniqueness of the present project involves the additional design and performance variables that need to be taken into account, particularly high temperatures and extended periods of time as well as the reliance on numerical models rather than empirical design methods. Resolving these issues will require the following actions:

- Gathering data for estimation of thermomechanical material behavior of the major rock mass geologic units that comprise the repository horizon, and determining how this behavior is affected by environmental conditions (i.e., temperature, moisture) and time

- Estimating the variability of the material behavior as a function of the geologic variability across the site, and examining the impact of uncertainties in rock property measurements and how this uncertainty propagates through the numerical modeling and design calculations

- Determining the preclosure ground support requirements and specifying a support system and maintenance strategy capable of ensuring waste retrieval

- Estimating the stability and possible failure modes of emplacement drifts due to preclosure and postclosure seismic shaking and general thermal and time-related degradation effects.

The above issues result in two major classifications of issues and data needs: those associated with gathering of material properties or geologic data, and those associated with use of numerical modeling for design and performance assessment.

\subsection{MATERIALS PROPERTIES AND GEOTECHNICAL CHARACTERIZATION ISSUES}

\subsubsection{Materials Properties and Geotechnical Characterization Issues/Needs}

As described in the previous section, the repository footprint is located approximately 70 percent within the Tptpll and 20 percent within the Tptpmn, with the remaining 10 percent falling inside the Tptpul and Tptpln. The solid groundmass of these sub-units of the Topopah Spring formation have approximately the same mineral composition and texture, but the distinctly different physical structure of the lithophysal and non-lithophysal units leads to different thermal and mechanical response.

The difference in physical character of these sub-units can be reduced to the character of the internal structures within them. The nonlithophysal units are generally hard, strong, fractured rocks with matrix porosities of 10 percent or less (Appendix B). The primary structures in these units are fractures that formed during the cooling process and have undergone little to no 
postformation shearing. The lithophysal units, on the other hand, have significantly fewer fractures of significant continuous length (i.e., trace length greater than $1 \mathrm{~m}$ ), but have relatively uniformly distributed porosity in the form of lithophysal cavities. Lithophysal porosity in the Tptpul and Tptpll is on the order of 10 to 30 percent by volume. The groundmass that makes up the rock matrix is heavily fractured with small scale (lengths on the order of $1 \mathrm{~cm}$ ) inter-lithophysal fractures in the Tptpll, but is relatively unfractured in the Tptpul.

The structural response of the lithophysal and nonlithophysal rock masses is expected to be distinctly different due to these structural differences. The mechanical response of the nonlithophysal units is expected to be governed by the longer cooling fractures whereas the lithophysal cavities and groundmass short trace length fracture density will control the response in the lithophysal units. The cavities in the lithophysal units also have an impact on the thermal properties of the rock mass.

Due to the difference in physical character of the units, different geomechanical issues will dominate for each unit.

\subsubsection{Nonlithophysal Units}

\subsubsection{Existing Database}

A significant database of thermal and mechanical properties from laboratory and field testing currently exists for the nonlithophysal rocks and fractures. A detailed review of the database is given in Appendix B, and only a brief overview given here. The number of tests for various properties that have been conducted is illustrated in Figure 15 below. As seen in this plot, the base of mechanical information is particularly extensive, including basic uniaxial, triaxial and tensile strength testing, rotary shear testing of fractures and basic physical properties testing.

Hundreds of thermal tests (including tests for thermal capacitance, conductivity, and expansion) have been conducted in the laboratory and at the site for both the lithophysal and nonlithophysal rocks.

The rock properties data base has recently been compiled in a convenient format by test type, and further subdivided as "Q", "non-Q", or "To Be Verified". Statistics of each test type have been determined, and CAD-based geometric plots made of the location of samples with respect to the repository footprint area and geologic unit for visualization purposes. An example of the graphical presentation of these data for the uniaxial compressive strength is given in Figure 16. 


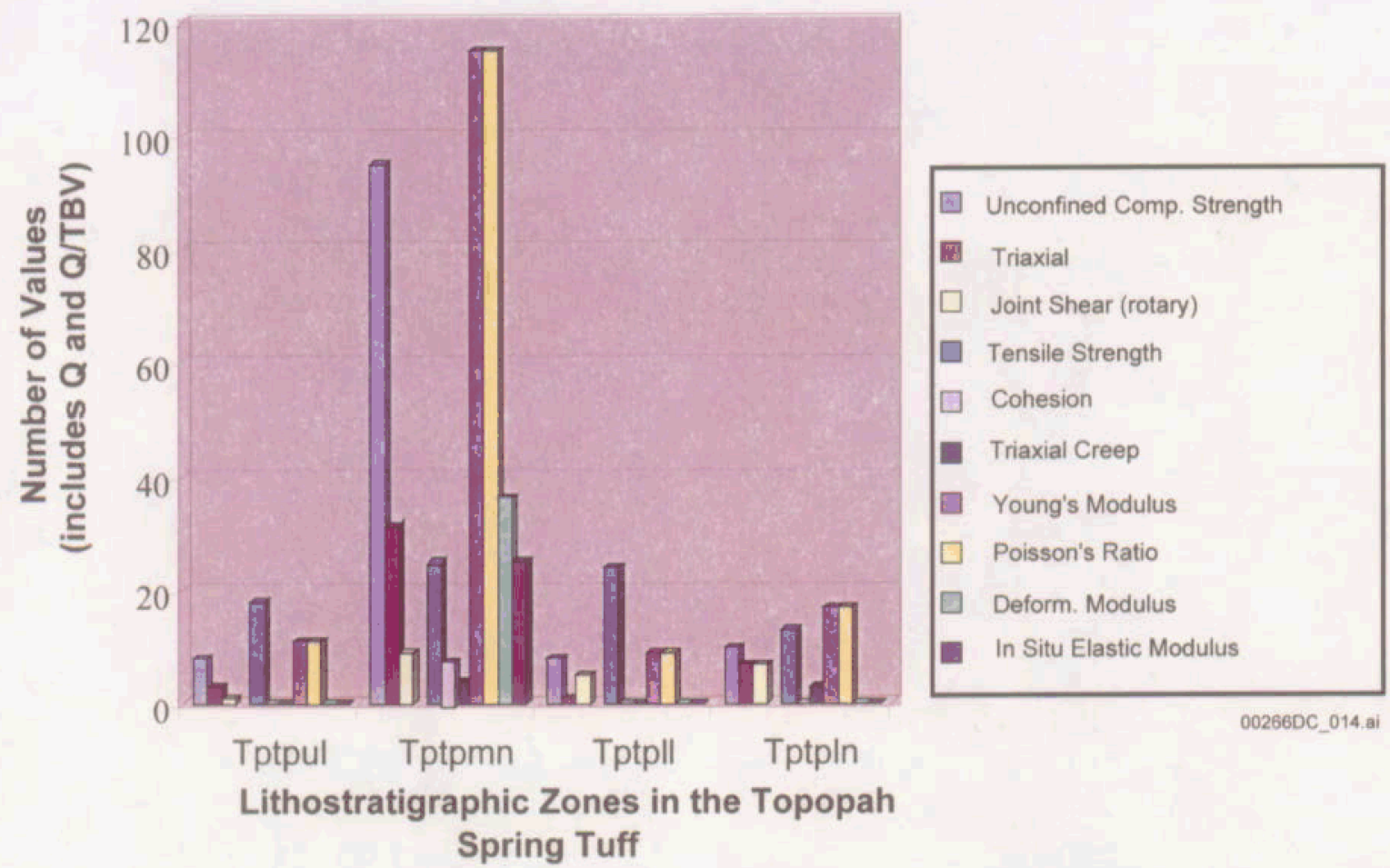

Figure 15. Number of Basic Mechanical Tests Conducted on Various Sub-Zones of the Topopah Spring Tuff as of 2001

In general, the testing on intact nonlithophysal rocks shows that they are hard, strong and brittle rocks with uniaxial compressive strengths averaging around 180 to $220 \mathrm{MPa}$ for $25 \mathrm{~mm}$ diameter samples. Underground observations indicate generally excellent mining conditions with minimal ground support. However, this is not always true in localized areas of the Tptpmn that are highly fractured. Since the mining and thermally induced stresses are expected to be relatively small in comparison to the intact block strength, the possible failure response of the openings will likely be controlled by the fracture geometry and properties, and not the intact rock strength. Therefore, the primary conclusions from a review of the Tptpmn database are that:

- A significant and adequate base of intact material properties data exists for the nonlithophysal rocks.

- The geometry and surface properties of fractures will likely control excavation mechanical behavior under excavation, thermal and seismically induced stresses. Additional information is needed on the fracture surface properties to supplement the existing rotary shear test results. Fracture geometry is discussed below.

- There is a need for additional testing for time-dependant strength response (e.g., static fatigue testing). 


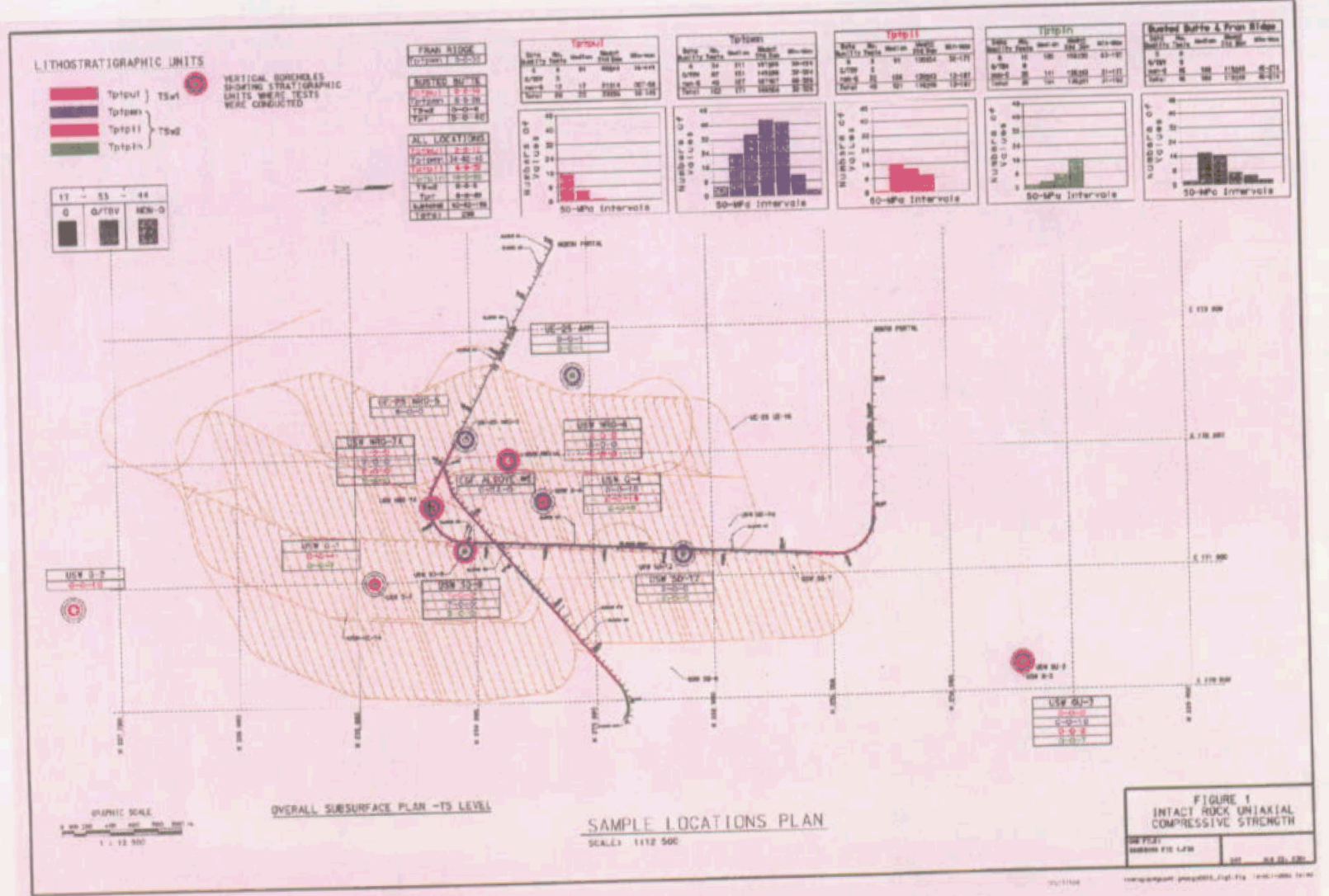

NOTE: Plan view of the ESF and the ECRB Cross-Drift with an overlay of the former Site Recommendation Repository Primary Block Layout. Summary statistics for each host unit are given at the top of the figure. This type of plot has been developed for all of the rock mechanical and thermal properties as a visualization tool.

Figure 16. Location of Uniaxial Compressive Strength Test Samples

\subsubsection{Summary - Major Issues for the Nonlithophysal Units}

The primary outstanding issues and their related KTI agreements are as follows:

- Need for development of a geometric representation of fracturing based on field database (associated agreements RDTME 3.04, 3.08, 3.10, 3.11, 3.15, 3.16, 3.17, 3.19), A fracture geometry representation is needed as input to discontinuum numerical models of ground support and rockfall. The fracture geometry representation, based on the existing extensive fracture data base, needs to reasonably reproduce the observed fracture geometry data within the ESF and the ECRB Cross-Drift. The model should include, in addition to the statistical variation in dip, dip direction and dip spacing, a representation of the discontinuous nature of the jointing (i.e., the trace length of the fractures and the presence and nature of solid rock "bridges" between joint tracks and joint terminations).

- Need for development of improved estimate of joint strength properties and roughness (dilation angle) (associated agreements: RDTME 3.06, 3.07, 3.17, 3.19, 3.20). 
- Need for development of an improved understanding of the time-dependent fatigue strength of the rock matrix (associated agreements: RDTME 3.07, 3.11, 3.17, 3.19).

- Need for development of an estimate of the time-dependent fatigue strength of the rock joints (associated agreements: RDTME 3.04, 3.11, 3.17, 3.19, 3.20).

The above items deal primarily with the description of the time-dependency of the rock matrix as well as the geometry and properties of rock joints, and how these are represented in numerical models of excavation response to mining effects and thermal and seismic stresses. It is the goal of the project to present a clear picture of the method for inclusion of the geology and its variability directly into the modeling. The proposed method for developing a model of the fracturing is described later.

\subsubsection{Lithophysal Units}

\subsubsection{Existing Data Base}

The current geomechanical data base in the lithophysal units includes primarily index properties, strength and thermal testing on small cores ( 1 to 2 in. [25 to $50 \mathrm{~mm}$ ] diameters) from the Tptpul and Tptpll (Appendix B). The mechanical testing data comprising this set are largely uniaxial compression and Brazilian tensile strengths. Triaxial testing is generally not possible due to the difficulty in jacketing samples for confinement.

The testing has shown that a strong relationship exists between compressive strength, modulus and porosity for all tuffs as shown in Figure 17. Here, the mechanical properties database, including tuffs from the Topopah Spring sub-units, as well as other welded and non-welded units, is given in terms of porosity. As noted in Appendix B, there is both porosity and size dependence to the mechanical properties. The porosity dependence is obvious from this figure, but the range of data for a given porosity is partially a function of the size of the sample as shown in Figure 18.

Uniaxial compression tests have been conducted in the Tptpll and Tptpul, primarily on cores with 1 to 2 in. ( 25 to $50 \mathrm{~mm}$ ) diameters, but with a few tests on 10.5 -in. ( $267 \mathrm{~mm}$ ) diameter samples, such as the one in Figure 19. The small diameter cores do not provide representative in situ strengths and moduli since samples of this size do not contain lithophysal cavities. Of greatest interest are the results from strength testing of 10 to 10.5 -in. (254 to $267 \mathrm{~mm}$ ) diameter cores from the Tptpul obtained from Busted Butte (Price et al. 1985). These tests give a better indication of the in situ strength of lithophysal rocks, and show uniaxial compressive strengths (UCS) ranging from 10.3 to $27.8 \mathrm{MPa}$, with moduli ranging from 10.9 to $21.5 \mathrm{GPa}$. Figure 20 shows the correlation between the UCS and elastic modulus for these tests. The linear relationship of these properties is probably linked to their dependence on porosity. 

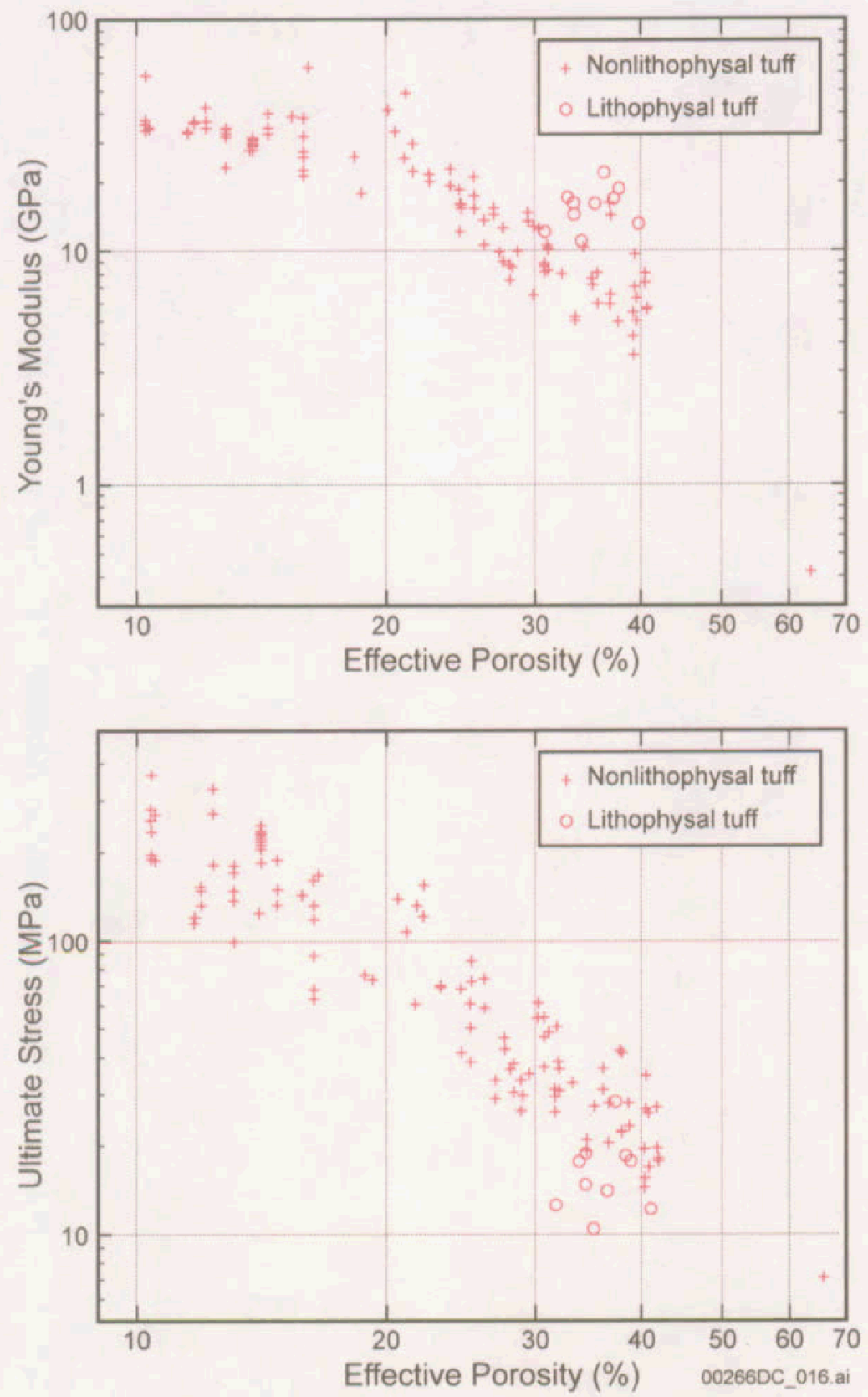

Source: Price et al. 1985.

Figure 17. Intact Rock Modulus and Strength as a Function of Effective Porosity 


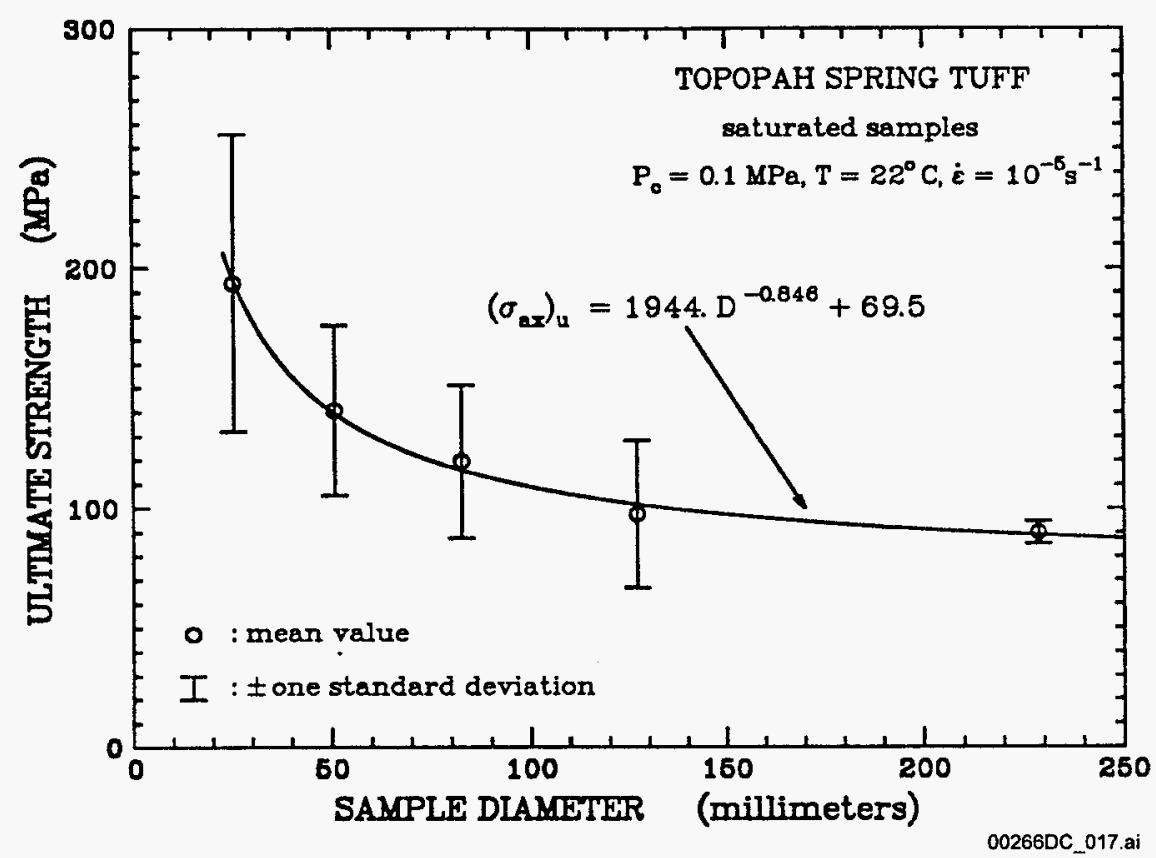

Source: Price 1986.

NOTE: $P_{c}=$ atmospheric confining pressure, $T=$ temperature, $\dot{\varepsilon}=$ strain rate, $\left(\sigma_{a x}\right)_{u}=$ ultimate strength $(\mathrm{MPa})$, and $\mathrm{D}=$ sample diameter $(\mathrm{mm})$.

Figure 18. Effects of Sample Size on the Uniaxial Compressive Strength of Welded Tuff from the Middle Nonlithophysal Zone (Tptpmn)

A significant base of laboratory-scale thermal properties testing (Appendix B) exists for the lithophysal rocks, including thermal capacitance, thermal conductivity and thermal expansion. As was the case with the mechanical properties testing, the thermal tests have largely been conducted on small diameter cores which do not take into account the presence of the lithophysal porosity. To address this issue, a number of in situ borehole heater tests are either complete or in progress in the Tptpll of the ECRB Cross-Drift for the purposes of measurement of thermal conductivity and thermal capacitance. The tests include:

- Single heater and single instrumentation borehole

- Array of 3 heaters, 3 instrumentation boreholes

- Single heater, 2 instrumentation boreholes.

Tests 1 and 3 are similar in geometry and are used to determine thermal properties using a simple test array. The second test, which includes more heaters, heats a larger rock volume. Results from tests 1 and 3 exhibit a bulk thermal conductivity of about $1.74 \mathrm{~W} / \mathrm{m}^{\circ} \mathrm{K}$ (BSC 2002, Table 7-9). The porosity at the test locations varied between about 8.1 and 31.5 percent (BSC 2002, Section 7.2.3). The bulk thermal conductivity is about a 15 to 20 percent decrease in value from the nonlithophysal rocks. The analysis of these tests has been used to develop an experimental basis for accounting for the effects of lithophysal porosity on thermal properties of the repository host rocks (BSC 2002). 


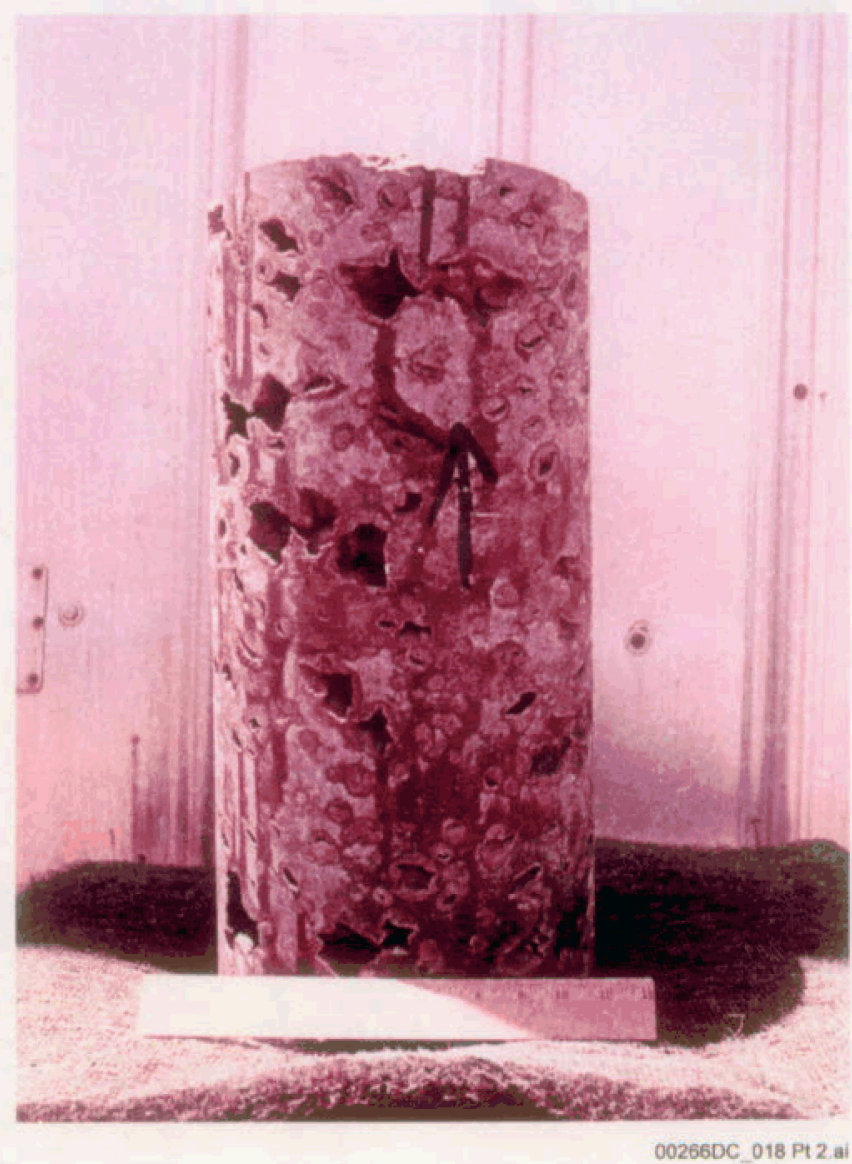

Source: Price et al. 1985.

Figure 19. Photograph of a 10.5-in Diameter Core Sample

\subsubsection{Discussion - Rock Testing Approaches in Lithophysal Rock}

The existing data show that porosity appears to be the most significant physical parameter that controls rock mass thermal and mechanical properties in the lithophysal sub-units. The total porosity of the tuffs is made up primarily of matrix porosity and lithophysal porosity. The matrix porosity, which is roughly the same for all of the Topopah Spring sub-units, is essentially grain to grain void space, and is around 10 percent by volume (Appendix B). In the lithophysal rocks, the lithophysal cavities add an additional 10 to 30 percent (approximate) void volume. The lithophysae range in size from a few centimeters up to approximately a meter, resulting in size as well as lithophysal-porosity dependence of rock mass properties. In the following discussions, the term "porosity" refers to total porosity.

Thermal properties of the rock mass can be measured in situ with relatively simple heating experiments as discussed in which the test porosity and saturation levels for the test site are documented carefully prior to testing.

Measurement of mechanical properties is more difficult. Typically, a rock mechanics characterization program aimed at understanding the mechanical constitutive behavior of the rock mass and defining the range of properties is based on a combination of laboratory testing 
and field rock mass classification. Both of these approaches are problematic in the lithophysal rocks. First, as mentioned above, the rock mass properties are both porosity and size dependent.

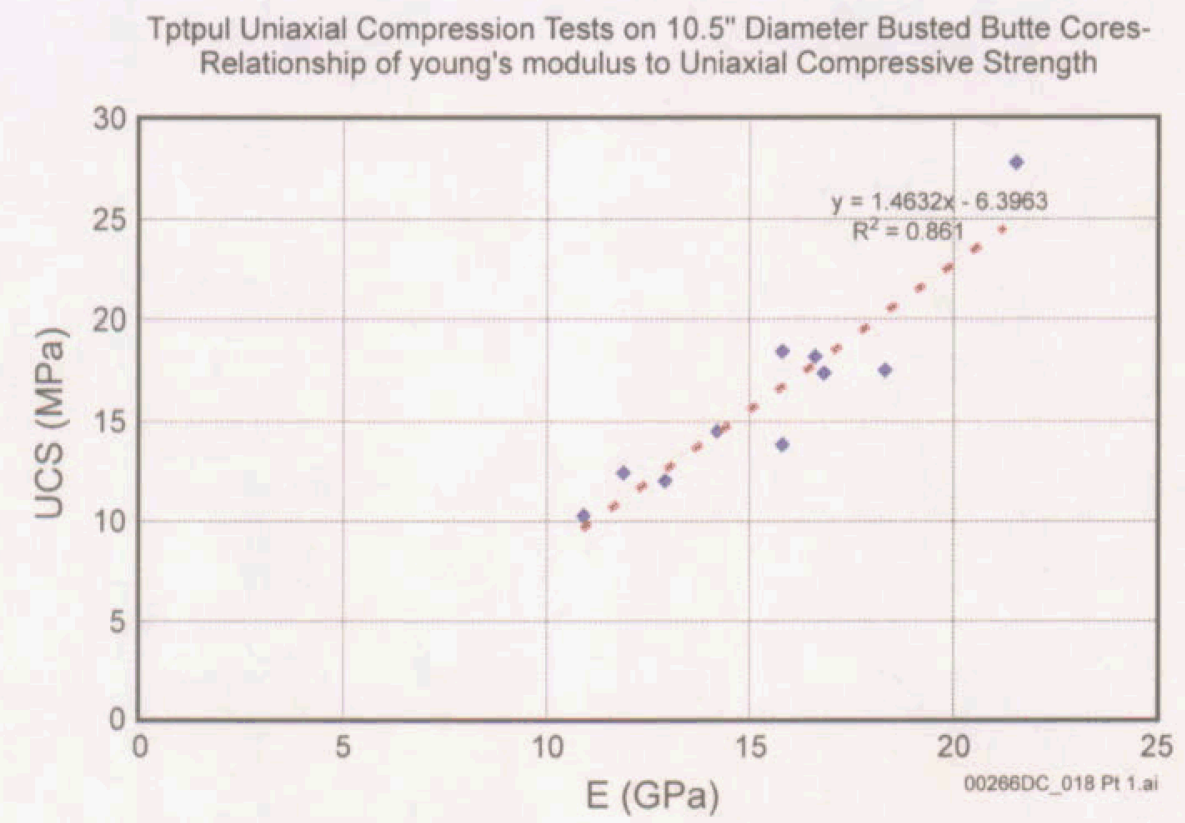

Source: Price et al. 1985.

Figure 20. Relationship of Uniaxial Compressive Strength and Young's Modulus for Large Core Testing from the Tptpul, Busted Butte

There are obvious difficulties in sampling and testing material with voids with a size range from a few centimeters to greater than a meter in diameter. Testing of small diameter cores, which make up the entirety of the surface exploration holes, is of limited value as they obviously sample only the solid matrix (the groundmass) and not matrix-plus-void. Large-diameter coring of this material is particularly difficult (although possible) as the core tends to break between lithophysae and along the ubiquitous small-scale fractures in the groundmass. Obtaining standard 2:1 length:diameter ratio samples for 10 to $12 \mathrm{in}$. ( 25 to $30 \mathrm{~cm}$ ) diameter core (i.e., 50 to $60 \mathrm{~cm}$ in length) is especially difficult. In situ compression testing on large samples is feasible, but time consuming and costly.

It is obvious from this discussion that a typical form of "statistical" rock testing program, based on testing of many small diameter cores from surface and underground-based drilling for the purpose of exploring the variability of the properties is not possible here.

Although rock mass classification and its use in estimation of rock mass properties is a valuable tool, it must be based on extensive past experience in the same or similar rock types. The existing classification schemes (Barton's Q-classification, Bieniawski's RMR, and Hoek's GSI) do not have case histories for highly porous rocks, or rocks with lithophysal or vesicular cavities. Therefore, the classification schemes typically employed in mining and construction are useful as a means of comparison, but of limited value in the lithophysal units. 
In conclusion, thermal and mechanical properties determination of the lithophysal rocks needs to be based on:

- Materials properties testing on samples of lithophysal rocks sufficiently large that they represent the in situ scale

- Observation of the mechanical response of the ESF and the ECRB Cross-Drift.

It is also required that an estimate be made of the variability of the mechanical behavior for the range of lithophysal conditions in the repository block. However, due to the limitations discussed above, only a small number of tests on large cores or in situ samples is possible. A strategy for resolving this issue involving calibration of appropriate numerical models for understanding the basic mechanisms of the rock mass behavior is given in Section 6 . Once validated, the intention is to use the model as a "test bed" or numerical tool for assisting in the understanding of the impacts of lithophysae geometry on rock mass properties.

\subsubsection{Summary - Major Issues for the Lithophysal Rocks}

The primary outstanding issues for the lithophysal rocks and their related KTI agreements are as follows:

- Documentation of geometric the variability of lithophysae and small-scale fracturing both vertically and laterally within the lithophysal rocks, particularly the Tptpll, which makes up the bulk of the repository emplacement area (RDTME KTIs 3.04, 3.05, 3.06, $3.08,3.17$ )

- Development of additional test data on the thermomechanical properties of the lithophysal rocks, and document the impact of lithophysal porosity and small-scale fracturing on the constitutive behavior and scaling effects (RDTME KTIs 3.04, 3.05, 3.20)

- Determination or estimation of the average and range of block sizes produced as a result of failure of the lower lithophysal unit (RDTME KTIs 3.17)

- Determination of the strength degradation (static fatigue) response of lithophysal rock as a function of loading level. Estimate how this time-dependent degradation impacts possible failure mechanism and extent in the emplacement drifts (RDTME KTIs 3.05, $3.07,3.11,3.20)$.

\subsection{NUMERICAL MODELING ISSUES}

The design and evaluation of performance of the repository excavations requires examination of loading conditions and time periods unprecedented in common practice. Additionally, there is little contemporary experience in excavation in lithophysal tuffs. For these reasons, there will be a greater reliance than in typical civil construction projects on predictions using numerical modeling methods. 
Numerical models for geomechanics purposes fall into several categories: continuum and discontinuum methods, two- or three-dimensional models, methods for inclusion of site-specific geologic conditions into the models, quasi-static or dynamic models, and initial and boundary conditions. Below, the background of the modeling issues raised in the KTI agreements are discussed.

\subsubsection{Continuum vs. Discontinuum Methods (Associated RDTME KTIs 3.11, 3.12, 3.20)}

In continuum methods, the effect of geologic structure in the rock mass (i.e., fractures or lithophysae) is "lumped" into a thermomechanical constitutive model that represents the overall effect of the structure. In a discontinuum model, the fractures (and possibly lithophysae) are represented explicitly in the model as interfaces or cavities. The difference between these techniques is therefore the level of detail that is necessary in the model to adequately capture the deformation and failure mechanisms.

In the nonlithophysal units, the failure mode of the rock mass is controlled by the fracture distribution and geometry (i.e., wedge-type failures). Predictions will be made of gravitational, thermally and seismically induced rockfall, which is clearly structurally controlled and three-dimensional in nature. Therefore, a three-dimensional discontinuum approach appears warranted in this case. From a ground support design perspective, both continuum and discontinuum models and both two- and three-dimensional approaches have merit. This is particularly true in examination of thermally induced loading scenarios. It is always advisable to begin analyses at the simplest possible level of rock mass geometry - in this case, two dimensional approaches that may be conservative in their structural representation, but allow ease of parametric examination and interpretation. Continuum-based models that use a constitutive model basis for rock mass description (e.g., Mohr-Coulomb) provide good tools for bounding analyses where the rock mass fracture spacing is small relative to the opening diameter.

In the lithophysal rocks, the plan is to perform modeling predictions to estimate the amount of rock that can fall into the tunnel as a function of time-related degradation and strength loss, as well as from thermal loading and seismic shaking. Geologic observation in the existing tunnels indicates that the size of rock particles will be controlled by the spacing of the lithophysae and the spacing of the ubiquitous, short-length inter-lithophysal fracturing. The widely spaced, discontinuous natural fractures in the lithophysal rocks appear to be of secondary importance in this regard. Although geologic and mechanical test data will be used to confirm the estimated block size, practical observation indicates it will be small, and on the order of inches. Therefore, the approach is not to use modeling to determine the size of rock particles, but only the total amount that will dislodge from a given earthquake event. The most reasonable approach to modeling drift degradation in the lithophysal rocks is to use a discontinuum approach. Here, the overall mechanical response of the rock mass is represented using a constitutive model derived from lab and in situ testing, but allows the rock mass to fracture or break apart as the stresses dictate. The approach is described in detail later. 


\subsubsection{Two vs. Three Dimensions, Isotropic vs. Anisotropic Models (Associated RDTME KTI 3.10)}

Due to fracturing, the response of non-lithophysal rocks are assumed to be anisotropic and three-dimensional in nature. In the lithophysal units, the large-scale fracturing appears to be less important than the impact of lithophysae and small-scale inter-lithophysal fracturing on rock mass strength. Since the lithophysae are laterally consistent within a sub-unit and roughly uniformly distributed through the rock mass, it is reasonable to assume that a mechanical constitutive model, dependent on porosity and matrix strength properties, can capture the general failure mechanisms. There is no reason to assume that the mechanical response is anisotropic since the porosity is distributed uniformly. In other words, the orientation of the opening would appear to be of lesser importance to its mechanical response. Additionally, the lithophysal cavity radius is much smaller than the radius of the opening, and therefore, as long as the properties are determined for size greater than a few lithophysae diameters, a two-dimensional approach would appear adequate.

\subsubsection{Geologic "Realism" in Numerical Models (Associated RDTME KTIs 3.04, 3.05, 3.08,} 3.10, 3.15, 3.16, 3.17, 3.19, 3.20)

Implicit in the above discussion is the need for a clear methodology for incorporating geologic reality into the numerical models. The proposed approach incorporates two types of mechanical representations based on rock type: a discrete, fracture-based discontinuum approach for modeling emplacement drifts in the fractured, nonlithophysal rocks, and an isotropic constitutive representation for modeling the deformation and failure of lithophysal rocks. The success of both of these approaches is dependent on the ability to demonstrate that the basic representations and rock mass properties have been developed from the geologic mapping and geotechnical characterization as well as field test data.

For example, the three-dimensional discontinuum models of the Tptpmn need to have joint geometries that have been directly derived from field mapping and geotechnical studies, and that sufficient representations are modeled to reflect the statistical variability of the joint orientation, length, and spacing. In a similar fashion, the mechanical constitutive model used to represent the Tptpll and Tptpul needs to be based on compression testing at a large enough scale so that the effect of the lithophysae are adequately accounted for. Additionally, the resulting rock mass property (i.e., strength and deformability) ranges need to be related to the porosity, size and distribution of lithophysae as determined from geologic mapping. Methodologies to ensure geologic "realism" are discussed in Section 6 of this report.

\subsubsection{Quasi-Static vs. Dynamic Models (Associated RDTME KTIs 3.12, 3.13, 3.19)}

The failure response of the rock mass to dynamic loading is of potential importance to performance assessment at Yucca Mountain. Two numerical approaches are often used to represent this type of problem: quasi-static and fully dynamic models. Since the wavelength of the earthquake ground motions in question are much greater in length than the dimension of the opening (the tunnel is 5.5 meters wide, while an earthquake wavelength would be hundreds of meters in length), the dynamic load is often represented as an equivalent static load, taking into account the ground acceleration of the motion. It is felt that this approach is inadequate for 
examination of rockfall since it does not account for the translational motion of the tunnel, the transient stress concentrations and complex load path and inertial loading that a tunnel can undergo during high acceleration, long duration earthquakes. The ORD is therefore developing fully dynamic large displacement models for rockfall examination. However, in preclosure time periods, where the accelerations are small, use of equivalent static models may be sufficient for ground support analyses. Therefore, flexibility will be maintained in choice of modeling approach for ground support studies.

\subsubsection{Initial and Boundary Conditions (Associated RDTME KTIs 3.13)}

The repository excavations are initially loaded by the in situ gravitational stresses. At Yucca Mountain, the vertical, gravitational stress is the maximum component, while the principal horizontal components vary somewhat, depending on the topography. On average, the major horizontal components at $300 \mathrm{~m}$ depth are approximately $0.62 \sigma_{\mathrm{v}}\left(\mathrm{NE}-\mathrm{SW}\right.$ ) and $0.36 \sigma_{\mathrm{v}}$ (NW-SE), where $\sigma_{\mathrm{v}}$ is the vertical component, which is approximately $0.024 \mathrm{MPa} / \mathrm{m}$ depth.

The repository will undergo thermal loading in which the rock mass temperature will peak within a few hundred years after closure (depending on heat loading and ventilation time), followed by a long cool-down phase. The heating will induce rock mass expansion that will result in increased horizontal stresses at the repository level. This will increase the tangential stresses around the opening that could result in shear failure near the free surface. During cool-down, these thermally induced stresses will decay, with the effect of possible "loosening" of the rock mass. The magnitude of the temperature and stress changes will depend on the thermal loading scenario. Currently, the project is examining a range of thermal loading options. A series of three-dimensional models that include the mountain topography have been run to determine the regional temperature and stress changes as a function of the thermal operating mode.

\subsection{CONCLUSIONS}

This section of the report has provided a discussion of the basic, overriding issues/information needs that have led to the explicit RDTME KTI agreements. These information needs are as follows:

A. Geological and geotechnical characterization

1. Development of a data base of rock fracture characteristics and lithophysal content and their variability over the repository host horizon sub-units.

B. Materials Properties Measurement

1. Nonlithophysal rocks

a. Development of a representation of the geometry and strength characteristics of fractures and the blocks they form

b. Development of an enhanced database of the strength properties of joints through direct shear testing. Supplement this laboratory database with 
analysis of existing field index properties for development of an empirical shear model of the various joint sets

c. Measurement of static fatigue properties of non-lithophysal rock and investigation of the static fatigue response of rock fractures typical of the Tptpmn.

2. Lithophysal rocks

a. Development of thermal and mechanical constitutive models and rock mass properties for lithophysal rocks that accounts for the size, shape, distribution and variability of lithophysae and inter-lithophysal fracturing

b. Investigation of the static fatigue response of lithophysal rocks under long-term mining and thermally induced stresses.

D. Numerical Modeling

1. Determine proper modeling technique for examination of thermomechanical rock mass response under quasi-static and dynamic loading. Investigate continuum vs. discontinuum methods of analysis for ground support and rockfall simulation.

2. Verify proper choice of model dimensions, initial and boundary conditions. This includes accounting for thermally induced stresses and their impact on drift and seismic stability, and the use of site-specific ground motions for earthquake analysis

3. Perform sensitivity studies of tunnel stability and ground support under gravitational, thermal, and seismic loading in the preclosure and postclosure periods. 


\section{APPROACH TO RESOLVING THE AGREEMENTS}

The overall approach to resolution of the information needs described in Section 5 and the RDTME agreements is given in Figure 21. The process involves a program of field and laboratory testing, coupled with numerical studies, aimed at providing additional information on the rock mass geology and structure, and their property variations for use as input to numerical sensitivity studies of excavation stability under gravitational, thermal and seismic loading. Integral to this process is development of a detailed and transparent geological and geotechnical basis for the development of the site-specific rock-mass models. The KTI agreements that are addressed at each stage in this process are given in the figure.

The process is composed of six basic program work elements, a through $f$, given from left to right in this figure. The approach initially involves development of a detailed understanding of the thermomechanical properties and variability of lithophysal and non-lithophysal rocks, and development of validated numerical models that can be used for design and performance assessment (elements a-e). The outcome of this process are material models and properties and their ranges that can be used as input to sensitivity studies. The design and performance assessment modeling (element $\mathrm{f}$ ) is aimed at estimating tunnel stability in the preclosure and postclosure time frames. In the preclosure time frame, the primary issue is the specification of ground support methods, and in the postclosure, estimation of drift degradation from either thermal or seismic loading, or time-dependent response of the rock mass. The basic program elements are as follows:

a. Field Geotechnical Characterization-Includes further analysis of the extensive, existing rock mass geological and geotechnical characterization data from the ESF and the ECRB Cross-Drift (as well as surface outcrops and boreholes) to estimate the geometrical variability of rock mass structure. This analysis provides the basic rock mass structural input to the modeling and analysis activities.

b. Laboratory Testing and Model Calibration-Perform laboratory testing of large diameter (12 in. [30.5 cm]) lithophysal cores for determination of mechanical and thermal properties as a function of porosity, temperature and saturation level. The results from the laboratory testing are used for estimating rock mass properties, but also provide data for initial testing and calibration of numerical models capable of representing the basic mechanisms of the deformability and yield of lithophysal rocks. A number of numerical approaches will be used for analysis of the lithophysal laboratory and field data. PFC, which uses a "micromechanical" discontinuum approach for representing rock is one approach that will be used for this purpose. This program has the capability of modeling lithophysae, inter-lithophysal fracturing, and complex failure mechanisms. Additionally, it is planned plan to calibrate the FLAC (continuum) (FLAC V3.5, 10167-3.5-00 V 3.5) and UDEC (discontinuum) programs as alternatives to the more conventional means of representing the mechanical behavior of the lithophysal rocks. Additional laboratory testing is planned to determine the shear properties of joints and the time-dependent, static fatigue properties of lithophysal and nonlithophysal rocks. 


\section{Increasing Confidence in Understanding and Predictability}

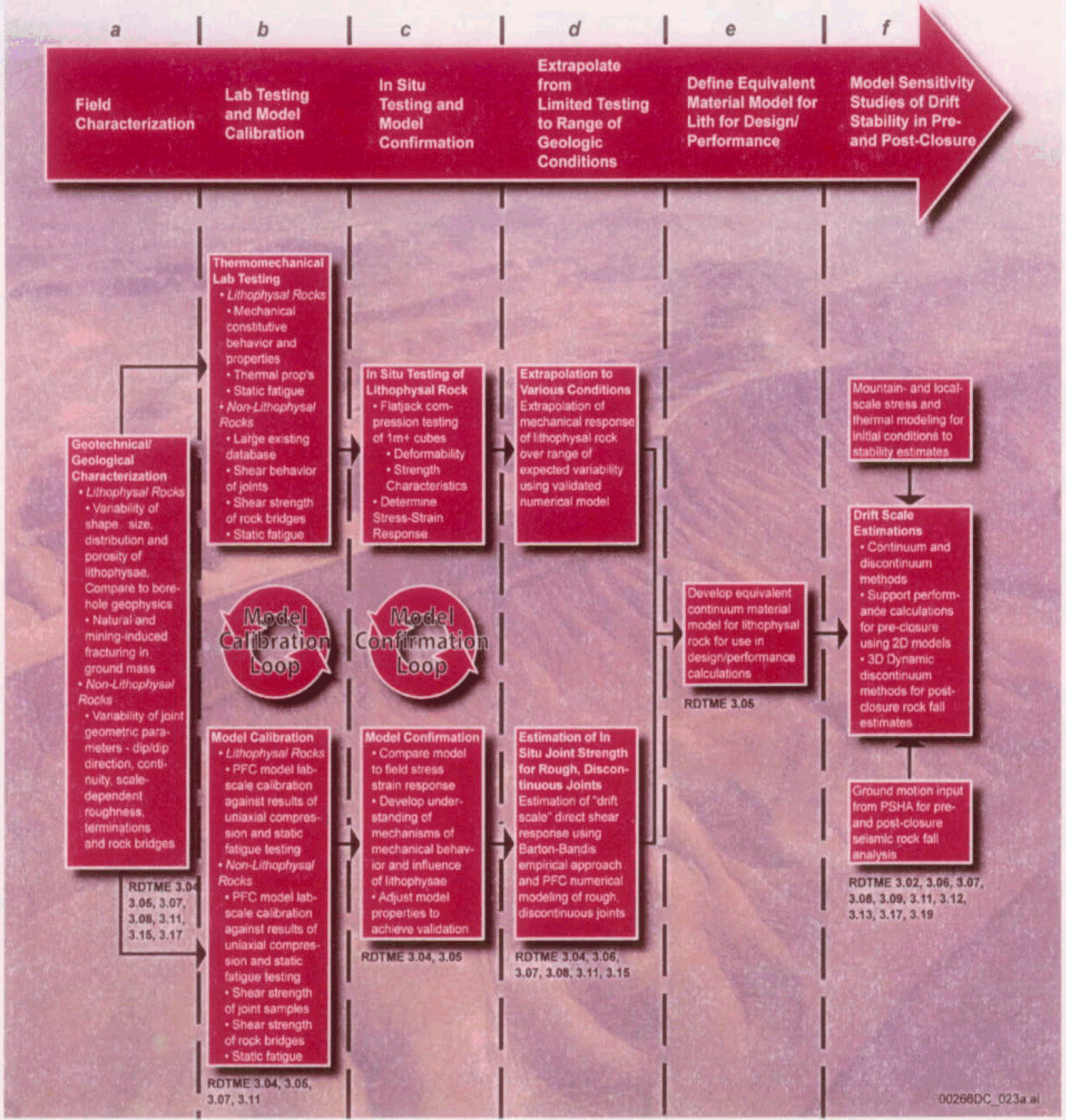

NOTE: Process starts with compilation and analysis of basic geotechnical mapping, followed by laboratory and field testing and model validation to develop rock mass property estimates for design and performance sensitivity studies.

Figure 21. General Approach to Resolution of the RDTME KTI Agreements 
c. In Situ Testing and Model Confirmation-In situ mechanical and thermal testing of lithophysal rocks to determine the size effect (porosity and fracture) on rock mass constitutive behavior. These tests will further be used for validation of the numerical model at increasing size scales. The outcome here is expected to be a model that can be used with confidence for extrapolating the mechanical response of lithophysal rocks.

d. Extrapolate from Limited Testing to Range of Geologic Conditions-Extrapolation of the properties of lithophysal rocks to the varying conditions of porosity, lithophysal shape, size distribution and spacing, and inter-lithophysal fracture density on mechanical properties. It is impractical to perform a statistically large number of in situ tests to determine strength properties. The goal of this project element is to provide a means by which the effect of lithophysal rock mass variability can be estimated. The results of static fatigue testing will also be included in the model for time-dependent strength representation.

e. Define Equivalent Material Model for Lith for Design/Performance-Here, the constitutive models and the numerical approaches in which they are embedded will be finalized for sensitivity studies. The rock property ranges defined for each geologic unit will need to reflect the impact of the variability of the geologic structure within the particular rock strata. The range of properties also need to reflect the uncertainty in the parameters. The uncertainty will be a function of the scope of rock testing for each unit. The intact rock property data base for the non-lithophysal rocks is large and thus the range of uncertainty in these parameters is more easily defined and evaluated. The properties of the lithophysal rock, on the other hand, are both size and lithophysal porosity-dependent. These dependencies require large scale testing methods, which limits the number and extent of testing, and thus increases the level of uncertainty. Uncertainties will be dealt with in detail in the Design Parameters Analysis Report (scheduled for completion in FY 2003). Additionally, the uncertainty in lithophysal rock properties will be addressed through use of large scale lab and in situ mechanical testing, numerical simulation of lithophysal effects using the PFC program, and numerical sensitivity studies using a wide range of input material properties to verify the sensitivity of the rock mass response to uncertainty in input properties.

f. Model Sensitivity Studies of Drift Stability in Preclosure and Postclosure-Sensitivity studies of excavation stability under gravitational, thermal and seismic loads in the preclosure and postclosure time frames. Here, numerical model sensitivity studies are performed using the range and distribution of rock mass properties determined from the previous project elements. The deformation and yield of the openings in preclosure time will be used to define ground support requirements and methods. A ground support observation and maintenance program for the preclosure period will be developed. The models will also be used to examine time-related degradation and seismic stability for site-specific ground motions at various annual exceedance frequencies. 


\subsection{PROGRAM ELEMENT A - GEOTECHNICAL AND GEOLOGICAL CHARACTERIZATION OF THE TOPOPAH SPRING FORMATION}

\subsubsection{Introduction}

As reviewed earlier, a very large base of geological and geotechnical data exists from the ESF and the ECRB Cross-Drift facilities. These data include:

- Fracture mapping from full periphery maps and detailed line surveys in which any fracture with a trace length greater than $1 \mathrm{~m}$ that crosses a tape line at the tunnel springline has been mapped. Data collected from the detailed line surveys include dip, dip direction, fracture trace length, spacing and position (offset of fracture centroid from the line survey position), and small and large scale roughness, using the U.S. Bureau of Reclamation (USBR) roughness scale. Barton's "Q" classification for the rock mass and joints were also recorded in conjunction with this work.

- Lithophysae mapping and description has been performed as part of the lithophysae study as reviewed earlier. This study provides data on the variability of porosity, size and shape of lithophysae and their distribution within the Tptpll.

- Inter-lithophysal fracture density is available from the detailed lithophysal panel maps constructed within the ECRB Cross-Drift across the Tptpll and from the "small-scale" fracture mapping study.

These data are currently being used for three purposes associated with RDTME KTI resolution:

- Development of representative fracture geometry and characteristics within a rock volume that reasonably represents the variability of those fractures with trace lengths of $1 \mathrm{~m}$ or more. This work is being performed for the Tptpmn, Tptpll and Tptpul.

- Development of an estimate of the range and variability of lithophysae shapes, sizes, and porosity within the Tptpll.

- Development of an estimate of the small-scale fracture fabric, density, and length within the Tptpll.

The results of the work described below will be described in a Science and Analysis Report, authored by USBR and U. S. Geological Survey staff, covering the geometric characteristics of fractures and lithophysae, to be released in January 2004. Data from this study will also be described and used in the revision of Drift Degradation Analyses (BSC 2001) to be completed in FY 2003. 


\subsubsection{Generation of a Representative Fracture Volume for Ground Support and Rockfall Studies}

\subsubsection{Fracture Data Base and the FracMAN Program}

Seismic analyses in the nonlithophysal rocks will be performed using a three-dimensional discontinuum modeling approach since it is assumed that its stability response will be controlled by the fractures. Therefore, a fracture model that reasonably represents the field geometry of the fractures and the rock blocks is essential. The FracMAN program is used here for generation of fracture patterns in three dimensions for use as input to the discontinuum modeling (Figure 22). FracMAN is a special-purpose fracture modeling tool that was developed for creation of synthetic fracture representations for use in hydrologic modeling, reservoir engineering and rock mechanics applications.

The detailed line survey data base is first subdivided by rock unit-the Tptpmn, Tptpul, Tptpll and Tptpln. The approach here is to use the detailed line survey statistics (i.e., dip, dip direction, fracture trace length, spacing and position [offset of the fracture centroid from the detailed line survey line]) to generate a statistically equivalent set of fractures in a volume of rock that can be sampled for the numerical modeling. The fracture set descriptive data are generally described by FracMAN as a form of power law (the proper form of law is determined initially). The fractures are then distributed within the volume assuming a Poisson process. A cubic volume is generated that has sufficient edge length to allow a large number of randomly located tunnels and the volume surrounding them to be developed for the ground support or seismic sensitivity simulations. The total number of tunnels and their associated rock volumes will be determined iteratively as the variability in rockfall introduced by the fracture geometry becomes apparent.

FracMAN has numerous capabilities that can be used to verify the generated fracture geometry. These include the ability to create detailed fracture statistics that can be compared to those from the actual detailed line surveys to make certain the populations have similar geometric and statistical characteristics. Also, synthetic full periphery maps can be created from the FracMAN results for a comparison to actual tunnel observations to make certain that the results make practical geological sense. Numerous index values related to fracture density and fracture surface area for the overall volume for each joint set can also be made within FracMAN to establish that the correct numbers, spacings and lengths of fractures are being generated. The generation of the fractures is somewhat of an iterative process, particularly establishing the fracture length (or radius, since the base case assumes circular disks to describe the fractures) and spacing. Due to the finite continuity of the fractures, the trace length distributions derived from the detailed line surveys are used as an initial guide to selection of fracture length. The length is iteratively adjusted to achieve a reasonable estimate to the in situ trace length distribution as seen from the detailed line surveys and on the full periphery maps. Since the detailed line survey values may show bias against structures whose dip is subparallel to the tunnel, correction factors are necessary. Mauldon corrections, which accommodate the finite size/persistence of the fractures, will be used instead of Terzaghi corrections that assume infinite persistence. 


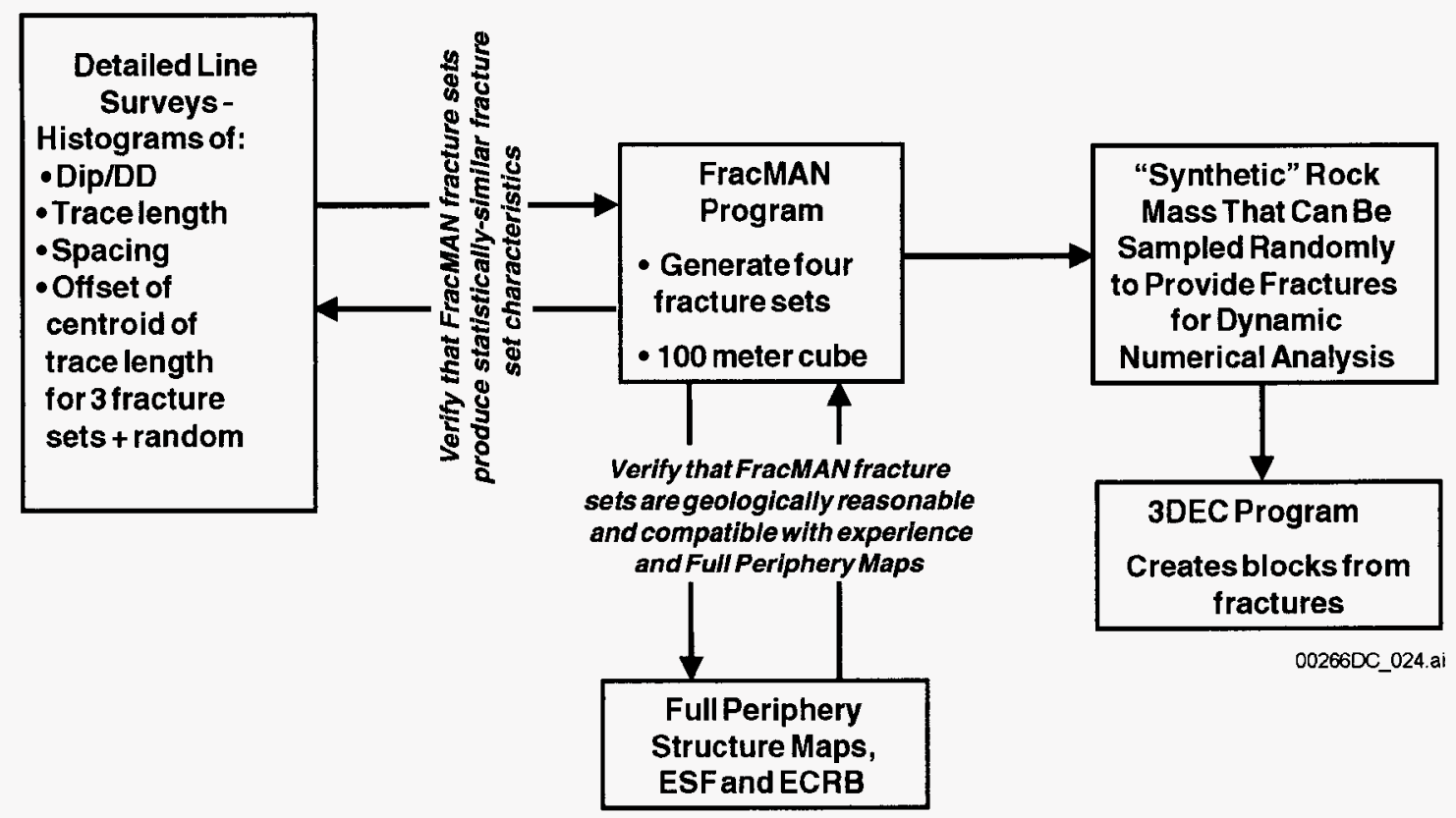

NOTE: The FracMAN program is used to create input to the 3DEC program.

Figure 22. Methodology for Generation and Verification of Fracture Geometries in Nonlithophysal Rocks

\subsubsection{Treatment of the "Intensely-Fractured Zone" Within the Tptpmn}

Within the Tptpmn, the region termed the "intensely-fractured zone" (encountered from Station $42+50$ to $52+50$ along the ESF Main Drift) is an area of intense fracture frequency (fracture spacing of approximately $0.25 \mathrm{~m}$ or less) which is uncharacteristic of the remainder of the Tptpmn. These fractures, which are high-angle and sub-parallel to Set 1, create thin, platy blocks. The origins of this zone, which lies along the Ghost Dance fault, is uncertain, and could be either related to the shear on this structure, or to the presence of a lithophysal-rich subzone within the Tptpmn. In any case, the lateral extent of this zone is not known, but it is not seen in the ECRB Cross-Drift, surface-based boreholes or surface outcroppings. This zone lies adjacent to Panel 5 (the possible expansion panel in Figure 14), and to the south of the area proposed to meet the 70,000 MTHM requirements (Panels 1 to 4). Therefore, the extent to which this zone actually impacts the base repository emplacement drifts is unknown at present, but is probably not particularly significant. The block sizes created in this zone are clear in the tunnel itself, where the intense fracturing results in small (about $0.25 \mathrm{~m}$ or less) block dimensions. Since this zone clearly represents a separate fracture population from the general Tptpmn, it will therefore be treated separately from the population used for the FracMAN and 3DEC rockfall analyses. At the current time, the plan is to empirically estimate the rock block size that can be created from this zone by examining the fracture spacings. The amount of rock that can fall due to seismic loading will be estimated from three-dimensional models in a conservative fashion. 


\subsubsection{Lithophysae Characteristics}

The panel mapping within the ECRB will be used to generate the following information:

- Lithophysal porosity as a function of depth within the Tptpll

- Description of alteration rims and spots and their contribution to porosity

- Variability of lithophysal shape and size

- Distribution of lithophysae within the rock mass and the thickening "webbing" between lithophysae.

These data will provide the basis for estimating variability of porosity and its impact on the distribution of thermal and mechanical properties within the Tptpll.

\subsection{PROGRAM ELEMENTS B-E-SUPPLEMENTAL MATERIAL PROPERTIES TESTING AND NUMERICAL MODEL VALIDATION}

\subsubsection{Introduction}

As discussed previously, KTI resolution requires developing a detailed understanding of the thermal and mechanical constitutive behavior of lithophysal rocks. The approach shown in Figure 22 involves use of laboratory and in situ testing to calibrate and validate a numerical model that can be used to understand the basic mechanisms of behavior of the lithophysal rocks, and as a test-bed for estimating rock mass properties through numerical extrapolation.

\subsubsection{Laboratory Testing}

A laboratory testing program has been designed to provide mechanical and thermal properties, primarily on lithophysal rocks. Additionally, long-term static fatigue of lithophysal and nonlithophysal rocks will be determined. The proposed testing can be subdivided into four areas:

- Compression testing of lithophysal rocks

- Thermal testing of lithophysal rocks (thermal expansion)

- Static fatigue testing of lithophysal and nonlithophysal rocks

- Direct shear of fractures from nonlithophysal and lithophysal rocks.

Due to the lithophysal porosity and size-dependence, it is necessary to test large sample sizes. Therefore, 12 in. $(30.5 \mathrm{~cm})$ diameter cores, containing approximately 5 or more lithophysae across a given sample diameter, are used for testing purposes. Table 3 reviews the primary test types and the environmental conditions to be applied. The majority of the compression and thermal testing will be completed at Sandia National Laboratories, while the joint direct shear and static fatigue testing will be accomplished at the USBR laboratories in Denver. The USBR has the capability to conduct shear tests on large diameter cores, and has extensive thermal creep testing facilities.

Coring of the Tptpll is difficult due to the presence of larger lithophysae and inter-lithophysal fracturing, making it quite difficult to obtain standard 2:1 length:diameter ratio samples. Lithophysal rock testing will therefore be centered on tests of the more easily cored Tptpul with 
a fewer number of Tptpll tests. In situ testing of the Tptpll will be necessary to determine the differences in behavior of these two lithophysal units. Additionally, the compression testing of lithophysal rocks will necessarily be in uniaxial compression due to difficulties in jacketing samples for triaxial compression.

\subsubsection{In Situ Compression Testing}

Due to the size dependence of the rock mass properties in lithophysal rocks and the difficulties in coring of the Tptpll, some in situ compression tests driven to rock mass failure will be necessary. A number of different in situ testing techniques were considered in the planning stages. In particular, in choosing the proper testing technique, it is necessary that the test not only obtain a measure of the deformation modulus of the lithophysal rocks, but that it also obtain data on the rock mass strength. These objectives can most easily be accomplished by conducting "slot" tests. The slot test involves cutting long, thin, parallel slots approximately $1 \mathrm{~m}$ apart in the wall or floor of the drift to create a "sample" whose length is greater than its width and is attached on three sides and free on three sides (Figure 23). Load is applied to the parallel slots through use of aluminum or steel flatjack bladders that are inflated in the slots, compressing the sample. Instrumentation for monitoring the deformation of the block is typically installed from the block surface as well as through boreholes drilled into the block. The flatjacks are capable of applying pressures up to about 30 to $40 \mathrm{MPa}$. To ensure that failure is achieved, a larger (approximately 12 in. $[30.5 \mathrm{~cm}]$ ) central hole can be drilled into the block to provide a means of achieving higher stresses and failure, as well as providing easier access for instrumentation and viewing inside the block.

Table 3. Testing Parameters and Conditions

\begin{tabular}{|l|l|}
\hline \multicolumn{1}{|c|}{ Test Type } & \multicolumn{1}{|c|}{ Parameters and Environmental Conditions } \\
\hline Uniaxial Compressive Strength Unconfined Modulus & $\begin{array}{l}\text { Temperature to roughly } 200^{\circ} \mathrm{C} \\
\text { Saturation - room dry and saturated } \\
\text { Spatial Variability/porosity variation }\end{array}$ \\
\hline Thermal Expansion & Spatial Variability/porosity variation \\
\hline Joint Shear Strength & $\begin{array}{l}\text { Normal stress } \\
\text { Variability - Various joint sets from nonlithophysal rocks }\end{array}$ \\
\hline $\begin{array}{l}\text { Uniaxial compression-Static Fatigue Strength (time to } \\
\text { failure) }\end{array}$ & $\begin{array}{l}\text { Function of applied stress (50 to } 90 \text { percent peak } \\
\text { strength) }\end{array}$ \\
\hline
\end{tabular}

It is proposed that three tests be conducted that span the best to poorest quality of the lithophysal rocks (Figure 24). To this end, the first test would be conducted in the uppermost portion of the Tptpll which, in general, has the poorest geotechnical quality of the various repository rocks. This upper $10 \mathrm{~m}$ or so of the Tptpll is characterized by large, irregular lithophysae and intense inter-lithophysal fracturing. The second test is planned for what may be considered the highest quality lithophysal rock located within the Tptpul, in uniformly sized and distributed, small (less than $10 \mathrm{~cm}$ diameter) lithophysae, with minimal inter-lithophysal fracturing. The third test is to be located within the central area of the Tptpll, characteristic of the bulk of the emplacement areas of the repository.

The basic testing strategy is to load the rock mass in a series of load cycles at increasing peak pressure levels. The deformation modulus of the rock mass is determined on loading, with a 
measure of the "intact" rock block modulus determined on unloading. The central hole allows both access for internal measurement as well as providing stress concentrations sufficient for failing the rock. It is planned to hold the load at constant pressure at each of the load peaks to examine time-dependent deformation of the rock mass. If time-dependence is present, the load will be held until steady conditions are reached. In at least one of the latter two tests, borehole heaters will be used to raise the temperature of the block to approximately $100^{\circ} \mathrm{C}$ to examine thermal expansion and temperature effects on deformation modulus and time-dependency.

At the completion of the test, the applied stresses will be raised to fail the rock in compression (i.e., shear). The failure mechanism will be observed on the block surface as well as in the central hole. A thorough video taping and geological mapping will be made of the surface, slots and central hole of the test before and after the testing.

Back-analysis of ongoing thermal conductivity tests as well as additional tests in the Tptpll are anticipated. Additional tests will include monitoring of pretest and posttest saturation conditions. The goal of this work is to produce a relationship of thermal conductivity to porosity and saturation for lithophysal rocks. The current approach uses a three-dimensional cubic model of the lithophysal rock mass for assessing the thermal conductivity. Rock mass conductivity is calculated based on the matrix thermal conductivity, the matrix saturation, and lithophysal porosity. A volume averaging procedure discussed in Thermal Conductivity of the Potential Repository Horizon Model Report (BSC 2002) is used to estimate the rock mass thermal conductivity from these parameters. The analytical model of porosity dependence is examined in light of the field tests described in Section 5 of this report. Further work will include extrapolation of the thermal conductivity based on lithophysal porosity.

\subsubsection{Model Calibration and Determination of a Rock Mass Mechanical Constitutive Model for Lithophysal Rocks}

The basic strategy for laboratory and field testing discussed above provides data from large cores and field sites at a number of locations within the ESF and the ECRB Cross-Drift. Due to the limited areas where samples can be taken, and to the general effort and cost necessary to prepare and conduct such large-scale tests, it is impractical to conduct a typical "statistically based" testing approach. As discussed previously, in the nonlithophysal rocks, the intact rock strength is significantly higher than the anticipated induced stresses. Non-linearity occurs due to the presence of the jointing along which slip and separation can occur. Typically, the blocks are represented as elastic materials and the joints as interfaces corresponding to a Mohr-Coulomb slip condition. Modeling of the nonlithophysal rocks can be represented using a discontinuum model in which the joints are given proper friction, cohesion and dilation angle.

This approach is reasonable for the nonlithophysal material, but cannot reliably be used for the lithophysal rocks due to the unknown impact of lithophysae and fractured matrix material on the shear failure criteria and possible volumetric compaction response. The only recourse in determining material response is to perform testing of samples large enough to encompass the non-linearities. 


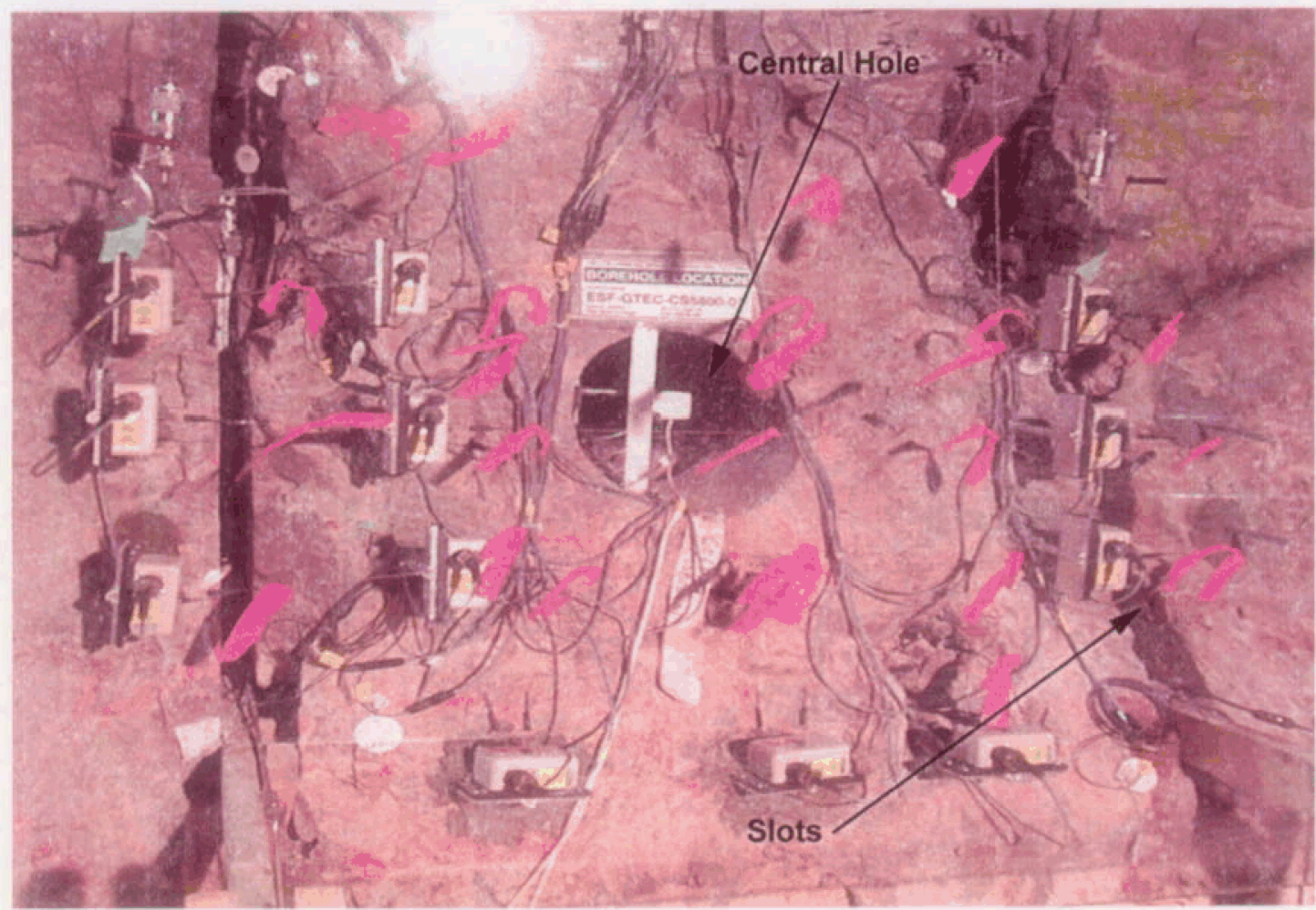

$00266 \mathrm{DC} 025$ ai

NOTE: Width of the test sample is approximately $1 \mathrm{~m}$. Surface deformation instruments shown.

Figure 23. Slot Test Combining Parallel Slots and a Central Drilled Hole

To overcome the testing limitations, several modeling approaches will be calibrated as an integral part of the lab and field testing program. Ultimately, the goal is to understand and reproduce the basic deformation and failure mechanisms of the lithophysal material so that the models can be used for extrapolation purposes (i.e., they can be used to examine the impact of parameters such as lithophysal porosity, shape, size, and distribution on rock mass design properties). In this manner, the models can be used as "test-beds" (i.e., numerical laboratories) for supplementing the testing program. For this approach to be feasible, models with the capability of representing the basic failure and deformation mechanisms must be used.

\subsubsection{1 "Micromechanical" Modeling Using the PFC Approach}

It is proposed here to use the "micromechanical" PFC program for calibration/verification against test results, beginning with the laboratory scale testing. The model can be used to simulate the lab testing stress paths, while predicting the stress and strain results. Detailed comparison to the laboratory test results and observations will be made and a constitutive model developed.

Why is use of this modeling approach suggested? This approach is used as it allows straightforward representation of holes in a matrix, and complex failure mechanisms of the webbing between holes without resorting to simplifying assumptions such as lumping holes and solid into an "equivalent" continuum material. It is felt that, without significantly greater amounts of test data upon which to build a constitutive model, a direct physical representation of the impact of void space is needed. The PFC program (Figure 25) represents rock as a number 
of small spherical grains that are bonded together at their contacts with a shear and tensile strength, as well as a grain to grain friction angle after the "contact bond" has been broken. If cementing exists between grains, it can be represented with a "parallel bond" that provides a rotational resistance as well. The deformability of the contacts between particles is represented by normal and shear stiffness at the contact point. Porosity is developed naturally in the model by control of the shape and size of void space between chains of bonded grains. Thus, the input assumptions necessary for the model are very simple: contact strength and stiffness. Constitutive behavior may develop naturally based on porosity and the few input properties. Calibration of the model against laboratory testing is necessary via sensitivity studies in which the contact strength and stiffness values are varied. A range of contact property values that reproduce the range of lithophysal rock properties will be developed and verified against lab and field test results.

An example of this approach on the existing laboratory testing of the solid samples of Tptpmn and Tptpul is given here. Figure 26 shows a PFC model of a uniaxial compression test of nonlithophysal rock that has been calibrated to produce the same modulus and strength properties as typical 1-in. diameter Tptpmn samples (about $200 \mathrm{MPa}$ compressive strength). The PFC sample is compressed by a velocity applied to the "sample" ends, as is the case in a laboratory. A picture of the sample in postpeak failure is superimposed by the stress-strain curve. The "calibration" is achieved by simply setting the contact stiffnesses and strength properties so that a match is achieved between test and model. The PFC model is able to spontaneously produce a macroscopic shear failure mechanism composed of coalescing tensile fractures that is quite realistic in comparison to typical laboratory behavior. Without changing the calibrated bond properties, porosity is then added to the PFC model by removing particles to form circular cavities. In this case, a total void porosity of approximately 20 percent is developed more-or-less uniformly across the sample (Figure 27). Compression of this sample leads to a completely different internal failure and deformation mechanism. The cavities provide internal holes that promote extensional fracture development between them, leading to a macroscopic shear failure mechanism that occurs at much lower peak stresses. In this case, a reduction in the uniaxial compressive strength of over 5 times results, even though the particle bond strength is the same as in the previous, nonlithophysal example. An actual test on a sample of Tptpul is shown in this figure, with similar results. Obviously, detailed examination of PFC strength and stiffness parameters will need to be examined for both Tptpul and Tptpll "samples" to reproduce the range of strength and moduli observed in the laboratory data, but even at the simplest level, this approach appears to yield considerable promise in understanding how porosity and inter-lithophysal fracturing impacts rock properties.

After calibration is achieved at the laboratory scale, validation will be explored through comparison to the in situ slot tests. The in situ testing will be conducted in the Tptpul and Tptpll, so comparison of size effect and rock quality (in the form of inter-lithophysal fracturing) will be possible. The ultimate goal is to develop a validated model for a range of rock types and qualities that can reproduce the general deformability and failure mechanisms for lithophysal rocks. Although only the PFC model is discussed here, it is probable that other modeling approaches, including the UDEC and FLAC programs will be used for comparison to lab and field data. A more traditional approach, which is fitting of standard material models, such as elastic-perfectly plastic models with shear and volumetric failure envelopes will be used to supplement the PFC modeling. 


\subsubsection{Extrapolation of Lithophysal Material Behavior Using Numerical Model}

Assuming validation, the PFC model (as well as others, if necessary) will be used as a numerical "laboratory" for extrapolation to obtain estimates of lithophysal rock mass properties and response mechanisms. Studies will be performed to examine mechanical response for the range of lithophysal porosity, sizes, shapes and distribution as determined from the lithophysal mapping study described in Section 6.1. Figure 28 shows a schematic of what these studies hope to accomplish. The uniaxial compressive strength (as an example) is shown plotted against porosity for all welded and non-welded tuffs. The existing large-scale tests from Busted Butte Tptpul samples area shown as open circles. This data base will be supplemented with the new laboratory and in situ tests on lithophysal rocks, further extending the knowledge of size effect/porosity on properties. The validated PFC model will then be used to examine the property range variations based on the estimated range of variability of lithophysal porosity, shape, and size as determined from the geologic mapping studies.

\subsubsection{Long-term Strength Degradation}

An additional issue that will need to be addressed is the long-term strength degradation of the lithophysal rocks. A number of samples of non-lithophysal tuff will be subjected to static fatigue testing. This testing will involve producing many cores from closely spaced blocks of material obtained in either the ECRB or ESF. A number of samples will be tested to determine their UCS. These data will provide an average value of the UCS for the ensuing static fatigue tests. A number of samples will then be loaded in uniaxial compression to a target stress that will range from about 70 to 95 percent of the average UCS value. These samples will be held at constant stress until the sample fails. This may require times from a few seconds to months. The time-to-failure at that load level will be plotted against the relative stress level and a relationship established between the ratio of stress to strength and time-to-failure (e.g., Figure 29, Lajtai et al. 1987). For typical hard rocks, significant time-dependence does not occur until stress levels of approximately 80 percent of the uniaxial compressive strength are achieved. 


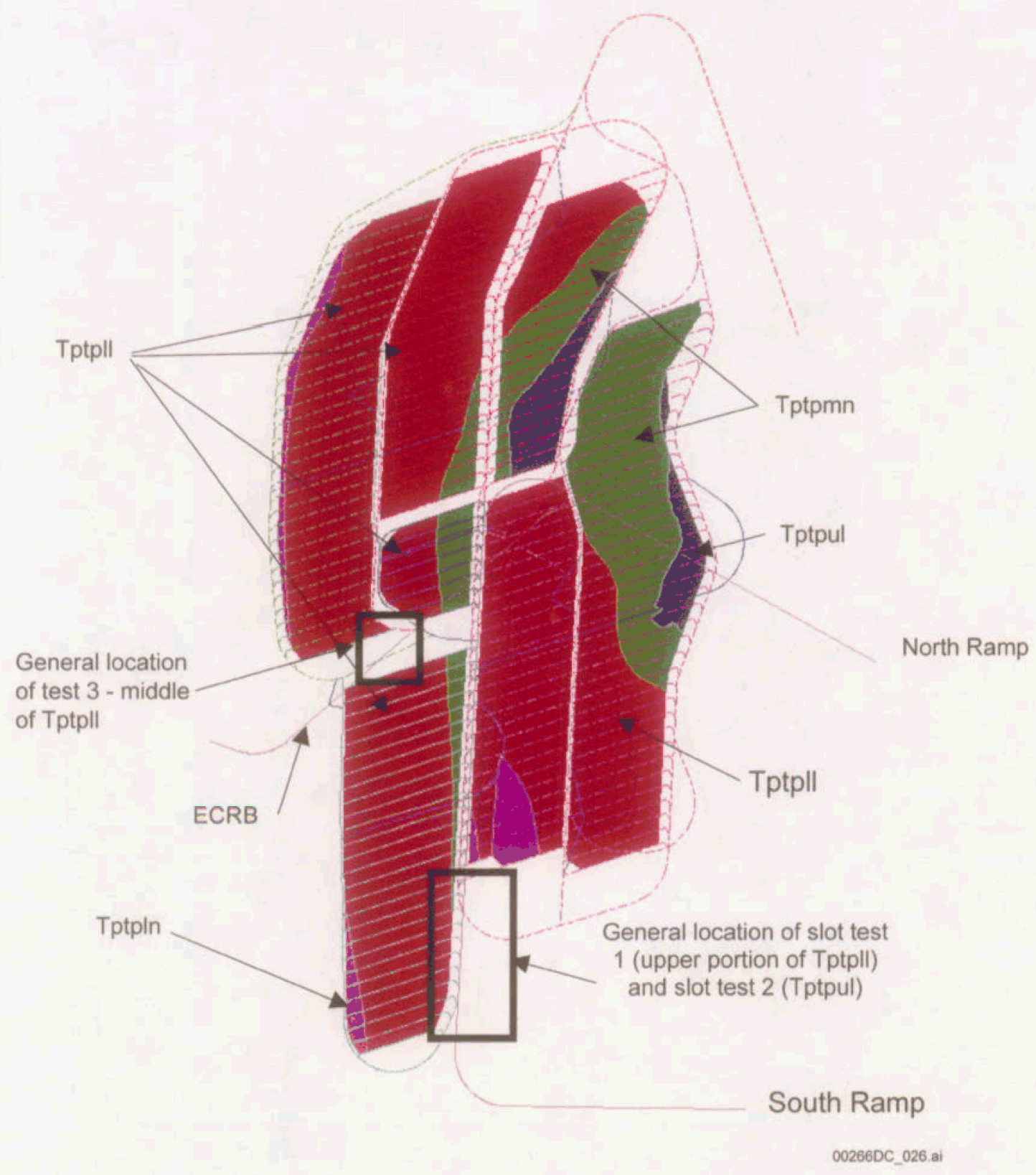

NOTE: Approximate locations of the slot testing are shown.

Figure 24. Repository Layout with Overlay of the Topopah Spring Sub-Unit 


\section{Physics of PFC Model for Rock}

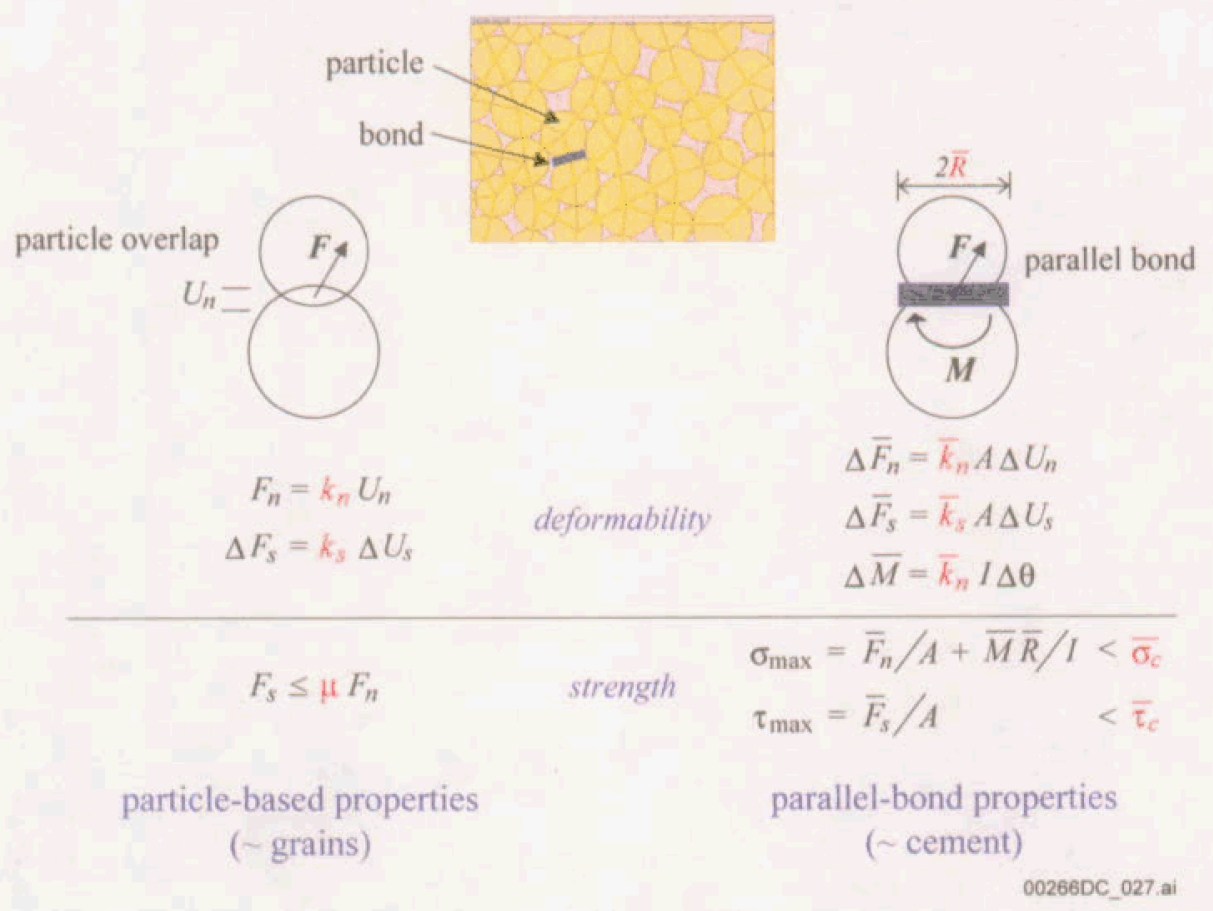

NOTE: The rock mass is composed of a large number of bonded circular (two-dimensional) or spherical (three-dimensional) particles. Porosity is developed naturally in the model by creation of pore space. The elastic moduli of the system are governed by contact shear and normal stiffness. The strength of the particle bonds is governed by a shear and tensile strength. Once a bond is broken, intergranular friction governs the shear strength of the material. Two types of bonds are possible: a simple contact bond and a "parallel" bond that represents intergranular cement and accounts for rotational resistance.

Symbols:

$F_{n}=$ normal contact force

$k_{n}=$ normal stiffness

$U_{n}=$ relative normal displacement

$\Delta F_{s}=$ shear contact force increment

$k_{s}=\quad$ shear stiffness

$\Delta U_{s}=$ relative shear displacement increment

$\Delta \bar{F}_{n}=$ axial-directed force increment for bond

$\bar{k}_{n}=$ bond normal stiffness

$A=$ area of bond cross-section

$\Delta U_{n}=$ relative normal displacement increment

$\Delta \bar{F}_{s}=$ shear-directed force increment for bond

$\bar{k}_{s}=$ bond shear stiffness

$\Delta U_{s}=$ relative shear displacement increment

\begin{tabular}{|c|c|}
\hline$\underset{I=}{\Delta \bar{M}}$ & $\begin{array}{l}\text { bending moment increment for bond } \\
\text { moment of inertia of the bond } \\
\text { cross-section }\end{array}$ \\
\hline & increment of rotational angle \\
\hline$\mu=$ & $\begin{array}{l}\text { shear contact force } \\
\text { contact friction coefficient }\end{array}$ \\
\hline$\sigma_{\max }$ & $\begin{array}{l}\text { maximum tensile stress acting on the } \\
\text { bond periphery }\end{array}$ \\
\hline$\tau_{\max }=$ & $\begin{array}{l}\text { maximum shear stress acting on the } \\
\text { bond periphery }\end{array}$ \\
\hline & particle radius \\
\hline & axial-directed force for bond \\
\hline & shear-directed force \\
\hline
\end{tabular}

Figure 25. Physical Basis of the PFC Modeling Approach 
This testing will supply needed information on non-lithophysal rocks, but will also be used as the basis for estimating time-dependency in the lithophysal rocks as well. Why do we not simply conduct a similar testing program for lithophysal rocks? Due to the general difficulty in obtaining significant numbers of large diameter samples, and due to the inherent variability of the strength due to local sample porosity, it is difficult to accurately judge the compressive strength of any individual lithophysal sample. Therefore, the "target" stress levels for every sample will vary and one would never be certain of the relationship between time-to-failure and stress to strength ratio, as the strength would be unknown. To overcome this difficulty, we make use of the understanding that the matrix material of the lithophysal and non-lithophysal rocks is the same, and therefore the non-lithophysal static fatigue testing applies to the lithophysal matrix as well. The PFC program provides a platform by which the impact of static fatigue can be accounted for. The particle bonding strength of the matrix material can be adjusted to account for the time-to-failure derived from the laboratory testing in a manner consistent with a fracturemechanics-based stress corrosion mechanism. The PFC model without lithophysal cavities is calibrated against the static fatigue behavior of non-lithophysal core samples. Then, lithophysae are added to the PFC model and numerical "lab tests" are performed. The model will account correctly for the stress concentration effect of the lithophysae, and allow numerical construction of time-to-failure plots for lithophysal rocks. A parametric study will allow the impact of porosity on time-to-failure in the same manner as a laboratory program if it were possible to control porosity from sample to sample. A level of validation of this approach will be achieved by PFC back-analysis of a limited number of progressive loading fatigue tests conducted on large lithophysal samples at the USBR laboratories in Denver. A series of approximately 10 uniaxial compression tests will be conducted on 6- to 12-in. (15.2- to 30.5-cm) diameter cores of lithophysal rock. The samples will be stressed to increasing levels of the axial load, which will be held constant while the axial strain is monitored. The load will be increased in increments until the samples indicate strain and failure. The stress level, sample porosity and time-to-failure will be recorded. This test is not a static fatigue test in the strict sense in that the complex load path could induce damage in the sample that could impact its time-to-failure. However, the test data can be used as a means of validation of the PFC model. 


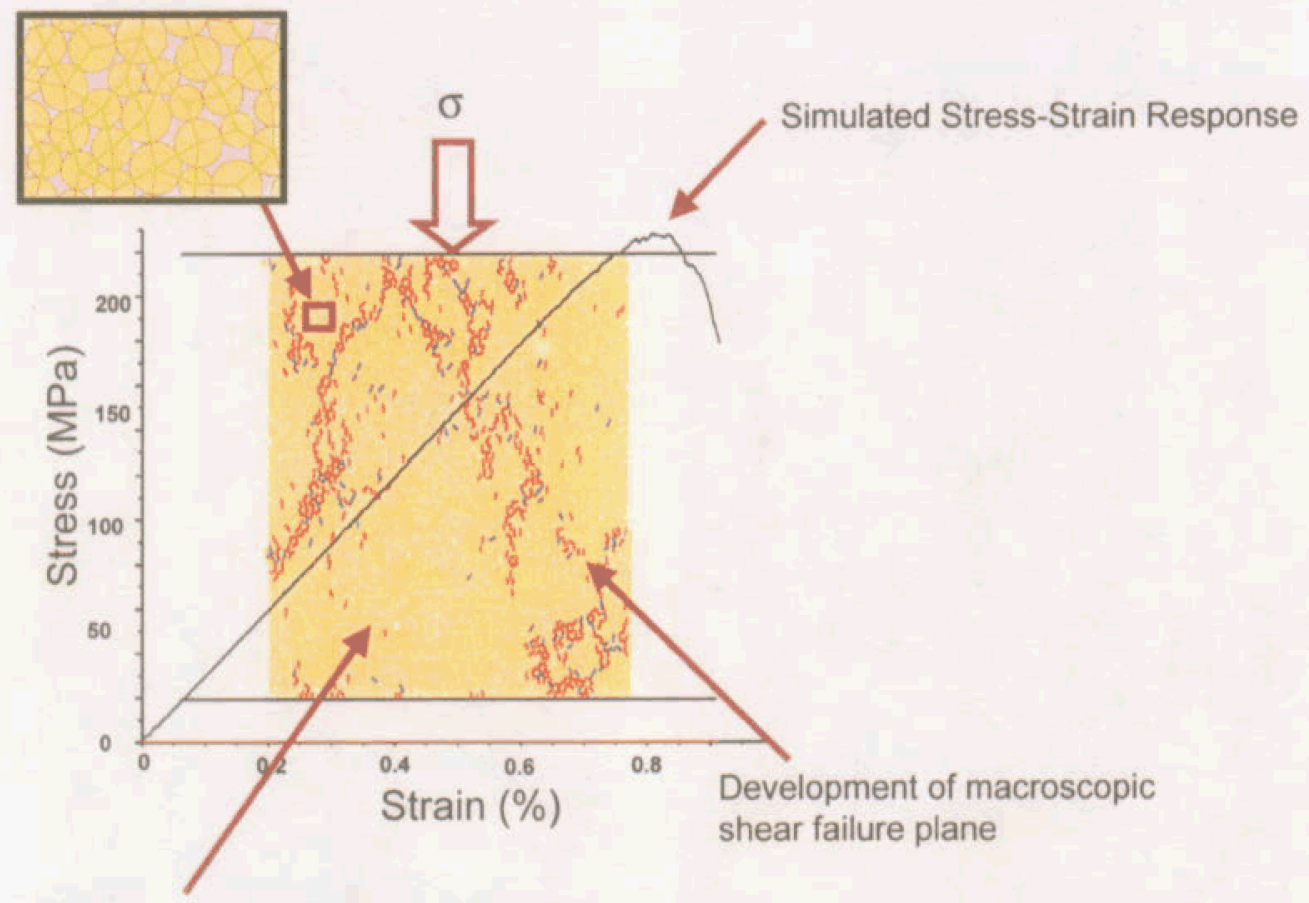

Simulated rock sample, loaded in compression

$002660 \mathrm{CC} \_28$ ai

NOTE: Model is calibrated to achieve typical Tptpmn modulus and peak strength from uniaxial compression testing. The PFC model is compressed axially by applying a velocity to the ends of the "sample". Here, the postpeak condition is shown with particle bonds failing primarily in tension to form macroscopic shear fracture planes through the sample.

Figure 26. Example of a PFC Model Calibration 


\section{(a) Applied Uniaxial Compression}

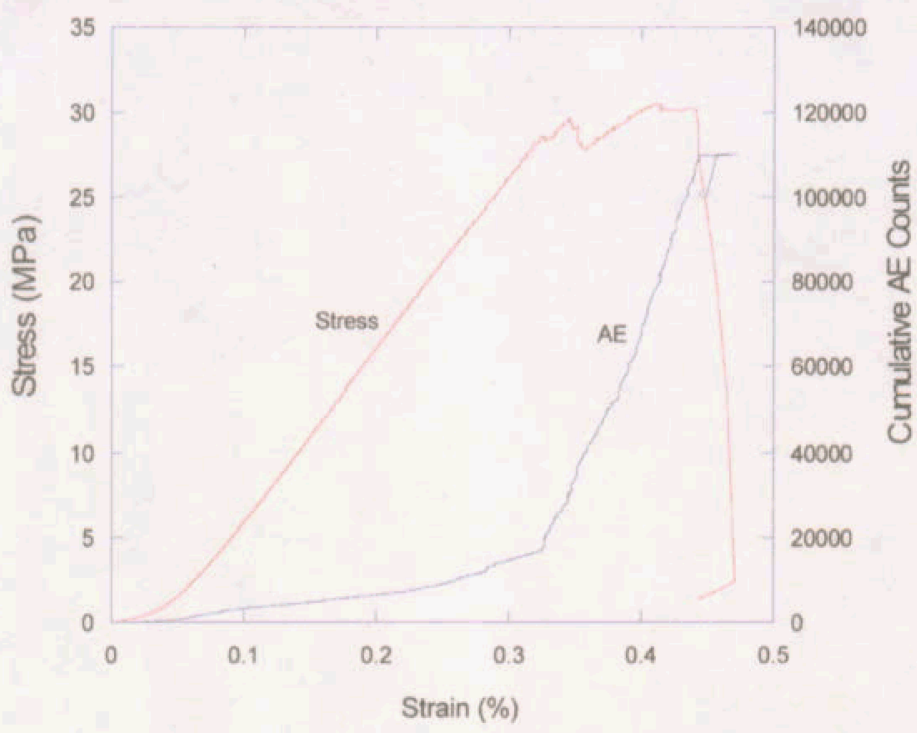

(b) Actual Test Data

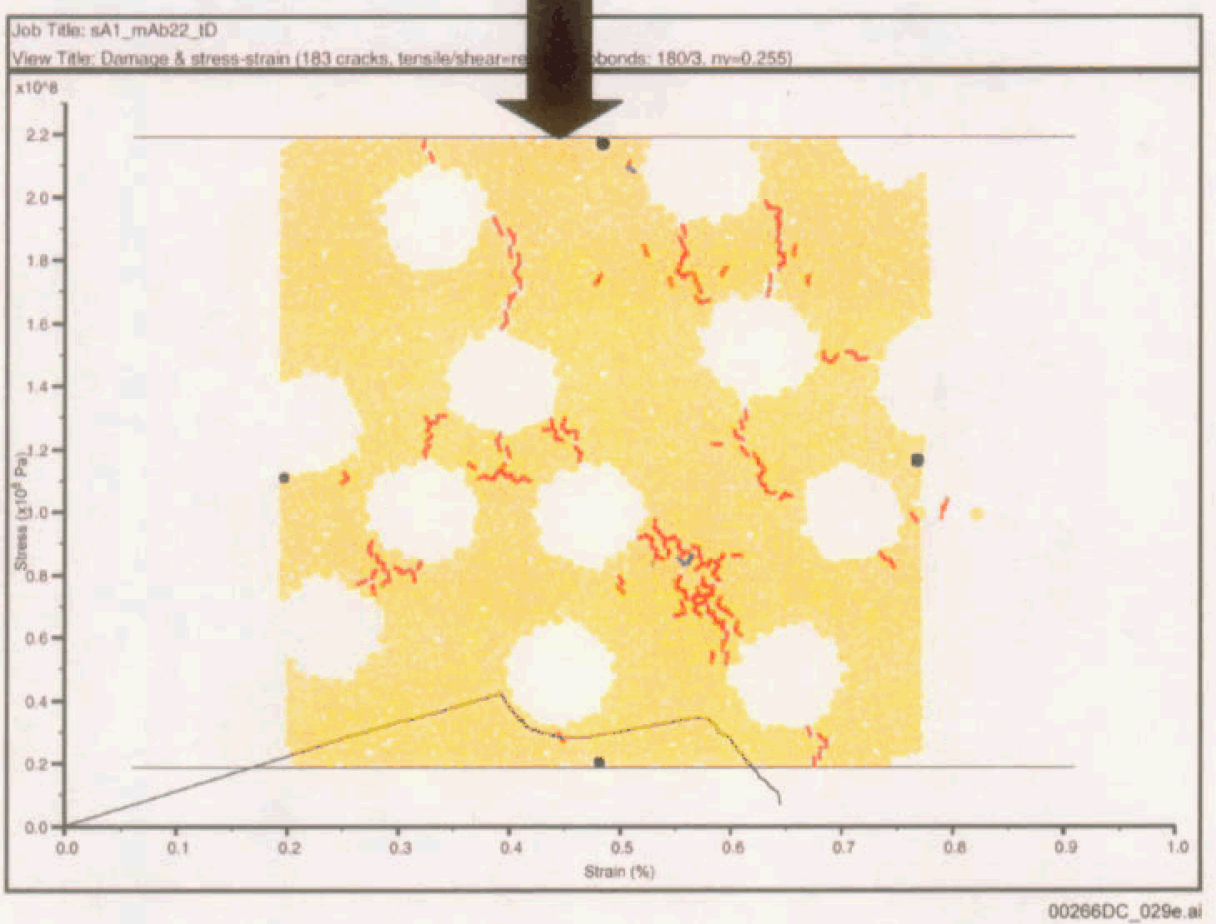

NOTE: Figure 27a shows uniaxial compression of the Tptpul, while $27 \mathrm{~b}$ shows actual test data. The PFC model represents lithophysae as physical circular voids in the sample (here at 26 percent porosity). Failure mechanism is by tensile splitting of the webbing between voids, resulting in a macroscopic shear failure plane through the sample. Modulus and failure strength is similar in model and actual sample.

Figure 27. PFC Model of Uniaxial Compression 


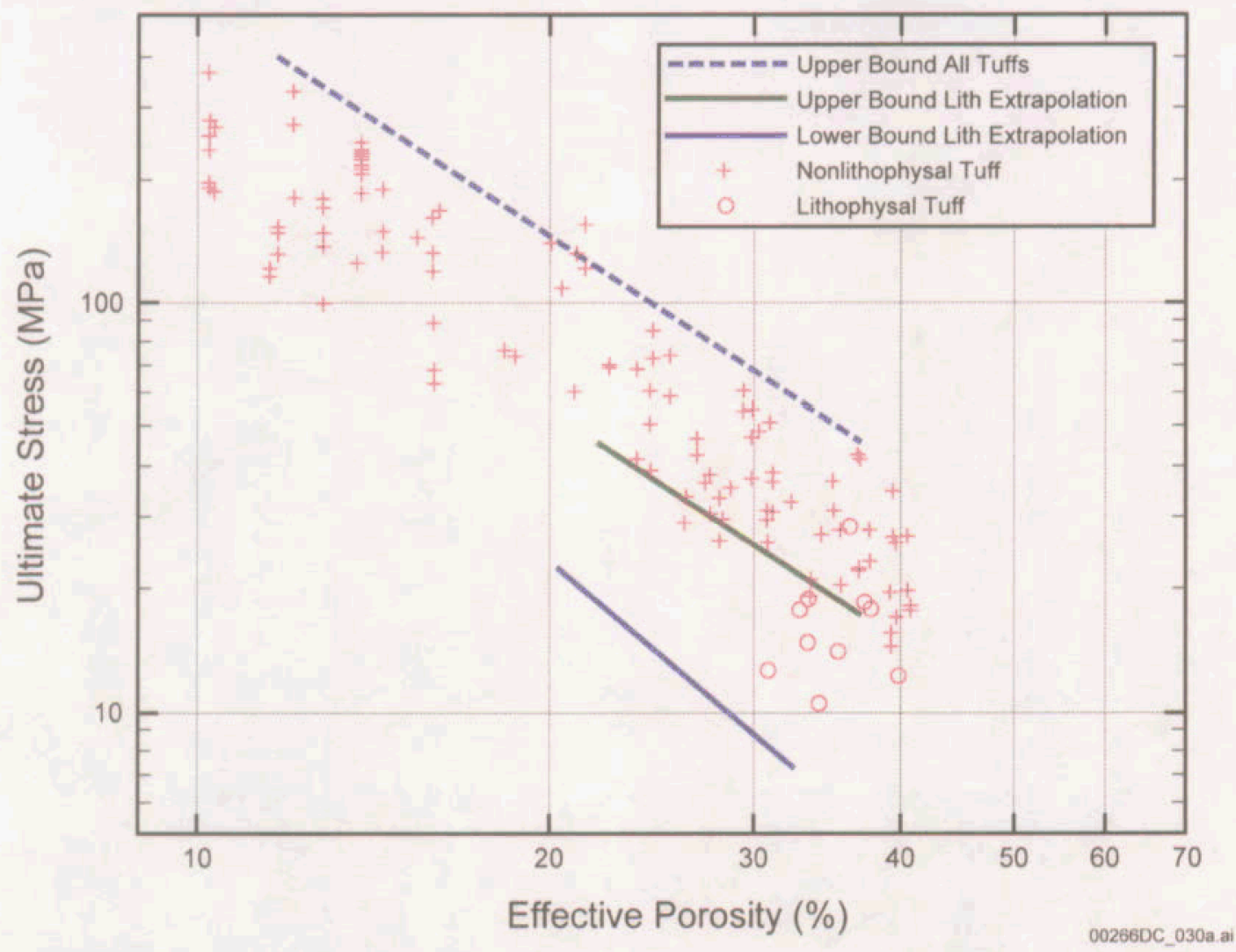

Source: Modified from Price et al. 1985.

NOTE: The current lab and field tests are shown schematically here, with ultimate upper and lower bounds defined for all lithophysal rocks using the validated numerical model.

Figure 28. Extrapolation Strategy to Define the Range in Design and Performance Properties for Lithophysal Rocks

An example of inclusion of time-related degradation in the PFC model is given by Potyondy and Cundall (2001). They conducted a back-analysis of time-dependent fatigue failure of granite from the Underground Research Laboratory (URL) in Canada using a stress-corrosion criteria embodied within the basic bonding strength logic of the PFC program. Basic laboratory uniaxial compression testing of granite was conducted in a fashion similar to that proposed here. The time to failure for samples loaded at 70 to 80 percent of peak strength was determined (Figure 29). The data was used to develop a time-dependent bond strength in the PFC program that was calibrated to reproduce the lab fatigue failure response. It was then applied to simulate the observed time-dependent development of stress-induced "notch" formation in the URL tunnels. Figure 30 is a composite picture showing the PFC model and field observations after 2 months time. The fracturing associated with the notch formation could be observed physically, but was more accurately defined during and after mining of the tunnels by using very sensitive acoustic emission monitoring (Young and Collins 1997). Good agreement in the prediction of time-dependent formation of the notch was found using the model. More importantly, the PFC model has provided a better understanding of the mechanisms of the yielding process and thus gives greater confidence in predictability. This methodology has been developed to examine the potential for time-related instabilities that could be encountered in a granite repository. 
The PFC model (and others, as appropriate) will be used to investigate the effect of the time-dependent failure response (static fatigue) for emplacement tunnels in the Tptpll based on the time-to-failure estimates derived from the above procedure. The models will be used to predict the progression of failure and possible raveling of rock particles to the ultimate equilibrium position of the tunnels, and the static load this applies to the drip shield.

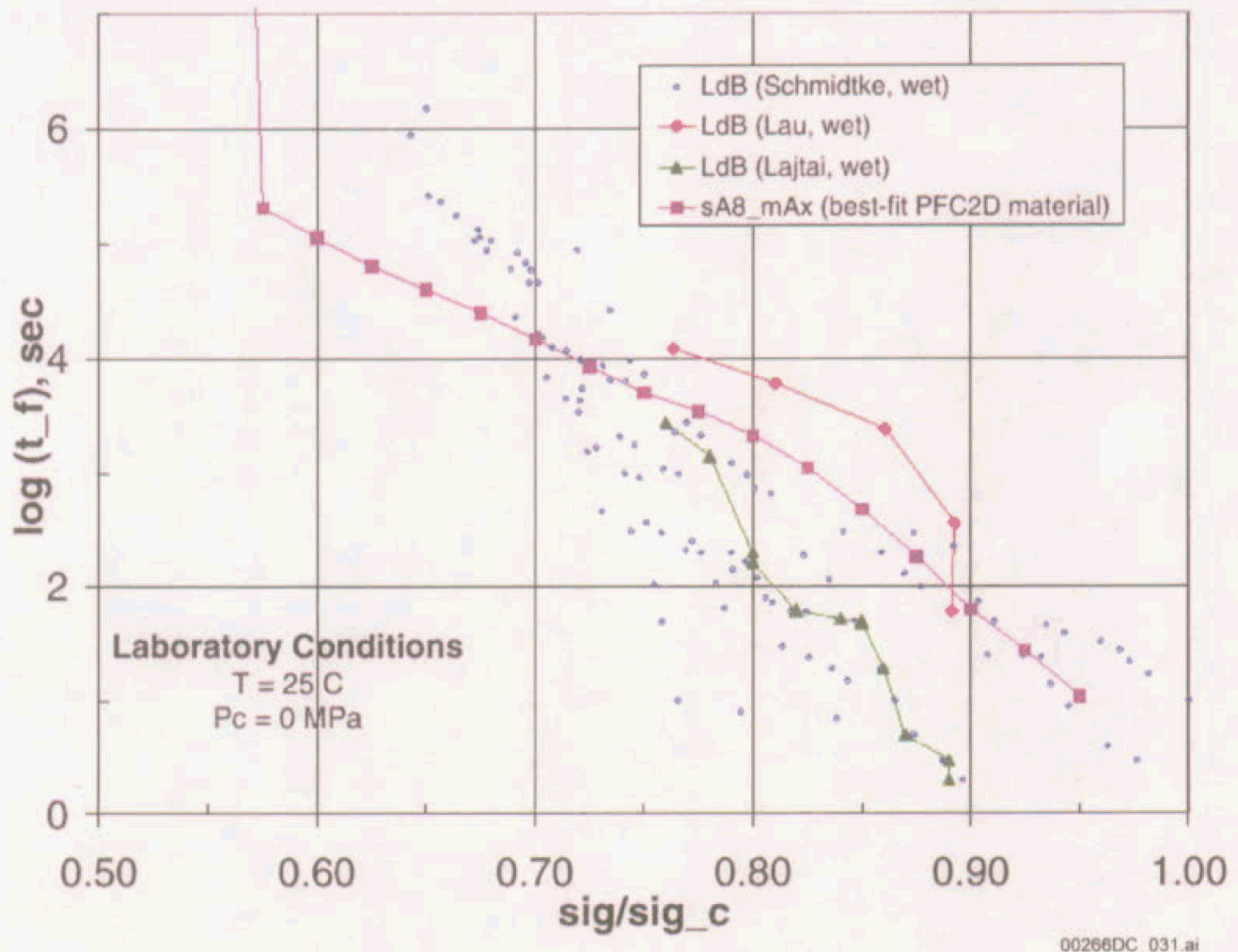

NOTE: Figure shows the static-fatigue curve (log time to failure) vs. stress level for Lac du Bonnet Granite in unconfined compression and best-fit PFC model predictions based on a bond strength stress-corrosion model.

Figure 29. Static-Fatigue Curve vs. Stress Level for Lac du Bonnet Granite 


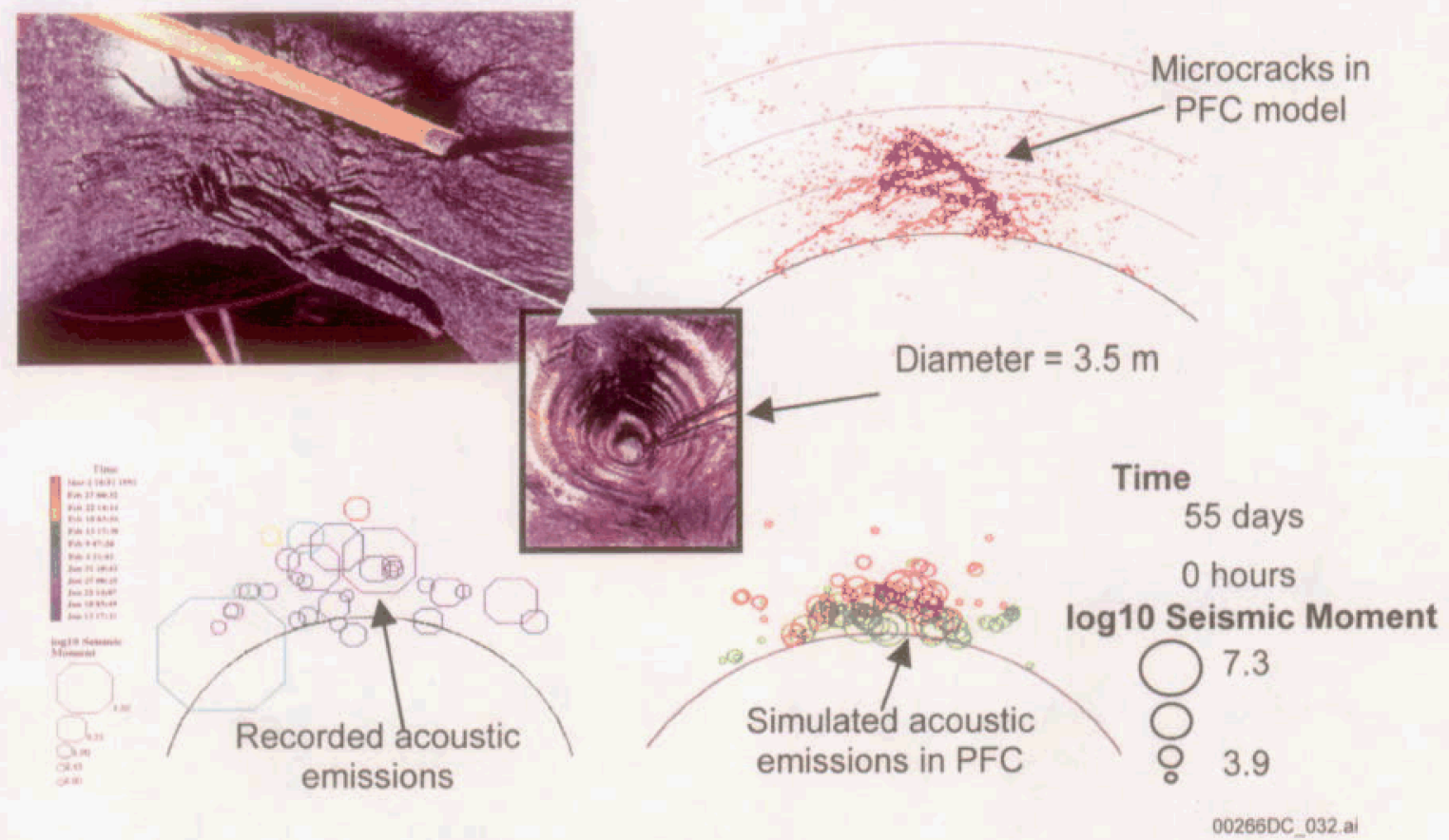

Source: Potyondy and Cundall 2001.

NOTE: Microcracks have formed in a fine resolution in the PFC model. Physical observation of the notching (upper left), and acoustic emission monitoring (lower left) and seismicity source locations "recorded" in the PFC coarse model (lower right).

Figure 30. Comparison of URL Mine-By Tunnel Time-Dependent Notch Formation with PFC Excavation-Scale Model with Bond Strength Governed by Time Dependent Degradation of Rock Strength Governed by Stress Corrosion (Upper Right) after 2 Months 


\section{GEOMECHANICAL DESIGN AND PERFORMANCE ASSESSEMENT-PRECLOSURE GROUND SUPPORT AND POSTCLOSURE DRIFT DEGRADATION ANALYSES}

As the rock mass material models and property ranges are defined, numerical models can be used for design and sensitivity studies to examine two major issues addressed in the RDTME KTI agreements. The first issue is the postclosure drift degradation resulting from thermally induced stresses, seismically induced rockfall, and possible static fatigue mechanisms. The second is the preclosure ground support design and evaluation as well as an inspection and maintenance strategy. Each of these issues is discussed here.

\subsection{ANALYSIS OF ROCKFALL UNDER POSTCLOSURE SEISMIC SHAKING}

The potential exists for rockfall to occur as a result of shaking induced by earthquakes. The current emplacement drift concept calls for waste packages to be placed on a metal pallet structure that will rest on an engineered, compacted fill in the invert of the $5.5 \mathrm{~m}$ diameter emplacement drifts. At postclosure, current design calls for the waste package to be covered with a continuous "drip shield" constructed of titanium that will act as both a seepage cover and a rockfall shield.

\subsubsection{General Methodology}

It is the intent of the rockfall analyses to quantify possible seismically induced rockfall (and, ultimately, drip shield and waste package mechanical damage) over the 10,000 year regulatory postclosure period. A general methodology for conducting these studies is given in Figure 31 . Geologic mapping will be used to define a "synthetic" or representative rock mass that can be sampled randomly to create possible rock masses in which the tunnel can be simulated. Numerical models (two- or three-dimensional, depending on the lithology in question), with input geometry and properties based on the geologic variability, will be used to make rockfall estimates for seismic events whose magnitude is based on the probability of occurrence in terms of annual exceedance frequency. For each annual exceedance frequency, a number of probabilistically determined, site-specific ground motions will be developed and used to provide the transient boundary conditions to the models. The resulting rockfall, in terms of the tonnage of the maximum size rock particle, total tonnage for a given simulated length of tunnel, and the velocity of rock particles, will be determined. A number of simulations will be conducted for each annual exceedance probability in which the rock mass geology and site-specific ground motion will be randomly sampled. The ultimate goal will be to conduct sufficient simulations to produce a probability density function of rockfall as a function of peak ground velocity level such that a mean and standard deviation can be defined. The rockfall is then used as input to the structural analysis of impact loading on the drip shield.

\subsubsection{Site-Specific Ground Motions}

Site-specific ground motions will be determined based on the estimates of peak ground acceleration or peak ground velocity obtained from the seismological expert elicitation process conducted previously (CRWMS M\&O 1998a). The probabilistic seismic hazard assessment process resulted in an estimate of the earthquake source characteristics and source locations as a 
function of their probability of occurrence, expressed in terms of peak ground acceleration or peak ground velocity for a given annual exceedance probability (probability of occurrence per year). The resulting relationship of annual probability and peak ground velocity is termed the hazard curve.

For each annual hazard level, a number of ground motions (15 are currently anticipated) representing characteristics from distinct actual earthquakes are compiled with magnitude, focal distances and frequency characteristics consistent with Probabilistic Seismic Hazard Analyses for Fault Displacement and Vibratory Ground Motion at Yucca Mountain, Nevada (CRWMS M\&O 1998a). The ground motions are selected to represent the variability of the potential ground motions. Each ground motion consists of three time history components: one vertical and two horizontal. These ground motions are scaled to the peak ground velocity for a given annual exceedance frequency derived from the hazard curve.

\subsubsection{Numerical Modeling Approach}

As discussed in depth earlier, it is anticipated that the lithophysal and nonlithophysal rock masses will respond in distinctly different fashion from the seismic shaking. The modeling assumptions and methods to be used for each of these rock types are discussed below.

\subsubsection{Nonlithophysal Rocks}

Due to the high intact strength and fracture-controlled nature of the nonlithophysal rocks, the following preliminary conclusions can be drawn:

1. The problem is three-dimensional and anisotropic in nature.

2. Failure and rockfall response is a function of fracture orientation, continuity, the resulting block geometry, fracture properties and ground motion characteristics.

As a result of the above, the 3DEC program is used for modeling of nonlithophysal rocks. This program is fully dynamic in nature, with provision for applying transient boundary conditions, and allows non-reflecting and free-field dynamic boundaries. The rock mass is represented as a number of intact rock blocks that are separated by interface planes whose mechanical behavior are represented by a standard Mohr-Coulomb slip condition. The intact blocks are subdivided into tetrahedral finite difference zones, and can be assigned any desired mechanical constitutive law. Here, due to the high strength of the rock mass, it is assumed that the blocks behave elastically.

The most important aspect of the 3DEC modeling is implementing the field fracture geometric data into the model, followed by the subsequent formation of blocks. This is particularly important since the fractures within the Tptpmn are non-persistent in nature, with mean trace lengths smaller than the diameter of the tunnel (i.e., many of the fractures are of insufficient length to form a regular block geometry). The fracture geometries used as input to 3DEC are derived from the FracMAN simulations as discussed in Section 6.1.2. Modifications to the 3DEC program have been made to accommodate the FracMAN output; namely, the discontinuous nature of the fractures. Previously, 3DEC had assumed that fractures are continuous in nature, and thus it was impossible to have a fracture that ends in solid rock. The 
program now allows circular or rectangular fracture surfaces consistent with FracMAN by bonding all fracture contact points outside the defined fracture surface. In this manner, it is possible for the contacts to be given the equivalent properties of the solid rock, thus joining the adjacent blocks to form a discontinuous fracture.

The detailed modeling methodology is illustrated in Figure 32. A number of potential fracture geometries (approximately 100 for each hazard level) are selected by generating random tunnel centroid locations within a $100 \mathrm{~m}$ cube of simulated FracMAN rock mass. At each of these locations, a representative rock mass volume, approximately two tunnel diameters around the tunnel centroid and $25 \mathrm{~m}$ in length, is selected. This volume is considered sufficient to contain the limits of damaged rock, and of sufficient length (approximately 5 times the tunnel diameter and over 10 times the mean trace lengths) to provide a representative volume for rockfall. For each of these volumes, a simulated full-periphery map can be developed to verify, from a practical geological perspective, that the fracture geometries are realistic. The outer boundaries of the 3DEC model are much larger than this internal, fractured zone, such that boundary effects are minimized.

One of the approximately 15 ground motions and one of the 100 fracture geometries are then randomly selected for each dynamic analysis. A base case of rock and fracture properties will be defined from existing data and used for the initial set of runs. This base case will use the best estimate intact elastic properties as well as the joint cohesion, stiffness and friction properties. Conservative assumptions will be made such that the joints are smooth and planar (i.e., zero dilation). The gravitational and mining-induced stresses will be defined as the initial state prior to seismic load application. The general factor of safety of the block system under gravitational load will be defined as the starting condition, followed by application of the ground motion.

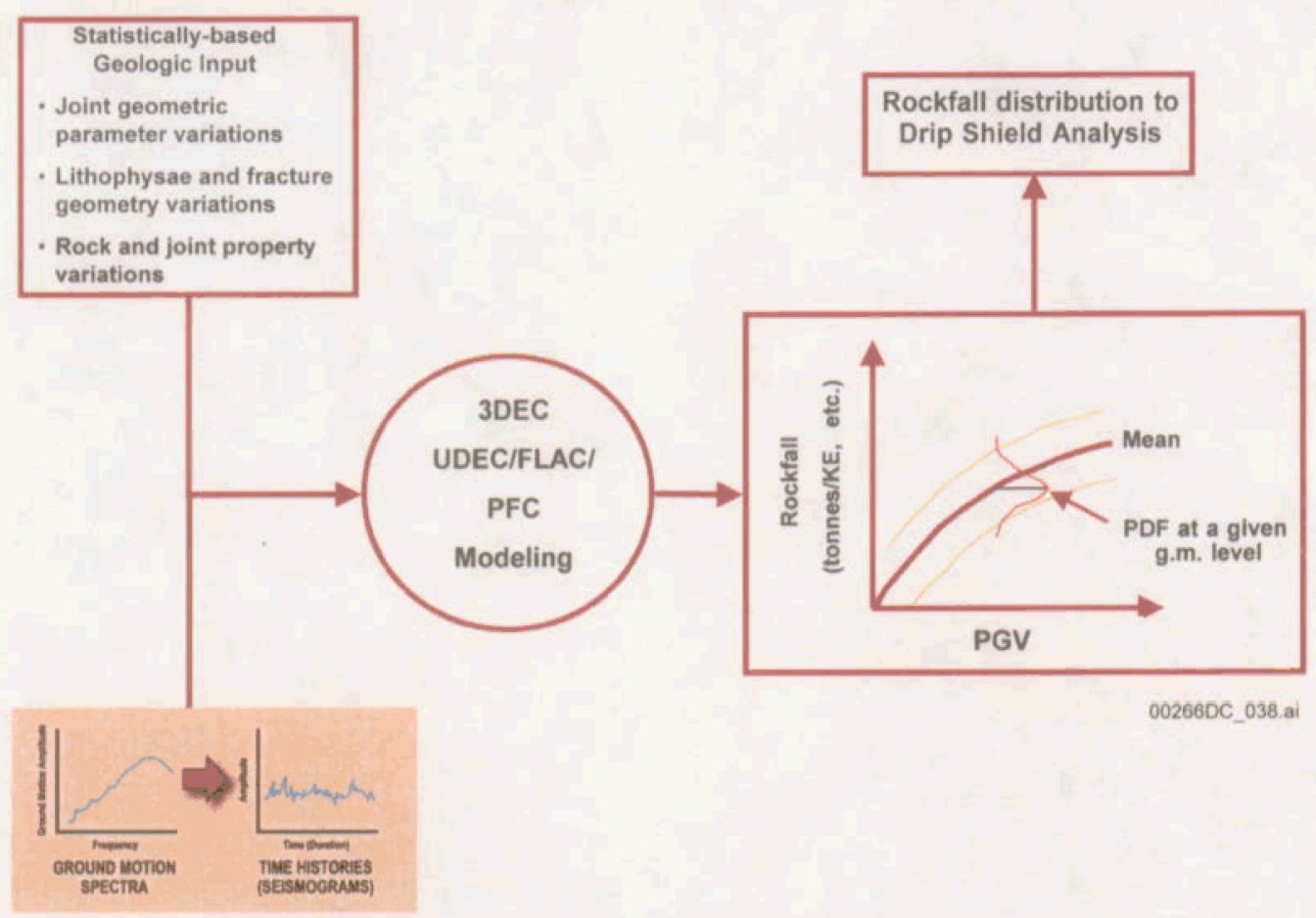

Figure 31. General Procedure for Rockfall Analysis 
The total number of runs to be made (probably greater than 50) is unknown at present, and can only be determined once the rockfall statistics are compiled and its variability determined. The output of the runs, as mentioned earlier, will be in terms of the mass and velocity of each block that is ejected and strikes the drip shield as well as the total mass of blocks. The location of each impact will be defined for ease of input to the structural analysis of the drip shield. After these initial runs are completed, which examine the variability of rockfall as a function of fracture geometry and ground motion, a series of simulations with selected models that span the range of greatest to least rockfall, will be run to examine the impact of the following items:

- Fracture properties-friction angle, dilation angle, cohesion, and fracture stiffness.

- Thermally induced stresses-thermal stresses derived from the regional topographic analysis described earlier will be applied as initial conditions. A number of points in time such as the peak stress condition and the equilibrium state after cool-down will be used.

The results of these runs will be compared to the compiled base case statistics to identify the impact of environment or properties variations on rockfall.

\subsubsection{Lithophysal Rocks}

\section{Modeling Assumptions}

The basic assumptions regarding lithophysal rocks include:

- Mechanical constitutive response is controlled by lithophysal porosity and inter-lithophysal fracture density. Constitutive behavior is determined by calibrating discontinuum model to lab and in situ testing data.

- Rock mass can be considered isotropic and homogeneous.

- Block size distribution a function of inter-lithophysal fracture density and lithophysae spacing.

- Amount of rockfall can be estimated from sensitivity analyses using bounding properties based on laboratory and in situ testing results.

- Two-dimensional modeling is adequate.

\section{Modeling Methodology}

The methodology proposed to perform the rockfall estimates within the lithophysal units is given in Figure 33. This flow diagram indicates that the UDEC program will be the primary modeling tool used to conduct parametric analyses of the range of assumed lithophysal rock properties derived from the large core testing of the Tptpul and Tptpll. As shown, the size of rock particles that are created from the lithophysal rocks will be estimated from geologic and empirical evidence and will not be calculated from the numerical modeling. As described previously, the Tptpll has a ubiquitous, short length interlithophysal fracturing fabric with spacing on the order of 1 to 2 in., while the large trace length, natural joints are widely spaced and discontinuous. The 
ubiquitous fractures, combined with the relatively abundant uniformly spaced lithophysae (that also provide natural breaking surfaces), the result is block sizes on failure that are on the order of a few inches in diameter. There is significant observational information in the tunnel that supports this assumption. For example, rock yield along the ribs of the ECRB indicates the rock tends to break into very small block sizes when stressed. Large-core drilling in the ECRB for the purpose of obtaining test samples shows abundant natural fractures between lithophysae (Figure 34). As seen in this photo, the fractures and lithophysae result in intact blocks that are a few inches across. This natural fracturing has resulted in significant difficulty in obtaining intact core lengths greater than a foot in length.

\section{Calibration of the UDEC Model to Represent an Equivalent Lithophysal Rock Mass}

The issue of numerical representation of lithophysal rocks and how this is used in a seismic analysis is documented here. It is numerically too large of a problem for a model such as PFC be used to attempt to represent the lithophysae structure and fractures in a tunnel-scale model. A method needs to be devised to represent a "mechanical equivalent" lithophysal material that incorporates the lessons learned from the testing and PFC modeling into a simpler numerical tool. Typically, a continuum constitutive model based on some form of shear and perhaps void compaction yield surfaces would be derived from the laboratory and in situ test data. This model would be embedded within a suitable dynamic numerical approach and used to estimate the failure mode and extent resulting from the earthquake excitation. The problem with a continuum-based approach is that it does not allow estimation of how much rock actually detaches itself from the rock mass, and bulks in the excavation. To overcome this problem, we propose here to calibrate a mechanically equivalent discontinuum model within the UDEC program. This model will provide the lithophysal rock mass yield behavior, but will also allow the rock mass to break into small blocks under the action of the dynamic stresses. The process of calibration of the model is described in detail below.

UDEC is a two-dimensional large-displacement discontinuum program. To determine the overall damage zone around the tunnels and the portion of that zone that is expected to dislodge and fall, the rock mass is subdivided into many small, irregularly shaped blocks that are much smaller in dimension than the tunnel diameter (Figure 35). The contacting surfaces between blocks have normal and shear stiffnesses that are matched to the elastic properties of the blocks themselves, thus creating a mass with isotropic elastic behavior. The contacting surfaces are also bonded with a shear and tensile strength to provide the overall rock mass shear and tensile failure characteristics. The overall behavior of this system - its elasticity and failure characteristics-is calibrated to laboratory and in situ testing.

Thus, this approach is similar to development of a continuum-based mechanical constitutive law with one important difference-the discontinuum method provides for discrete fracture or failure networks to develop when stressed, thereby providing realistic failure mechanisms and the ability to form detached blocks. The detached blocks may consist of one or more of the basic unit blocks within the model. Of course, the primary limitation of this method is the block size needs to be smaller than the expected size of the detached blocks. The size of the unit blocks that make up the model will be verified during calibration and testing. 


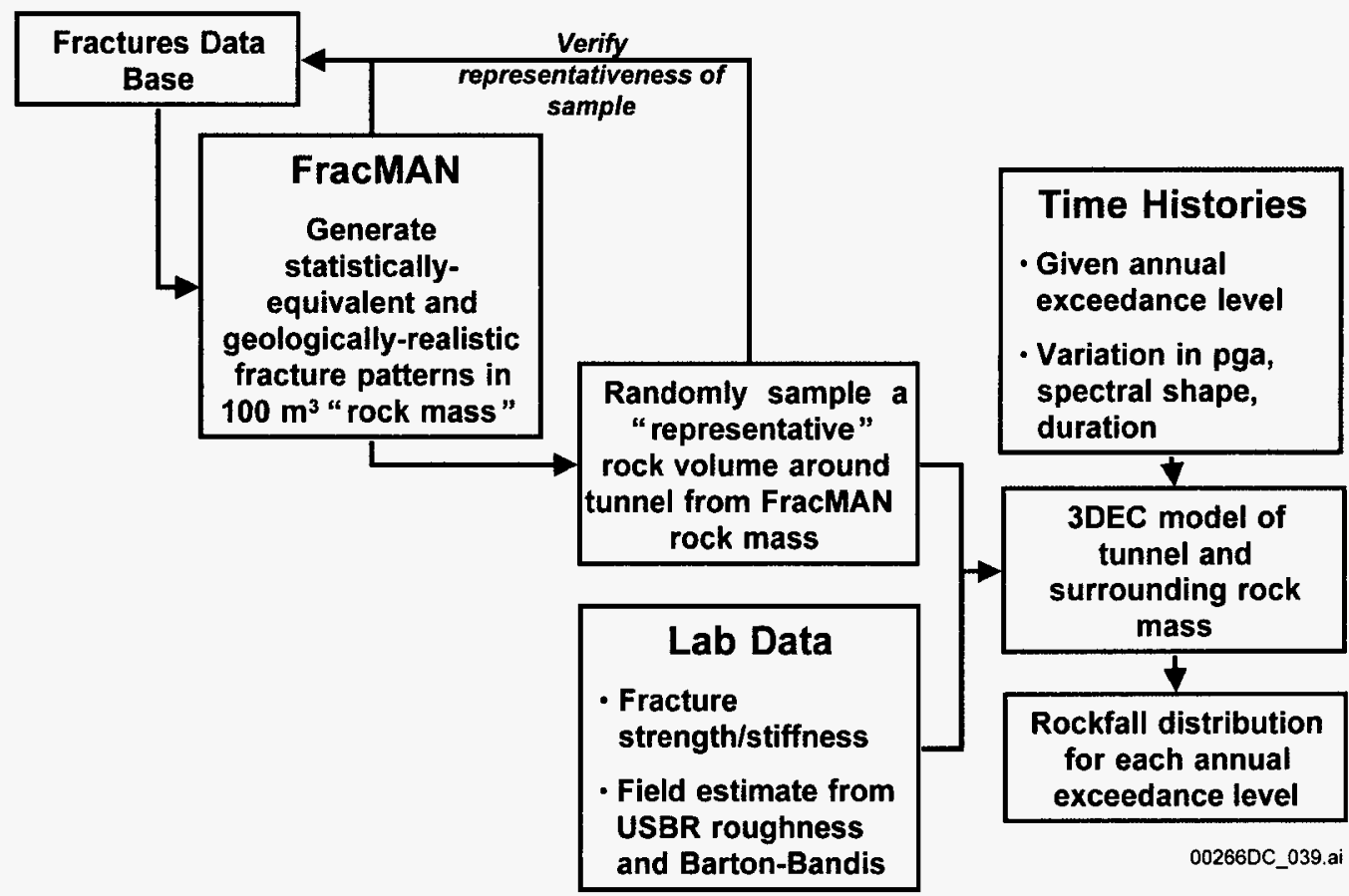

Figure 32. General Methodology for Rockfall Calculations in the Nonlithophysal Rocks

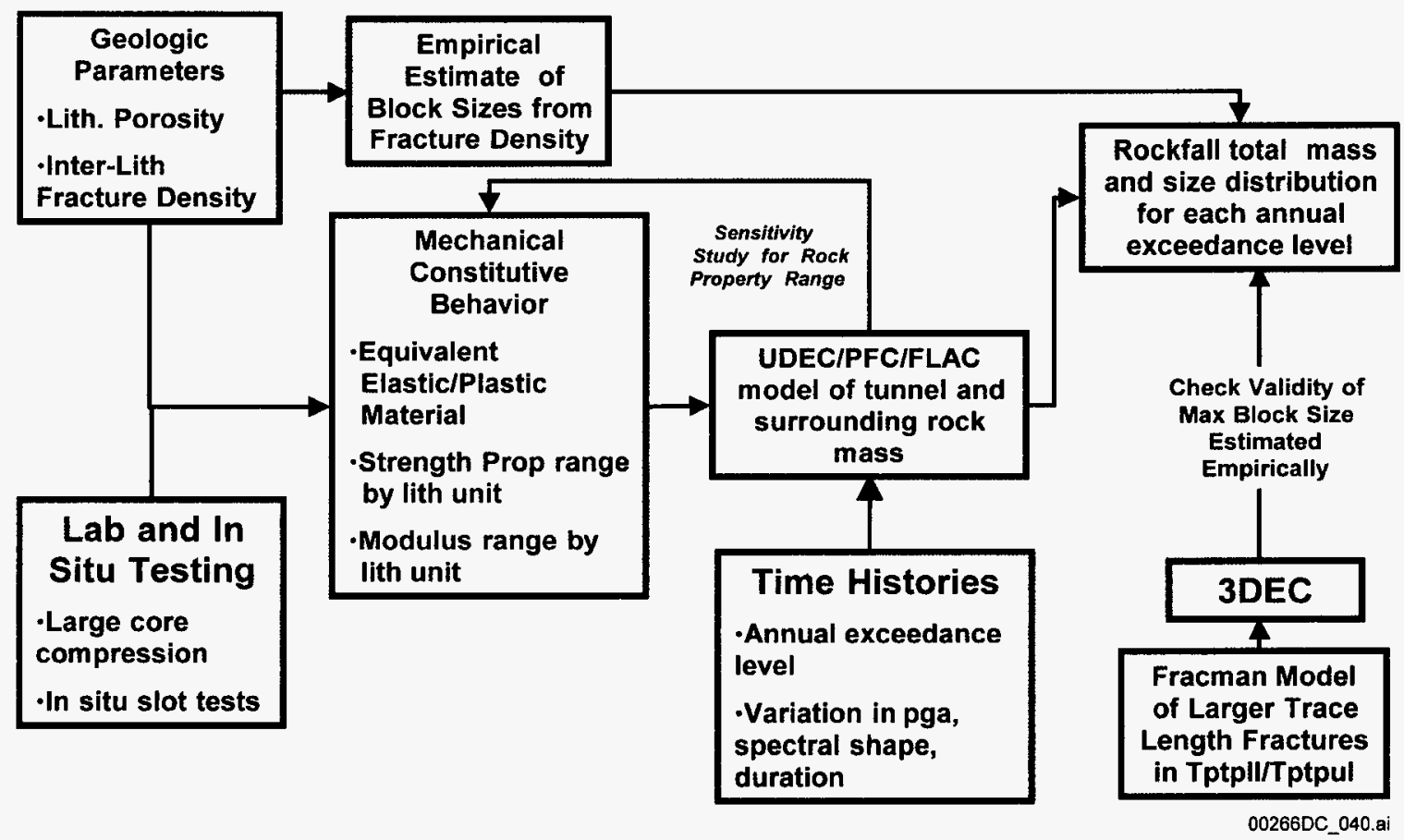

Figure 33. Methodology for Rockfall Analysis in Lithophysal Rocks 


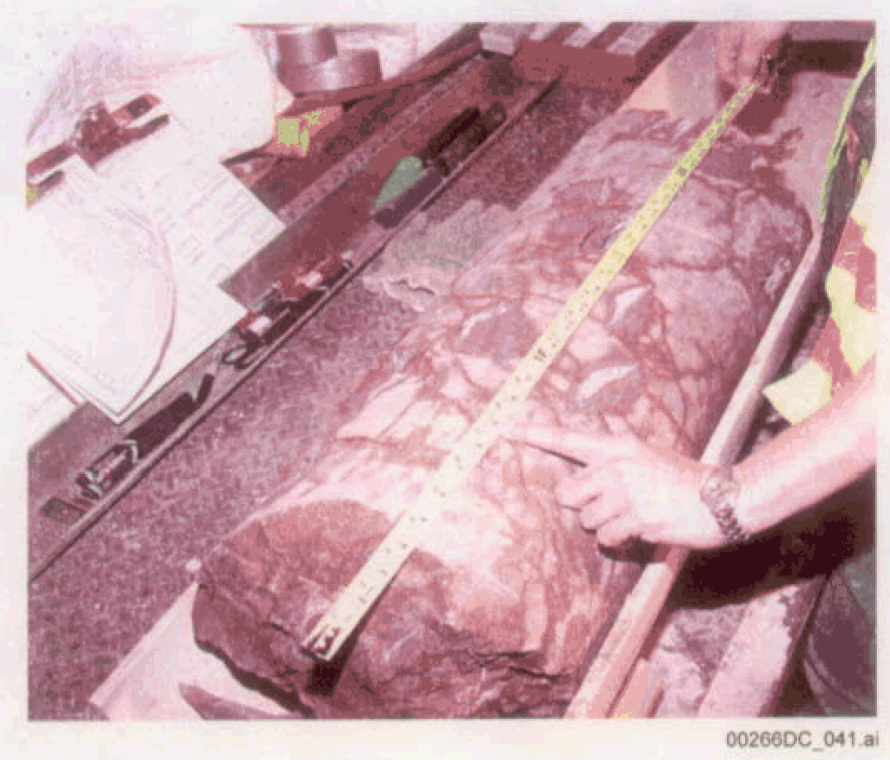

NOTE: A core sample from the Tptpll with a diameter of 12 in. $(30.5 \mathrm{~cm})$. Note the widespread, closely spaced fracturing along the length of the sample. The core will fail along these preexisting fractures.

Figure 34. Example of a Core Sample from the Tptpll

Laboratory and field testing is currently underway primarily on lithophysal rocks to supplement the existing database. The existing core testing from the Tptpul and Tptpll described earlier, showing a uniaxial compressive strength range from approximately 10 to $30 \mathrm{MPa}$ and Young's Modulus of about 10 to $23 \mathrm{GPa}$ will be used initially for calibration of the range of properties for the UDEC model. The equivalent UDEC model rock mass will be calibrated against the laboratory compression test data to ensure that the correspondence of the model to rock behavior is understood. In many ways, this calibration process is similar to that described for the PFC program earlier. The calibration is run by conducting numerical tests on "core" samples that have been "extracted" from the UDEC tunnel model block structure, much as one would take a rock core from the field and test in the laboratory. This rock sample is then tested in uniaxial and triaxial compression, and the output stress-strain response determined. The block surface contact properties are adjusted to achieve a calibration against the lab and in situ testing. Figure 36 shows an example of such a calibration of model stress-strain response and failure mechanism for the case of a higher strength lithophysal rock with a UCS of $20 \mathrm{MPa}$. The figure shows the ability of the model to produce typical failure modes that are observed in the lab testing-from axial splitting in uniaxial compression to shear failure modes in confined compression. Many parameter analyses with varying block sizes and shapes as well as surface properties will allow a detailed understanding of the actual material behavior that is represented by the model. In other words, numerical experiments will be performed so that the material response that is modeled is fully transparent. Since it is very difficult to conduct true triaxial compression tests on large lithophysal core, it is planned to use the calibrated PFC model to numerically examine the mechanical effects of confinement on lithophysal rocks. The PFC model is currently being calibrated against the UCS testing to achieve an understanding of the impact of porosity on both modulus and strength. The PFC model will then be used to conduct triaxial tests on three-dimensional "samples" of various porosity to understand the postfailure dilation properties of the material, thus allowing development of a true shear and compaction constitutive model for 
the lithophysal rock. These results will be used to verify that the UDEC model reasonably represents postpeak response (dilation) for varying levels of porosity.

\section{Rockfall Parametric Analyses}

It is the intent to calibrate a number of UDEC representations of lithophysal rock with varying levels of porosity that span the range from lowest to highest strength and deformability. For each ground motion annual exceedance level, a parametric study will be conducted in which the strength and deformability properties of the UDEC model will be varied from lowest to highest strength in approximately 5 steps. These 5 property cases will be randomly matched to one of the approximately 15 ground motions to examine effects of both properties and ground motion variability. The total number of analyses will be determined empirically, as the variability in the response becomes evident.

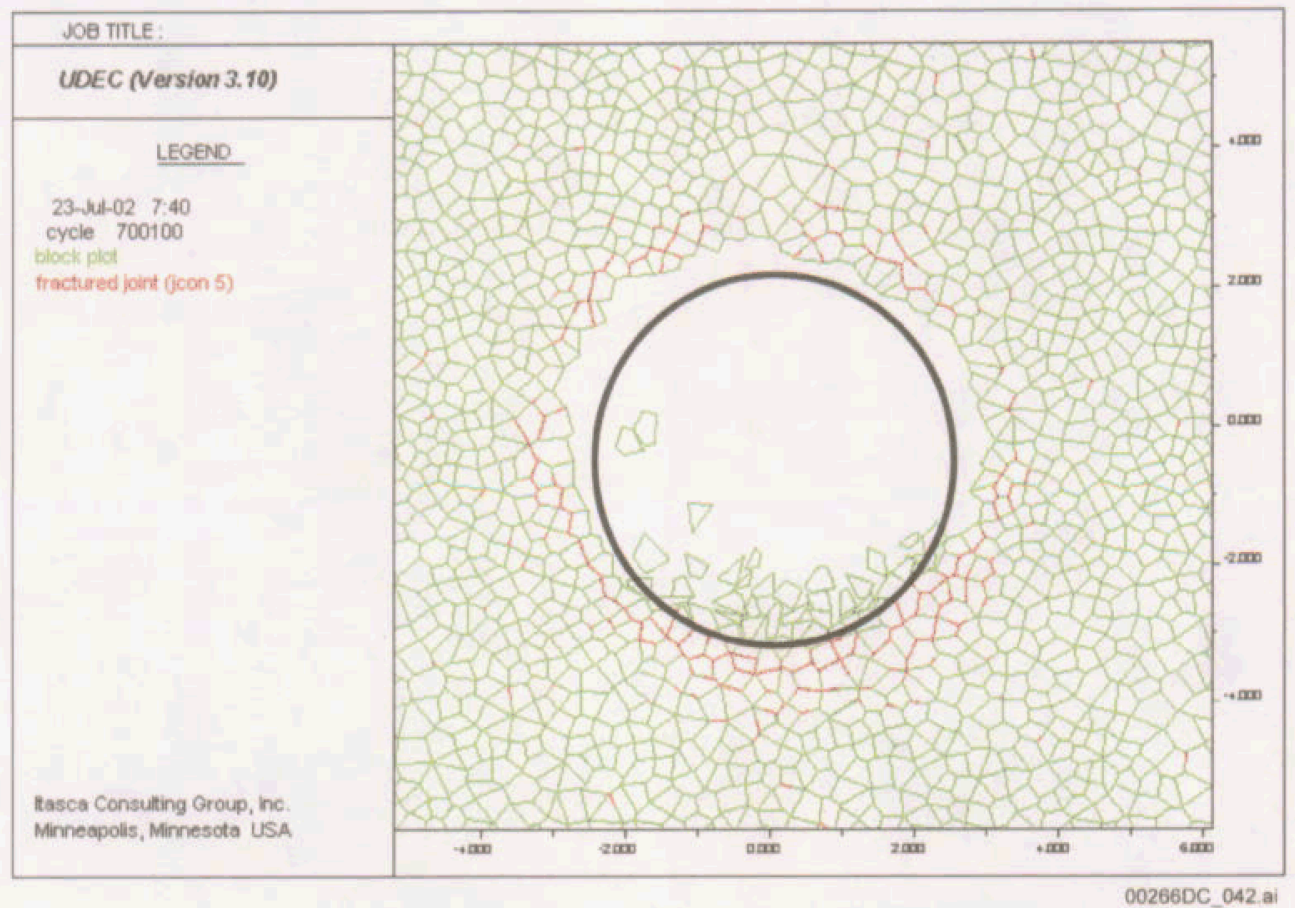

NOTE: This figure shows subdivision of the rock mass into many small and irregular blocks whose equivalent behavior conforms to an elastic-plastic material with Mohr-Coulomb yield condition. Seismic shaking results in blocks breaking free from the rock mass falling into the tunnel. Developing shear or extensional fractures are shown in red. Units are in meters.

Figure 35. Conceptual UDEC Model of Lithophysal Rocks 

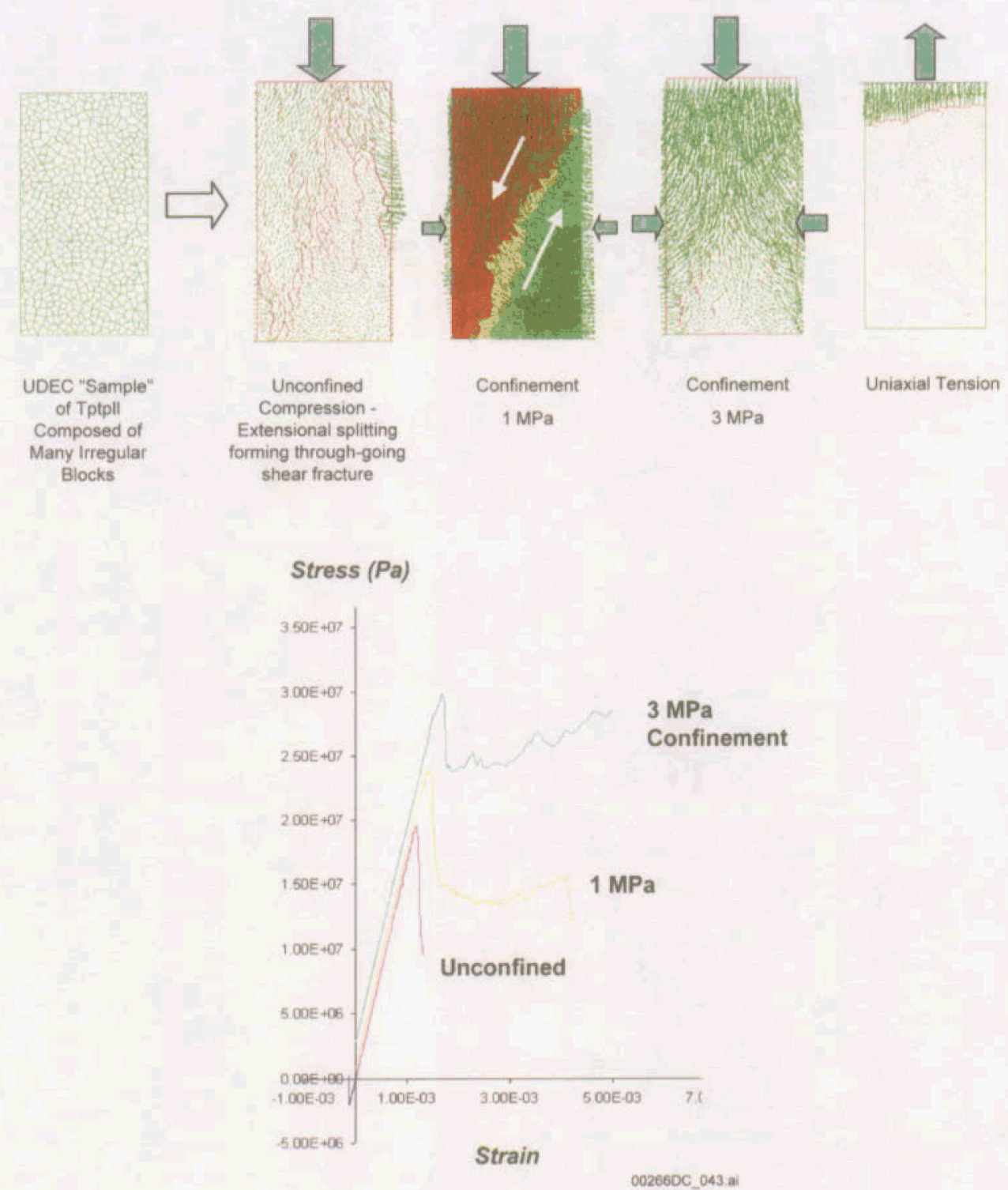

NOTE: This approach shows uniaxial and triaxial compression testing. Spontaneous sample failure modes occur as the sample is compressed, and the resulting equivalent rock mass stress-strain curves are shown here. The unconfined strength and modulus is calibrated to measured laboratory behavior.

Figure 36. Example of UDEC model Calibration Approach 


\subsection{THERMAL LOADING EFFECTS AND LONG-TERM STRENGTH DEGRADATION}

\subsubsection{Discussion}

The rock mass surrounding the excavations may undergo damage from thermally induced stresses and/or time-dependent damage associated with static fatigue resulting from stress corrosion mechanisms. This damaged material may result in a slow unraveling (Tptpll) or block fallout (Tptpmn) mode of failure with some extent of drift filling. The effect of thermal stress on rock failure extent can be examined using the numerical techniques discussed in the previous section. Time-dependent degradation-rockfall from a tunnel or other unsupported excavation over long time periods-is currently not well understood, particularly in hard, strong rocks. It certainly seems reasonable that time-related rockfall would be a greater issue in the more heavily fractured rocks such as the Tptpll, and will be related to the ratio of induced stress to rock mass strength. The goal here is to provide a reasonable estimate of the propensity for yield and rockfall as a function of the induced stress levels and time.

Assume that, over time, the yielded rock surrounding the tunnels (particularly within the Tptpll) begins to ravel and fall as ground support corrodes and loses effectiveness. As fallen rock accumulates on the excavation floor and drip shield, it will increase in volume due to volumetric bulking. Also, the crown of the tunnel would extend vertically in an elliptical fashion. Two mechanisms will eventually arrest the raveling response. First, the confinement at the crown would increase as the excavation becomes more elliptical. Second, the bulking rock volume (which forms a backfill that eventually will choke itself off) will arrest the failure as the confinement supplied by the bulked rock to the excavation walls tends to provide a reinforcing backpressure.

Since the current repository concept involves a drip shield, the fallen rock could eventually build up around the drip shield. It is relevant to examine the time and volume of rock ultimately produced from this degradation process since the settled rock could have impacts on:

- Seismically induced rockfall (non-seismic degradation could reduce or prevent seismically induced rockfall in the lithophysal rocks if it occurs early enough and with enough volume).

- Igneous intrusion mechanisms (it could prevent magma intrusion into tunnels).

- Waste package temperatures and seepage mechanisms.

It would seem reasonable to assume that the mechanism of time-related degradation could be a result of either thermally induced stresses or static fatigue via a stress corrosion mechanism. In the nonlithophysal rocks, static fatigue failure of asperity-related roughness along fracture surfaces is possible, and could result in gravitationally induced block failures through reduction in dilation. Static fatigue of hard rocks typically is associated with stress levels on the order of 80 percent or greater of the uniaxial compressive strength. In the case of the lithophysal rocks, the compressive stress concentrations along the immediate rib springline of the emplacement 
drifts is locally near the uniaxial compressive strength at repository depth in the Tptpll, making long-term static fatigue mechanisms of importance.

\subsubsection{Approach}

\subsubsection{Thermal Stress Degradation}

It is planned to investigate possible thermal stress-induced degradation effects using the same general UDEC model and property ranges described previously for rockfall studies (Section 7.2.3.2). Predicted temperature profiles around emplacement drifts will be predicted using other numerical approaches as part of the waste package and ventilation aspects of the project. The rock mass temperatures from these models for preclosure and postclosure times will be interpolated at gridpoint locations in the UDEC model. These temperatures will then be used to develop the associated thermally induced stresses and produce yield and failure within the fracture network that comprises the equivalent rock mass as described previously. Calculations will be made of the depth of yield, the characteristics of the failing rock mass (i.e., the strains as a function of depth from the tunnel surface), and an estimate of the amount of rock that can potentially detach and fall into the tunnel. These calculations will be done for the range of probable rock mass properties of Tptpll. A validation of the thermal fracturing predictive capability of this approach through back-analysis of the thermally induced roof spalling observed in the Drift Scale Test recently conducted in the ESF. In this test, the room temperature was overdriven (to about $200^{\circ} \mathrm{C}$ ), with resulting minor levels of thermal stress-driven slabbing of the crown of the drift. A UDEC equivalent Tptpmn rock mass will be developed and calibrated against large core compression testing results as discussed in Section 7.2.3.2 (see Section 2 for discussion of size effect on compressive strength in the Tptpmn). The UDEC model will be subjected to the measured temperatures and predictions made of the development of slabbing for the estimated in situ strength of the Tptpmn.

Thermal stress-induced degradation calculations will also be performed for the general Tptpmn case using the 3DEC and UDEC programs to examine the potential for both slabbing and block displacement during heating and cooling.

\subsubsection{Modeling Approach for Time-Dependent Degradation}

\section{Time-Dependency of Fractures in Tptpmn}

Fractures under constant shear and normal loads will develop stress concentrations in the asperities that comprise the joint roughness. It is conceivable that, over time, these asperities could undergo stress corrosion cracking, and shear, thereby reducing the roughness on the joint and its dilation. Therefore, in the worst case, the joint surfaces would be reduced to their condition of residual friction. A second mechanism may be shearing of solid rock bridges between non-persistent fracture branches, also due to a stress corrosion mechanism.

It is proposed that fracture degradation be addressed in the following ways:

- The potential for stress corrosion cracking and shearing of roughness and/or solid rock bridges from the joints will be examined through numerical analysis with the PFC 
program. Static fatigue results from Tptpmn testing (see Section 6.2.4.3) will be used as a basis for a stress corrosion model.

- Worst case assumptions will be examined in the models-i.e., fractures will be assumed to be planar (no roughness) and will assume to completely cut the block in which they would normally terminate (i.e., no solid rock bridges).

- Comparison of the above two methods should give a picture of the conservatism inherent in worst case assumptions.

The data from static fatigue testing of the Tptpmn will be used as a basis for examination of time-dependency of roughness failure and its impact on the shear strength of discontinuities. To assess the likelihood of significant time-dependency of joint shear strength, the stress concentrations in roughness asperities, and its relation to their strength, needs to be examined for the major joint sets in the Tptpmn. Recall that there are four basic sets: two subvertical sets, the subhorizontal vapor phase partings, and the random set with intermediate dip. Of these sets, only the vapor phase partings are highly rough, with joint roughness coefficient values around 15 to 18 . It is logical that only these joints would be particularly susceptible to strength degradation.

The PFC program will be used to conduct numerical shearing tests on simulated joints with roughness profiles derived from the Tptpmn mapping. Figure 37, Figure 38, and Figure 39 show a series of examples of simulated shearing tests on a rough joint using PFC, and the comparison of this model to the empirical joint shear behavior developed by Barton and Choubey (1977). Time-dependency in the PFC model can be examined using techniques similar to that discussed previously for modeling static fatigue in the Lac duBonnet granite, in which the particle bond strength is a function of the bond stress and time (as derived from calibration against lab static fatigue tests). The long-term shear and normal stress conditions existing on fractures will be estimated from the predictions of mining and thermally induced stresses.

The PFC modeling, including time dependence of the Tptpmn will be used to conduct a sensitivity study in which various levels of shear and normal stress are applied and held constant. The fracturing can assume both inherent roughness on the fracture surfaces as well as intact rock bridges between fracture segments. The potential for time-dependent damage will occur as a result of stress concentrations within the asperities along the fracture surface. The sensitivity study will identify what ratios of shear to normal stress will result in significant time-dependent damage. This will be used for comparison to the predicted stress conditions that have been calculated by regional thermomechanical modeling as discussed previously. If the models indicate a significant time dependence in the Tptpmn, then greater reliance will need to be placed on the base case of the seismic rockfall studies in which joints are assumed to be planar with no dilation on shearing. It is emphasized that the base case for rockfall simulations in the Tptpmn assumes planar joints with no short trace length roughness.

\section{Time-Dependency in Lithophysal Rocks}

The effect of time-dependent strength reduction in lithophysal rocks will be addressed through progressively detailed calculations as more data are obtained from laboratory testing. 


\section{Initial Bounding Analysis}

Initial, worst-case analyses will examine the possible extent of caving and drip shield loading assuming the rock mass reaches its residual frictional strength. The most simplistic assumption, in the absence of any time-related strength degradation data are to assume that strength reduction can be related to a loss of cohesion of the material. The time-dependency aspects of this strength loss can eventually be related to static fatigue testing; however, it is initially instructive to simply determine how much strength loss is significant to rockfall. A parametric analysis can be conducted in which the cohesion is incrementally reduced while monitoring the resulting failure and rockfall. In this manner, it is possible to provide an initial bounding analysis that addresses the following points:

1. How much strength reduction (as a percentage of preexisting strength) is necessary for rockfall to occur - how does this relate to the results of laboratory static fatigue testing? How much time is expected for this process to occur?

2. What is the ultimate shape of the excavation when equilibrium is achieved? How is the bulking of the broken rock related to the shape of the blocks produced (i.e., the bulking factor), and the strength of the rock mass.

3. The static load on the drip shield or waste package, in absence of a drip shield.

\section{Rigorous Approach}

A second, and more rigorous approach to the problem was described previously in Section 6.2.4.3 in which a combination of laboratory static fatigue testing on Tptpmn and the PFC program to develop an understanding of static fatigue in lithophysal rocks. The strength time-dependency gained from this approach will be embedded within the PFC or other programs such as UDEC for parametric studies of the impact of static fatigue on tunnel failure mechanisms and the time for failure. It is envisaged that the impact of porosity on static fatigue will be used as the basis for the parametric studies. Predictions can be made as to the progression of damage and its impact on gravity-induced groundfall, with ultimate prediction of the equilibrium shape of the excavations and the static load distribution on the drip shields and waste packages. 


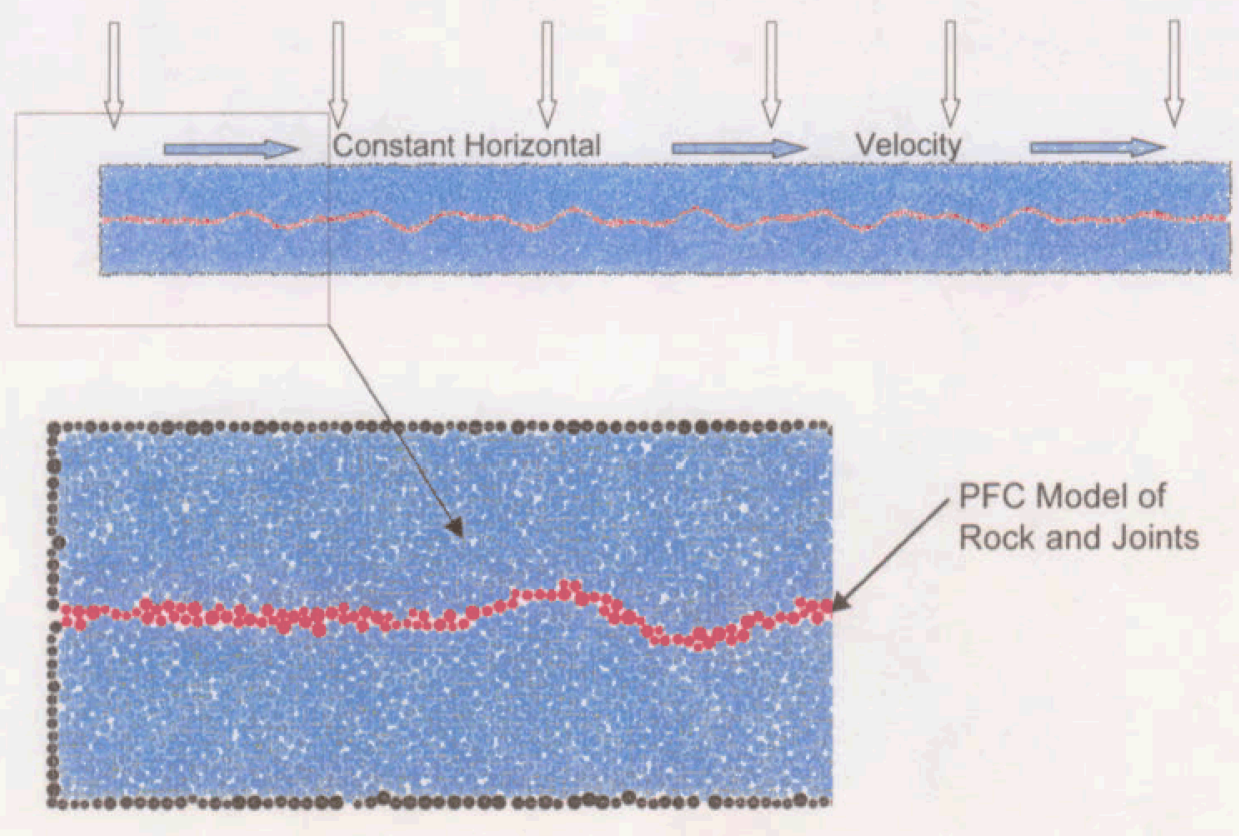

00268DC_044.a)

NOTE: Blue particles are given bonding properties that represent the solid Tptpmn; red particles represent the joint itself. Rock "sample" is subjected to normal stress and shear velocity to represent shear test.

Figure 37. PFC Model of a Rough Joint

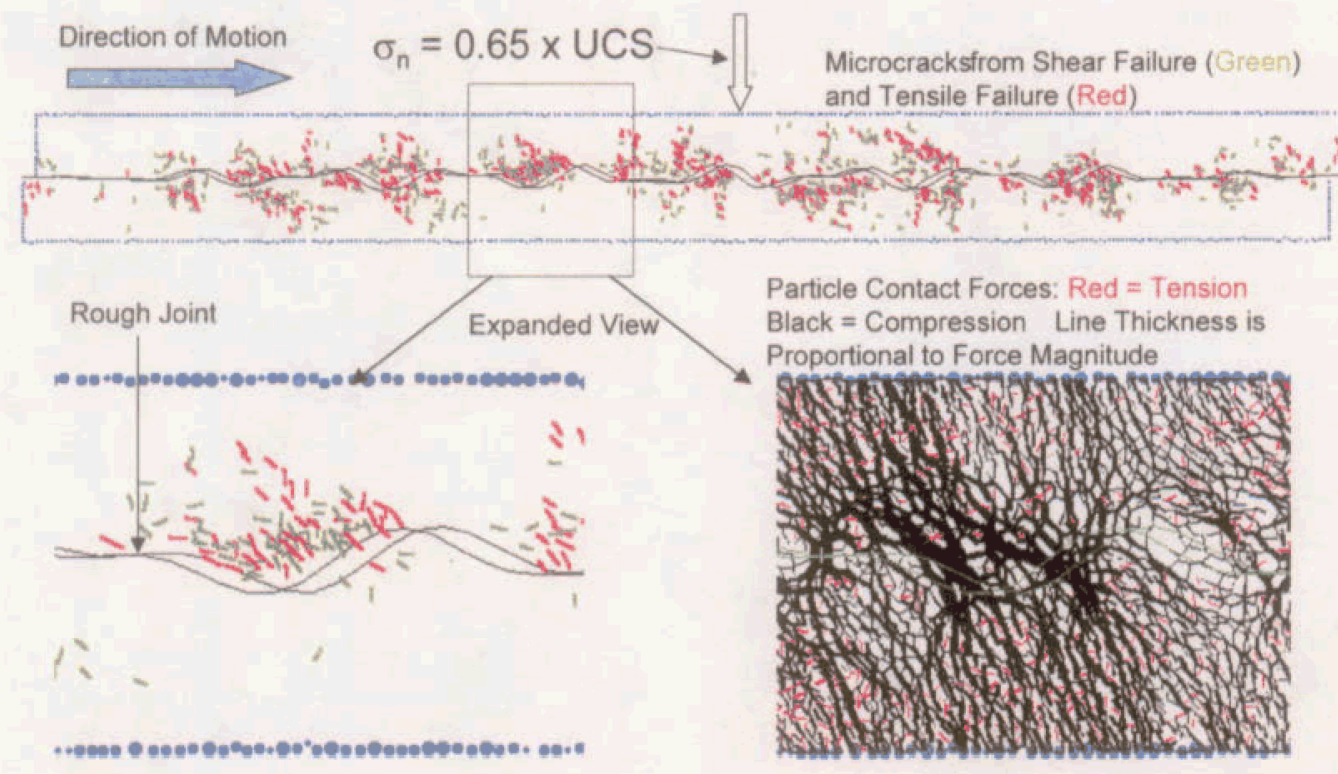

$002660 \mathrm{C} \_045$ ai

Figure 38. Example of PFC Prediction of Damage Induced in Asperities for a Particular Case of Normal Stress as a Joint is Sheared 
Comparison to Barton-Bandis equations:

$\tau=\sigma_{n} \tan \left\{\mathrm{JRC} \log \left(\mathrm{JCS} / \sigma_{n}\right)+\sigma_{r}\right\}$

$d_{n}=\mathrm{JRC} \log \left(\mathrm{JCS} / \sigma_{n}\right)$

Solid curves show values calculated by these equations for:

$$
\emptyset_{r}=24
$$

$\mathrm{JRC}=20$

$\mathrm{JCS}=\sigma_{c}(\mathrm{UCS}$ of solid $)$

Crosses show results from seven PFC simulations

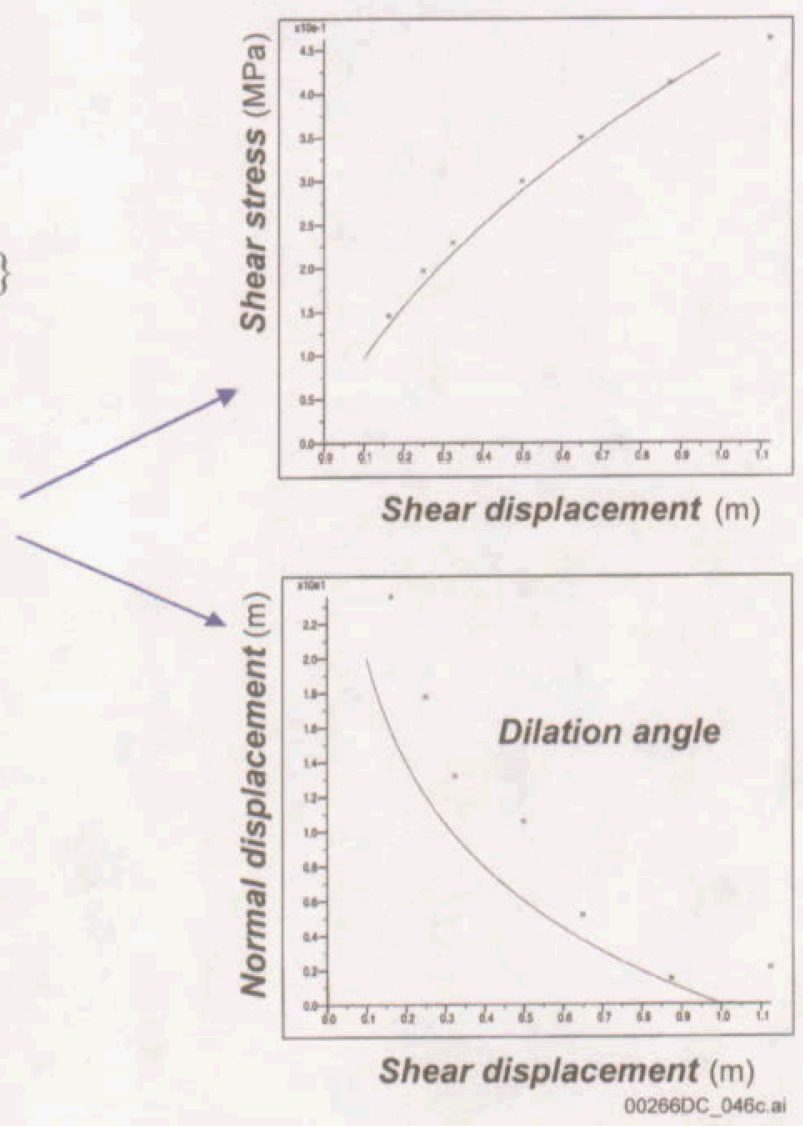

Figure 39. Comparison of PFC Model Results to Barton-Bandis Empirical Joint Constitutive Model for Joint Shear and Normal Response

\subsection{GROUND SUPPORT DESIGN AND EVALUATION}

Ground support generally has one of three overall functions, depending on the type and quality of rock, and the stress conditions. First, it may be used to stabilize weak or overstressed ground and limit deformations to acceptable levels. Second, it may prevent gravitational loosening and fall of rock wedges in blocky, strong rock masses under low stress conditions. Finally, it can be used to maintain control of the rock surface in heavily fractured ground under low stress, by preventing unraveling or running. For repository emplacement drifts, ground support must:

- Ensure the stable conditions required for operational worker safety

- Limit the potential for rockfall ${ }^{2}$ onto unprotected waste packages during the ventilated preclosure

- Allow for performance confirmation activities (which will include remote observation and possible testing functions), waste retrieval operations, and closure operations (which may include installation of permanent drip shields).

\footnotetext{
${ }^{2}$ Specifications for maximum size of rock particles contacting the waste package are not yet determined.
} 
Furthermore, ground support needs to function throughout a repository preclosure period that could range from 50 to perhaps as high as 300 years. It is desired that the ground support require little of no maintenance due to the special requirements introduced by nuclear materials.

The following section describes the general methodology being developed for design of the ground support, and definition of support observation and maintenance over the retrieval period. This logic is currently under development and will be described in greater detail in a future Technical Data Report.

\subsubsection{Current Drift Stability and Ground Support Function Under Gravitational Loading at Repository Depths-Predictions and Correspondence to Observations in the ESF and the ECRB Cross-Drift}

\subsubsection{Stress State}

It is instructive to first examine the current stress conditions at the Yucca Mountain site, and their relation to the estimated rock mass strength and observations, particularly in the Tptpll within the ECRB, as a guide to ground support requirements.

The estimated stress conditions at the repository level are given in Table 4. The current repository design calls for emplacement drifts at a depth of approximately $300 \mathrm{~m}$, oriented at $\mathrm{N} 72^{\circ} \mathrm{E}$. This orientation results in maximum and minimum stresses in the plane perpendicular to the axis of the drifts of about $7 \mathrm{MPa}$ vertical and $3 \mathrm{MPa}$ lateral. With these stress levels, the stress concentrations (assuming elastic behavior) at the springline will be approximately $18 \mathrm{MPa}$, and will be about $2 \mathrm{MPa}$ at the crown (Figure 40). The stress levels at the floor will be the same.

\subsubsection{Observations of Stability of the Tptpmn in the ESF and the ECRB}

Due to the high uniaxial compressive strength of intact blocks of the Tptpmn, these stress concentrations will not result in any intact rock failure mechanisms. However, the fractured nature of the ground, and the presence of multiple joint sets, including a sub-horizontal set, results in the potential for gravity-induced wedge-type failures. In the ECRB Cross-Drift excavations, only a small number (less than 10) of wedge-type failures have occurred, with wedge sizes being roughly on the order of 1 ton or less. A larger number of loosened wedges (not fully documented) can be seen in the ESF, particularly in the area of the highly fractured zone. These wedges are formed by fracture sets 1 and 2 and the sub-horizontal vapor phase partings. These wedges were removed by the TBM during the excavation process, or by subsequent scaling operations; there are no known failures that have occurred at a later date. In the case of the Tptpmn, it appears reasonable that the primary function of the ground support is to prevent gravity fall of relatively small wedge sizes. Rockbolts of suitable length and spacing, supplemented by wire mesh perform well under these circumstances. 
Table 4. In Situ Stress Estimates at Yucca Mountain Site

\begin{tabular}{|c|c|c|}
\hline Stress Component & Magnitude & Direction \\
\hline$\sigma_{1}$ & $\sim 0.023^{\star}$ depth $(\mathrm{m})$ & Vertical \\
\hline$\sigma_{2}$ & $0.617^{\star} \sigma_{1}$ & $\mathrm{~N} 15^{\circ} \mathrm{E}$ \\
\hline$\sigma_{3}$ & $0.361^{\star} \sigma_{1}$ & $\mathrm{~N} 105^{\circ} \mathrm{E}$ \\
\hline
\end{tabular}

Source: WBS 1.2.3.2.7.3.4, WA-0065:QA:L

\subsubsection{Observations of Stability in the Tptpll in the ECRB}

Portions of both the ESF main tunnel and the ECRB are excavated in lithophysal rocks, and are generally quite stable using only rockbolts (Swellex ${ }^{\mathrm{TM}}$ and split sets) and wire mesh in the crown and walls as support. Observations in the Tptpll show obvious or intense small-scale fracture development at the tunnel springline, with the tunnel crown having less obvious fracture development. The origin of these fractures and the hackly appearance of the tunnel walls appears to be largely related to the action of the TBM cutters during the excavation process. However, observation of large $(12 \mathrm{in} .[30.5 \mathrm{~cm}])$ diameter cores and the core hole walls drilled into the side walls of the tunnels indicate that there is a ubiquitous, natural fracture "fabric" within the Tptpll, with closely spaced (a few inches), irregular inter-lithophysal fractures of various orientations. These small-scale fractures often have vapor phase alteration on their surfaces, indicating their origin during the cooling process. A number of the large core holes drilled in the springline area show mining-induced, wall-parallel fractures that extend to a depth of about 12 to $18 \mathrm{in}$. $(30.5$ to $45.7 \mathrm{~cm})$ from the tunnel wall. These fractures are not observed in similar holes in the Tptpul or Tptpmn.

The ground support function within this rock can be estimated from practical observation of the fracture density, as well as examination of the stress state in relation to the estimated rock mass strength. A simple parametric analysis of the yield zone around a tunnel in lithophysal rocks at $300 \mathrm{~m}$ depth can be conducted assuming the range of compressive strength data from the large core (10.5 in. [27 cm] diameter) Tptpul testing at Busted Butte. The relationship between uniaxial compressive strength and Young's modulus for this rock was shown in Figure 20. 


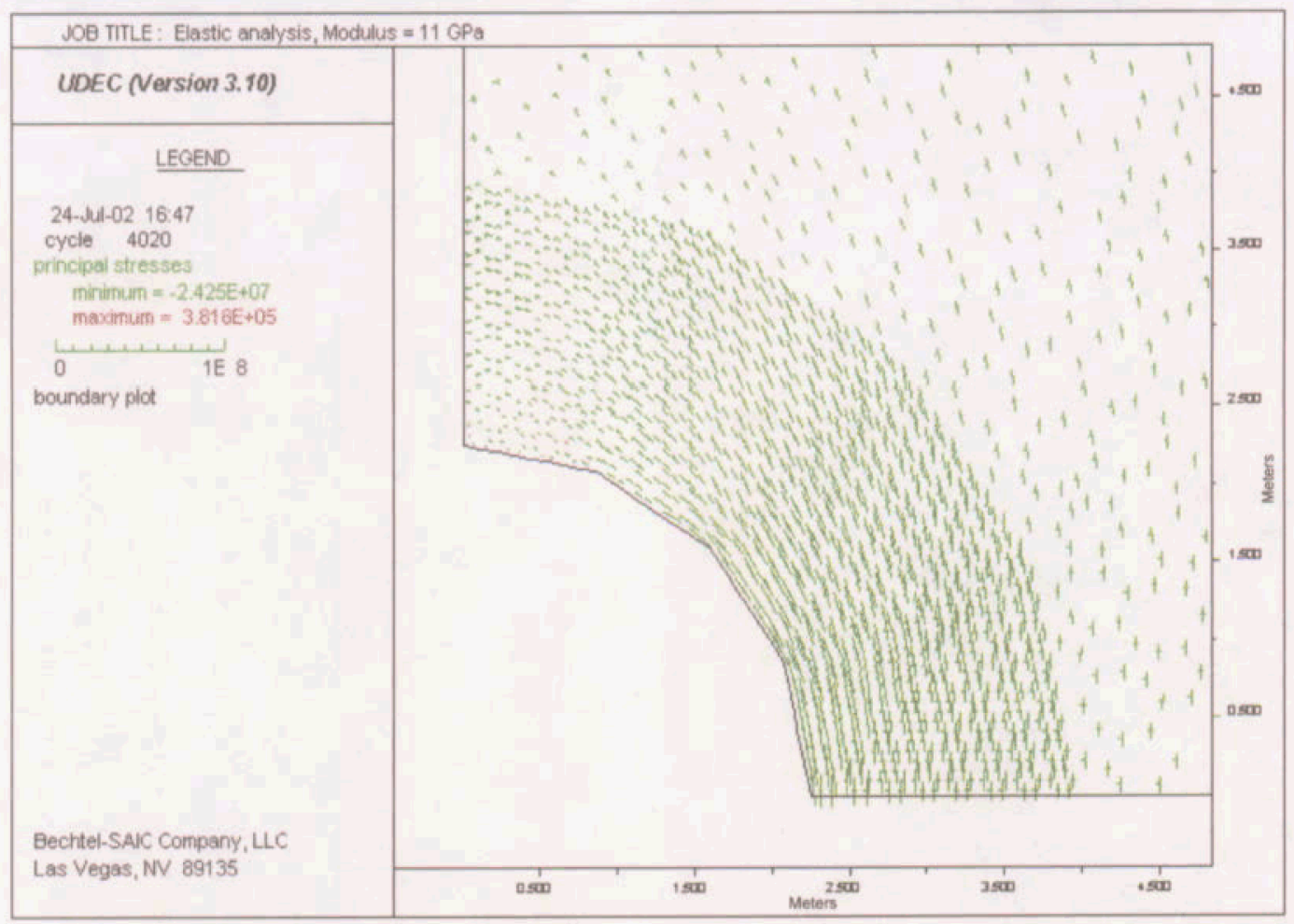

00266DC 051.ai

NOTE: Figure shows elastic rock at a depth of $300 \mathrm{~m}$ with vertical to horizontal stress ratio of $7 \mathrm{MPa}$ to $3 \mathrm{MPa}$. Stress level is highest at the tunnel springline and lowest at the crown.

Figure 40. Mining-Induced Stress Around Quarter-Symmetry Tunnel

It is instructive to perform a simple modeling exercise in which the rock is assumed to behave as an elastic-plastic material with Mohr-Coulomb yield condition, and assuming the low end of the strength range presented in Figure 20 (uniaxial compressive strength of about $10 \mathrm{MPa}$, resulting in a cohesion of $1.28 \mathrm{MPa}$, assuming an angle of internal friction of $50^{\circ}$ ). For the stress state considered in Figure 40, an estimate of the extent of yield for an unsupported tunnel at repository depth can be made. Figure 41 shows the predicted stable tunnel with the extent of the failed zone for this case, which is about one-third to one-half of a meter at the tunnel springline (location of maximum stress difference), with no yield at the tunnel crown. This depth of failure is approximately the same as the depth of wall-parallel fracturing observed in the springline core holes as discussed above. The additional observation of a lack of mining-induced fracturing in the crown is also consistent with the calculations. Increasing the strength properties of the rock mass indicates that no yield is predicted when a uniaxial compressive strength of approximately $20 \mathrm{MPa}$ (i.e., the maximum tangential stress at the springline) is reached. This observation shows that the general strength measurements determined thus far in the laboratory for lithophysal rocks is in reasonable agreement with observations in the ECRB - i.e., the level of yield predicted for the proposed rock strength is reasonable with respect to the observations of fracturing in the tunnel side walls.

Additionally, the tunnel is in equilibrium with only a few millimeters of total inward deformation, the maximum being at the roof centerline. These preliminary analyses point out 
that the depth of yield under the current stress conditions is small, and overall equilibrium of the tunnel can be achieved without ground support. Therefore, under typical non-thermal or non-seismic loading conditions, the function of the ground support in the Tptpll is purely to retain small pieces of loosened or damaged material from gravity fall, and prevent any form of raveling response.

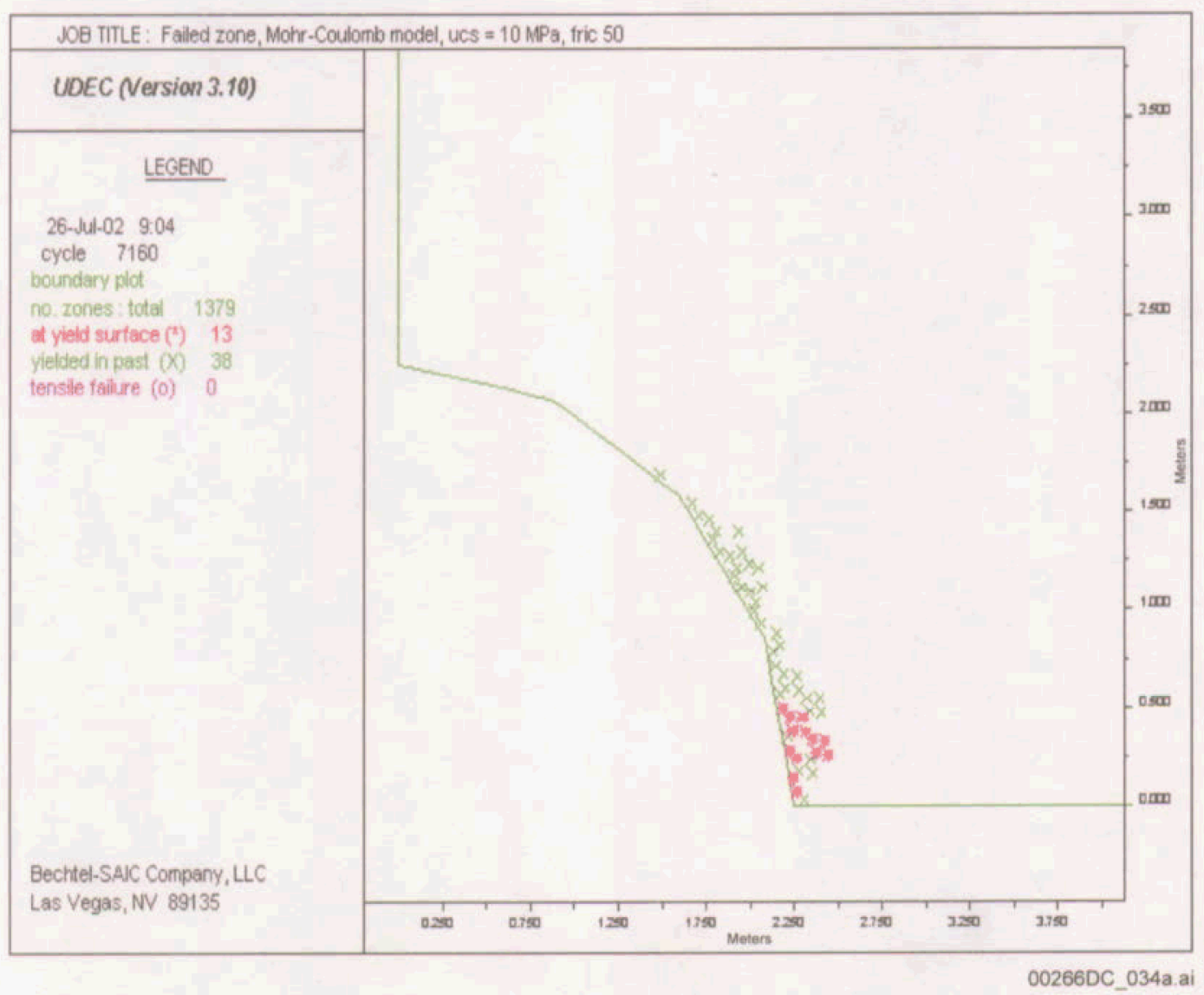

NOTE: Under gravitational stress, the tunnel shows a small (approx. $0.5 \mathrm{~m}$ ) yield zone in the side wall.

Figure 41. Yield Zone Around Tunnels in Tptpll

Figure 42 provides a check of the assumed ground support methods against typical industry-practice. This chart illustrates the role of ground support for the case of jointed rock (e.g., Tptpmn) and heavily fractured rock (e.g., Tptpll) under low stress conditions. 


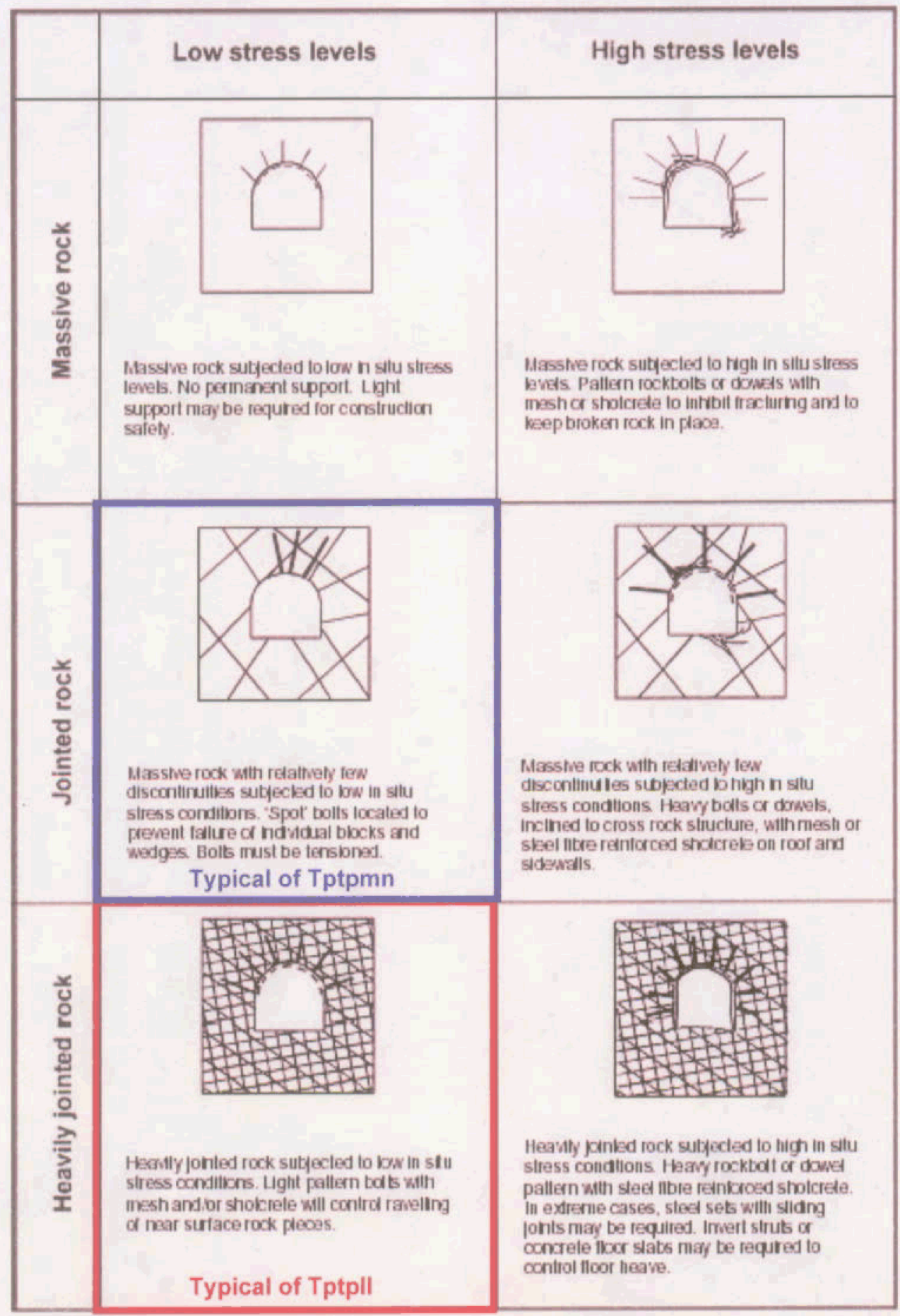

00266DC_035 ai

Source: Hoek 2000.

Figure 42. Typical Ground Support for Various Joint Densities and Stress Levels Showing Conditions Typical of the Tptpmn and Tptpll. 


\subsubsection{Ground Support Design and Assessment Methodology}

During the preclosure period, heat production from the emplaced waste packages will slowly raise the drift temperature and elevate the surrounding rock temperature, resulting in small stress changes around the excavations. The stress change will be dependent on a number of factors, including the initial waste canister heat output, the canister spacing, drift spacing, age of waste package, the amount of forced ventilation to be used, and the rock mass moduli. In any case, thermally induced stresses in the rock mass and ground support system are time-dependent. The current design basis for the preclosure ground support calls for a standard support of cement-grouted rockbolts and wire mesh with the potential for steel sets to be used where ground conditions dictate. It is recognized that:

- The current preclosure period of 50 to possibly as much as 300 years is a considerable length of time in terms of underground construction practice,

- Corrosion of the ground support will likely occur, and

- Depending on the length of the preclosure period, the type of ground support, and the degree of forced ventilation (to remove heat and moisture from the rock mass) the ground support may need to be maintained or supplemented at appropriate intervals.

The approach to preclosure ground support design and specification can be defined by the following methodology (Figure 43):

1. Define the Support Operational Requirements - Determine the requirements of the ground support during the preclosure period, including:

a. Tunnel deformation limits (i.e., ensuring an operational envelope) for passage of vehicles and equipment, tilt limits for waste canisters and rails for remote retrieval, etc.

b. Maximum rock particle size that can fall from in situ, thermal or seismically induced stresses and either strike the waste package and/or lie on rail or roadbed without compromising the ability to retrieve

c. Support corrosion and degradation requirements,

d. Impact of ground support on performance (i.e., the support may impact overall performance of the system). Preclosure use of ground support materials (cement and steel) depends on the postclosure effects of these materials on waste package corrosion and radionuclide transport. As currently planned, use of cementitious materials (e.g., concrete or shotcrete linings in emplacement drifts) will be minimized, use of exposed steel components (e.g., steel sets with steel lagging) will be also minimized, and loss of grout to fractures and lithophysae during rock bolt installation needs to be minimized. 
2. Define In Situ Conditions - Includes rock mass in situ stresses, rock mass geotechnical characterization and properties. A detailed review of the rock mass characterization in the ESF and ECRB was given by Barton (2000).

3. Initial Design of Suitable Ground Support Methods Under In Situ Conditions - Use industry practice and empirical techniques (e.g., Barton 2000) to identify potentially suitable support methods.

4. Detailed Mechanical and Environmental Examination of Support Suitability Under In Situ and Repository Loading Conditions - Detailed design analysis of the deformation and possible failure extent and failure mode of the excavations considering range of input rock mass properties for the lithophysal and nonlithophysal rocks. Account for proper combinations of in situ, thermal, and seismic loads. Account for practical considerations in support design such as the fracture density and block sizes and the practicality of installation and servicing of the support methods. Consider environmental conditions including temperature, humidity and seepage. Consider the bounding scenarios and estimate the support loads and deformations and verify it fulfills operational requirements. Design calculations and considerations will be based on multiple approaches: computer modeling, empirical estimation, ESF and the ECRB experience, and drift scale testing and observation.

5. Compare Proposed Support Methods to Repository Operational Requirements Identify possible support methods that fulfill the basic repository operational requirements. The operational requirements include definition of those structures, systems and components important to safety. Determine practicality of implementation of the support on a standard basis, including cost and maintainability. Estimate corrosion potential and life expectancy of support.

6. Monitoring, Inspection and Maintenance Program - Details of monitoring, inspection, and maintenance programs for the emplacement drifts will be developed as the program progresses from the conceptual design to the detailed design phase. DOE will specify structures, systems and components important to safety and natural and engineered barriers important to waste isolation. These structures, systems and components will be compatible with the risk-informed, performance-based approach embodied in 10 CFR Part 63. Parameters, measurements, and observations that are appropriate for inclusion in the performance confirmation program will be included in the detailed emplacement drift design based on their importance to repository performance and to addressing the detailed functional and quality level requirements of the ground support systems.

\subsubsection{Methodology for Use of Numerical Models in Determining Ground Support Functions Under Repository Loading}

A discussion is given below on possible ground support evaluation methods using numerical models. Why will numerical models be used for support evaluation? Normally, ground support is defined empirically. Rock mass classification schemes (e.g., the Q system) are used to define initial support methods and the tunnel construction management and engineer use observation, instrumentation, and practical judgment to adjust methods as necessary to fit actual conditions as 
they unfold. Due to the obvious extenuating factors in the project (the thermal and seismic loading, the long time periods of support function, and the inability to easily observe and rehab the ground support) there is a greater reliance on detailed calculation and conservatism in the design. This implies the use of validated numerical modeling tools for examining rock mass yield and deformation, and the impact of rock mass variability on design requirements. As was shown in the overall resolution strategy diagram (Figure 22), the goal, prior to the ground support final specification, is to have a reasonable understanding of the in situ rock mass properties and their variability as input to numerical modeling. In this way, one can perform performance calculations that will predict rock mass response to the average and bounding rock quality conditions.

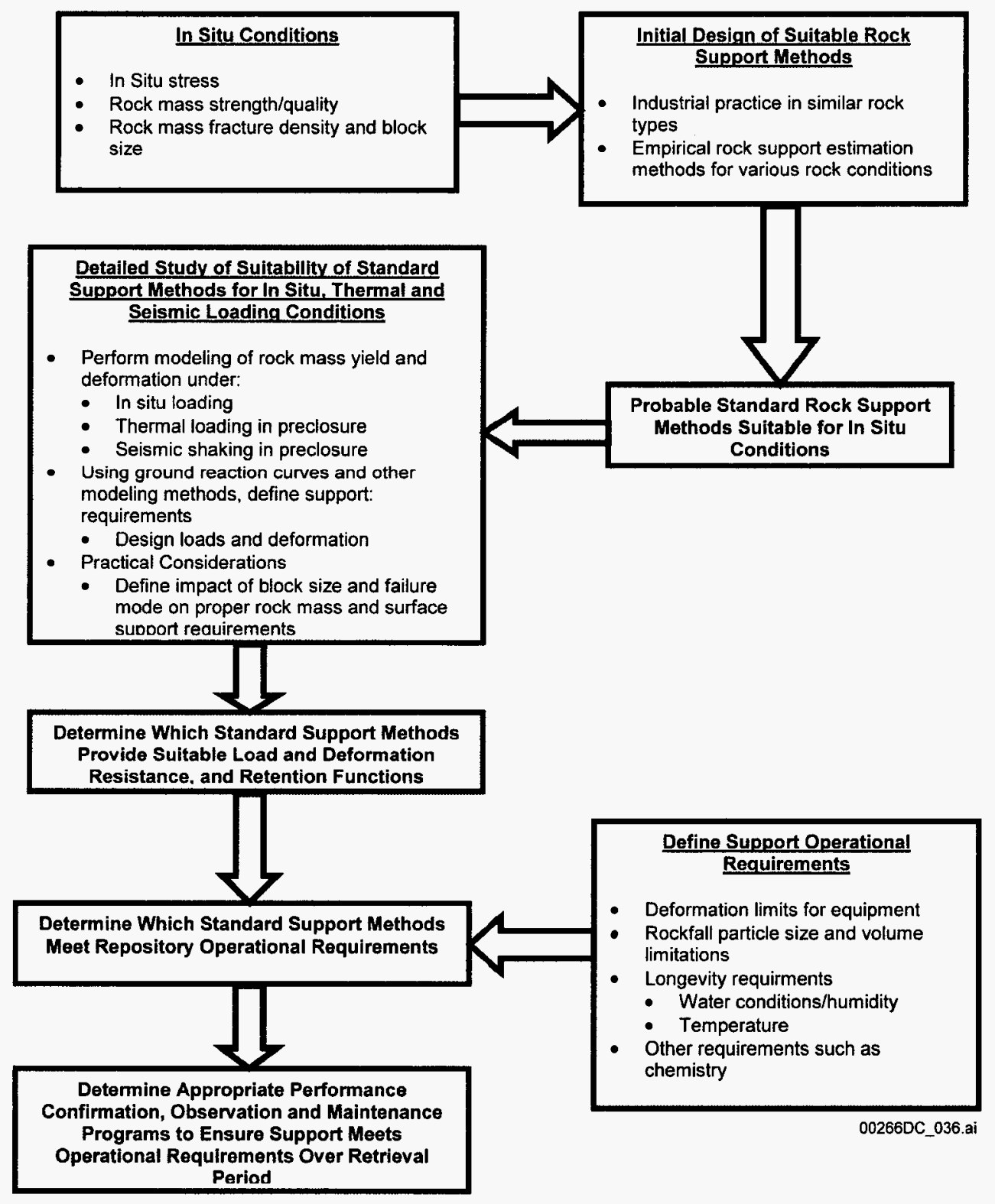

Figure 43. Ground Support Design and Assessment Methodology 


\subsubsection{Numerical Modeling of Rock Reinforcement}

Numerical analyses of reinforced and unreinforced excavations will be performed for both the fracture-controlled Tptpmn as well as the lithophysal rocks.

\section{Non-Lithophysal Rock}

The design of rock support in the non-lithophysal rocks is based primarily on the geometric and surface properties of the fracturing. As discussed above, empirical methods (the $Q$ system) will be used for the initial support specification in the Tptpmn. This support (which may consist of grouted or frictional bolts, wire mesh and perhaps fiber-reinforced shotcrete) will then be subjected to parametric numerical analysis using discontinuum numerical methods. Both the two-dimensional UDEC and three-dimensional 3DEC programs will be used for analysis of the support loads and rock mass yield and deformation when subjected to in situ, thermal and possible seismic loading over the preclosure period. The parametric analysis will include variation of fracture geometry and fracture properties, including cohesion, friction and dilation angles. It is convenient to utilize the three-dimensional synthetic fracture geometries (FracMAN) developed for the Tptpmn postclosure analysis as a basis for the ground support calculations. Here, a sensitivity study using various fracture realizations from this model can be used as input to the 3DEC program in the same way as discussed in Section 7.1. The models can be used to directly represent the ground support (Itasca 2002) and the application of transient loading from thermal and seismic sources. The rock mass temperature variation around the emplacement drifts with time during ventilated periods is obtained directly from the three-dimensional regional thermomechanical modeling. These temperatures will induce transient thermal stresses in the rock and expansion of support elements. The deformation of the rock and support loads can be determined directly from the model, and the factor of safety against failure for rock blocks determined in an automated fashion. It is possible that deterioration of the support elements due to corrosion can be included in the analyses through reduction of strength properties.

\section{Lithophysal Rocks}

As discussed previously, the lithophysal rocks are represented numerically using the UDEC program with mass properties calibrated to laboratory and in situ testing. The strength and stiffness properties of the rock mass are porosity dependent, resulting in a range of values that covers the range of in situ porosity variability. These properties provide the basic input data for thermomechanical sensitivity studies using the UDEC approach as described. As a secondary check on the analysis method, a more traditional continuum-based FLAC analysis assuming standard Mohr-Coulomb strength parameters will also be run.

A parametric analysis will be conducted in which various proposed rock support methods will be examined for the range of rock mass strength and stiffness properties. As with the 3DEC program, UDEC and FLAC allow various forms of rock support to be modeled directly within the analysis. The support load and deformation will be determined from the model as a function of time in the transient analyses. It is probable that both UDEC and FLAC approaches will be used here to define the general yield depth and deformation of the rock mass, and the expected overbreak or loosened zone and size of rock fragments that will need to be supported. This information will provide the performance requirements (load, deformability and block size to be supported) of the ground support. 
The above calculations define the general operational conditions of the ground support based on the expected rock mass yield and deformation. This information is used as basic input to the final design of the ground support. The final design of the ground support is performed taking into account the results of these analyses and is combined with practical experience gained from working in the various rock units on site as well as similar conditions elsewhere. The experience to date has shown that excavations are quite stable with a minimum of ground support, as discussed previously. Experience has shown that in the nonlithophysal rocks (Tptpmn and Tptpln), the rock is moderately fractured but strong, with failure limited to the formation of an occasional small, removable wedge. Here, rockbolts are used to prevent loosening of wedges. In the Tptpul, the rock is weaker due to the uniformly distributed lithophysae, but only sparsely fractured, resulting in no observable yield and stable conditions under mining stress conditions. The Tptpll is heavily fractured with short length fractures between lithophysae, but with only widely spaced and relatively discontinuous fractures with lengths greater than a meter. The excavations are currently stable with support required only for retention of small pieces of loosened rock from the excavation periphery. In all of these rock types, the primary role of the support is a retention function under low stress conditions, and standard rockbolts and mesh prove successful. Ideal long-term support methods in ground such as the Tptpll would be those that provide a continuous lining and retention function such as fiber-reinforced shotcrete and bolts plated on the exterior surface. After selection of a number of alternative support methods, final selection will be based on the additional factors of the impact of support on postclosure performance and longevity of the support method.

\subsubsection{Support Longevity and Other Items}

An important aspect that will receive significant attention is the longevity of support elements. Currently, testing is underway to examine the general corrosion rates of steel support elements including rockbolts and steel sets subject to Yucca Mountain water chemistries. Additionally, grout-water interaction experiments relating to chemical effects on seepage water from rockbolt grouting are also underway. Additional aging studies on shotcrete including determination of carbonation rates may be conducted. This information will assist in understanding the longevity of ground support and its potential impacts on in-drift chemistry. Testing will also be performed on grout loss and rockbolt pull strength in lithophysal rocks.

Future examinations will include performance confirmation activities that will be conducted during construction of the repository. This will include geotechnical mapping and classification and determination of in situ property variability in the repository emplacement drifts. Testing of the mechanical properties of ground support and observation of performance during the preclosure period will be an integral part of performance confirmation. 
INTENTIONALLY LEFT BLANK 


\section{SUMMARY}

This document provides an approach to resolution of the geomechanically-related RDTME KTI agreements. The primary geomechanical issues are identified, and a program of geotechnical mapping and analysis, laboratory and in situ testing, in combination with numerical modeling are proposed for issue resolution.

Geomechanically-related KTI agreements (Appendix A) can be subdivided into five primary areas:

A. Rock mass properties and geotechnical characterization

1. Development of a basic understanding of how the structural characteristics of the repository host horizon impacts rock mass behavior and, consequently, the design and performance properties. This work can be used to establish a connection between geologic characteristics and their use in models and calculations.

2. Develop an understanding of the variability of geologic structure and, using the developments of the above item, identify how variability affects rock mass thermomechanical behavior.

3. Enhance the database of thermomechanical materials properties of repository rock units, including mechanical and thermal testing of lithophysal rocks, estimation of the mechanical properties of rock fractures, and determination of the time-dependent response of lithophysal rocks. Development or choice of proper constitutive models for the different distinct rock units is a portion of this effort.

B. Modeling

1. Determination or development of the proper type of modeling tools to use for sensitivity studies of excavation stability under gravitational, thermal and seismic shaking. Specific agreements cited in the KTI include:

a. Under what circumstances are continuum and discontinuum models appropriate?

b. Under what circumstances are two- and three-dimensional models appropriate?

c. Under what circumstances are assumptions of rock mass homogeneity or anisotropy appropriate?

2. Determination of the proper model boundary and initial conditions

a. Need to address the initial stress state for models and inclusion of thermally induced stress history from regional models applied to local scale models for problems such as rockfall 
b. Need to address special boundary conditions for dynamic analyses, including non-reflecting and free-field boundaries

c. Need for development of preclosure and postclosure site-specific ground motion time histories

C. Seismic Stability

1. Use of site-specific ground motions

2. Use of appropriate dynamic models for estimation of rockfall induced by seismic shaking

3. Methodology for inclusion of geologic structure and its variability into models for estimation of rockfall

D. Thermal and Long-term Degradation

1. Need to examine potential for thermal-stress induced rockfall

2. Need to examine impact of long-term static fatigue of the rock mass and its impact on drift degradation and rockfall

E. Ground Support and Drift Degradation

1. Verification of the functional and operational requirements and specification of ground support during the preclosure period.

2. Development of a plan for observation and maintenance of the ground support.

3. Estimation of the effect of postclosure in situ, thermal and seismically induced stresses on the degradation and potential rockfall of the emplacement drifts. Included here is the potential effect of time-related static fatigue mechanisms in intact rock and joints. 


\section{REFERENCES}

\subsection{DOCUMENTS CITED}

Albin, A.L.; Singleton, W.L.; Moyer, T.C.; Lee, A.C.; Lung, R.C.; Eatman, G.L.W.; and Barr, D.L. 1997. Geology of the Main Drift - Station 28+00 to 55+00, Exploratory Studies Facility, Yucca Mountain Project, Yucca Mountain, Nevada. Milestone SPG42AM3. Denver, Colorado: Bureau of Reclamation and U.S. Geological Survey. ACC: MOL.19970625.0096.

Barr, D.L, Moyer, T.C.; Singleton, W.L.; Albin, A.L.; Lung, R.C.; Lee, A.C.; Beason, S.C.; and Eatman, G.L.W. 1996. Geology of the North Ramp - Stations 4+00 to 28+00, Exploratory Studies Facility, Yucca Mountain Project, Yucca Mountain, Nevada. Denver, Colorado: U.S. Geological Survey. ACC: MOL.19970106.0496.

Barton, N. 2000. A Review of the Site Characterization, and Suggestions for a Site Specific Method of Design for Long Term Ground Control at the Yucca Mountain Project. 20001174. Oslo, Norway: Norwegian Geotechnical Institute. TIC: 248878.

Barton, N. and Choubey, V. 1977. "The Shear Strength of Rock Joints in Theory and Practice." Rock Mechanics, 10, (1-2), 1-54. New York, New York: Springer-Verlag. TIC: 218374.

Barton, N.; Lien, R.; and Lunde, J. 1974. "Engineering Classification of Rock Masses for the Design of Tunnel Support.” Rock Mechanics, 6, (4), 189-236. New York, New York: Springer-Verlag. TIC: 219995.

Beason, S.C.; Turlington, G.A.; Lung, R.C.; Eatman, G.L.W.; Ryter, D.; and Barr, D.L. 1996. Geology of the North Ramp - Station 0+60 to 4+00, Exploratory Studies Facility, Yucca Mountain Project, Yucca Mountain, Nevada. Denver, Colorado: U.S. Geological Survey. ACC: MOL.19970106.0449.

Bieniawski, Z.T. 1989. Engineering Rock Mass Classifications. New York, New York: John Wiley \& Sons. TIC: 226350.

Board, M. Linden, A.; and Zhu, M. 2002. Design Evolution Study-Underground Layout. TDR-MGR-MG-000003 REV 00. Las Vegas, Nevada: Bechtel SAIC Company. ACC: MOL.20020429.0023.

Brechtel, C.E.; Lin, M.; Martin, E.; and Kessel, D.S. 1995. Geotechnical Characterization of the North Ramp of the Exploratory Studies Facility. SAND95-0488/1 and 2. Two volumes. Albuquerque, New Mexico: Sandia National Laboratories. ACC: MOL.19950502.0004; MOL.19950502.0005.

Broxton, D.E.; Chipera, S.J.; Byers, F.M., Jr.; and Rautman, C.A. 1993. Geologic Evaluation of Six Nonwelded Tuff Sites in the Vicinity of Yucca Mountain, Nevada for a Surface-Based Test Facility for the Yucca Mountain Project. LA-12542-MS. Los Alamos, New Mexico: Los Alamos National Laboratory. ACC: NNA.19940224.0128. 
BSC 2001. Drift Degradation Analysis. ANL-EBS-MD-000027 REV 01 ICN 01. Las Vegas, Nevada: Bechtel SAIC Company. ACC: MOL.20011029.0311.

BSC 2002. Thermal Conductivity of the Potential Repository Horizon Model Report. MDL-NBS-GS-000005 REV 00. Las Vegas, Nevada: Bechtel SAIC Company. ACC: MOL.20020923.0167.

Buesch, D.C.; Spengler, R.W.; Moyer, T.C.; and Geslin, J.K. 1996. Proposed Stratigraphic Nomenclature and Macroscopic Identification of Lithostratigraphic Units of the Paintbrush Group Exposed at Yucca Mountain, Nevada. Open-File Report 94-469. Denver, Colorado: U.S. Geological Survey. ACC: MOL.19970205.0061.

Byers, F.M., Jr.; Carr, W.J.; Orkild, P.P.; Quinlivan, W.D.; and Sargent, K.A. 1976. Volcanic Suites and Related Cauldrons of Timber Mountain-Oasis Valley Caldera Complex, Southern Nevada. Professional Paper 919. Washington, D.C.: U.S. Geological Survey. TIC: 201146.

Christiansen, R.L.; Lipman, P.W.; Carr, W.J.; Byers, F.M., Jr.; Orkild, P.P.; and Sargent, K.A. 1977. "The Timber Mountain-Oasis Valley Caldera Complex of Southern Nevada." Geological Society of America Bulletin, 88, (7), 943-959. [Boulder, Colorado]: Geological Society of America. TIC: 201802.

CRWMS M\&O 1997. Confirmation of Empirical Design Methodologies. BABEE0000-017175705-00002 REV 00. Las Vegas, Nevada: CRWMS M\&O. ACC: MOL.19980219.0104.

CRWMS M\&O 1998a. Probabilistic Seismic Hazard Analyses for Fault Displacement and Vibratory Ground Motion at Yucca Mountain, Nevada. Milestone SP32IM3, September 23, 1998. Three volumes. Las Vegas, Nevada: CRWMS M\&O. ACC: MOL.19981207.0393.

CRWMS M\&O 1998b. Geology of the Exploratory Studies Facility Topopah Spring Loop. BAB000000-01717-0200-00002 REV 01. Las Vegas, Nevada: CRWMS M\&O. ACC: MOL.19980415.0283.

CRWMS M\&O 1999. TBV-361 Resolution Analysis: Emplacement Drift Orientation. B00000000-01717-5705-00136 REV 00. Las Vegas, Nevada: CRWMS M\&O.

ACC: MOL.19990802.0316.

Day, W.C.; Dickerson, R.P.; Potter, C.J.; Sweetkind, D.S.; San Juan, C.A.; Drake, R.M., II; and Fridrich, C.J. 1998. Bedrock Geologic Map of the Yucca Mountain Area, Nye County, Nevada. Geologic Investigations Series I-2627. Denver, Colorado: U.S. Geological Survey.

ACC: MOL.19981014.0301.

DOE (U.S. Department of Energy) 2002. Yucca Mountain Science and Engineering Report. DOE/RW-0539, Rev. 1. Washington, D.C.: U.S. Department of Energy, Office of Civilian Radioactive Waste Management. ACC: MOL.20020404.0042. 
Eatman, G.L.W.; Singleton, W.L.; Moyer, T.C.; Barr, D.L.; Albin, A.L.; Lung, R.C.; and Beason, S.C. 1997. Geology of the South Ramp - Station 55+00 to 78+77, Exploratory Studies Facility, Yucca Mountain Project, Yucca Mountain, Nevada. Denver, Colorado:

U.S. Department of Energy. ACC: MOL.19980127.0396.

Gibson, J.D.; Shephard, L.E.; Swan, F.H.; Wesling, J.R.; and Kerl, F.A. 1990. "Synthesis of Studies for the Potential of Fault Rupture at the Proposed Surface Facilities, Yucca Mountain, Nevada." High Level Radioactive Waste Management, Proceedings of the International Topical Meeting, Las Vegas, Nevada April 8-12, 1990. 1, 109-116. La Grange Park, Illinois: American Nuclear Society. TIC: 202058.

Hoek, E. 2000. "Rock Engineering: Course Notes." Practical Rock Engineering. Toronto, Ontario: Rocscience Inc. Accessed Wednesday, November 13, 2002. TIC: 253544. http://www.rockscience.com/roc/Hoek/Hoeknotes2000.htm.

Itasca Consulting Group. 2002. Itasca Software-Cutting Edge Tools for Computational Mechanics. Minneapolis, Minnesota: Itasca Consulting Group. TIC: 252592.

Kicker, D.C.; Martin, E.R.; Brechtel, C.E.; Stone, C.A.; and Kessel, D.S. 1997. Geotechnical Characterization for the Main Drift of the Exploratory Studies Facility. SAND95-2183. Albuquerque, New Mexico: Sandia National Laboratories. TIC: 227586.

Kirsten, H.A.D. 1988. "Discussion on Q-System." Rock Classification Systems for Engineering Purposes, Symposium held in Cincinnati, Ohio, June 25, 1987. Kirkaldie, L., ed. Pages 85-88. Philadelphia, Pennsylvania: American Society for Testing and Materials. TIC: 221986.

Lajtai, E.Z., Schmidtke, R.H., and Bielus, L.P. The Effect of Water on the Time-dependent Deformation and Fracture of a Granite. Int. J. Rock Mech. Min. Sci.. Vol. 24, No. 4, pp. 247 to 255,1987 . TIC: 236692.

Lipman, P.W.; Christiansen, R.L.; and O'Connor, J.T. 1966. A Compositionally Zoned AshFlow Sheet in Southern Nevada. Professional Paper 524-F. Washington, D.C.: U.S. Geological Survey. TIC: 219972.

Mongano, G.S.; Singleton, W.L.; Moyer, T.C.; Beason, S.C.; Eatman, G.L.W.; Albin, A.L.; and Lung, R.C. 1999. Geology of the ECRB Cross Drift - Exploratory Studies Facility, Yucca Mountain Project, Yucca Mountain, Nevada. [Deliverable SPG42GM3]. Denver, Colorado: U.S. Geological Survey. ACC: MOL.20000324.0614.

NRC (U.S. Nuclear Regulatory Commission) 2000. Issue Resolution Status Report Key Technical Issue: Repository Design and Thermal-Mechanical Effects. Rev. 3. Washington, D.C.: U.S. Nuclear Regulatory Commission. ACC: MOL.20010201.0256.

Ortiz, T.S.; Williams, R.L.; Nimick, F.B.; Whittet, B.C.; and South, D.L. 1985. $A$ Three-Dimensional Model of Reference Thermal/Mechanical and Hydrological Stratigraphy at Yucca Mountain, Southern Nevada. SAND84-1076. Albuquerque, New Mexico: Sandia National Laboratories. ACC: MOL.19980602.0331. 
Potyondy, D. and Cundall, P. 2001. The PFC Model for Rock: Predicting Rock-Mass Damage at the Underground Research Laboratory. Itasca Consulting Group, Inc., Report To Atomic Energy of Canada Limited (AECL), March. Issued as Ontario Power Generation. Nuclear Waste Management Division Report No. 06819-REP-01200-10061-R00. Minneapolis, Minnesota: Itasca Consulting Group.

Price, R.H. 1986. Effects of Sample Size on the Mechanical Behavior of Topopah Spring Tuff. SAND85-0709. Albuquerque, New Mexico: Sandia National Laboratories.

ACC: NNA.19891106.0125.

Price, R.H.; Nimick, F.B.; Connolly, J.R.; Keil, K.; Schwartz, B.M.; and Spence, S.J. 1985. Preliminary Characterization of the Petrologic, Bulk, and Mechanical Properties of a Lithophysal Zone Within the Topopah Spring Member of the Paintbrush Tuff. SAND84-0860. Albuquerque, New Mexico: Sandia National Laboratories. ACC: NNA.19870406.0156.

Sawyer, D.A.; Fleck, R.J.; Lanphere, M.A.; Warren, R.G.; Broxton, D.E.; and Hudson, M.R. 1994. "Episodic Caldera Volcanism in the Miocene Southwestern Nevada Volcanic Field: Revised Stratigraphic Framework, 40Ar/39Ar Geochronology, and Implications for Magmatism and Extension." Geological Society of America Bulletin, 106, (10), 1304-1318.

Boulder, Colorado: Geological Society of America. TIC: 222523.

Schuraytz, B.C.; Vogel, T.A.; and Younker, L.W. 1989. "Evidence for Dynamic Withdrawal from a Layered Magma Body: The Topopah Spring Tuff, Southwestern Nevada." Journal of Geophysical Research, 94, (B5), 5925-5942. Washington, D.C.: American Geophysical Union. TIC: 225936.

Scott, R.B. 1990. "Tectonic Setting of Yucca Mountain, Southwest Nevada." Chapter 12 of Basin and Range Extensional Tectonics Near the Latitude of Las Vegas Nevada. Wernicke, B.P., ed. Memoir 176. Boulder, Colorado: Geological Society of America. TIC: 222540.

Scott, R.B. and Bonk, J. 1984. Preliminary Geologic Map of Yucca Mountain, Nye County, Nevada, with Geologic Sections. Open-File Report 84-494. Denver, Colorado: U.S. Geological Survey. ACC: HQS.19880517.1443.

Young, R.P. and Collins, D.S. 1997. Acoustic Emission/Microseismicity Research at the Underground Research Laboratory, Canada. AECL Report Series, 00670367. Ontario, Canada: Atomic Energy of Canada, Ltd. TIC: 253464.

\subsection{CODES, STANDARDS, REGULATIONS, AND PROCEDURES}

10 CFR 63. Energy: Disposal of High-Level Radioactive Wastes in a Geologic Repository at Yucca Mountain, Nevada. Readily available.

\subsection{SOURCE DATA, LISTED BY DATA TRACKING NUMBER}

GS990408314224.004. Full-Periphery Geologic Maps for Station 10+00 to 15+00, ECRB Cross Drift. Submittal date: 09/09/1999. 


\subsection{SOFTWARE CODES}

Software code: 3DEC. V2.0. 10025-2.0-00.

Software Code: FLAC V3.5. V 3.5. PC. 10167-3.5-00.

Software code: FracMAN. V.2.511. PC Windows NT. 10114-2.511-00.

Software Code: PFC 2D. V.2.0. PC. 10828-2.0-00.

Software Code: PFC 3D. V.2.0. PC. 10830-2.0-00.

Software code: UDEC V3.0. V 3.0. PC. 10173-3.0-00. 
INTENTIONALLY LEFT BLANK 
APPENDIX A

OVERVIEW OF THE RESOLUTION STRATEGY FOR EACH GEOMECHANICALLY-RELATED KTI AGREEMENT 


\section{INTENTIONALLY LEFT BLANK}




\section{APPENDIX A: OVERVIEW OF THE RESOLUTION STRATEGY FOR EACH GEOMECHANICALLY-RELATED KTI AGREEMENT}

The relevant geomechanically-related KTI agreements and an overview of the resolution strategy for each of the agreements covered by this document are listed below. Details of the overall resolution strategy are given in Sections 5 and 6 of this report.

\section{RDTME 3.02}

Provide the critical combinations of in-situ, thermal, and seismic stresses, together with their technical bases, and their impacts on ground support performance. The DOE will examine the critical combinations of in-situ, thermal, and seismic stresses, together with their technical bases and their impacts on preclosure ground support performance. These results will be documented in a revision to Ground Control for Emplacement Drifts for SR, ANL-EBS-GE-000002 (or other document) supporting any potential license application. This is expected to be available to NRC in FY 2003.

\section{General Approach:}

Numerical sensitivity studies will be conducted using continuum and discontinuum methods that examine the combined effect of preclosure stress conditions. The following work will be used to address this issue.

- Laboratory and in situ testing will be used to define strength and deformability property ranges for lithophysal rocks. Lithophysal mapping and numerical extrapolation will be used to define impact of lithophysal variability on rock mass properties.

- Field mapping of joint geometry and roughness characteristics will be used to define rock block geometries. Laboratory testing will be conducted to determine joint surface characteristics using direct shear testing. Fracture geometries will be developed using FracMAN fracture modeling program.

- Numerical modeling sensitivity studies will be performed using 3DEC, UDEC, and FLAC programs to examine yield and deformation in lithophysal and non-lithophysal tunnels. Models will use thermal, in situ, and seismic stresses in preclosure to examine effectiveness of ground support in preventing rockfall. Models will account for range of estimated properties of rock mass and fractures, as well as variability in joint geometries.

\section{RDTME 3.04}

Provide in the Design Parameter Analysis Report (or some other document) sitespecific properties of the host rock, as a minimum those included in the NRC handout, together with the spatial and temporal variations and uncertainties in such properties, as an update to the information contained in the March 1997 Yucca Mountain Site Geotechnical Report. The DOE will: (1) evaluate the adequacy of the currently available measured and derived data to support the potential repository licensing case and identify areas where available data may 
warrant additional field measurements or testing to reduce uncertainty. DOE will provide a design parameters analysis report (or other document) that will include the results of these evaluations, expected to be available to the NRC in FY 2002; and (2) acquire data and/or perform additional analyses as necessary to respond to the needs identified in 1 above. The DOE will provide these results prior to any potential license application.

\section{General Approach:}

- The current rock properties data base is reviewed in Appendix B, and an assessment of thermomechanical data needs made.

- Areas identified that require additional data include:

- Thermomechanical properties of the lithophysal rocks, including strength, deformability and thermal properties

- Static fatigue properties of lithophysal and non-lithophysal rocks

- Shear stress-displacement behavior of joints in the non-lithophysal units

- Description of large-scale roughness in joints in the non-lithophysal units and variation of lithophysae shape, size and porosity in the lithophysal rocks.

- A laboratory and field testing program and an additional geological characterization program have been developed to gather these data. Underground and surface mapping will be combined with borehole logging to define the variability of geologic structure within the repository block. A laboratory and field testing program for lithophysal rocks is underway at Sandia National Laboratories. Tests include large $(12$-in. [30.5-cm]) diameter core and in situ slot compression testing to obtain compressive strength and deformability. Direct shear testing on 12 -in. $(30.5-\mathrm{cm})$ core fractures is underway at the United States Bureau of Reclamation (USBR) laboratories in Denver to obtain shear constitutive behavior. Static fatigue testing of a small number of lithophysal and non-lithophysal samples is also planned at the USBR laboratories. Calibration of the PFC model is planned to allow exploration of impact of lithophysae variability on properties.

- Design parameters sensitivity analyses will be used to examine effects of property variations on ground support and drift degradation. A revision of Drift Degradation Analyses (BSC 2001) will be completed in FY 2003, and Ground Control Analysis for Emplacement Drifts will be completed in the first quarter of FY 2004.

\section{RDTME 3.05}

Provide the Rock Mass Classification Analysis (or some other document) including the technical basis for accounting for the effects of lithophysae. The DOE will provide a rock mass classification analysis (or other document), 
including the technical basis for accounting for the effects of lithophysae, expected to be available to NRC in FY 2002.

\section{General Approach:}

The effect of lithophysae on rock mass properties will be determined directly via:

- Testing of large cores in the laboratory

- In situ compression testing in Tptpul and Tptpll

- Validation of the PFC numerical model against these data to provide a predictive tool capable of modeling the stress-strain response of lithophysal rock. Geologic mapping and geometric description of the lithophysae as a function of depth in the ECRB will provide direct descriptions of lithophysal porosity, shape and size variability. This mapping will provide basis of extrapolation of lithophysal variability impacts on rock properties via PFC.

- Testing, supplemented by model extrapolations will be used to define the variability of properties of the lithophysal rocks.

- This analysis will be included in two documents: a revision of Drift Degradation Analyses (BSC 2001) in FY 2003, and Fracture and Lithophysae Characteristics of the Repository Host Horizon in the first quarter of FY 2004.

\section{RDTME 3.06}

Provide the design sensitivity and uncertainty analyses of the rock support system. The DOE will prepare a scoping analysis to determine the significance of the input parameters for review by NRC staff by August 2002. Once an agreed set of significant parameters has been determined by the DOE and NRC staff, the DOE will prepare an analysis of the sensitivity and uncertainty of the preclosure rock support system to design parameters in a revision to Ground Control for Emplacement Drifts for SR, ANL-EBS-GE-000002 (or other document) supporting any potential license application. This is expected to be available to NRC in FY 2003.

\section{General Approach:}

Sensitivity studies of ground support will be conducted for non-lithophysal and lithophysal rocks using continuum and discontinuum numerical methods.

- Ground support requirements (maximum rockfall size, environmental conditions, longevity, etc.) developed as part of project System Design Description.

- Initial ground support methods will be defined empirically. Value Engineering studies will be used to determine candidate support methods for further analysis. 
- Input rock mass, fracture and support data parameters are derived from lab and in situ testing and numerical extrapolation, geologic mapping, in situ support testing, and literature - see discussion for RDTME 3.04 for a discussion of rock properties.

- Modeling sensitivity studies will be primarily discontinuum modeling using range of input properties and stress conditions in preclosure. Several methods will be used to examine support design, including direct modeling of the ground support, and use of the ground reaction curve method.

- Loading conditions in preclosure will include in situ, thermal and seismic stresses.

- Scoping analyses will be presented in Ground Control Analysis for Emplacement Drifts in the first quarter of FY 2004.

\section{RDTME 3.07}

The DOE should account for the effect of sustained loading on intact rock strength or provide justification for not accounting for it. The DOE will assess the effects of sustained loading on intact rock strength. The DOE will provide the results of this assessment in a design parameters analysis report (or other document), expected to be available to NRC in FY 2002.

General Approach:

The effect of sustained loading will be addressed through a combination of rock mechanics testing and numerical modeling. The following work is planned:

- Estimates of static fatigue strength of non-lithophysal and lithophysal rock samples will be determined from laboratory and limited time-scale in situ tests. Lab tests on 6 to 12 in. $(15.2$ to $30.5 \mathrm{~cm})$ diameter cores tested at about $90^{\circ} \mathrm{C}$. Load developed in steps from approx. 50 percent peak strength to 90 percent.

- Estimated time-to-failure will be determined as a function of percent of the uniaxial compression strength and will be used with modeled stresses to determine estimated time to failure for rock mass. Estimated time-to-failure can be incorporated into simple constitutive model to allow time-related degradation to occur.

- Joint shear strength degradation will be developed using static fatigue testing of non-lithophysal cores. The PFC model will be used to conduct numerical shear loading in which time-to-failure as a function of stress is accounted for in strength logic in model. Will estimate whether this mode of failure could have impact on long-term degradation in non-lithophysal materials.

- Will be addressed in the revision of Drift Degradation Analyses (BSC 2001) as longterm fatigue data becomes available. 


\section{RDTME 3.08}

Provide the design sensitivity and uncertainty analyses of the fracture pattern (with respect to Subissue 3, Component 1). The DOE will provide sensitivity and uncertainty analysis of fracture patterns (based on observed orientation, spacing, trace length, etc) on the preclosure ground control system design in a revision to Ground Control for Emplacement Drifts for SR, ANL-EBS-GE-000002 (or other document) supporting any potential license application. This is expected to be available to NRC in FY 2003.

\section{General Approach:}

A detailed analysis of the fracture patterns in the non-lithophysal and lithophysal rocks will be performed. Work effort will include:

- Data base will include existing ECRB and ESF detailed line surveys and full periphery mapping. These data include $1 \mathrm{~m}$ or longer trace lengths.

- Fracture geometry will be analyzed by using the FracMAN program to develop structural input to rockfall analysis and by creating a $100-\mathrm{m}$ cube representative fractured rock mass. Tunnel centroids within representative volume will be determined randomly.

- Back-checking output from FracMAN against actual detailed line survey statistics. Creating full periphery trace maps from FracMAN to check against actual maps for practical geologic check.

- Fracture geometries will be input to 3DEC discontinuum modeling package that defines block geometries from non-persistent fracture systems. 3DEC will be used to determine rock mass stability. Many runs with various fracture geometries will be conducted to determine sensitivity of preclosure response to fracture patterns.

- This work will be documented in two places: the revision of Drift Degradation Analyses (BSC 2001) in FY 2003, and Fracture and Lithophysae Characteristics of the Repository Host Horizon in the first quarter of FY 2004.

\section{RDTME 3.09}

Provide appropriate analysis that shows rock movements in the invert are either controlled or otherwise remain within the range acceptable to provide for retrieval and other necessary operations within the deposal drifts. DOE will provide appropriate analysis that shows rock movements in the floor of the emplacement drift are within the range acceptable for preclosure operations. The analysis results will be provided in a revision to Ground Control for Emplacement Drifts for SR, ANL-EBS-GE-000002 (or other document) supporting any potential license application. This is expected to be available to NRC in FY 2003. 


\section{General Approach:}

- Numerical modeling of excavation stability under in situ, thermal and seismic loading will examine deformation of the tunnel.

- An output of these studies will be drift periphery deformations, which will be examined with reference to opening performance specifications for emplacement operations and retrieval.

- Work will be documented in Ground Control Analysis for Emplacement Drifts in the first quarter of FY 2004.

\section{RDTME 3.10}

Provide technical basis for the assessment that two-dimensional modeling of emplacement drifts is considered to be adequate, considering the fact that neither the in-situ stress field nor the principle fracture orientation are parallel or perpendicular to emplacement drift orientation. The DOE will provide the technical bases for the modeling methods used in ground control analysis in a revision to Ground Control for Emplacement Drifts for SR, ANL-EBS-GE-000002 (or other document) supporting any potential license application. This is expected to be available to NRC in FY 2003.

\section{General Approach:}

- This assessment will be provided as part of the revision of Drift Degradation Analyses (BSC 2001) in FY 2003.

- Three-dimensional modeling will be used for rockfall and ground support studies in the non-lithophysal rocks as the mechanical response is expected to be fracture controlled, and thus three-dimensional and anisotropic.

- It will be justified that the lithophysal rock is effectively isotropic and homogenous due to the roughly uniform distribution of lithophysae within the unit. This results in ability to use two-dimensional models in this case.

\section{RDTME 3.11}

Provide continuum and discontinuum analyses of ground support system performance that take into account long-term degradation of rock mass and joint strength properties. The DOE will justify the preclosure ground support system design (including the effects of long-term degradation or rock mass and joint strength properties) in a revision to Ground Control for Emplacement Drifts for $S R, A N L-E B S-G E-000002$ (or other document) supporting any potential license application. This is expected to be available to NRC in FY 2003. 


\section{General Approach:}

- Both two-dimensional and three-dimensional discontinuum and continuum models will be used for rockfall and long-term strength degradation studies. It is questionable if the preclosure period ( 50 to perhaps as much as 300 years) is considered "long-term" in terms of strength degradation.

- See RDTME 3.07 above for description of strength degradation measurement strategy.

- The 3DEC, UDEC and PFC discontinuum programs and FLAC continuum programs will be used for thermomechanical calculations. Estimates of static fatigue effects on joint and rock mass strength will be accounted for in constitutive models for joints and the rock mass. It is assumed that ground support systems have preclosure functionality, and therefore long-term degradation does not necessarily impact ground support unless static fatigue testing indicates exceptionally short times to failure.

- Work will be documented in Ground Control Analysis for Emplacement Drifts in the first quarter of FY 2004.

\section{RDTME 3.12}

Provide dynamic analyses (discontinuum approach) of ground support system performance using site-specific ground motion history as input. The DOE will provide appropriate analyses to include dynamic analyses (discontinuum approach) of preclosure ground support systems, using site-specific ground motion time histories as input, in a revision to Ground Control for Emplacement Drifts for SR, ANL-EBS-GE-000002 (or other document) supporting any potential license application. This is expected to be available to NRC in FY 2003.

\section{General Approach}

- Approach to dynamic analysis of rockfall documented in the RDTME KTI Agreement Resolution Document.

- Both two-dimensional (UDEC, discontinuum, lithophysal) and three-dimensional (3DEC, discontinuum for non-lithophysal) dynamic analysis methods will be used for preclosure and postclosure rockfall analyses.

- Site-specific ground motions developed from Probabilistic Seismic Hazard Analyses for Fault Displacement and Vibratory Ground Motion at Yucca Mountain, Nevada (CRWMS M\&O 1998). The Appendix 7 meeting with NRC in August of 2002 described ground motion development methodology.

- Dynamic analyses will be completed for preclosure and postclosure time histories. Rockfall documented in terms of rock particle size distribution, velocity and impact location. 
- The results will be documented in the revision of Drift Degradation Analyses (BSC 2001) in FY 2003 and in Ground Control Analysis for Emplacement Drifts in the first quarter of FY 2004.

\section{RDTME 3.13}

Provide technical justification for boundary conditions used for continuum and discontinuum modeling used for underground facility design. The DOE will provide the technical justification for boundary conditions used in modeling for preclosure ground control analyses, in a revision to Ground Control for Emplacement Drifts for SR, ANL-EBS-GE-000002 (or other document) supporting any potential license application. This is expected to be available to NRC in FY 2003.

\section{General Approach:}

- Ground Control Analysis for Emplacement Drifts and the revision of Drift Degradation Analyses (BSC 2001) will have justification for boundary and initial conditions used in all modeling.

- Dynamic analyses will use site-specific ground motions as well as free field and nonreflecting boundaries.

- Initial conditions to dynamic analyses will include temperature from heating. Mountainscale three-dimensional topographic thermomechanical models will be used to define the thermally induced stress state for postclosure analyses.

- Temperature input to preclosure mechanical and ground support models will be derived from NUFT ventilation and thermal analysis programs used for LA thermal analysis.

\section{RDTME 3.15}

Provide field data and analysis of rock bridges between rock joints that are treated as cohesion in DRKBA modeling together with a technical basis for how a reduction in cohesion adequately accounts for thermal effects. The DOE will provide clarification of the approach and technical basis for how reduction in cohesion adequately accounts for thermal effects, including any additional applicable supporting data and analyses. Additionally, the adequacy of the cohesion reduction approach will be verified according to the approach described in Subissue 3, Agreement 22, of the Repository Design and Thermal-Mechanical Effects Technical Exchange. This will be documented in a revision to the Drift Degradation Analysis, ANL-EBS-MD-000027, expected to be available to NRC in FY 2003.

General Approach:

- Analyses of non-lithophysal rocks will be conducted with three-dimensional discontinuum analyses. 
- The fracture input to these models will be derived from simulated fracture networks developed from the FracMAN program. FracMAN will be used to develop statistically equivalent synthetic fracture networks based on field detailed line surveys and full periphery mapping in the ESF and ECRB. This method will automatically include nonpenetrating fracture planes, and thus the solid rock between joints will be defined statistically.

- 3DEC parametric analyses will be used to model and test assumption of both solid rock bridges and fully penetrating fractures to determine the level of non-conservatism in assuming solid, non-failing rock bridges.

- Laboratory shear tests on simulated non-lithophysal rock bridges will be conducted by USBR as a means of calibration of numerical models of rock bridge shear strength. The PFC and UDEC programs will be used to identify impact of rock bridges on shear and tension behavior of joints. The assumed shear strength derived from these studies will be used in numerical analysis for comparison to assumed partially penetrating and fully penetrating joints.

- The level of conservatism will be documented in the revision of Drift Degradation Analyses (BSC 2001), to be completed in FY 2003.

\section{RDTME 3.16}

Provide a technical basis for the DOE position that the method used to model joint planes as circular discs does not under-represent the smaller trace-length fractures. The DOE will analyze the available small trace-length fracture data from the Exploratory Studies Facility and Enhanced Characterization of the Repository Block, including their effect on block development. This will be documented in a revision to the Drift Degradation Analysis, ANL-EBS-MD000027 , expected to be available to NRC in FY 2003.

\section{General Approach:}

- As discussed in RDTME 3.08, FracMAN will be used for developing fracture geometries based on $1 \mathrm{~m}$ and greater trace length joints. Data for FracMAN is derived from fractures data base in ESF and ECRB.

- The FracMAN approach currently provides a centroid and radius of the fracture plane. The 3DEC model that utilizes this information allows the fractures to fully penetrate the block that it cuts (i.e., conservative assumptions can be made that over-estimate the trace length of the fractures).

- Parametric studies will be conducted to examine the level of non-conservatism that arises from the assumption of fractures with disc shapes. Additionally, synthetic full-periphery structure maps will be created from the FracMAN circular disc models and compared, empirically, to actual full periphery maps to ensure the fracture patterns are geologically reasonable. 
- Rockfall analyses in lithophysal rocks will determine block sizes empirically based on the density of ubiquitous, short trace length interlithophysal fracturing and the spacing of lithophysae. Density will be described in terms of fractures per cubic meter, leading to relatively small rock sizes. It will be established that the major large trace length fractures in the lithophysal rocks will not control block sizes.

- Documentation will be provided in the revision of Drift Degradation Analyses (BSC 2001) to be completed in FY 2003, and in Fracture and Lithophysae Characteristics of the Repository Host Horizon in the first quarter of FY 2004.

\section{RDTME 3.17}

Provide the technical basis for effective maximum rock size including consideration of the effect of variation of the joint dip angle. The DOE will provide the technical basis for effective maximum rock size including consideration of the effect of variation of the joint dip angle. This will be documented in revisions to Drift Degradation Analysis, ANL-EBS-MD-000027, and Rockfall on Drip Shield, CAL-EBS-ME-000001, expected to be available to NRC in FY 2003.

\section{General Approach:}

- The maximum rock size in the non-lithophysal rock will be determined directly from the 3DEC model, whose block geometry is determined from FracMAN simulated fracture networks. A large number of simulations will be conducted from probabilistically determined fracture networks that will be based on the mapped variability of fracture characteristics, including: dip and dip direction, trace length, centroid location, and spacing.

- Directional bias for dip of fractures will be accounted for in FracMAN simulations using Mauldon correction for non-persistent fractures.

- Maximum block sizes in the Tptpll will be determined empirically using observational data from the ECRB and ESF. These data will include:

- Density of ubiquitous fractures in terms of fractures per cubic meter

- Observations of block sizes during large diamond coring operations in ECRB

- Documentation will be provided in the revision of Drift Degradation Analyses (BSC 2001) to be completed in FY 2003.

\section{RDTME 3.19}

The acceptability of the process models that determine whether rockfall can be screened out from performance assessment abstractions needs to be substantiated by the DOE by doing the following: (1) provide revised DRKBA analyses using appropriate range of strength properties for rock joints from the Design Analysis 
Parameters Report, accounting for their long-term degradation; (2) provide an analysis of block sizes based on the full distribution of joint trace length data from the Fracture Geometry Analysis Report for the Stratigraphic Units of the Repository Host Horizon, including small joints trace lengths; (3) verify the results of the revised DRKBA analyses using: (a) appropriate boundary conditions for thermal and seismic loading; (b) critical fracture patterns from the DRKBA Monte Carlo simulations (at least two patterns for each rock unit); (c) thermal and mechanical properties for rock blocks and joints from the Design Analysis Parameters Report; (d) long-term degradation of rock block and joint strength parameters; and (e) site-specific ground motion time histories appropriate for postclosure period; provide a detailed documentation of the analyses results; and (4) in view of the uncertainties related to the rockfall analyses and the importance of the outcome of the analyses to the performance of the repository, evaluate the impacts of rockfall in performance assessment calculations. DOE believes that Drift Degradation Analysis is consistent with current understanding of the Yucca Mountain site and the level of detail of the design to date. As understanding of the site and the design evolve, DOE will: (1) provide revised $D R K B A$ analyses using appropriate range of strength properties for rock joints from a design parameters analysis report (or other document), accounting for their long-term degradation; (2) provide an analysis of block sizes based on the full distribution of joint trace length data from the Fracture Geometry Analysis for the Stratigraphic Units of the Repository Host Horizon, ANL-EBS-GE-000006, supplemented by available small joint trace length data; (3) verify the results of the revised DRKBA analyses using: (a appropriate boundary conditions for thermal and seismic loading; (b) critical fracture patterns from the DRKBA Monte Carlo simulations (at least two patterns for each rock unit); (c) thermal and mechanical properties for rock blocks and joints from a design parameters analysis report (or other document); (d) long-term degradation of joint strength parameters; and (e) site-specific ground motion time histories appropriate for postclosure period. This will be documented in a revision to Drift Degradation Analysis, ANL-EBS-MD-00027, expected to be available to NRC in FY 2003. Based on the results of the analyses above and subsequent drip shield calculation revisions, DOE will reconsider the screening decision for inclusion or exclusion of rockfall in performance assessment analysis. Any changes to screening decisions will be documented in analyses prior to any potential license application.

\section{General Approach:}

The keyblock approach is no longer being used as the primary method for drift degradation and rockfall analysis. Following is the revised methodology for rockfall analyses and drift degradation (details provided in Appendix B):

- 3DEC, three-dimensional discontinuum analyses (non-lithophysal rocks) will be conducted for the combination of in situ, thermal and seismic loading over the preclosure and postclosure periods. 
- The 3DEC analyses will be based on fracture and block geometries defined by analysis of the detailed line surveys and full periphery mapping from the ESF and ECRB. These data will feed the FracMAN program that will be used to define statistically equivalent rock mass fracture geometries that are, in turn, used as data input to the 3DEC, three-dimensional discontinuum program that will generate the block geometries.

- Fully dynamic analyses will be used to conduct a large number of probabilistic analyses (in which fracture geometry, site-specific ground motions, joint properties and trace length characteristics are varied) to derive a probability density function of rockfall sizes and shapes.

- UDEC, two-dimensional discontinuum analyses will be used to conduct rockfall and degradation studies resulting from in situ, thermal and seismic loading in the lithophysal rocks.

- An equivalent mechanical material model, using a finely discretized UDEC block geometry will be calibrated to the range of lithophysal rock mass properties as determined from laboratory and in situ compression testing. Mechanical properties will be directly related to lithophysal porosity and its variability. Model will allow rock mass failure, fracturing and rockfall.

- Parametric studies will be conducted for the full range of variability of the lithophysal rock mass properties.

- Site-specific ground motions will be applied to the models, based on hazard curves derived from Probabilistic Seismic Hazard Analyses for Fault Displacement and Vibratory Ground Motion at Yucca Mountain, Nevada (CRWMS M\&O 1998).

- These studies will provide rock size, shape and velocity to analyses of the drip shield as a function of time.

All of this work will be documented in the revision of Drift Degradation Analyses (BSC 2001), to be completed in FY 2003.

\section{A.2 REFERENCES}

\section{A.2.1. DOCUMENTS CITED}

BSC (Bechtel SAIC Company, LLC) 2001. Drift Degradation Analysis. ANL-EBS-MD000027 REV 01 ICN 01. Las Vegas, Nevada: Bechtel SAIC Company.

ACC: MOL.20011029.0311.

CRWMS M\&O (Civilian Radioactive Waste Management System Managing and Operating Contractor) 1998. Probabilistic Seismic Hazard Analyses for Fault Displacement and Vibratory Ground Motion at Yucca Mountain, Nevada. Milestone SP32IM3, September 23, 1998.

Three volumes. Las Vegas, Nevada: CRWMS M\&O. ACC: MOL.19981207.0393. 
APPENDIX B

THERMAL AND MECHANICAL ROCK PROPERTIES DATA BASE 


\section{INTENTIONALLY LEFT BLANK}




\section{APPENDIX B: THERMAL AND MECHANICAL ROCK PROPERTIES DATA BASE}

\section{B.1 LABORATORY PROPERTIES DATA BASE}

Over the past 22+ years a vast amount of data has been collected on the mechanical properties of the intact rock within Yucca Mountain, Nevada (Table B-1, Table B-2, and Table B-3). All of the studies were performed under the existing guidelines at the time, and, therefore, not all of the data were gathered under a qualified QA program (Table B-1). No matter what the pedigree of the data, we can, however, gain much insight from all of the data.

\section{B.1.1 MECHANICAL DATA}

In the late 1970's and through the mid-1980's, many samples were tested from units extending from the upper-most parts of the Paintbrush Tuff down through the lower regions of the Crater Flat Tuff. From the beginning, an approach was adopted to assign a baseline set of conditions and then study the effects of all other conditions (i.e., sample related, environmental and inherent rock characteristics) relative to that standard. Initially, samples were difficult to obtain, so the baseline conditions were defined as: each test specimen was machined as a right-circular-cylinder, with a nominal diameter of $25 \mathrm{~mm}$ (1 in.) and a 2:1 length:diameter ratio, and tested in a water-saturated state at room temperature, atmospheric pressure, and a nominal axial strain rate of $10^{-5} \mathrm{~s}^{-1}$. The results from these test series (Olsson and Jones 1980; Nimick et al. 1985; Price and Jones 1982; Price, Jones, and Nimick 1982; Price and Nimick 1982; Price, Nimick and Zirzow 1982; Price, Spence, and Jones 1984) revealed that there is some lateral (i.e., within a unit) and vertical (i.e., unit to unit) variability. However, the variabilities in the elastic and strength properties of the tuffs (all having similar chemical constituents) are predominantly a function of the tuff porosity (Figure B-1, Price 1983 and Price and Bauer 1985). In addition, while it is not a significant factor within the Topopah Spring Member tuffs, in a broader sense the relationships were found to be stronger when the properties were fit to functional porosity-defined as pore space plus the volume fraction of montmorillonite, a very low strength clay mineral (Price and Bauer 1985) illustrates this relationship. In addition, some of the data also helped in the early understanding of the effects of changes in saturation, temperature, pressure, and rate (Price 1983).

Beginning in the mid-1980's, effort was concentrated on the Topopah Spring Member tuff, and specifically on the unit referred to today as the middle Tptpmn, which was considered at that time to be the target horizon for the potential repository. Because of the larger inhomogeneities in the welded tuffs of the Topopah Spring Member, the size of the baseline samples was increased to nominally $51 \mathrm{~mm}$ ( $2 \mathrm{in}$.) in diameter. The remainder of the baseline conditions remained the same. The studies also began to incorporate some detailed information on the petrology and pore distribution of both the lithophysal and nonlithophysal zones (Price et al. 1985 and Price, Connolly, and Keil 1987, respectively). These studies determined that the most predominant secondary factor in the scatter of the plots of strength or Young's modulus vs. porosity is the distribution of the porosity. In Busted Butte samples of the middle nonlithophysal zone, the vast majority of pores were found to be intergranular openings (usually less than $5 \mu \mathrm{m}$ across) (Price, Connolly and Keil 1987). In general for the welded tuffs, a study on Busted Butte samples of the upper lithophysal zone found that there are four size classes of pores (Figure B-2). They are: large lithophysal cavities (few millimeters on up), small pores in the 
vapor-phased-altered zones (up to $0.2 \mathrm{~mm}$ ), intergranular pores in vapor-phased-altered zones (in the range of $1-5 \mu \mathrm{m}$, and $0.2 \mathrm{~mm}$ ), intergranular pores in vapor-phased-altered zones (in the range of $1-5 \mu \mathrm{m}$ ), and submicroscopic intergranular pores in the devitrified matrix (smaller than $1 \mu \mathrm{m})$ (Price et al. 1985).

The next key study (Price 1986) examined the effect of sample size on the elastic and strength properties of the middle nonlithophysal zone of the Topopah Spring tuff (Figure B-3). Sometime later a model relating strength, sample size and functional porosity was developed (Price 1993) from these data in combination with the early fits of strength vs. functional porosity.
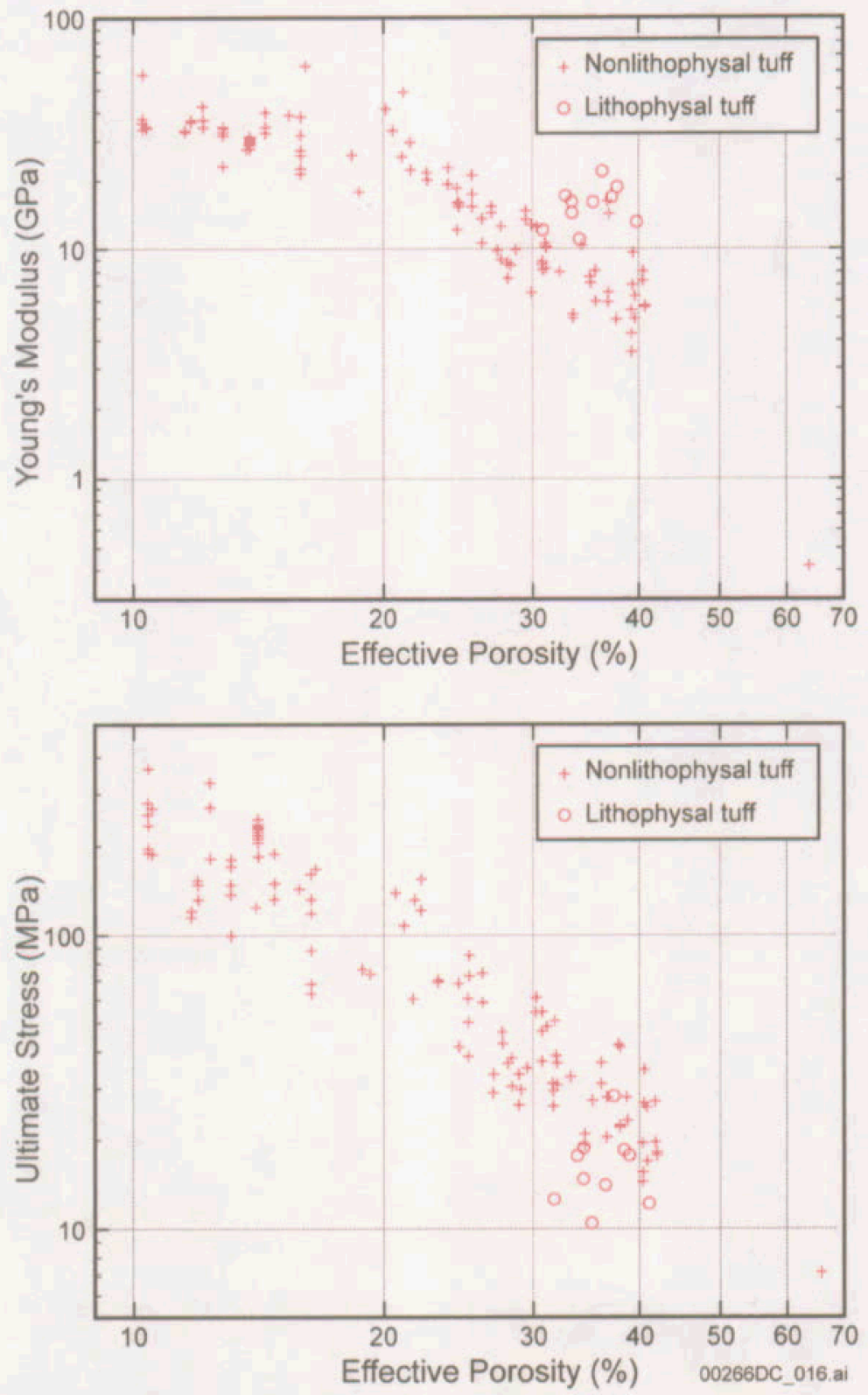

Source: Price et al. 1985.

Figure B-1. Intact Rock Modulus and Strength as a Function of Effective Porosity 


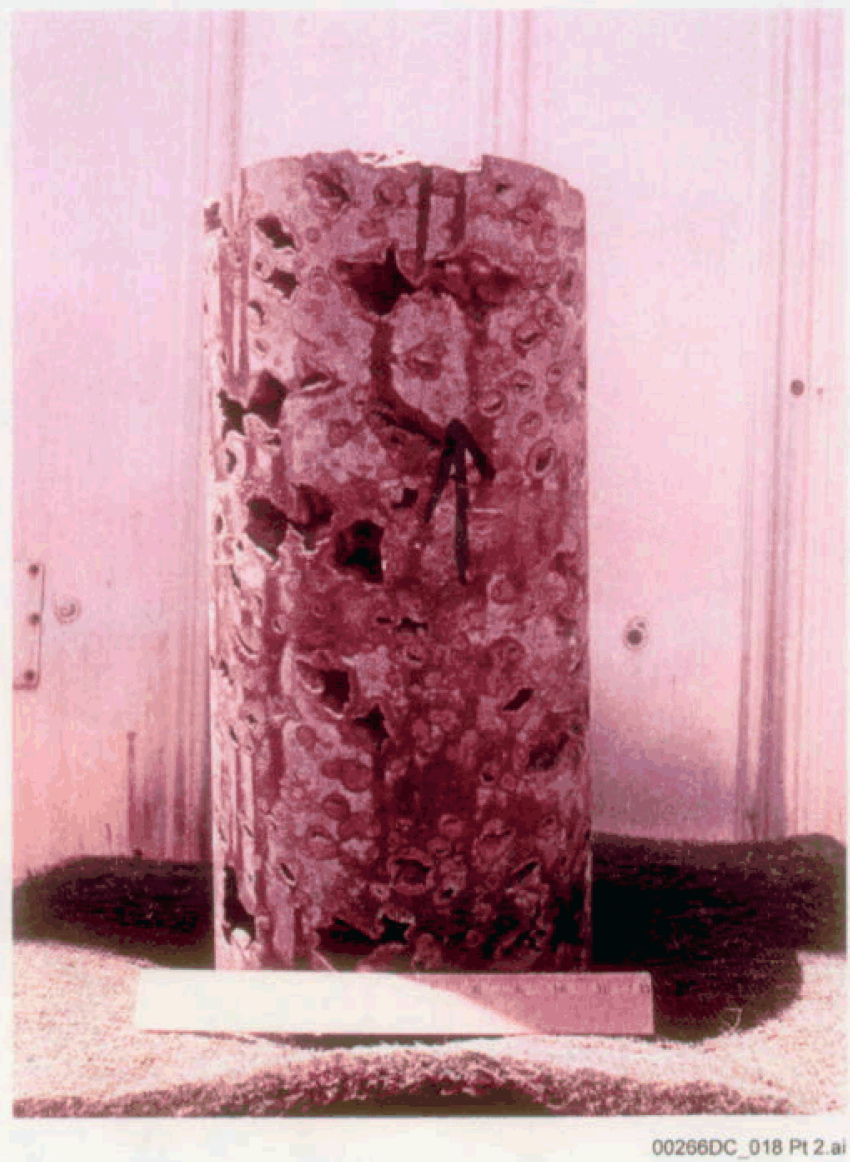

\section{Source: Price et al. 1985}

Figure B-2. Photograph of Busted Butte Sample from the Upper Lithophysal Zone (Tptpul)

During the early to mid-1990's, techniques were formalized (e.g., Boyd, Martin and Price 1994; Martin et al. 1991; Price, Martin and Haupt 1994) and data were collected under a qualified QA program. Most of the data from this period of time were published in a series of data reports (Boyd, Martin, and Price 1995; Boyd et al. 1996a and 1996b; Martin et al. 1994 and 1995; Martin, Noel, Boyd, and Price 1997a). In addition to the standard reporting of elastic and strength properties, these reports present detailed bulk properties (e.g., average grain density, bulk density, porosity), compression- and shear-wave velocity measurements, and CT (computerized tomography) scans on the samples. Analyses (Price et al. 1994 and 1996) showed that the relationships between elastic and strength properties vs. porosity were very similar for these data on larger samples (with the baseline diameter of $51 \mathrm{~mm}$ ) to those found earlier on the smaller samples (with the baseline diameter of $25 \mathrm{~mm}$ ). The only significant change was a shift downward (i.e., lower) in the strength data, which would be expected because of the larger sample size (Figure B-4).

During this same time span, some studies have focused on the inherent mechanical property characteristics, as well as the effects of changes in many environmental conditions on the mechanical properties of the intact tuffs. For example, many data have been collected showing that the anisotropy in velocity measurements is almost universally less than 10 percent. The results of a specific study on this effect revealed a velocity anisotropy of about 7 percent (Martin 
et al. 1992), which is a relatively minor effect with respect to the natural scatter in the tuff data, in general.

The attenuation properties of the nonlithophysal tuffs were also examined (Haupt et al. 1992; Price, Martin and Haupt 1994). Extensional attenuation was found to be virtually unaffected by frequency (for dry samples) or strain amplitude changes (for both dry and saturated samples). However, attenuation did increase with increasing frequency for the saturated samples.

The collecting of CT scans has provided information in addition to that collected in the mid-1980's for the study on the distribution of porosity within the Topopah Spring tuffs. An initial analysis (Price, Martin and Boyd 1993) relating qualities observed on the CT scans to the Young's modulus and ultimate strength of nonlithophysal tuff samples produced good correlations.

Many studies have shown strong relationships between static Young's modulus and effective porosity and ultimate strength and effective porosity. In order to investigate whether the dynamic properties showed the same types of relationships or not, the results from a series of samples were analyzed (Price et al. 1994). Initially, velocity measurements were taken, dynamic Young's moduli were calculated, and then the samples were tested at the baseline set of conditions. Both the P-wave velocities and the dynamic Young's moduli showed similar correlation with porosity, as do the static Young's moduli. Furthermore, in a direct comparison of the static and dynamic Young's moduli, the dynamic moduli are consistently higher in value than the static moduli. This result was not surprising, because this is the normal relationship between static and dynamic moduli for brittle materials.

Several studies (Martin et al. 1993a, 1993b, 1995; Martin, Noel, Boyd, and Price 1997b and 1997c) have produced indications that the strength properties of the tuffs are somewhat time dependent. Except at very fast rates of deformation (i.e., an axial strain rate of $10^{-3} \mathrm{~s}^{-1}$ ), the strengths of the tuffs were found to decrease with decreasing strain rate (from $10^{-5} \mathrm{~s}^{-1}$ to $10^{-9} \mathrm{~s}^{-1}$ ), although the average change was relatively minor (about a 10 percent decrease in strength per decade change in strain rate). In addition, constant stress (creep) experiments at fairly high stresses (most tests at $100 \mathrm{MPa}$ and higher) resulted in very little strain accumulating after several million seconds. In one study on Topopah Spring tuffs from Busted Butte (having an average quasi-static, unconfined compression strength of nearly $150 \mathrm{MPa}$ ), the fit of the data from static fatigue tests predicts that under a constant load of $100 \mathrm{MPa}$, the rock would fail in $7.1 \times 10^{9}$ years.

In summary, a large amount of data has been collected to date on tuffaceous samples from Yucca Mountain at a baseline set of conditions. These data have shown that the variabilities in elastic and strength properties are not a function of lateral or vertical position, but primarily a function of porosity. In stratigraphic zones that contain montmorillonite (a very weak clay material), the fits are improved by adding the volume of this mineral to the porosity and calling this quantity functional porosity. Even though there are excellent trends in the Young's modulus, strength, and compression velocity data when plotted against porosity, the data has a significant scatter to it. The secondary effect that is creating the scatter is the distribution of the porosity. Other investigations have examined the effects of many other conditions (i.e., sample related, environmental and inherent rock characteristics); for example, sample size, saturation, pressure, 
temperature, deformation rate, attenuation, anisotropy have all been studied. In conclusion, the intact rock mechanical property information collected over the last two decades has provided a good understanding of many aspects of the behavior of Yucca Mountain tuffs. However, the data set available for licensing type activities would be more complete with the collection of some additional data on several issues within the requirements of a qualified QA program. A few of the major issues needing additional data include studying the effects of lithophysal cavities, sample size, and constant stress loading.

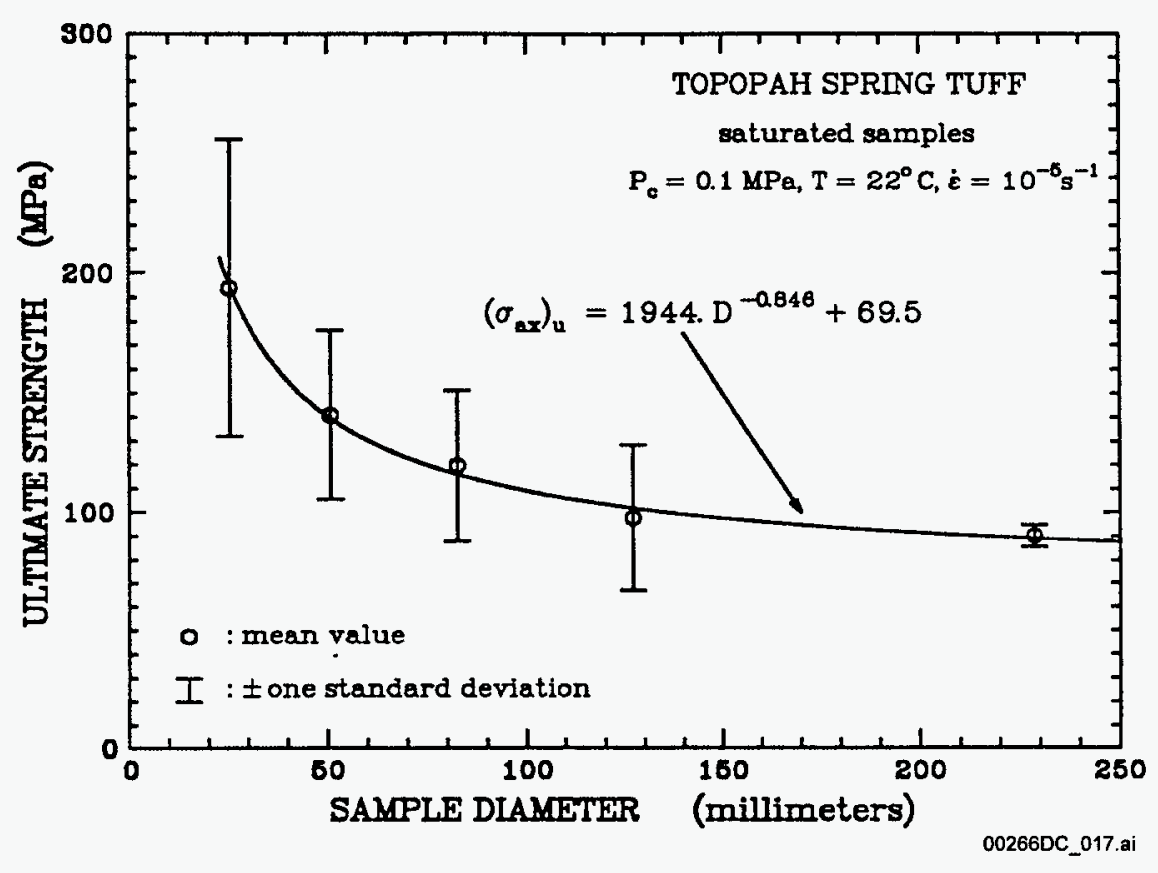

Source: Price 1986.

Figure B-3. Effect of Sample Size on the Uniaxial Compressive Strength of Welded Tuff from the Middle Nonlithophysal Zone (Tptpmn) 

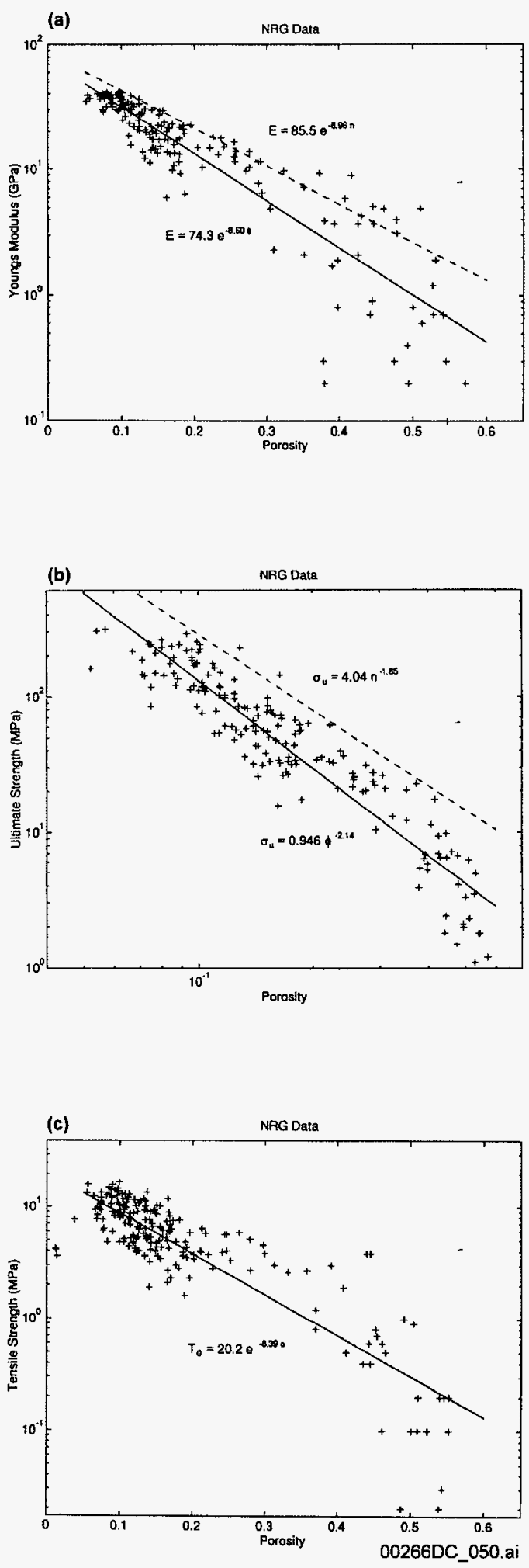

Source: Price et al. 1996.

Figure B-4. Modulus (a), Compressive Strength (b), and Tensile Strength (c) as Functions of Porosity 


\section{B.1.2 THERMAL DATA}

A significant amount of thermal properties data have also been collected since the early 1980 's. Primary parameters of interest are thermal conductivity, thermal capacity, and thermal expansion. Thermal properties are largely a function of mineralogy, and so a phenomenological understanding of these properties requires that mineralogy be determined. The most complete data sets of thermal properties data from the repository horizon as well as units above and below were developed from specimens taken from four boreholes drilled along the North Ramp of the Exploratory Studies Facility (boreholes UE25 NRG-4, UE25 NRG-5, USW NRG-6, and USW NRG-7/7A). A total of 143 thermal conductivity tests, 132 thermal expansion tests, and 10 specific heat tests were conducted from specimens taken from various horizons in theses boreholes. Thermal expansion and thermal conductivity tests were also performed on test specimens taken from Alcoves 5 and 7 within the Exploratory Studies Facility (ESF). In these tests, specimens were oriented orthogonally and so anisotropy as well as lateral variability of thermal properties could be measured. Results from all thermal tests show very limited evidence of lateral variability and anisotropy within each tuff unit.

Standard test conditions for thermal conductivity measurements included four saturation levels: vacuum saturated, partially saturated, air-dried (no effort was made to preserve or alter the moisture content), and oven-dried. Thermal expansion test specimens were either air-dried, oven-dried, or vacuum saturated. All specific heat measurements were made on air-dried specimens. Tests were conducted at room pressure and at temperatures between $25^{\circ} \mathrm{C}$ and $300^{\circ} \mathrm{C}$. Because many specimens were tested at multiple saturation states, there are more tests than test specimens. Thermal conductivity, thermal expansion, specific heat, and X-ray diffraction measurement methods are discussed in detail in Brodsky et al. 1997. The thermal properties measurements were made by the Testing Services Division of Holometrix, Inc. and the X-ray diffraction measurements were conducted at the University of New Mexico.

The thermal conductivity data from the NRG boreholes are summarized in Table B-1. Data are consistent with previous values reported in Nimick (1989) which includes both published and previously unpublished results. Thermal conductivities measured on saturated specimens exceeded those measured on dried specimens. For dried specimens, conductivity is essentially constant with increasing temperature. For saturated specimens, conductivities sometimes increased and sometimes decreased with increasing temperature. Decreases in thermal conductivity in specimens containing moisture may be affected by specimen dehydration. There were no consistent differences in thermal conductivities among the boreholes and so the data were averaged together. PTn consistently shows the lowest conductivities while the TCW and TSw2 units have the highest conductivity values. TSw1 specimens span a larger range of thermal conductivity and are intermediate in value. These data show that there is no substantial temperature dependence. 
Table B-1. Low Temperature $\left(<100^{\circ} \mathrm{C}\right)$ Rock Thermal Conductivities ${ }^{(a)}$

\begin{tabular}{|c|c|c|c|c|c|c|c|c|c|c|c|c|}
\hline \multirow[b]{3}{*}{$\begin{array}{c}\text { Thermal/ } \\
\text { Mechanical } \\
\text { Unit }\end{array}$} & \multicolumn{12}{|c|}{ Thermal Conductivity ( $\mathrm{W} / \mathrm{mK})$} \\
\hline & \multicolumn{3}{|c|}{ Saturated } & \multicolumn{3}{|c|}{ Partially Saturated } & \multicolumn{3}{|c|}{ Air Dry } & \multicolumn{3}{|c|}{ Dry } \\
\hline & $\begin{array}{c}\text { Sample } \\
\text { Mean }\end{array}$ & \begin{tabular}{|l|} 
Sample \\
Standard \\
Deviation \\
\end{tabular} & $\begin{array}{c}\text { Sample } \\
\text { Count }\end{array}$ & $\begin{array}{c}\text { Sample } \\
\text { Mean }\end{array}$ & $\begin{array}{l}\text { Sample } \\
\text { Standard } \\
\text { Deviation }\end{array}$ & $\begin{array}{c}\text { Sample } \\
\text { Count }\end{array}$ & $\begin{array}{c}\text { Sample } \\
\text { Mean }\end{array}$ & \begin{tabular}{|l} 
Sample \\
Standard \\
Deviation \\
\end{tabular} & $\begin{array}{c}\text { Sample } \\
\text { Count }\end{array}$ & $\begin{array}{c}\text { Sample } \\
\text { Mean } \\
\end{array}$ & \begin{tabular}{|l|} 
Sample \\
Standard \\
Deviation \\
\end{tabular} & $\begin{array}{c}\text { Sample } \\
\text { Count }\end{array}$ \\
\hline TCw & 1.89 & 0.12 & 18 & 1.39 & 0.56 & 18 & 1.58 & 0.16 & 9 & 1.17 & 0.35 & 18 \\
\hline PTn & 0.92 & 0.13 & 42 & 0.57 & 0.12 & 33 & 0.35 & 0.13 & 12 & 0.38 & 0.10 & 49 \\
\hline TSw1 & 1.70 & 0.19 & 50 & 1.23 & 0.46 & 11 & 1.21 & 0.12 & 30 & 0.98 & 0.26 & 59 \\
\hline TSw2 & 2.29 & 0.42 & 51 & ND & ND & ND & 1.66 & 0.10 & 24 & 1.50 & 0.44 & 48 \\
\hline
\end{tabular}

(a) ND: No Data. "Sample" refers to the number of test measurements, not the number of specimens tested. Measurements were made during both heating and cooling for some specimens.

Table B-2. High Temperature $\left(>100^{\circ} \mathrm{C}\right)$ Rock Thermal Conductivities ${ }^{(a)}$

\begin{tabular}{|l|c|c|c|}
\hline \multirow{2}{*}{$\begin{array}{c}\text { Thermal/ } \\
\begin{array}{c}\text { Mechanical } \\
\text { Unit }\end{array}\end{array}$} & \multicolumn{3}{|c|}{ Thermal Conductivity (W/mK) } \\
\cline { 2 - 4 } & Sample Mean & $\begin{array}{c}\text { Sample } \\
\text { Standard } \\
\text { Deviation }\end{array}$ & $\begin{array}{c}\text { Sample } \\
\text { Count }\end{array}$ \\
\hline TCw & 1.53 & 0.17 & 57 \\
\hline PTn & 0.42 & 0.14 & 102 \\
\hline TSw1 & 1.15 & 0.15 & 173 \\
\hline TSw2 & 1.59 & 0.10 & 125 \\
\hline
\end{tabular}

"Sample" refers to the number of test measurements, not the number of specimens tested. Measurements were made during both heating and cooling for some specimens.

Attempts have been made to correlate thermal conductivity with an easily measured physical property such as porosity. Figure B-5 shows thermal conductivities obtained at $30^{\circ} \mathrm{C}$ on oven dry specimens plotted vs. porosity. Both the Woodside and Messmer (1961) and the Brailsford and Major (1964) equations, which predict this relationship, are shown. The models were fitted to the data as follows. Based on the measured saturation and porosity of each specimen, the matrix conductivity (i.e., conductivity at zero porosity) for each specimen was calculated for each model. These matrix conductivities were then averaged for each model to obtain the conductivity at zero porosity. The change in conductivity with increasing porosity was then calculated directly from each model. Unfortunately, lithologies also change with increasing porosity and so it is difficult to isolate the effects of changing one variable. The TSw2 data appear to cluster into three groups. The high and low thermal conductivity groups are both from NRG-5 and include the Tptpmn lithostratigraphic unit (Buesh et al. 1996). The intermediate thermal conductivity group is from NRG-6 and includes both the Tptpmn and Tptpln lithostratigraphic units.

The mean coefficients of thermal expansion (MCTE) are summarized in Table B-3 for heating. Similar data exist for the cooling cycles. Within each table, the information is grouped according to $\mathrm{T} / \mathrm{M}$ unit and moisture content. 


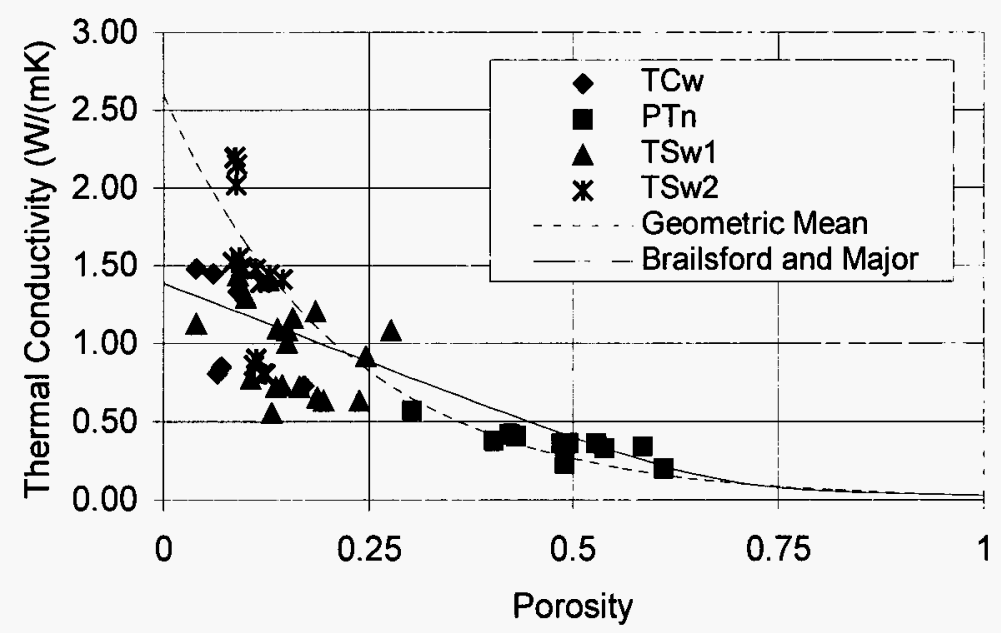

Figure B-5. Thermal Conductivity vs. Porosity for Oven-Dried Specimens from NRG Boreholes

As shown in Table B-3, MCTEs are highly temperature dependent. The strains increase (expansion is positive) for both tuffs until a "transition temperature" of approximately $150^{\circ}$ to $225^{\circ} \mathrm{C}$ is reached. In both cases, the strain-versus-temperature curves then become more highly nonlinear; however, the slope increases for the welded specimen while it decreases for the nonwelded specimen. For the welded specimens, thermal expansion was independent of saturation state; however, thermal strains did depend upon saturation for the nonwelded rocks (Brodsky et al. 1997).

The increase in thermal strains between $150^{\circ} \mathrm{C}$ and $225^{\circ} \mathrm{C}$ (the "transition temperature" range) observed for many of the welded devitrified specimens is likely to be due to phase transitions in the constituent minerals of tridymite and cristobalite. These minerals occur, with or without quartz, as primary devitrification products in many samples of Yucca Mountain welded tuffs. Phase transitions in synthetic tridymite occur at approximately $117^{\circ} \mathrm{C}$ and $163^{\circ} \mathrm{C}$, and in synthetic cristobalite at approximately $272^{\circ} \mathrm{C}$ (Papike and Cameron 1976), and involve notable changes in volume. Phase transition temperatures have been shown to vary significantly due to lattice variations found in natural occurrences of these minerals which are usually mixed phase material (Thompson and Wennemer 1979). Previous and current work on the mineralogy of welded tuff from TCw, TSw1, TSw2, and TSw3 suggest that these mixed phase assemblages are dominant. Hysteresis is associated with the phase.changes because the phases invert at higher temperature during heating than during cooling. The irreversible expansion may be a consequence of incomplete phase inversion on cooling.

For the nonwelded specimens, some of the strain decrease (near $100^{\circ} \mathrm{C}$ ) is attributable to loss of pore water, but most of the irreversible strain is probably a consequence of dehydration of perlitic volcanic glass and clay minerals at elevated temperatures which results in a permanent volume decrease.

Some specimens that displayed sensitivity to transition temperature were analyzed to assess the role of the maximum test temperature. Specimens from approximately the same depth (i.e., from the same piece of original core) were tested to different temperatures. The results showed that as 
long as the maximum test temperature remained below the transition temperature, the specimens did not permanently change dimension (i.e., no hysteresis was evident). The specimens expanded during the heating phase along a nearly linear curve and contracted during cooling along the same curve, with no discontinuity. These tests indicated that the transition temperatures probably caused physical changes in tuff that altered the expansion characteristics. The maximum temperature to which the specimens were exposed affected the magnitude of the hysteresis in the strain-versus-temperature curves.

Table B-3. Mean Coefficient of Thermal Expansion During Heat-Up

\begin{tabular}{|c|c|c|c|c|c|c|c|c|c|c|c|c|}
\hline \multirow[t]{2}{*}{\begin{tabular}{c|} 
Saturation \\
State
\end{tabular}} & \multirow[t]{2}{*}{ Statistics $^{(a)}$} & \multicolumn{11}{|c|}{ Mean CTE on Heat-up $\left(10^{-6} /{ }^{\circ} \mathrm{C}\right)$} \\
\hline & & $\begin{array}{c}25- \\
50^{\circ} \mathrm{C} \\
\end{array}$ & $\begin{array}{c}50- \\
75^{\circ} \mathrm{C} \\
\end{array}$ & $\begin{array}{c}75- \\
100^{\circ} \mathrm{C} \\
\end{array}$ & $\begin{array}{c}100- \\
125^{\circ} \mathrm{C} \\
\end{array}$ & $\begin{array}{c}125- \\
150^{\circ} \mathrm{C} \\
\end{array}$ & $\begin{array}{c}150- \\
175^{\circ} \mathrm{C}\end{array}$ & $\begin{array}{c}175- \\
200^{\circ} \mathrm{C} \\
\end{array}$ & $\begin{array}{r}200- \\
225^{\circ} \mathrm{C} \\
\end{array}$ & $\begin{array}{c}225- \\
250^{\circ} \mathrm{C} \\
\end{array}$ & $\begin{array}{c}250- \\
275^{\circ} \mathrm{C} \\
\end{array}$ & $\begin{array}{c}275- \\
300^{\circ} \mathrm{C} \\
\end{array}$ \\
\hline \multirow[t]{3}{*}{ Saturated } & Mean & 7.09 & 7.62 & 8.08 & 10.34 & 13.17 & 15.20 & 16.99 & 18.99 & 21.38 & 27.42 & 42.99 \\
\hline & Std. Dev. & 0.43 & 0.15 & 0.50 & 1.52 & 1.23 & 1.57 & 1.41 & 0.96 & 1.23 & 1.94 & 37.35 \\
\hline & Count & 4 & 4 & 4 & 4 & 4 & 4 & 4 & 3 & 3 & 3 & 3 \\
\hline \multirow[t]{4}{*}{ Dry } & Mean & 6.60 & 8.29 & 9.62 & 10.53 & 12.69 & 14.90 & 17.03 & 20.68 & 29.64 & 36.49 & 49.15 \\
\hline & Std. Dev. & 1.49 & 0.99 & 1.06 & 1.60 & 1.55 & 1.91 & 2.31 & 5.41 & 21.88 & 16.97 & 34.24 \\
\hline & Count & 10 & 10 & 10 & 7 & 7 & 7 & 7 & 7 & 7 & 7 & 7 \\
\hline & & $\begin{array}{c}25- \\
50^{\circ} \mathrm{C}\end{array}$ & $\begin{array}{c}50- \\
75^{\circ} \mathrm{C}\end{array}$ & $\begin{array}{c}75- \\
100^{\circ} \mathrm{C}\end{array}$ & $\begin{array}{c}100- \\
125^{\circ} \mathrm{C} \\
\end{array}$ & $\begin{array}{c}125- \\
150^{\circ} \mathrm{C}\end{array}$ & $\begin{array}{c}150- \\
175^{\circ} \mathrm{C}\end{array}$ & $\begin{array}{r}175- \\
200^{\circ} \mathrm{C} \\
\end{array}$ & $\begin{array}{r}200- \\
225^{\circ} \mathrm{C} \\
\end{array}$ & $\begin{array}{c}225- \\
250^{\circ} \mathrm{C} \\
\end{array}$ & $\begin{array}{c}250- \\
275^{\circ} \mathrm{C}\end{array}$ & $\begin{array}{c}275- \\
300^{\circ} \mathrm{C}\end{array}$ \\
\hline \multirow[t]{3}{*}{ Saturated } & Mean & 4.46 & 4.28 & -1.45 & -30.42 & 5.54 & 4.47 & 0.64 & -4.65 & -9.79 & -13.46 & -12.96 \\
\hline & Std. Dev. & 0.38 & 1.61 & 3.63 & 21.47 & 0.41 & 0.79 & 1.03 & 4.05 & 7.85 & 11.12 & 12.90 \\
\hline & Count & 4 & 4 & 4 & 4 & 3 & 3 & 3 & 2 & 2 & 2 & 2 \\
\hline \multirow[t]{4}{*}{ Dry } & Mean & 4.55 & 4.24 & 3.36 & -4.78 & 6.46 & 5.69 & 3.61 & 0.56 & -2.98 & -5.81 & -7.25 \\
\hline & Std. Dev. & 0.74 & 1,46 & 2,40 & 11.12 & 0.98 & 1.41 & 2.58 & 5.81 & 9.12 & 11.36 & 10.80 \\
\hline & Count & 12 & 12 & 12 & 10 & 10 & 10 & 10 & 10 & 10 & 10 & 10 \\
\hline & & $\begin{array}{c}25- \\
50^{\circ} \mathrm{C} \\
\end{array}$ & $\begin{array}{c}50- \\
75^{\circ} \mathrm{C} \\
\end{array}$ & $\begin{array}{c}75- \\
100^{\circ} \mathrm{C}\end{array}$ & $\begin{array}{c}100- \\
125^{\circ} \mathrm{C}\end{array}$ & $\begin{array}{r}125- \\
150^{\circ} \mathrm{C} \\
\end{array}$ & $\begin{array}{c}150- \\
175^{\circ} \mathrm{C} \\
\end{array}$ & $\begin{array}{r}175- \\
200^{\circ} \mathrm{C} \\
\end{array}$ & $\begin{array}{c}200- \\
225^{\circ} \mathrm{C} \\
\end{array}$ & $\begin{array}{c}225- \\
250^{\circ} \mathrm{C} \\
\end{array}$ & $\begin{array}{r}250- \\
275^{\circ} \mathrm{C} \\
\end{array}$ & $\begin{array}{c}275- \\
300^{\circ} \mathrm{C} \\
\end{array}$ \\
\hline \multirow[t]{3}{*}{ Saturated } & Mean & 6.56 & 7.32 & 6.83 & 6.92 & 10.72 & 14.28 & 20.98 & 36.82 & 41.64 & 42.76 & 43.81 \\
\hline & Std. Dev. & 1.16 & 0.60 & 1.60 & 3.28 & 1.74 & 3.26 & 7.01 & 20.49 & 17.35 & 13.19 & 13.65 \\
\hline & Count & 10 & 10 & 10 & 10 & 10 & 9 & 9 & 8 & 8 & 8 & 8 \\
\hline \multirow[t]{4}{*}{ Dry } & Mean & 6.29 & 7.60 & 8.39 & 8.96 & 10.37 & 15.51 & 23.67 & 34.24 & 34.00 & 36.07 & 38.74 \\
\hline & Std. Dev. & 1.22 & 1.02 & 0.89 & 1.20 & 1.38 & 4.53 & 11.07 & 20.30 & 13.70 & 13.23 & 13.78 \\
\hline & Count & 33 & 33 & 33 & 28 & 28 & 27 & 26 & 25 & 25 & 25 & 25 \\
\hline & & $\begin{array}{c}25- \\
50^{\circ} \mathrm{C} \\
\end{array}$ & $\begin{array}{c}50- \\
75^{\circ} \mathrm{C}\end{array}$ & $\begin{array}{c}75- \\
100^{\circ} \mathrm{C}\end{array}$ & $\begin{array}{c}100- \\
125^{\circ} \mathrm{C}\end{array}$ & $\begin{array}{c}125- \\
150^{\circ} \mathrm{C} \\
\end{array}$ & $\begin{array}{r}150- \\
175^{\circ} \mathrm{C} \\
\end{array}$ & $\begin{array}{r}175- \\
200^{\circ} \mathrm{C} \\
\end{array}$ & $\begin{array}{c}200- \\
225^{\circ} \mathrm{C} \\
\end{array}$ & $\begin{array}{c}225- \\
250^{\circ} \mathrm{C}\end{array}$ & $\begin{array}{r}250- \\
275^{\circ} \mathrm{C} \\
\end{array}$ & $\begin{array}{c}275- \\
300^{\circ} \mathrm{C}\end{array}$ \\
\hline \multirow[t]{3}{*}{ Saturated } & Mean & 7.14 & 7.47 & 7.46 & 9.07 & 9.98 & 11.74 & 13.09 & 15.47 & 19.03 & 25.28 & 37.19 \\
\hline & Std. Dev. & 0.65 & 1.51 & 1.21 & 2.41 & 0.77 & 1.28 & 1.40 & 1.75 & 3.09 & 6.87 & 14.27 \\
\hline & Count & 19 & 19 & 19 & 19 & 19 & 19 & 19 & 16 & 16 & 16 & 16 \\
\hline \multirow[t]{3}{*}{ Dry } & Mean & 6.67 & 8.31 & 8.87 & 9.37 & 10.10 & 10.96 & 12.22 & 14.52 & 20.79 & 25.13 & 35.13 \\
\hline & Std. Dev. & 1.20 & 0.42 & 0.40 & 0.55 & 0.88 & 1.16 & 1.50 & 2.57 & 17.03 & 10.07 & 14.56 \\
\hline & Count & 40 & 40 & 40 & 40 & 40 & 38 & 38 & 35 & 35 & 35 & 35 \\
\hline
\end{tabular}

Std. Dev,$=$ standard deviation. 
All of the thermal expansion data presented in Table 4-3 were obtained at ambient pressure. Mineralogical phase changes are pressure sensitive and the temperatures at which these transitions occur increase with pressure. Additionally, pressure will suppress volume expansion within fractures and voids. A suite of confined thermal expansion tests was therefore conducted to determine if strain hysteresis and transition temperature effects would be suppressed by elevated pressures. These tests are discussed in detail in Thermal Expansion of the Paintbrush Tuff Recovered from Borehole USW SD-12 at Pressures $30 \mathrm{MPa}$ : Data Report (Martin et al. 1997). This report concluded that pressure effects for specimens tested between 1 and $30 \mathrm{MPa}$ were very small, so data from these pressures were averaged together.

Thermal capacitance data from the NRG boreholes are summarized in Table B-4. Thermal capacitance is higher for TSw2 than for TSw1. All specimens show a localized peak in thermal capacitance at $150^{\circ} \mathrm{C}-170^{\circ} \mathrm{C}$. In general, thermal capacitance increases monotonically until this temperature range is reached. For all TSw1 specimens and some TSw2 specimens, thermal capacitance then decreases slightly with increasing. Above $150^{\circ} \mathrm{C}-170^{\circ} \mathrm{C}$, other $\mathrm{TSw} 2$ specimens show initial decreases in thermal capacitance followed by nearly constant values.

Table B-4. Thermal Capacitance ( $\rho \cdot C p)$ of Topopah Spring Tuff

\begin{tabular}{|c|c|c|c|c|c|c|c|}
\hline \multicolumn{4}{|c|}{ TSw1 } & \multicolumn{4}{|c|}{ TSw2 } \\
\hline $\begin{array}{c}\text { Temperature } \\
\left({ }^{\circ} \mathrm{C}\right)\end{array}$ & $\begin{array}{l}\text { Mean } \rho \cdot C p \\
\left(J \cdot \mathrm{cm}^{-3} \cdot \mathrm{K}^{-1}\right)\end{array}$ & $\begin{array}{r}\text { Standard } \\
\text { Deviation } \\
\left(\mathrm{J} \cdot \mathrm{cm}^{-3} \cdot \mathrm{K}^{-1}\right)\end{array}$ & $\begin{array}{l}\text { No. of } \\
\text { Tests }\end{array}$ & $\begin{array}{c}\text { Temperature } \\
\left({ }^{\circ} \mathrm{C}\right)\end{array}$ & $\begin{array}{l}\text { Mean } \rho \cdot C p \\
\left(J \cdot \mathrm{cm}^{-3} \cdot \mathbf{K}^{-1}\right)\end{array}$ & $\begin{array}{c}\text { Standard } \\
\text { Deviation } \\
\left(\mathrm{J} \cdot \mathrm{cm}^{-3} \cdot \mathrm{K}^{-1}\right)\end{array}$ & $\begin{array}{l}\text { No. of } \\
\text { Tests }\end{array}$ \\
\hline 25 & 1.58 & 0.05 & 3 & 25 & 1.79 & 0.11 & 7 \\
\hline 50 & 1.68 & 0.05 & 3 & 50 & 1.88 & 0.11 & 7 \\
\hline 75 & 1.80 & 0.05 & 3 & 75 & 1.97 & 0.11 & 7 \\
\hline 100 & 1.91 & 0.05 & 3 & 100 & 2.16 & 0.11 & 7 \\
\hline 125 & 2.03 & 0.06 & 3 & 125 & 2.32 & 0.11 & 7 \\
\hline 150 & 2.14 & 0.11 & 3 & 150 & 2.45 & 0.13 & 7 \\
\hline 175 & 2.13 & 0.10 & 3 & 175 & 2.43 & 0.18 & 7 \\
\hline 200 & 2.09 & 0.07 & 3 & 200 & 2.40 & 0.16 & 7 \\
\hline 225 & 2.07 & 0.06 & 3 & 225 & 2.39 & 0.17 & 7 \\
\hline 250 & 2.05 & 0.05 & 3 & 250 & 2.39 & 0.19 & 7 \\
\hline 275 & 2.03 & 0.05 & 3 & 275 & 2.39 & 0.22 & 7 \\
\hline 300 & 2.03 & 0.06 & 3 & 300 & 2.43 & 0.26 & 7 \\
\hline
\end{tabular}

It is believed that the peaks in specific heat shown in Table B-4 are related to phase changes; however, the data presented here are insufficient to correlate these peaks more specifically with mineralogy. It is worth noting that the peaks in specific heat at $150^{\circ} \mathrm{C}-170^{\circ} \mathrm{C}$ occur at a temperature range associated with the phase change in tridymite $\left(163^{\circ} \mathrm{C}\right)$. It is also evident that there were no significant changes in specific heat for these air-dried specimens at $100^{\circ} \mathrm{C}$, indicating that dehydration effects were minor.

Values of thermal capacitance were calculated by Nimick and Connolly (1991) from chemical and mineralogical data and published heat capacity data for the constituent minerals. For both the theoretical and experimental data, values for TSw2 are higher than for TSw1. The two sets of data roughly coincide, which is very encouraging considering that there were many 
assumptions inherent in Nimick and Connolly's work. Measurements of specific heat are very sensitive to moisture content and to the types of water present. The experimental data were obtained on air-dried specimens containing 0.3 percent to 0.7 percent water by weight, whereas the calculated data were based on a water content of 5.5 percent by weight. Additionally, Nimick and Connolly (1991) believed that calculated values above $100^{\circ} \mathrm{C}$ would probably be high because they assumed that all $\mathrm{H}_{2} \mathrm{O}^{+}$remained in the glass during heating. Calculated values near $100^{\circ} \mathrm{C}$ were omitted from the plot because they were highly influenced by heat of vaporization of water.

Mineralogies were examined to determine if correlations exist between thermal properties and the presence of certain minerals. Thermal conductivity data did not indicate any dependence on apparent mineral phase changes. The thermal expansion test results showed temperatures over which MCTEs increased steeply and hysteresis was observed. These characteristics of the thermal expansion curves were discussed in light of phase changes expected in tridymite and cristobalite.

In summary, a very extensive data set for thermal conductivity and thermal expansion exists, primarily from boreholes UE25 NRG-5, UE25 NRG-5, USW NRG-6, and USW NRG-7/7A; but supplemented by data from Alcoves 5 and 7 . For the NRG test series, a total of 143 thermal conductivity tests were conducted on 95 test specimens, 132 thermal expansion tests were conducted on 120 specimens, and 10 specific heat tests were conducted on 10 specimens. Specimens were tested at several saturation states, at room pressure, and at temperatures up to $300^{\circ} \mathrm{C}$. Petrologic data were obtained from $97 \mathrm{NRG}-6$ samples.

Thermal conductivities are highest for saturated specimens and lowest for dried specimens. Thermal conductivities, averaged over all boreholes, ranged (depending upon temperature and saturation state) from $1.2 \mathrm{~W} / \mathrm{m}^{\circ} \mathrm{K}$ to $1.9 \mathrm{~W} / \mathrm{m}^{\circ} \mathrm{K}$ for $\mathrm{TCw}$, from $0.4 \mathrm{~W} / \mathrm{m}^{\circ} \mathrm{K}$ to $0.9 \mathrm{~W} / \mathrm{m}^{\circ} \mathrm{K}$ for PTn, from $1.0 \mathrm{~W} / \mathrm{m}^{\circ} \mathrm{K}$ to $1.7 \mathrm{~W} / \mathrm{m}^{\circ} \mathrm{K}$ for TSwl, and from $1.5 \mathrm{~W} / \mathrm{m}^{\circ} \mathrm{K}$ to $2.3 \mathrm{~W} / \mathrm{m}^{\circ} \mathrm{K}$ for TSw2. Thermal conductivity results showed that for oven dried specimens, thermal conductivities increased slightly or remained constant as temperature increased from $25^{\circ} \mathrm{C}$ to $300^{\circ} \mathrm{C}$. The PTn $\mathrm{T} / \mathrm{M}$ unit consistently showed the lowest thermal conductivities while the TCw and TSw2 units had the highest conductivity values. TSwl specimens spanned a large range of thermal conductivities and were intermediate in value.

Mean coefficients of thermal expansion were highly temperature dependent and values, averaged over all boreholes, range (depending upon temperature and saturation state) from $6.6 \times 10^{-6 \circ} \mathrm{C}^{-1}$ to $49 \times 10^{-6 \circ} \mathrm{C}^{-1}$ for $\mathrm{TCw}$, from the negative range to $16 \times 10^{-6}{ }^{\circ} \mathrm{C}^{-1}$ for $\mathrm{PTn}$, from $6.3 \times 10^{-6 \circ} \mathrm{C}^{-1}$ to $44 \times 10^{-60} \mathrm{C}^{-1}$ for $\mathrm{TSw} 1$, and from $6.7 \times 10^{-6 \circ} \mathrm{C}^{-1}$ to $37 \times 10^{-6 \circ} \mathrm{C}^{-1}$ for $\mathrm{TSw} 2$. Thermal expansion coefficients showed substantive differences between welded and nonwelded specimens. Moisture effects were apparent in nonwelded specimens. Even for oven dried specimens, the nonwelded PTn T/M unit showed dehydration and volume loss at $100^{\circ} \mathrm{C}$. At more elevated temperatures, these specimens generally continued to shorten as bound water was released. Thermal expansion of the welded specimens showed no moisture dependence. At temperatures near $200^{\circ} \mathrm{C}$, hysteresis in the strain-versus-temperature curves became apparent in most specimens. Most of this was probably caused by phase changes in trydimite and cristobalite; however, this was not clear from comparison of thermal expansion and 
mineralogical data. Although most expansion reversed during cooling, substantial permanent elongations (up to 200 microns or 0.4 percent strain) were observed.

Thermal capacitance values are lower for TSw1 specimens from NRG-4 than for TSw2 specimens from NRG5. Mean values of thermal capacitance (averaged over all specimens) ranged from $1.6 \mathrm{~J} \cdot \mathrm{cm}^{-3} \cdot \mathrm{K}^{-1}$ to $2.1 \mathrm{~J} \cdot \mathrm{cm}^{-3} \cdot \mathrm{K}^{-1}$ for $\mathrm{TSwl}$ and from $1.8 \mathrm{~J} \cdot \mathrm{cm}^{-3} \cdot \mathrm{K}^{-1}$ to $2.5 \mathrm{~J} \cdot \mathrm{cm}^{-3} \cdot \mathrm{K}^{-1}$ for TSw2. The irregular slopes of the specific heat-versus-temperature curves are most likely related to phase changes. No mineralogical data were obtained for NRG-4 and NRG-5 specimens.

There is very little evidence of lateral variability of thermal properties within units. There is also very little data to suggest thermal properties show any degree of anisotropy (vertical vs. horizontal).

\section{B.2 IN SITU THERMAL AND MECHANICAL PROPERTIES}

The Yucca Mountain Project has supported collection of information on in situ thermomechanical properties since the mid-1990's. In situ thermal conductivity, thermal expansion, and rock mass modulus were estimated in the Single Heater Test and in the Drift Scale Test. From the Single Heater Test, the rock mass thermal expansion was estimated from displacement and temperature measurements to be between $2.5 \times 10^{-6} /{ }^{\circ} \mathrm{C}$ to $6 \times 10^{-6} /{ }^{\circ} \mathrm{C}$ for temperatures up to about $160^{\circ} \mathrm{C}$ (DTN: SNF35110695001.009), although analyses of the test suggest that intact thermal expansion coefficients provide a better match to the overall measured displacements and temperatures. Likewise, the thermal conductivity (of matrix materials) derived from back-fitting in situ data and numerical modeling suggest thermal conductivities of $2.1 \mathrm{~W} /(\mathrm{m} \cdot \mathrm{K})$ for wet and $1.67 \mathrm{~W} /(\mathrm{m} \cdot \mathrm{K})$ for dry conditions respectively (DTN: SNF35110695001.009). For rock mass modulus, the Plate Loading Test conducted as part of the larger Drift-Scale Test estimated rock mass modulus from $11.4 \mathrm{GPa}$ to $29.5 \mathrm{GPa}$ for ambient and thermally perturbed fractured tuffs in the vicinity of the Drift-Scale Test (George et al. 1999). A later test conducted in the same location showed higher general modulus recommended values ranging from $17.3 \mathrm{GPa}$ to $43 \mathrm{GPa}$ (Williams 2001). It is also possible to garner information about the rock mass strength by estimation of the stresses surrounding the Drift-Scale Test, and by estimating the strength to be some value greater than the estimated stress (by virtue of no known major rock mass failures surrounding the Drift-Scale Test).

\section{B.3 REFERENCES}

\section{B.3.1. DOCUMENTS CITED}

Boyd, P.J.; Martin, R.J., III; and Price, R.H. 1994. An Experimental Comparison of Laboratory Techniques in Determining Bulk Properties of Tuffaceous Rocks. SAND92-0119. Albuquerque, New Mexico: Sandia National Laboratories. ACC: NNA.19940315.0003.

Boyd, P.J.; Price, R.H.; Martin, R.J.; and Noel, J.S. 1996. Bulk and Mechanical Properties of the Paintbrush Tuff Recovered from Boreholes UE25 NRG-2, 2A, 2B, and 3: Data Report. SAND94-1902. Albuquerque, New Mexico: Sandia National Laboratories. ACC: MOL.19970102.0002. 
Boyd, P.J.; Price, R.H.; Noel, J.S.; and Martin, R.J. 1996. Bulk and Mechanical Properties of the Paintbrush Tuff Recovered from Boreholes UE25 NRG-4 and -5: Data Report.

SAND94-2138. Albuquerque, New Mexico: Sandia National Laboratories.

ACC: MOL.19970102.0004.

Brailsford, A.D. and Major, K.G. 1964. "The Thermal Conductivity of Aggregates of Several Phases, Including Porous Materials." British Journal of Applied Physics, 15, 313-319.

London, England: Institute of Physics. TIC: 223876.

Brodsky, N.S.; Riggins, M.; Connolly, J.; and Ricci, P. 1997. Thermal Expansion, Thermal Conductivity, and Heat Capacity Measurements for Boreholes UE25 NRG-4, UE25 NRG-5, USW NRG-6, and USW NRG-7/7A. SAND95-1955. Albuquerque, New Mexico: Sandia National Laboratories. ACC: MOL.19980311.0316.

George, J.T., Finley, R.E., and Riggins, M. 1999. "Conduct of Plate Loading Tests at Yucca Mountain, Nevada." $37^{\text {th }}$ U.S. Rock Mechanics Symposium, Vail Colorado, June 6-9. pp. 721-727. Vail, Colorado: American Rock Mechanics Association. TIC: 245246.

Haupt, R.W., Martin, R.J., Price, R.H., Dupree, W.J., and Tang, X. 1992. "Modulus Dispersion and Attenuation in Tuff and Granite." $33^{\text {rd }}$ US Rock Mechanics Symposium, Santa Fe, New Mexico. pp. 899-908. Rotterdam, Netherlands: American Rock Mechanics Association. TIC: 212624.

Martin, R.J., Boyd P.J., Noel J.S., and Price R.H. 1991. Procedure Development Study: Low Strain Rate and Creep Experiments. SAND91-0527. Albuquerque, NM: Sandia National Laboratory. ACC: NNA.19911010.0047.

Martin, R.J., Noel, J.S., Boyd, P.J., and Price, R.H. 1997a. The Effects of Confining Pressure on the Strength and Elastic Properties of the Paintbrush Tuff Recovered from Boreholes USW NRG-6 and USW NRG-7/7A: Data Report. SAND95-1887. Albuquerque, New Mexico: Sandia National Laboratories. ACC: MOL.19971017.0662.

Martin, R.J., Noel, J.S., Boyd, P.J., and Price, R.H. 1997b. "Creep and Static Fatigue of Welded Tuff from Yucca Mountain, Nevada." $36^{\text {th }}$ U.S. Rock Mechanics Symposium, Columbia University, New York, June 29-July 2, 1997. p. 382. New York, New York: American Rock Mechanics Association. TIC: 250241.

Martin, R.J., Noel, J.S., Boyd, P.J., and Price, R.H. 1997c. Creep Properties of the Paintbrush Tuff Recovered from Borehole USW NRG-7/7A: Data Report. SAND95-1759. Albuquerque, New Mexico: Sandia National Laboratories. ACC: MOL.19971017.0661.

Martin, R.J.; Noel, J.S.; Boyd, P.J.; Riggins, M.; and Price, R.H. 1997. Thermal Expansion of the Paintbrush Tuff Recovered from Borehole USW SD-12 at Pressures 30 MPa: Data Report. SAND95-1904. Albuquerque, New Mexico: Sandia National Laboratories.

ACC: MOL.19971017.0680. 
Martin, R.J., Price, R.H., Boyd, P.J, and Haupt, R.W. 1992. Anisotropy of the Topopah Spring Member Tuff. SAND91-0894. Albuquerque, New Mexico: Sandia National Laboratory. ACC: NNA.19920522.0041.

Martin, R.J., Price, R.H., Boyd, P.J., and Noel, J.S. 1993a. The Influence of Strain Rate and Sample Inhomogeneity on the Moduli and Strength of Welded Tuff. Las Vegas, Nevada:

CRWMS M\&O. ACC: NNA.19930514.0013.

Martin, R.J., Price, R.H., Boyd, P.J., and Noel, J.S. 1993b. Unconfined Compression Experiments on Topopah Spring Member Tuff at $22^{\circ} \mathrm{C}$ and a Strain Rate of $10^{-9} \mathrm{~s}^{-1}$.

SAND92-1810. Albuquerque, NM: Sandia National Laboratory. ACC: NNA.19930728.0088.

Martin, R.J., Price, R.H., Boyd, P.J., and Noel, J.S. 1995. Creep in Topopah Spring Member Welded Tuff. SAND94-2585. Albuquerque, New Mexico: Sandia National Laboratories. ACC: MOL.19950502.0006.

Martin, R.J.; Price, R.H.; Boyd, P.J.; and Noel, J.S. 1994. Bulk and Mechanical Properties of the Paintbrush Tuff Recovered from Borehole USW NRG-6: Data Report. SAND93-4020. Albuquerque, New Mexico: Sandia National Laboratories. ACC: MOL.19940811.0001.

Martin, R.J.; Price, R.H.; Boyd, P.J.; and Noel, J.S. 1995. Bulk and Mechanical Properties of the Paintbrush Tuff Recovered from Borehole USW NRG-7/7A: Data Report. SAND94-1996. Albuquerque, New Mexico: Sandia National Laboratories. ACC: MOL.19950316.0087.

Nimick, F.B. 1989. Thermal-Conductivity Data for Tuffs from the Unsaturated Zone at Yucca Mountain, Nevada. SAND88-0624. Albuquerque, New Mexico: Sandia National Laboratories. ACC: NNA.19890515.0133.

Nimick, F.B. and Connolly, J.R. 1991. Calculation of Heat Capacities for Tuffaceous Units from the Unsaturated Zone at Yucca Mountain, Nevada. SAND88-3050. Albuquerque, New Mexico: Sandia National Laboratories. ACC: NNA.19910308.0017.

Nimick, F.B.; Price, R.H.; Van Buskirk, R.G.; and Goodell, J.R. 1985. Uniaxial and Triaxial Compression Test Series on Topopah Spring Tuff from USW G-4, Yucca Mountain, Nevada. SAND84-1101. Albuquerque, New Mexico: Sandia National Laboratories.

ACC: MOL.19980602.0332.

Olsson, W.A. and Jones, A.K. 1980. Rock Mechanics Properties of Volcanic Tuffs from the Nevada Test Site. SAND80-1453. Albuquerque, New Mexico: Sandia National Laboratories. ACC: NNA.19870406.0497.

Papike, J.J. and Cameron, M. 1976. "Crystal Chemistry of Silicate Minerals of Geophysical Interest." Reviews of Geophysics and Space Physics, 14, (1), 37-80. Washington, D.C.: American Geophysical Union. TIC: 240938.

Price, R.H. 1983. Analysis of the Rock Mechanics Properties of Volcanic Tuff Units from Yucca Mountain, Nevada Test Site. SAND82-1315. Albuquerque, New Mexico: Sandia National Laboratories. ACC: NNA.19870406.0181. 
Price, R.H. 1986. Effects of Sample Size on the Mechanical Behavior of Topopah Spring Tuff. SAND85-0709. Albuquerque, New Mexico: Sandia National Laboratories.

ACC: NNA.19891106.0125.

Price, R.H. 1993. "Strength-Size-Porosity Empirical Model for Yucca Mountain Tuff." EOS, Transactions, American Geophysical Union, 1993 Fall Meeting, October 26, 1993. 74, 571. Washington, D.C.: American Geophysical Union. TIC: 210057.

Price, R.H. and Bauer, S.J. 1985. "Analysis of the Elastic and Strength Properties of Yucca Mountain Tuff, Nevada." Research \& Engineering Applications in Rock Masses, Proceedings of the $26^{\text {th }}$ U.S. Symposium on Rock Mechanics, Rapid City, South Dakota, June 26-28, 1985. Ashworth, E., ed. Pages 89-96. Boston, [Massachusetts]: A.A. Balkema. TIC: 218790.

Price, R.H. and Jones, A.K. 1982. Uniaxial and Triaxial Compression Tests Series on Calico Hills Tuff. SAND82-1314. Albuquerque, New Mexico: Sandia National Laboratories. ACC: NNA.19900810.0480.

Price, R.H. and Nimick, K.G. 1982. Uniaxial Compression Test Series on Tram Tuff. SAND82-1055. Albuquerque, New Mexico: Sandia National Laboratories.

ACC: HQS.19880517.1699.

Price, R.H., Martin, R.J., Boyd, P.J., Boitnott, G.N. 1995. Mechanical and Bulk Properties of Intact Rock Collected in the Laboratory in Support of the Yucca Mountain Site Characterization Project. SAND94-2243C. Albuquerque, New Mexico: Sandia National Laboratories.

ACC: MOL.19950130.0056.

Price, R.H., Martin, R.J., Haupt, R.W. 1994. The Effect of Frequency on Young's Modulus and Seismic Wave Attenuation. SAND92-0847. Albuquerque, NM: Sandia National Laboratory. ACC: NNA.19940628.0140.

Price, R.H., Connolly, J.R., and Keil, K. 1987. Petrologic and Mechanical Properties of Outcrop Samples of the Welded, Devitrified Topopah Spring Member of the Paintbrush Tuff. SAND86-1131. Albuquerque, New Mexico: Sandia National Laboratories.

ACC: NNA.19870601.0013.

Price, R.H., Jones, A.K., and Nimick, K.G. 1982. Uniaxial Compression Test Series on Bullfrog Tuff. SAND82-0481. Albuquerque, New Mexico: Sandia National Laboratories.

ACC: HQS.19880517.1700.

Price, R.H.; Martin, R.J., III; and Boyd, P.J. 1993. "Characterization of Porosity in Support of Mechanical Property Analysis." High Level Radioactive Waste Management, Proceedings of the Fourth Annual International Conference, Las Vegas, Nevada, April 26-30, 1993. 2, 1847-1853. La Grange Park, Illinois: American Nuclear Society. TIC: 208542.

Price, R.H., Nimick, F.B., Connolly, J.R., Keil, K.; Schwartz, B.M.; and Spence, S.J. 1985. Preliminary Characterization of the Petrologic, Bulk, and Mechanical Properties of a Lithophysal Zone Within the Topopah Spring Member of the Paintbrush Tuff. SAND84-0860. Albuquerque, New Mexico: Sandia National Laboratories. ACC: NNA.19870406.0156. 
Price, R.H., Nimick, K.G., and Zirzow, J.A. 1982. Uniaxial and Triaxial Compression Test Series on Topopah Spring Tuff. SAND82-1723. Albuquerque, New Mexico: Sandia National Laboratories. ACC: NNA.19870406.0063.

Price, R.H., Spence, S.J., and Jones, A.K. 1984. Uniaxial Compression Test Series on Topopah Spring Tuff from USW GU-3, Yucca Mountain, Southern Nevada. SAND83-1646.

Albuquerque, New Mexico: Sandia National Laboratories. ACC: NNA.19870406.0252.

Price, R.J., Boyd, P.J, Noel, J.S., Martin, R.J. 1994. Relation Between Static and Dynamic Rock Properties in Welded and Nonwelded Tuff. SAND940306C. Albuquerque, New Mexico:

Sandia National Laboratories. TIC: 213482.

Thompson, A.B. and Wennemer, M. 1979. "Heat Capacities and Inversions in Tridymite, Cristobalite, and Tridymite-Cristobalite Mixed Phases." American Mineralogist, 64, 1018-1026. Washington, D.C.: Mineralogical Society of America. TIC: 239133.

Williams, N.H. 2001. "Contract \#: DE-AC08-01NV12101 -- Thermal Test Progress Report \#6." Letter from N.H. Williams (BSC) to S.P. Mellington (DOE/YMSCO), April 19, 2001, PROJ.04/01.030, with enclosure. ACC: MOL.20010612.0531.

Woodside, W. and Messmer, J.H. 1961. "Thermal Conductivity of Porous Media, I. Unconsolidated Sands." Journal of Applied Physics, 32, (9), 1688-1699. New York, New York: American Institute of Physics. TIC: 217510.

\section{B.3.2 SOURCE DATA, LISTED BY DATA TRACKING NUMBER}

SNF35110695001.009. Thermal and Thermomechanical Data for the Single Heater Test Final Report. Submittal date: 08/24/1998. 